US Army Corps

of Engineers ${ }_{\circledast}$

Engineer Research and

Development Center

Environmental Security Technology Certification Program (ESTCP)

The Demonstration and Validation of a

Linked Watershed-Riverine Modeling System for DoD Installations - Patuxent Watershed, Maryland

Billy E. Johnson and Zhonglong Zhang

September 2020

A - high infiltration

$B$ - moderate infiltration

$B / D$ - medium/very slow infiltration

$\mathrm{C}$ - slow infiltration

C/D - medium/very slow infiltration

$D$ - very slow infiltration 
The U.S. Army Engineer Research and Development Center (ERDC) solves the nation's toughest engineering and environmental challenges. ERDC develops innovative solutions in civil and military engineering, geospatial sciences, water resources, and environmental sciences for the Army, the Department of Defense, civilian agencies, and our nation's public good. Find out more at www.erdc.usace.army.mil.

To search for other technical reports published by ERDC, visit the ERDC online library at https://erdclibrary.on.worldcat.org/discovery. 


\section{The Demonstration and Validation of a Linked Watershed-Riverine Modeling System for DoD Installations - Patuxent Watershed, Maryland}

Billy E. Johnson and Zhonglong Zhang

U.S. Army Engineer Research and Development Center (ERDC)

Environmental Laboratory (EL)

Vicksburg, MS 39180-6199

Final Technical Report (TR)

Approved for public release; distribution is unlimited.

Alexandria, VA 22350-3605

Under ESTCP Project \# RC-201302 


\section{Abstract}

This work evaluated a linked watershed and riverine modeling system for the Patuxent River Watershed, Maryland against observed field data and model output from a watershed model. The performance objectives were computed for streamflow, sediment, total phosphorus, orthophosphorus, total nitrogen, ammonium, and nitrate using daily and monthly average model predictions and measured data. Hydrological Simulation Program Fortran (HSPF) was used to compute runoff, sediment, and nutrient loadings, whereas the Hydrologic Engineer Center - River Analysis System (HEC-RAS) was used to evaluate in-stream flow, channel sedimentation, and the fate/transport of nutrients. Model results were successful for calibration, validation, and management scenario analysis. Contaminants were not simulated for this watershed due to a lack of observed data to compare against. The study identified two implementation issues. First, while the Patuxent River did not experience dry bed conditions, where a stream may be intermittent, one can incorporate a very narrow slot at the low point in the cross-section to numerically keep the channel wet during very low flows. Second, to set up the linked model, there needs to be more observed water quality data to better constrain the HSPF output being used as boundary conditions to the HEC-RAS model.

DISCLAIMER: The contents of this report are not to be used for advertising, publication, or promotional purposes. Citation of trade names does not constitute an official endorsement or approval of the use of such commercial products. All product names and trademarks cited are the property of their respective owners. The findings of this report are not to be construed as an official Department of the Army position unless so designated by other authorized documents.

DESTROY THIS REPORT WHEN NO LONGER NEEDED. DO NOT RETURN IT TO THE ORIGINATOR. 


\section{Contents}

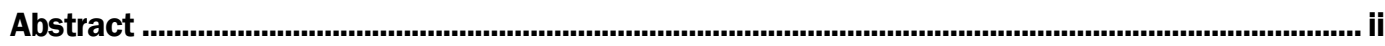

Figures and Tables...............................................................................................................................

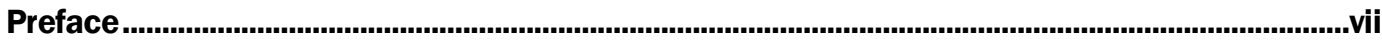

Executive Summary ..................................................................................................................... ix

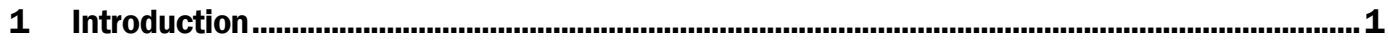

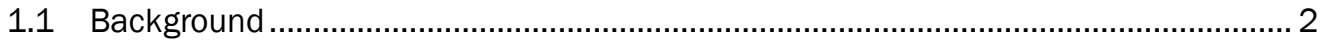

1.2 Objective of the demonstration........................................................................... 4

1.3 Regulatory drivers ...................................................................................... 4

1.3.1 National Environmental Policy Act (NEPA) ................................................................. 4

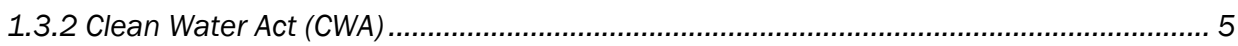

1.3.3 Presidential Executive Order 13508 ........................................................................... 5

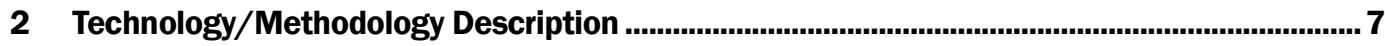

2.1 Technology/methodology overview................................................................. 7

2.2 HSPF (Hydrological Simulation Program-Fortran) .................................................. 9

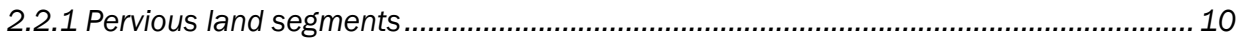

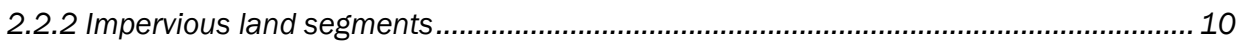

2.2.3 Streams and reservoirs .................................................................................... 11

2.2.4 HEC-RAS (Hydrologic Engineering Center - River Analysis System).............................. 11

2.2.5 Steady flow water surface profiles ...................................................................... 11

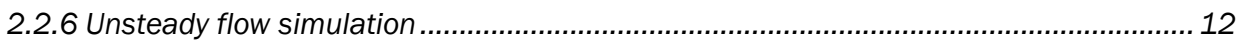

2.2.7 Sediment transport/movable boundary computations............................................. 13

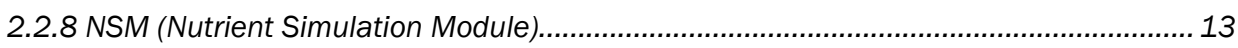

2.2.9 CTT\&F (Contaminant Transport, Transformation and Fate)........................................ 14

2.3 Advantages and limitations of the technology/methodology .................................. 14

3 Performance Objectives ...................................................................................................16

3.1 Nash-Sutcliffe Efficiency (NSE) ...................................................................... 19

3.2 Percent Bias (PBIAS) ...................................................................................... 19

3.3 RMSE-Observations Standard Deviation Ratio (RSR) ..........................................20

4 Site Description .....................................................................................................................22

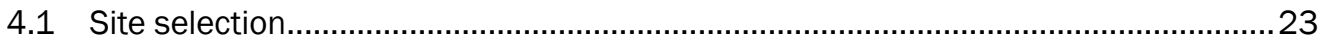

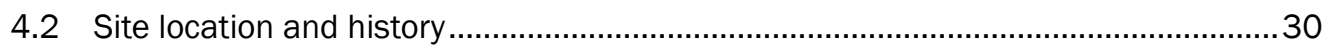

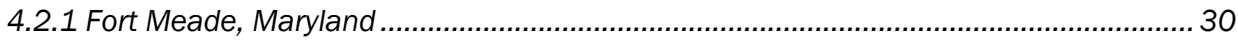

4.2.2 NAS Patuxent River, Maryland ................................................................................ 32

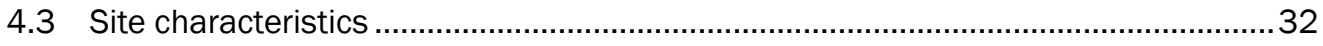

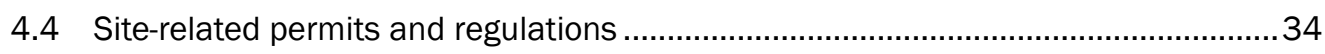

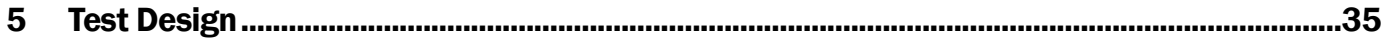

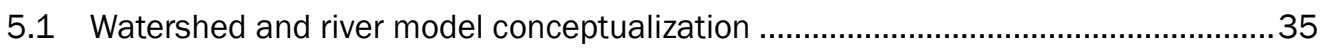

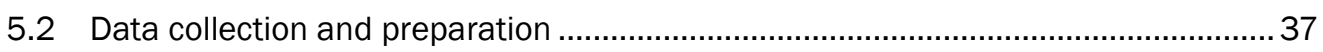

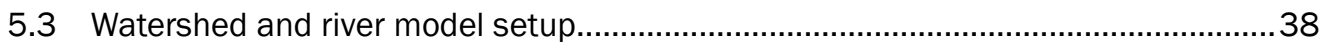




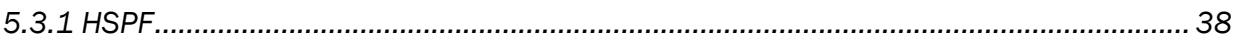

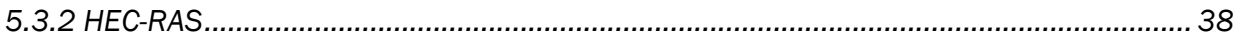

5.4 Watershed and river model calibration ............................................................. 40

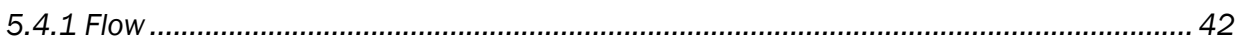

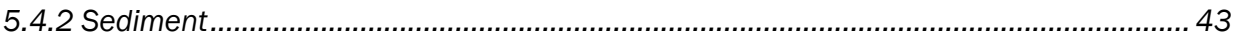

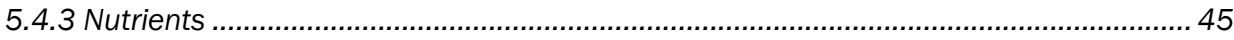

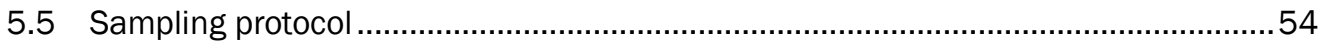

5.6 Equipment calibration and data quality issues...................................................5

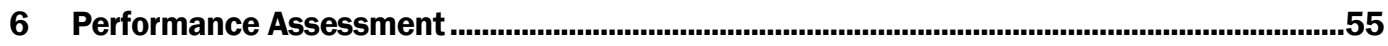

6.1 Watershed and river model validation ..............................................................55

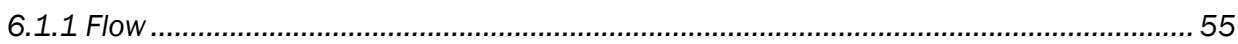

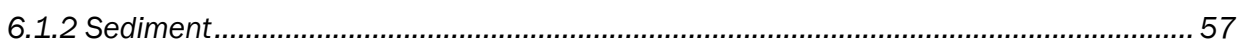

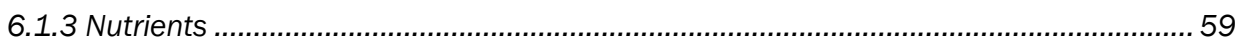

6.2 Modeling best management practices (management scenarios) ...........................64

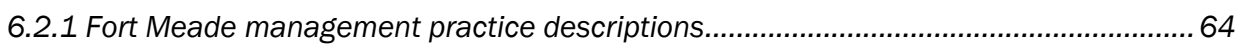

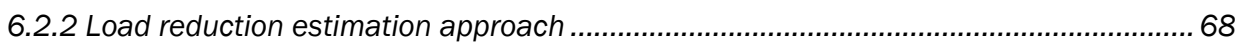

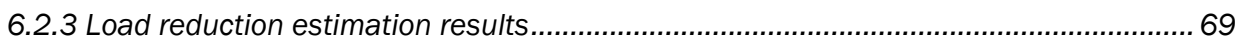

6.3 Summary and conclusions ............................................................................ 70

6.4 Model performance as related to the performance objectives...................................72

6.4.1 Performance Objective 1 - Linked model accurately simulates major components of hydrologic cycle and stream flow ................................................. 72

6.4.2 Performance Objective 2 - Linked model accurately simulates soil erosion

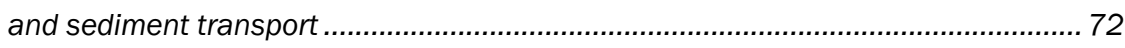

6.4.3 Performance Objective 3 - Linked model accurately simulates contaminant

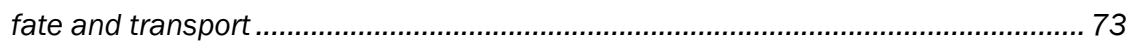

6.4.4 Performance Objective 4 - Linked model accurately simulates nutrient fate

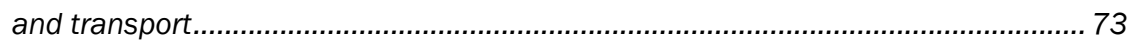

6.4.5 Performance Objective 5 - Management scenarios.................................................. 74

6.4.6 Performance Objective 6 - Data availability................................................................. 74

6.4.7 Performance Objective 7 - Ease of use.................................................................... 75

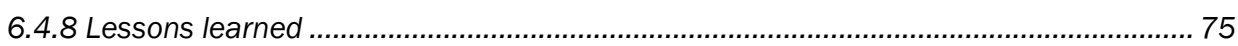

References .............................................................................................................................................76

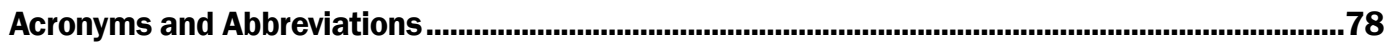

Appendix A: Health and Safety Plan (HASP)

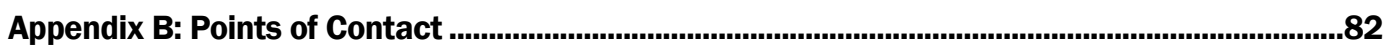

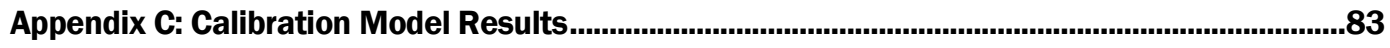

Appendix D: Validation Model Results...................................................................................107

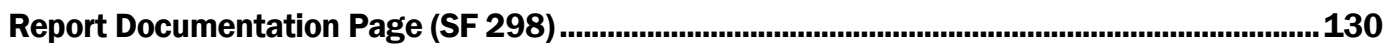




\section{Figures and Tables}

Figures

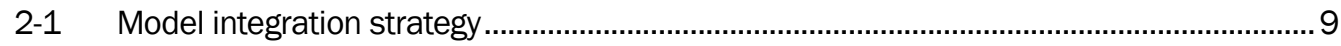

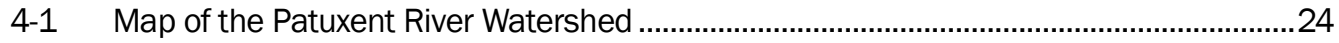

4-2 Map of hydrologic soil groups in the Patuxent River Watershed .....................................25

4-3 Patuxent Watershed flow and water quality gages ............................................................26

4-4 Patuxent Watershed precipitation and meteorological gages ...........................................28

5-1 Map of the Patuxent River Watershed HSPF model delineation.........................................36

5-2 Patuxent River HEC-RAS model domain ...........................................................................37

5-3 Sample Google image with cross-section cutlines ..........................................................39

5-4 HEC-RAS model reach representation of Patuxent River ...................................................40

6-1 Club Meade bioretention practices depicted on construction plan documents and before and after satellite imagery.......................................................65

6-2 Gym and Chapel bioretention practice depicted on construction plan documents and before and after satellite imagery..........................................................66

6-3 8500 Area infiltration trench depicted on construction plan documents and before and after satellite imagery,

6-4 Donohue Field area practices - bioretention and pavement removal depicted on construction plan documents and before and after satellite imagery.

6-5 Building 6300 infiltration basin depicted on construction plan documents and before and after satellite imagery.

6-6 Division Hill pavement removal depicted on construction plan documents and before and after satellite imagery...............................................................................68

6-7 Linked HSPF and HEC-RAS model domain ...................................................................... 71

\section{Tables}

3-1. Demonstration Validation Performance Objectives and Thresholds .....................................16

3-2 General performance ratings for recommended statistics .............................................20

4-1 Inventory (count and start/end years) of streamflow and water quality observations for sampling stations in the Patuxent River Watershed................................26

4-2 Site selection criteria for Patuxent Watershed...............................................................28

5-1 HSPF Calibration performance objectives for streamflow ………………………….....42

5-2 HEC-RAS Calibration performance objectives for streamflow .........................................43

5-3 HSPF Calibration performance objectives for sediment loading.......................................44

5-4 EC-RAS Calibration performance objectives for total suspended solids ...........................45

5-5 HEC-RAS Calibration performance objectives for Algae and DO

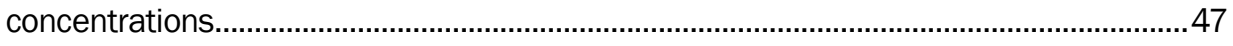

5-6 HSPF Calibration performance objectives for nutrient loading .......................................50

5-7 HEC-RAS Calibration performance objectives for nutrient concentration.........................50 
5-8 HSPF Calibrated values for key hydrology, sediment, and nutrient

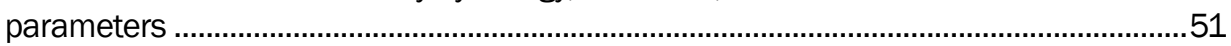

5-9 HEC-RAS Calibrated parameter values for nutrients and sediment ................................53

6-1 HSPF Validation performance objectives for streamflow ................................................56

6-2 HEC-RAS Validation performance objectives for streamflow ..............................................57

6-3 HSPF Validation performance objectives for sediment loading ..........................................58

6-4 HEC-RAS validation performance objectives for total suspended solids ..........................59

6-5 HEC-RAS validation performance objectives for Algae, DO and CBOD

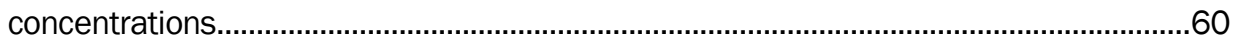

6-6 HSPF Validation performance objectives for nutrient loading............................................63

6-7 HEC-RAS validation performance objectives for nutrient concentration...........................64

6-8 Project sites, practices, surface areas, drainage areas, and

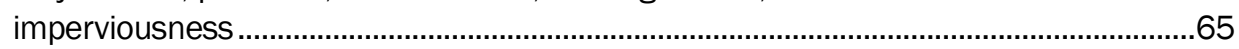

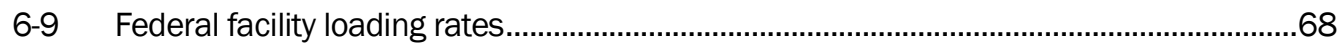

6-10 Assumed load removal efficiencies..................................................................................69

6-11 Estimated annual N, P, and sediment load reductions associated with the six project sites. 


\section{Preface}

This project was funded under the Environmental Security Technology Certification Program (ESTCP) as Project RC-201302. Dr. Kurt Preston served as the ESTCP Program Manager with Mr. Lee Mulkey, Mulkey Consultants, serving as lead technical reviewer.

The work was performed by the Water Quality \& Contaminant Modeling Branch of the Environmental Processes and Engineering Division, U.S. Army Engineer Research and Development Center, Environmental Laboratory (ERDC-EL). At the time of publication, Mr. Mark Noel was Chief of the Water Quality \& Contaminant Modeling Branch and Mr. Warren Lorenz was Chief of the Environmental Processes and Engineering Division. Thanks are owed to Mr. Derek Schlea, Mr. Todd Redder, and Ms. Amanda Flynn, LimnoTech; Mr. Craig Thomas, U.S. Army Corps of Engineers Baltimore District; Mr. Gary Shenk and Mr. Gopal Bhatt, Chesapeake Bay Program Office, who provided technical support for the model calibration and data collection so the authors would like to especially thank them for their contributions. Finally, a number of individuals and organizations were instrumental in providing data, technical support, and guidance. The authors want to thank everyone for their assistance in gathering necessary model data. The Deputy Director of ERDC-EL was Dr. Brian Lafferty and the Director was Dr. Jack Davis.

COL Teresa A. Schlosser was Commander of ERDC, and Dr. David W. Pittman was the Director. 
THIS PAGE INTENTIONALLY LEFT BLANK 


\section{Executive Summary}

\section{Objectives of the demonstration}

The objective of this project was to evaluate a linked watershed and riverine modeling system for Patuxent River Watershed, Maryland against observed field data, as well as against model output from only the watershed model (HSPF-only). 1 The model evaluation consisted of calibrating the models for the period of record from 1991 to 2000 (HSPF-only) and 1992 to 2000 (linked models), and validating the models for 2001 to 2005 (HSPF-only) and 2001 to 2005 (linked models). The performance objectives (Nash-Sutcliffe Efficiency [NSE], percent bias [PBIAS], and RSR) were computed for streamflow, sediment, total phosphorus, orthophosphorus, total nitrogen, ammonium, and nitrate using both daily and monthly average model predictions and measured data.

\section{Technology description and results}

HSPF was used to compute runoff, sediment, and nutrient loadings, whereas the Hydrologic Engineer Center - River Analysis System (HECRAS) was used to evaluate in-stream flow, channel sedimentation, and the fate/transport of nutrients.

Model results were deemed successful for calibration, validation, and management scenario analysis. Contaminants were not simulated for this watershed due to a lack of observed data to compare against.

\section{Implementation issues}

The study identified two implementation issues from the Patuxent River Watershed Demonstration Study. The first was investigating the methods for dealing with dry bed conditions in the HEC-RAS model. While the Patuxent River did not experience dry bed conditions, we do want to discuss one method used by hydraulic engineers. In cases where a stream may be intermittent, one can incorporate a very narrow slot at the low point in the cross-section to numerically keep the channel wet during very low flows. The volume of water in the slot is negligible, but numerically the channel never goes dry while practically it does.

\footnotetext{
1 HSPFL Hydrological Simulation Program - Fortran
} 
The second issue is that if one wishes to set up the linked model, there needs to be more observed water quality data (frequency and nutrient species) to better constrain the HSPF output being used as boundary conditions to the HEC-RAS model. Across demonstration studies done as part of this project, that was a continuing data gap that would need to be closed to make full use of this system. 


\section{Introduction}

A linked watershed-river modeling system is being developed for multiple installations using existing watershed and riverine models where applicable. HSPF will be used to compute watershed processes and HEC-RAS will be used to compute river processes. Information will be fed from HSPF to HEC-RAS as time series data using the Better Assessment Science Integrating point and Non-point Sources (BASINS) Water Data Management (WDM) database and the HEC Data Storage System (HEC-DSS). A tool has been created that will easily transfer time series data between the two data storage systems. This tool will be made available for use by others and will be available via download from an U.S. Army Engineer Research and Development Center (ERDC) tools web page.

The Hydrological Simulation Program (HSPF) simulates the hydrologic and associated water quality processes on pervious and impervious land surfaces and in streams and well-mixed impoundments for extended periods of time. More comprehensive than most watershed modeling systems, HSPF is a valuable tool for land managers.

The Hydrologic Engineering Centers River Analysis System (HEC-RAS) model contains four one-dimensional river analysis components for: (1) steady flow water surface profile computations, (2) unsteady flow simulation, (3) movable boundary sediment transport computations; and (4) water quality analysis (via the Nutrient Simulation Module [NSM] and the Contaminant Transport, Transformation, and Fate [CTT\&F] submodel). A key element is that all four components use a common geometric data representation and common geometric and hydraulic computation routines. NSM is a set of nutrient kinetic libraries developed within HECRAS. NSM computes riverine multiple algal biomass, nitrogen, phosphorus, and carbon cycling, as well as dissolved oxygen, chemical oxygen demand, alkalinity, $\mathrm{pH}$, and pathogens. CTT\&F enables a user to assess the impacts of contaminated areas on military installations and ranges as well as Superfund sites. The HEC-RAS/CTT\&F model addresses transport and fate of multi-species and multi-phase contaminants; as a result, it is able to handle military contaminants such as explosives and heavy metals. 
The HSPF and HEC-RAS models were linked via time series data to create a comprehensive watershed modeling tool required to address flow, sediment, and landuse impact at Patuxent River Watershed, Fort Meade, Maryland. Benefits were derived from the ability of the linked modeling system being able to determine sediment loads entering the stream network. The linked modeling system was used to assess the reduction in sediment load to the streams in addition to demonstrating the usefulness of the system for assessing future reductions based on additional implementations of these best management practices (BMPs).

\subsection{Background}

The National Environmental Policy Act (NEPA 1970) requires all Federal agencies to evaluate the environmental implications of their plans, policies, programs, and projects. In addition, Clean Water Act (CWA) regulations concerning water quality and effluent standards have grown exponentially in the past 20 years. Military impacts on training lands are well documented and understood (Milchunas et al. 1999, Shaw and Diersing 1989). These impacts include soil compaction, complete loss of vegetative cover, increased erosion rates, and shifts from native vegetation communities. Consequently, since streams and rivers are functionally linked to the watershed, training can degrade water quality in the form of sediment, nutrient, and contaminant loading and general decline in aquatic ecosystem health (Quist et al. 2003).

In addition to impacts from military training, deficient landuse management practices outside of military installations can also pose a threat to installation natural resources and mission readiness. U.S. Department of Defense (DoD) installation missions and assets are increasingly threatened by encroachment, which can include watersheds traversing both public/private and DoD property. Encroachment is often caused by a lack of upstream land management practices that contribute to sediment loading, erosion, trash disposal, invasive plant species, and other environmental and biological stressors that ultimately impact the watershed at the DoD installation and the training mission. Erosion and sediment loading is exacerbated when there is an absence of flood control measures, and the river system at the installation is located within a flood plain. In some cases, DoD installations are located within a Tsunami inundation zone, and installation contained rivers are listed on the 303(d) list of impaired 
waters. These conditions, coupled with a lack of land management practices, create an unbalanced system that threatens installation assets, resources, and operational capabilities.

Quantitative assessments of past, current, and future mission impacts on wetland and surface water ecosystems are often difficult tasks requiring expensive monitoring efforts. Changing and/or extreme weather events and improper loading of a river with a variety of contaminants creates a high level of variability and uncertainty to preserving installation habitat(s), operation and maintenance of facilities, and conducting night/day military training exercises. As such, watershed modeling systems are becoming increasingly critical in assessing mission impact and managing military training lands. To demonstrate the linked modeling system's ability to assess past, current, and future mission impacts, the project team coordinated with local land managers to identify appropriate landuse coverage to account for temporal changes in cover type.

Installation decision makers require a system that enables proactive decision-making and strategic investments that support erosion and flood control measures, prevention of pollutant loading, preservation of critical habitat, and mission readiness enabled by unhindered military training exercises; and that promotes buy in from a variety of stakeholders. The linked Hydrological Simulation Program -Fortran [HSPF]-Hydrologic Engineering Center- River Analysis System [HEC-RAS] (HSPF/HEC-RAS) model provides predictions so that managers can determine optimum times for training in addition to being used to evaluate mitigation scenarios supporting issues with flow, sediment, and/or constituent runoff. The chosen models are mechanistic models with a track record of performing military as well as non-military analyses. They all are able to use available national databases and cover all climatic regions, hence making them transferrable to all military installations. A demonstration and validation project is required to assess and quantify the overall performance of the linked modeling system. Specifically, the demonstration project aims to quantify the accuracy of the linked system compared with the HSPF-only model performance and document the added information provided by the linked system that the HSPF-only model does not provide.

President Obama issued Executive Order 13508 on May 12, 2009 (White House 2009), which directed the Federal government to lead a renewed 
effort to restore and protect the Chesapeake Bay and its watershed. The downstream requirements of the bay require upstream management to achieve the goals of the Total Maximum Daily Load (TMDL). The Chesapeake Bay TMDL is a keystone commitment in the strategy developed by 11 Federal agencies to meet the President's Executive Order (USEPA 2010b). As stated in the order, reductions in nonpoint loads have been targeted and are to be met by all Federal lands (including military installations).

\subsection{Objective of the demonstration}

The overall objective of this project was to demonstrate and validate a linked watershed and riverine modeling system, HSPF/HEC-RAS, for DoD installations across varying climatic and hydrologic regions. The linked model can be used to assess outcomes resulting from military activities and support installation sustainability through informed watershed management of water, water quality, contaminant, and landuse impacts (where applicable) at all demonstration sites. Simulation results from the linked HSPF/HEC-RAS model have been compared against observed field data as well as results from the HSPF-only model using standards for assessing modeling efficacy.

\subsection{Regulatory drivers}

The two major national regulatory drivers at military installations are: (1) NEPA; and (2) CWA.

\subsubsection{National Environmental Policy Act (NEPA)}

NEPA was signed into law by President Richard Nixon on January 1, 1970. Acknowledging the decades of environmental neglect that had significantly degraded the nation's landscape and damaged the human environment, the law was established to foster and promote the general welfare, to create and maintain conditions under which man and nature can exist in productive harmony, and to fulfill the social, economic, and other requirements of present and future generations of Americans.

NEPA advanced an interdisciplinary approach to Federal project planning and decision-making through environmental impact assessment. This approach requires Federal officials to consider environmental values alongside the technical and economic considerations that are inherent factors in 
Federal decision-making. Environmental impact assessment also calls for the evaluation of reasonable alternatives to a proposed Federal action; solicitation of input from organizations and individuals that could potentially be affected; and the unbiased presentation of direct, indirect, and cumulative environmental impacts. This information is used by a Federal official before a decision is made. Doing so results in informed, and ultimately, improved Federal decision-making.

The Council on Environmental Quality's (CEQ's) regulations (40 C.F.R. Parts 1500-1508 [CEQ 2005]) set the standard for NEPA compliance. They also require agencies to create their own NEPA implementing procedures. These procedures must meet the CEQ standard while reflecting each agency's unique mandate and mission.

\subsubsection{Clean Water Act (CWA)}

The CWA establishes the basic structure for regulating discharges of pollutants into the waters of the United States and regulating quality standards for surface waters. The basis of the CWA was enacted in 1948 and was called the Federal Water Pollution Control Act, but the Act was significantly reorganized and expanded in 1972. The "Clean Water Act" became the Act's common name with amendments in 1972.

Under the CWA, the U.S. Environmental Protection Agency (USEPA) has implemented pollution control programs such as setting wastewater standards for industry. USEPA also sets water quality standards for all contaminants in surface waters. The CWA made it unlawful to discharge any pollutant from a point source into navigable waters unless a permit was obtained. USEPA's National Pollutant Discharge Elimination System (NPDES) permit program controls discharges.

\subsubsection{Presidential Executive Order 13508}

On May 12, 2009, President Barack Obama signed an Executive Order that recognizes the Chesapeake Bay as a national treasure and calls on the Federal government to lead a renewed effort to restore and protect the nation's largest estuary and its watershed.

The Chesapeake Bay Protection and Restoration Executive Order established a Federal Leadership Committee that oversees the development and 
coordination of reporting, data management and other activities by agencies involved in Bay restoration. The committee is chaired by the Administrator of the Environmental Protection Agency and includes senior representatives from the departments of Agriculture, Commerce, Defense, Homeland Security, Interior, Transportation, and others.

The Executive Order required that these agencies prepare and submit by September 9, 2009 draft reports that made recommendations to:

- Define the next generation of tools and actions to restore water quality in the Bay and describe the changes to be made to regulations, programs, and policies to implement these actions (USEPA).

- Target resources to better protect the Bay and its rivers, particularly in agricultural conservation practices (U.S. Dept. of Agriculture).

- Strengthen storm water management practices for Federal facilities and Federal land within the Bay watershed and develop a best practices guide for reducing polluted runoff (USEPA, DoD).

- Assess the impacts of climate change on the Bay and develop a strategy for adapting programs and infrastructure to these impacts (U.S. Dept. of Interior, U.S. Dept. of Commerce).

- Expand public access to the Bay and its rivers from Federal lands and conserve landscapes of the watershed (U.S. Dept. of Interior).

- Expand environmental research, monitoring and observation to strengthen scientific support for decision-making on Bay restoration issues (U.S. Dept. of Interior, U.S. Department of Commerce).

- Develop focused and coordinated habitat and research activities that protect and restore living resources and water quality (U.S. Dept. of Interior, U.S. Dept. of Commerce).

Federal agencies consult extensively with the state governments of the seven Bay jurisdictions in preparing their reports: Delaware, Maryland, New York, Pennsylvania, Virginia, West Virginia, and the District of Columbia. 


\section{Technology/Methodology Description}

\subsection{Technology/methodology overview}

The linked modeling system provides predictions so that training range managers can determine optimum times for training in addition to being used to evaluate mitigation scenarios supporting issues with flow, sediment, and/or constituent runoff.

For each demonstration site, the modeling system is developed from existing watershed and riverine models if possible. Otherwise, new model applications will be developed using existing national, regional, and local data sets. The chosen modeling systems are composed of mechanistic models with a track record of performing military as well as non-military analyses. They all are able to use available national databases and cover all climatic regions, hence making them transferrable to all military installations. Where local data exists, the models are able to incorporate them into the model construct. Typically, local data such as landuse/land cover, channel cross-sections, installation facilities, stream flows, constituent flows, precipitation, and meteorological data are locally available and required by the models.

The modeling systems are available for download along with detailed documentation describing the model theory and user's manuals to help in training people on their use.

- HSPF - http://ches.communitymodeling.org/models/CBPhase5/index.php

- HEC-RAS - https://www.hec.usace.army.mil/software/hec-ras/.

These modeling systems have been used across broad spatial (acres to many square miles) and temporal scales (seconds to years), which allows one the flexibility to solve a host of environmental modeling problems associated with military installations. These modeling systems require the user to have a working knowledge of hydraulics, hydrology, erosion and sedimentation, and water quality. Based on previous experience a person with a Bachelor of Science degree in the Water Resources and Land Management technical areas along with two to 5 years of work experience should be able to setup, use, and interpret model results. One of the goals of this demonstration study is to verify that this is the case for the linked watershed modeling approach. 
Computationally, both of the proposed models (HSPF and HEC-RAS) are able to simulate years to decades in a matter of minutes to a few hours of computer time. These models are mature systems that have excellent documentation and training opportunities. For each system, a user should be able to take a 1- to 2-week training session, per model, and be able to setup, parameterize, and run the respective model.

As with any numerical model, these models do need to be calibrated and validated for each new application site. If these models are used over a long period of time, then it may be necessary to recalibrate them as more data becomes available. In calibrating either model, a sufficiently long data set needs to be gathered whereby model results can be compared with field observations. One portion of the data set is used for the calibration phase and the remainder of the period of record is used to validate the model parameters. In the calibration phase, those parameters that are deemed most sensitive to the simulations are allowed to vary within acceptable ranges until the model results best fit the field observations. Once this has been accomplished, then the remainder of the period of record is used to simulate model results with the parameters unadjusted. If the model results are able to reproduce the field observations within acceptable error criteria, then the model is said to be validated and useful for making predictions. This process, while not difficult, can be time consuming due to having to make many model runs and parameter adjustments.

For the Patuxent Watershed, HSPF, Chesapeake Bay Model Phase 5.3, was used to compute watershed processes while HEC-RAS 5.0.4 was used for the riverine environment. HSPF simulates for extended periods of time the hydrologic and associated water quality processes on pervious and impervious land surfaces and in streams and well-mixed impoundments. HSPF is a valuable tool to land managers. Because it is more comprehensive than most systems, it permits effective planning. Benefits to the user include:

- Flexibility in solving a wide range of water quantity and quality problems using a single model

- Convenient data management features that save time and money

- Modular program structure, which facilitates program changes and additions for special applications. 
While HSPF encompasses flow, sediment, nutrients, and contaminants within its model formulations, HEC-RAS has been integrated with the NSM and the CTT\&F sub-model, thus providing flow, sediment, nutrient, and contaminant fate and transport within the riverine environment (Figure 2-1).

Figure 2-1. Model integration strategy.

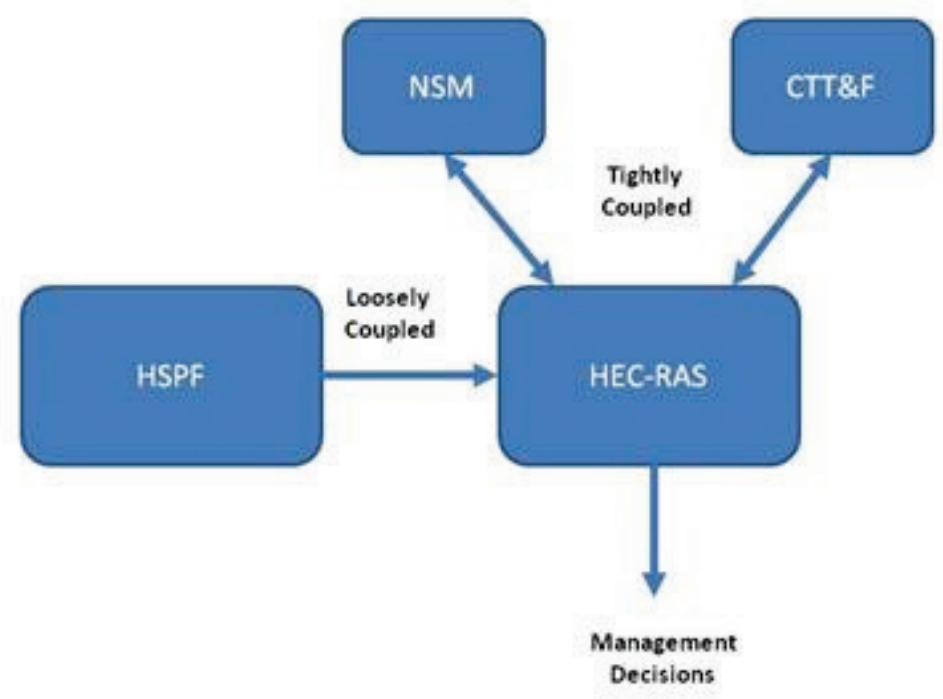

\subsection{HSPF (Hydrological Simulation Program-Fortran)}

HSPF simulates for extended periods of time the hydrologic and associated water quality processes on pervious and impervious land surfaces and in streams and well-mixed impoundments. The model uses continuous rainfall and other meteorological records to compute streamflow hydrographs and pollutographs (Bicknell et al. 2005). HSPF simulates interception soil moisture, surface runoff, interflow, base flow, snowpack depth and water content, snowmelt, evapotranspiration, groundwater recharge, dissolved oxygen, biochemical oxygen demand, temperature, pesticides, conservatives, fecal coliforms, sediment detachment and transport, sediment routing by particle size, channel routing, reservoir routing, constituent routing, $\mathrm{pH}$, ammonia, nitrite-nitrate, organic nitrogen, orthophosphate, organic phosphorus, phytoplankton, and zooplankton. The program can simulate one or many pervious or impervious unit areas discharging to one or many river reaches or reservoirs. Frequency-duration analysis can be done for any time series. Any time step, from 1 minute to 1 day, into which 1 day can be equally divided, can be used. Any period from a few minutes to hundreds of years may be simulated. HSPF is generally used to 
assess the effects of landuse change, reservoir operations, point or nonpoint source treatment alternatives, flow diversions, etc. Programs, available separately, support data preprocessing and postprocessing for statistical and graphical analysis of data saved to the WDM file.

\subsubsection{Pervious land segments}

A land segment (polygon) is a subdivision of the simulated watershed. The boundaries are established according to the user's needs, but generally, a segment is defined as an area with similar hydrologic characteristics. For modeling purposes, water, sediment, and water quality constituents leaving the watershed move laterally to a downslope segment or to a reach/reservoir. A segment of land that has the capacity to allow enough infiltration to influence the water budget is considered pervious. In HSPF, PERLND is the module that simulates the water quality and quantity processes that occur on a pervious land segment.

The primary module sections in PERLND simulate snow accumulation and melt, the water budget, sediment produced by land surface erosion, and water quality constituents by various methods. Other sections perform the auxiliary functions of correcting air temperature for use in snowmelt and soil temperature calculations, producing soil temperatures for estimating the outflow temperatures and influencing reaction rates in the agri-chemical sections, and determining outflow temperatures that influence the solubility of oxygen and carbon dioxide.

\subsubsection{Impervious land segments}

In an impervious land segment (polygon), little or no infiltration occurs; however, land surface processes do occur. Snow may accumulate and melt, and water may be stored or may evaporate. Various water quality constituents accumulate and are removed. Water, solids, and various pollutants flow from the segments by moving laterally to a downslope segment or to a reach/reservoir.

The HSPF IMPLND module simulates a number of processes with many of them similar to the corresponding sections in the PERLND module. In fact, since s snow and air temperature components perform functions that can be applied to pervious or impervious segments, they are shared by both modules. 


\subsubsection{Streams and reservoirs}

This module simulates the processes that occur in a single reach of open or closed channel or a completely mixed lake. For convenience, such a processing unit is referred to as a RCHRES. In keeping with the assumption of complete mixing, the RCHRES consists of a single zone situated between two nodes, which are the extremities of the RCHRES.

Flow through a RCHRES is assumed to be unidirectional. Water and other constituents that arrive from other RCHRES's and local sources enter the RCHRES through a single gate. Outflows may leave the RCHRES through one of several gates or exits. A RCHRES can have up to five outflow exits. Precipitation, evaporation, and other fluxes also influence the processes that occur in the RCHRES, but do not pass through the exits.

\subsubsection{HEC-RAS (Hydrologic Engineering Center - River Analysis System)}

The HEC-RAS system contains four one-dimensional river analysis components for: (1) steady flow water surface profile computations; (2) unsteady flow simulation; (3) movable boundary sediment transport computations; and (4) water quality analysis (via NSM and CTT\&F). A key element is that all four components use a common geometric data representation and common geometric and hydraulic computation routines. In addition to the four river analysis components, the system contains several hydraulic design features that can be invoked once the basic water surface profiles are computed.

\subsubsection{Steady flow water surface profiles}

This component of the modeling system is intended for calculating water surface profiles for steady gradually varied flow. The system can handle a full network of channels, a dendritic system, or a single river reach. The steady flow component is capable of modeling subcritical, supercritical, and mixed flow regimes water surface profiles.

The basic computational procedure is based on the solution of the one-dimensional energy equation. Energy losses are evaluated by friction (Manning's equation) and contraction/expansion (coefficient multiplied by the change in velocity head). The momentum equation may be used in situations where the water surface profile is rapidly varied. These situations 
include mixed flow regime calculations (i.e., hydraulic jumps), hydraulics of bridges, and evaluating profiles at river confluences (stream junctions).

The effects of various obstructions such as bridges, culverts, weirs, and structures in the flood plain may be considered in the computations. The steady flow system is designed for application in flood plain management and flood insurance studies to evaluate floodway encroachments. Also, capabilities are available for assessing the change in water surface profiles due to channel improvements, and levees.

Special features of the steady flow component include multiple plan analyses, multiple profile computations, multiple bridge and/or culvert opening analyses, and split flow optimization.

\subsubsection{Unsteady flow simulation}

This component of the HEC-RAS modeling system is capable of simulating one-dimensional unsteady flow through a full network of open channels. The unsteady flow equation solver was adapted from the Unsteady Network (UNET) model (Barkau 1992, HEC 1997). The unsteady flow component was developed primarily for subcritical flow regime calculations. However, with the latest release of HEC-RAS, the model can now perform mixed flow regime (subcritical, supercritical, hydraulic jumps, and drawdowns) calculations in the unsteady flow computations module.

HEC-RAS solves the complete one-dimensional Saint-Venant equations of unsteady flow. The model is able to simulate back water flow effects and a variety of hydraulic structures, thus allowing one to model tidally influenced streams and rivers. As an example, the National Weather Service used HECRAS to model the Potomac River under tidal influence (Mashriqui et al. 2010) using observed time series as the tidal boundary conditions.

The hydraulic calculations for cross-sections, bridges, culverts, and other hydraulic structures that were developed for the steady flow component were incorporated into the unsteady flow module.

Special features of the unsteady flow component include dam break analysis, levee breaching and overtopping, pumping stations, navigation dam operations, and pressurized pipe systems. 


\subsubsection{Sediment transport/movable boundary computations}

This component of the modeling system is intended for the simulation of one-dimensional sediment transport/movable boundary calculations resulting from scour and deposition over moderate time periods (typically years, although applications to single flood events are possible).

The sediment transport potential is computed by grain size fraction, thereby allowing the simulation of hydraulic sorting and armoring. Major features include the ability to model a full network of streams, channel dredging, various levee and encroachment alternatives, and the use of several different equations for the computation of sediment transport.

The model is designed to simulate long-term trends of scour and deposition in a stream channel that might result from modifying the frequency and duration of the water discharge and stage, or from modifying the channel geometry. This system can be used to evaluate deposition in reservoirs, design channel contractions required to maintain navigation depths, predict the influence of dredging on the rate of deposition, estimate maximum possible scour during large flood events, and evaluate sedimentation in fixed channels.

\subsubsection{NSM (Nutrient Simulation Module)}

The NSM includes two kinetics: NSMI and NSMII. The levels of NSM are determined by the number of interacting state variables involved in water quality simulation and the degree of their interactions. NSMI simulates nutrients and eutrophication processes using 16 state variables. Water quality state variables may be individually activated or deactivated. Using 24 state variables, NSMII simulates nutrients and eutrophication processes in the water column. Sediment oxygen demand and nutrient release can be simulated using zero-order approach or a sediment diagenesis module. Carbon, nitrogen, and phosphorus have complex cycles that are mediated by physical, chemical, and biotic processes in the water and in the bed sediment. The NSMI consists of three nitrogen species, two phosphorus species, three carbon species (particulate organic carbon, dissolved organic carbon, and dissolved inorganic carbon). Algae, benthic algae, dissolved oxygen (DO), carbonaceous biochemical oxygen demand (CBOD), pathogen, and alkalinity are also simulated in NSMI. The incorporation of NSM water quality capabilities in HEC-RAS provides a fully integrated 
riverine hydraulic, sediment and water quality model that encompasses diagnostic, predictive, and operational applications that greatly aid in TMDL development and implementation required by the Clear Water Act.

\subsubsection{CTT\&F (Contaminant Transport, Transformation and Fate)}

The Contaminant Transport, Transformation, and Fate [CTT\&F] submodel was renamed as the Contaminant Simulation Module (CSM) in HEC-RAS. The CSM is capable of modeling contaminants in an aquatic system as influenced by the following processes: ionization, multi-phase partitioning, degradation, photolysis, hydrolysis, volatilization, generalized second-order reaction, and transformations where one chemical undergoes a reaction and is transformed to a daughter product. Any process in CSM can be ignored by use of switches where such processes are not applicable. Each contaminant in the water column is subject to adsorption and desorption with dissolved organic carbon (DOC) and solids. The dissolved phase in the bulk water (aqueous phase), the adsorbed phase to DOC in the bulk water, and the adsorbed phases to organic and inorganic solids are simulated in CSM. Two types of contaminant partitioning options are included for algae and solid particulates; equilibrium and nonequilibrium, in which adsorption/desorption can be affected by rate limiting processes. The water column exchange with underlying sediments and exchange with the atmosphere are also simulated in CSM. The CSM can model multiple contaminants in one simulation. The contaminants themselves are arbitrary, in that the specific contaminant to be simulated is defined through the specification of processes and kinetic rates.

\subsection{Advantages and limitations of the technology/methodology}

HSPF simulates the hydraulics in the river channel network by using a simplified hydraulic function table (FTABLE) of water depth, surface area, water volume, and outflow of a reach. The FTABLE in the HSPF model is the essential component for flow routing in reaches. It describes a fixed functional relationship between water depth, surface area, water volume, and outflow in the river reach. Under the assumption of a fixed depth, area, volume, and outflow relationship, the HSPF model cannot account for reverse flow and backwater effects to the upstream reaches in a timedependent way. It is very important to perform the flow routing process accurately because routed results affect sediment routing and the instream contaminant process, both of which are strongly tied to water 
routing. The limitations of a standalone HSPF model (HSPF-only) and the demands of assessing the attainability of contaminant standards derived from the model-based results require additional capabilities not available within HSPF. These needed capabilities will be accomplished through the linked HSPF/HEC-RAS system. For the HEC-RAS boundary requirements, HSPF will provide discharge, sediment, and contaminant loads from the major streams and drainages tributary to the HEC-RAS model segments. HSPF is used to estimate flow, sediment, and water quality loadings based on watershed characteristics and landuse practices for all demonstration sites. HEC-RAS is used to estimate in-stream aquatic sediment and contaminant concentrations and to relate these concentrations to the contaminant criteria. Therefore, a linked modeling system, HSPF/HEC-RAS, should better address regulatory compliance and the range of environmental migration pathways and potential exposures.

To demonstrate the improvements HSPF/HEC-RAS may have over HSPFonly, the Performance Objectives and Assessments (PO 1 through PO 7) discussed in Chapters 3 and 6 have been assessed for HSPF-Only and HSPF/HEC-RAS. In cases where no improvement is observed between HSPF-Only and HSPF/HEC-RAS, we discuss the factors that contribute to no improvement and make recommendations for the cases where a linked modeling system may not be advantageous to an installation.

Given that HSPF/HEC-RAS computes more state variables than HSPF-only, one limitation may be the availability of field data sufficient to calibrate and validate the system for all the required model state variables. As a part of this demonstration, we assess existing data being collected at the various sites to see if sufficient data is being collected; if not, then we make recommendations on additional sampling efforts that could improve the models.

Model linkage procedures must consider spatial and temporal characteristics of the systems being linked, correspondence and transference of the state variables between the models, and file format specifics for proper communications between two models. All of these issues were investigated and analyzed to ensure proper representation of the watershed and riverine system.

Additional model details can be found in Chapter 5 - Test Design. 


\section{Performance Objectives}

Table 3-1 lists the linked modeling system performance objectives. Performance metrics include qualitative and quantitative parameters. Quantitative parameter threshold values are based on the recommended model performance evaluation statistics from literature review (ASCE 1993, Moriasi et al. 2007). Qualitative parameters are based on visual comparison of modeled and observed data and previous modeling experience. According to Legates and McCabe (1999), graphical techniques are essential to appropriate model evaluation. A graph is defined as a time series plot of modeled results and observed data throughout the calibration and validation periods. Time series graphs help identify model bias and can identify differences in timing and magnitude of peak flows. Performance metrics are organized by demonstration/validation study component and methodology component.

Table 3-1. Demonstration Validation Performance Objectives and Thresholds.

\begin{tabular}{|c|c|c|c|}
\hline Performance Objective & Metric & Data Requirements & Success Criteria \\
\hline \multicolumn{4}{|c|}{ Quantitative and Qualitative Performance Objectives } \\
\hline \multirow[t]{2}{*}{$\begin{array}{l}\text { 1. Linked model (HSPF+HEC-RAS) } \\
\text { accurately simulates major } \\
\text { components of hydrologic cycle } \\
\text { and stream flow }\end{array}$} & $\begin{array}{l}\text { 1.1. Linked model improves accuracy } \\
\text { in simulating monthly observed stream } \\
\text { flow at watershed outlet when } \\
\text { compared to field observations. }\end{array}$ & $\begin{array}{l}\text { - } \text { Climate data } \\
\text { - } \text { minimum of one site for each } \\
\text { watershed } \\
\text { - Soil survey } \\
\text { - Landuse/Land cover data } \\
\text { - Channel Cross-Sections } \\
\text { - Observed daily flow discharge } \\
\text { data }\end{array}$ & $\begin{array}{l}\text { At each site, the linked } \\
\text { model's performance will be } \\
\text { evaluated as "successful" if } \\
\text { NSE }>0.5, \text { RSR }<0.7 \text {, } \\
\text { PBIAS<25\% of monthly } \\
\text { observed stream flow volume } \\
\text { at the watershed outlet. } \\
\text { Visual comparison of modeled } \\
\text { monthly time series stream } \\
\text { flow and observed data is } \\
\text { acceptable. }\end{array}$ \\
\hline & $\begin{array}{l}\text { 1.2. Linked model improves accuracy } \\
\text { in simulating daily average observed } \\
\text { stream flow at watershed outlet when } \\
\text { compared to field observations. }\end{array}$ & $\begin{array}{l}\text { - } \text { Climate data } \\
\text { - Stream flow over time at a } \\
\text { minimum of one site for each } \\
\text { watershed } \\
\text { - Soil survey } \\
\text { - Landuse/cover data } \\
\text { - Channel Cross-Sections } \\
\text { Observed daily flow discharge } \\
\text { data }\end{array}$ & $\begin{array}{l}\text { At each site, the linked } \\
\text { model's performance will be } \\
\text { evaluated as "successful" if } \\
\text { NSE }>0.5, \text { RSR }<0.7 \text {, } \\
\text { PBIAS }<25 \% \text { of daily observed } \\
\text { stream flow volume at the } \\
\text { watershed outlet. } \\
\text { - Visual comparison of modeled } \\
\text { daily time series stream flow } \\
\text { and observed data is } \\
\text { acceptable. }\end{array}$ \\
\hline $\begin{array}{l}\text { 2. Linked model accurately } \\
\text { simulates soil erosion and } \\
\text { sediment transport }\end{array}$ & $\begin{array}{l}\text { 2.1. Linked model improves accuracy } \\
\text { in simulating monthly sediment load } \\
\text { discharging from watershed when } \\
\text { compared to field observations. }\end{array}$ & 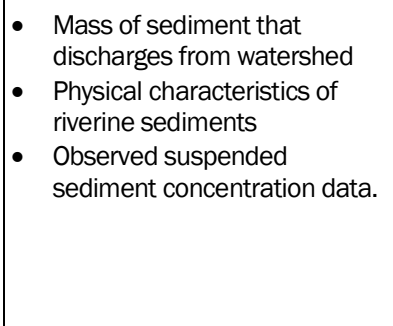 & $\begin{array}{l}\text { - Linked models' performance } \\
\text { will be evaluated as } \\
\text { "successful" if NSE }>0.5 \text {, } \\
\text { RSR }<0.7, \text { PBIAS }<55 \% \text { of } \\
\text { monthly sediment load } \\
\text { discharging from watershed. } \\
\text { Visual comparison of modeled } \\
\text { monthly time series stream } \\
\text { sediment load and observed } \\
\text { data is acceptable. }\end{array}$ \\
\hline
\end{tabular}




\begin{tabular}{|c|c|c|c|}
\hline Performance Objective & Metric & Data Requirements & Success Criteria \\
\hline & $\begin{array}{l}\text { 2.2. Linked model improves accuracy } \\
\text { in simulating daily average sediment } \\
\text { load discharging from watershed when } \\
\text { compared to field observations. }\end{array}$ & $\begin{array}{l}\text { - Mass of sediment that } \\
\text { discharges from watershed } \\
\text { - Physical characteristics of } \\
\text { riverine sediments } \\
\text { - Observed suspended } \\
\text { sediment concentration data. }\end{array}$ & $\begin{array}{l}\text { Linked model's performance } \\
\text { will be evaluated as } \\
\text { "successful" if NSE }>0.5 \text {, } \\
\text { RSR<0.7, PBIAS }<70 \% \text { of daily } \\
\text { sediment load discharging } \\
\text { from watershed. } \\
\text { Visual comparison of modeled } \\
\text { daily time series stream } \\
\text { sediment load and observed } \\
\text { data is acceptable. }\end{array}$ \\
\hline \multirow[t]{2}{*}{$\begin{array}{l}\text { 3. Linked model accurately } \\
\text { simulates selected contaminant } \\
\text { fate and transport }\end{array}$} & $\begin{array}{l}\text { 3.1. Linked model improves accuracy } \\
\text { in simulating monthly contaminant } \\
\text { load discharging from watershed when } \\
\text { compared to field observations. }\end{array}$ & 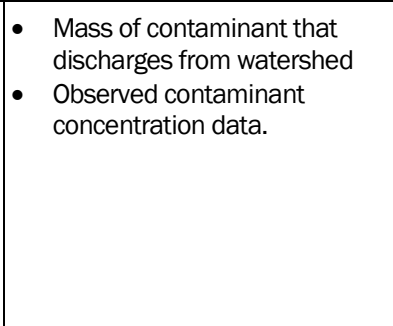 & $\begin{array}{l}\text { - Linked model's performance } \\
\text { will be evaluated as } \\
\text { "successful" if NSE }>0.5 \text {, } \\
\text { RSR }<0.7, \text { PBIAS }<70 \% \text { of } \\
\text { monthly contaminant load } \\
\text { discharging from watershed. } \\
\text { Visual comparison of modeled } \\
\text { monthly time series stream } \\
\text { contaminant load and } \\
\text { observed data is acceptable. }\end{array}$ \\
\hline & $\begin{array}{l}\text { 3.2. Linked model improves accuracy } \\
\text { in simulating daily average } \\
\text { contaminant load discharging from } \\
\text { watershed compared to field } \\
\text { observations. }\end{array}$ & $\begin{array}{l}\text { - Mass of contaminant that } \\
\text { discharges from watershed } \\
\text { - Observed contaminant } \\
\text { concentration data. }\end{array}$ & $\begin{array}{l}\text { Linked model's performance } \\
\text { will be evaluated as } \\
\text { "successful" if NSE }>0.5 \text {, } \\
\text { RSR }<0.7, \text { PBIAS }<70 \% \text { of daily } \\
\text { contaminant load discharging } \\
\text { from watershed. } \\
\text { Visual comparison of modeled } \\
\text { daily time series stream } \\
\text { contaminant load and } \\
\text { observed data is acceptable. }\end{array}$ \\
\hline \multicolumn{4}{|c|}{ Qualitative Performance Objectives } \\
\hline \multirow[t]{2}{*}{$\begin{array}{l}\text { 4. Linked model accurately } \\
\text { simulates nutrient (nitrogen and } \\
\text { phosphorus) fate and transport }\end{array}$} & $\begin{array}{l}\text { 4.1. Linked model improves accuracy } \\
\text { in simulating monthly nutrient load } \\
\text { discharging from watershed compared } \\
\text { to field observations. }\end{array}$ & $\begin{array}{l}\text { - Mass of nutrients that } \\
\text { discharge from watershed } \\
\text { - Observed nutrient } \\
\text { concentration data. }\end{array}$ & $\begin{array}{l}\text { Linked model's performance } \\
\text { will be evaluated as } \\
\text { "successful" if NSE }>0.5 \text {, } \\
\text { RSR }<0.7, \text { PBIAS }<70 \% \text { of } \\
\text { monthly nutrient load } \\
\text { discharging from watershed. } \\
\text { Visual comparison of modeled } \\
\text { monthly time series stream } \\
\text { nutrient load and observed } \\
\text { data is acceptable. }\end{array}$ \\
\hline & $\begin{array}{l}\text { 4.2. Linked model improves accuracy } \\
\text { in simulating daily average nutrient } \\
\text { load discharging from watershed } \\
\text { compared to the field observations. }\end{array}$ & $\begin{array}{l}\text { - Mass of nutrients that } \\
\text { discharge from watershed } \\
\text { Observed nutrient } \\
\text { concentration data. }\end{array}$ & $\begin{array}{l}\text { - Linked model's performance } \\
\text { will be evaluated as } \\
\text { "successful" if NSE }>0.5 \text {, } \\
\text { RSR<0.7, PBIAS }<70 \% \text { of daily } \\
\text { nutrient load discharging from } \\
\text { watershed. } \\
\text { Visual comparison of modeled } \\
\text { daily time series stream } \\
\text { nutrient load and observed } \\
\text { data is acceptable. }\end{array}$ \\
\hline $\begin{array}{l}\text { 5. Ability of Linked Model to } \\
\text { Simulate Management Scenarios }\end{array}$ & $\begin{array}{l}5.1 \text { Linked model is able to simulate } \\
\text { the effect of management scenarios } \\
\text { on monthly flows, sediment, nutrients, } \\
\text { and contaminants }\end{array}$ & $\begin{array}{l}\text { - } \quad \text { Management Scenarios } \\
\text { 1.1, 2.1, 3.1, and 4.1. }\end{array}$ & $\begin{array}{l}\text { If no observed data is } \\
\text { available, then a visual } \\
\text { comparison between base } \\
\text { conditions and management } \\
\text { scenarios. } \\
\text { If observed data is available, } \\
\text { then same criteria as stated in } \\
\text { POs 1.1, 2.1, 3.1, and 4.1. }\end{array}$ \\
\hline
\end{tabular}




\begin{tabular}{|c|c|c|c|}
\hline Performance Objective & Metric & Data Requirements & Success Criteria \\
\hline & $\begin{array}{l}5.2 \text { Linked model is able to simulate } \\
\text { the effect of management scenarios } \\
\text { on daily average flows, sediment, } \\
\text { nutrients, and contaminants }\end{array}$ & $\begin{array}{l}\text { - } \quad \text { Management Scenarios } \\
\text { 1.2, 2.2, 3.2, and 4.2. }\end{array}$ & $\begin{array}{l}\text { - If no observed data is } \\
\text { available, then a visual } \\
\text { comparison between base } \\
\text { conditions and management } \\
\text { scenarios. } \\
\text { - If observed data is available. } \\
\text { then same criteria as stated in } \\
\text { POs 1.1, 2.1, 3.1, and 4.1. }\end{array}$ \\
\hline \multirow[t]{3}{*}{ 6. Data Availability } & $\begin{array}{l}\text { 6.1. Degree model is capable of using } \\
\text { readily available national data sets } \\
\text { versus installation specific data to run } \\
\text { the model. }\end{array}$ & $\begin{array}{l}\text { - All data required by model to } \\
\text { obtain "successful" results. }\end{array}$ & $\begin{array}{l}\text { Most data required for model } \\
\text { is readily available in national } \\
\text { datasets. }\end{array}$ \\
\hline & $\begin{array}{l}\text { 6.2. If local data are required or useful, } \\
\text { degree to which it is typically available. }\end{array}$ & $\begin{array}{l}\text { - Local data required by model } \\
\text { to obtain "successful" results. }\end{array}$ & $\begin{array}{l}\text { - Local data required for model } \\
\text { is readily available at } \\
\text { installation or able to be } \\
\text { obtained with minimal } \\
\text { resource requirements. }\end{array}$ \\
\hline & $\begin{array}{l}\text { 6.3. Resource requirements to collect } \\
\text { local data (if necessary) are } \\
\text { acceptable. }\end{array}$ & $\begin{array}{l}\text { - Local data required by model } \\
\text { to obtain "successful" results. }\end{array}$ & $\begin{array}{l}\text { Resources required to obtain } \\
\text { necessary local data are } \\
\text { reasonable in time and cost. }\end{array}$ \\
\hline \multirow[t]{4}{*}{ 7. Ease of use } & $\begin{array}{l}\text { 7.1. Resources and expertise required } \\
\text { to run linked model. }\end{array}$ & $\begin{array}{l}\text { - Interviews with range } \\
\text { personnel and contractors. }\end{array}$ & $\begin{array}{l}\text { - } \text { Resources and expertise to } \\
\text { run linked model are } \\
\text { reasonable. }\end{array}$ \\
\hline & $\begin{array}{l}\text { 7.2. Time requirement to obtain output } \\
\text { variables is reasonable. }\end{array}$ & $\begin{array}{l}\text { - Interviews with range } \\
\text { personnel and contractors } \\
\text { - } \quad \text { Time required to run model } \\
\text { and summarize results. }\end{array}$ & $\begin{array}{l}\text { Engineer with } 1 \text { to } 5 \text { years of } \\
\text { experience in modeling, } \\
\text { hydrology, and water quality } \\
\text { can run the model in a matter } \\
\text { of minutes to hours. }\end{array}$ \\
\hline & $\begin{array}{l}\text { 7.3. Expertise required to setup, } \\
\text { parameterize, run, and interpret the } \\
\text { results of the model is reasonable. }\end{array}$ & $\begin{array}{l}\text { - Interviews with range } \\
\text { personnel and contractors } \\
\text { - Time required to train on } \\
\text { system use. }\end{array}$ & $\begin{array}{l}\text { Engineer with } 1 \text { to } 5 \text { years of } \\
\text { experience in modeling, } \\
\text { hydrology, and water quality } \\
\text { can be trained on model use } \\
\text { and results interpretation in } 2 \\
\text { weeks. (Based on previous } \\
\text { modeling experience). }\end{array}$ \\
\hline & $\begin{array}{l}\text { 7.4. Degree and ease to which the } \\
\text { model needs to be calibrated and } \\
\text { validated to set the model up at new } \\
\text { application site. }\end{array}$ & $\begin{array}{l}\text { - Interviews with range } \\
\text { personnel and contractors } \\
\text { - Time required to calibrate and } \\
\text { validate model at a new site. }\end{array}$ & $\begin{array}{l}\text { - Linked model can be set up } \\
\text { for one watershed within } \\
2 \text { months. (Based on previous } \\
\text { modeling experience) } \\
\text { - Linked model can be } \\
\text { calibrated and validated for } \\
\text { one watershed within } \\
4 \text { months. (Based on previous } \\
\text { modeling experience). }\end{array}$ \\
\hline
\end{tabular}

As mentioned in Table 3-1, three statistical measures are computed to assess how well the linked modeling system performs when compared to observed data: (1) Nash-Sutcliffe Efficiency; (2) Percent Bias (PBIAS); and (3) RMSE-observations standard deviation ratio (RSR). ${ }^{*}$ Table $3-2$ indicates the general performance ratings for recommended statistics for a monthly time step. 


\subsection{Nash-Sutcliffe Efficiency (NSE)}

NSE is a normalized statistic that determines the relative magnitude of the residual variance ("noise") compared to the observed data variance ("information"). NSE indicates how well the plot of observed versus modeled data fits the 1:1 line. NSE ranges between $-\infty$ and 1.0 ( 1 inclusive), with $\mathrm{NSE}=1$ being the optimal value. Values between 0.0 and 1.0 are generally viewed as acceptable levels of performance, whereas values $<0.0$ indicate that the mean observed value is a better predictor than the modeled value, which indicates unacceptable performance.

$$
N S E=1.0-\frac{\sum_{i}\left(O V_{i}-M V_{i}\right)^{2}}{\sum_{i}\left(O V_{i}-\overline{O V}\right)^{2}}
$$

Based on Moriasi et al. (2007), a "successful" NSE for flow, sediment, contaminants, and nutrients will be greater than 0.5 .

NSE is the best objective function for reflecting the overall fit of a hydrograph (shape, peak, timing, etc.).

\subsection{Percent Bias (PBIAS)}

PBIAS measures the average tendency of the modeled data to be larger or smaller than their observed counterparts. The optimal value of PBIAS is o.o, with low-magnitude values indicating accurate model simulation. Positive values indicate model underestimation bias, and negative values indicate model overestimation bias. PBIAS has the ability to clearly indicate poor model performance.

$$
\text { PBIAS }=\frac{\sum_{i}\left(O V_{i}-M V_{i}\right)}{\sum_{i} O V_{i}} * 100
$$

Based on Moriasi et al. (2007), a "successful" PBIAS for monthly and peak flows will be less than $25 \%$; for monthly sediment, less than $55 \%$; for peak sediment, less than $70 \%$; and for monthly and peak contaminants and nutrients it will be less than $70 \%$. 
PBIAS is commonly used to quantify water balance (streamflow volume) errors and can be easily extended to evaluate load (mass load) errors.

\subsection{RMSE-Observations Standard Deviation Ratio (RSR)}

RSR standardizes root mean square error (RMSE) using the observations' standard deviation. RSR incorporates the benefits of error index statistics and includes a scaling/normalization factor so that resulting statistics and reported values can apply to various constituents. RSR varies from the optimal value of $o$, which indicates zero RMSE or residual variation and therefore perfect model simulation, to a large positive value. The lower the RSR, the lower the RMSE, and the better the model simulation performance.

$$
R S R=\frac{R M S E}{O V_{\text {STDEV }}}=\frac{\sqrt{\frac{1}{n} \sum_{i}\left(O V_{i}-M V_{i}\right)^{2}}}{\sqrt{\frac{1}{n} \sum_{i}\left(O V_{i}-\overline{O V}\right)^{2}}}
$$

where $n$ is the number of observations during the simulation period, $O V_{i}=$ observed value, $\overline{O V}=$ mean observed value, $M V_{i}=$ modeled value, $\overline{M V}=$ mean modeled value.

Table 3-2. General performance ratings for recommended statistics.

\begin{tabular}{|c|c|c|c|}
\hline $\begin{array}{c}\text { Statistical Modeling } \\
\text { Metrics }\end{array}$ & $\begin{array}{l}\text { Performance } \\
\text { Rating }\end{array}$ & $\begin{array}{l}\text { Daily } \\
\text { Average }\end{array}$ & $\begin{array}{l}\text { Monthly } \\
\text { Average }\end{array}$ \\
\hline \multicolumn{4}{|c|}{ Stream Flow } \\
\hline Nash-Sutcliffe (NSE) & $\begin{array}{l}\text { Very Good (VG) } \\
\text { Good (G) } \\
\text { Satisfactory (S) } \\
\text { Unsatisfactory (U) }\end{array}$ & NSE $>=0.5$ & $\begin{array}{l}0.75<=\mathrm{NSE}<=1.0 \\
0.65<\mathrm{NSE}<=0.75 \\
0.5<=\mathrm{NSE}<=0.65 \\
\mathrm{NSE}<0.5\end{array}$ \\
\hline $\begin{array}{l}\text { RMSE-observation } \\
\text { standard deviation ratio } \\
\text { (RSR) }\end{array}$ & $\begin{array}{l}\text { Very Good (VG) } \\
\text { Good (G) } \\
\text { Satisfactory (S) } \\
\text { Unsatisfactory (U) }\end{array}$ & RSR $<0.8$ & $\begin{array}{l}0.0<=\mathrm{RSR}<=0.5 \\
0.5<\mathrm{RSR}<=0.6 \\
0.6<\mathrm{RSR}<=0.7 \\
\mathrm{RSR}>0.7\end{array}$ \\
\hline Percent Bias (PBIAS \%) & $\begin{array}{l}\text { Very Good (VG) } \\
\text { Good (G) } \\
\text { Satisfactory (S) } \\
\text { Unsatisfactory (U) }\end{array}$ & PBIAS $<=|35|$ & $\begin{array}{l}\text { PBIAS }<|10| \\
|10|<=\text { PBIAS }<|15| \\
|15|<=\text { PBIAS }<|25| \\
\text { PBIAS }>=|25|\end{array}$ \\
\hline
\end{tabular}




\begin{tabular}{|c|c|c|c|}
\hline $\begin{array}{l}\text { Statistical Modeling } \\
\text { Metrics }\end{array}$ & $\begin{array}{l}\text { Performance } \\
\text { Rating }\end{array}$ & $\begin{array}{l}\text { Daily } \\
\text { Average }\end{array}$ & $\begin{array}{l}\text { Monthly } \\
\text { Average }\end{array}$ \\
\hline \multicolumn{4}{|c|}{ Sediment Load Discharging } \\
\hline Nash-Sutcliffe (NSE) & $\begin{array}{l}\text { Very Good (VG) } \\
\text { Good (G) } \\
\text { Satisfactory (S) } \\
\text { Unsatisfactory (U) }\end{array}$ & NSE $>=0.25$ & NSE $>0.4$ \\
\hline $\begin{array}{l}\text { RMSE-observation } \\
\text { standard deviation ratio } \\
\text { (RSR) }\end{array}$ & $\begin{array}{l}\text { Very Good (VG) } \\
\text { Good (G) } \\
\text { Satisfactory (S) } \\
\text { Unsatisfactory (U) }\end{array}$ & RSR $<0.9$ & RSR $<0.75$ \\
\hline Percent Bias (PBIAS \%) & $\begin{array}{l}\text { Very Good (VG) } \\
\text { Good (G) } \\
\text { Satisfactory (S) } \\
\text { Unsatisfactory (U) }\end{array}$ & PBIAS $<=|75|$ & $\begin{array}{l}\text { PBIAS }<|15| \\
|15|<=\text { PBIAS }<|30| \\
|30|<=\text { PBIAS }<|55| \\
\text { PBIAS }>=|55|\end{array}$ \\
\hline \multicolumn{4}{|c|}{ Water Quality/Nutrients } \\
\hline Nash-Sutcliffe (NSE) & $\begin{array}{l}\text { Very Good (VG) } \\
\text { Good (G) } \\
\text { Satisfactory (S) } \\
\text { Unsatisfactory (U) }\end{array}$ & NSE $>=0.35$ & NSE $>0.5$ \\
\hline $\begin{array}{l}\text { RMSE-observation } \\
\text { standard deviation ratio } \\
\text { (RSR) }\end{array}$ & $\begin{array}{l}\text { Very Good (VG) } \\
\text { Good (G) } \\
\text { Satisfactory (S) } \\
\text { Unsatisfactory (U) }\end{array}$ & RSR $<0.85$ & RSR $<0.7$ \\
\hline Percent Bias (PBIAS \%) & $\begin{array}{l}\text { Very Good (VG) } \\
\text { Good (G) } \\
\text { Satisfactory (S) } \\
\text { Unsatisfactory (U) }\end{array}$ & PBIAS $<=|85|$ & $\begin{array}{l}\text { PBIAS }<|25| \\
|25|<=\text { PBIAS }<|40| \\
|40|<=\text { PBIAS }<|70| \\
\text { PBIAS }>=|70|\end{array}$ \\
\hline
\end{tabular}




\section{Site Description}

This chapter provides a concise description of the proposed third demonstration site, Patuxent Watershed, Maryland. The overall ESTCP project calls for sequential demonstrations at Fort Hood (House Creek Watershed), at Naval Base Ventura County Point Mugu (Calleguas Creek watershed), and Patuxent Watershed. Within the Patuxent Watershed, there are two DoD facilities: (1) Fort Meade and (2) Patuxent Naval Air Station. The sequential plan design was developed with the intent of applying the lessons learned at each previous demonstration site to the next demonstration location. Additionally, in consultation with ESTCP and the DoD Clean Water Act Services Steering Committee, the Patuxent Watershed demonstration site was selected.

In regard to the Fort Hood demonstration, there were a number of lessons learned. Good meteorological gage data that reflect the watershed weather conditions are necessary for applying the HSPF-only and the linked model to the demonstration site to fairly evaluate the model performance. In the selection of the Calleguas Creek Watershed demonstration site, meteorological gages were identified within the watershed boundaries and we did not rely solely on gages outside the watershed boundary.

The HSPF-only and linked model are limited in their ability to model surface water and groundwater interactions; therefore, this technology may not be applicable for the sites where the surface water (stream flow) is heavily affected by groundwater. For the Fort Hood demonstration study, we focused the modeling on surface runoff and channel transport.

The development of a continuous period of record for sediment, or other constituents requires sufficient field samples for the period of record covering a range of storm events. If there are not sufficient samples to develop a comprehensive period of record then the U.S. Geological Survey (USGS) LOADEST (load estimator) model results should not be useful in computing performance statistics (e.g., NSE, RSR, and PBIAS), and thus only visual comparisons between model results and field samples should be used in evaluating model performance. For the Calleguas Creek watershed demonstration study, we did evaluate whether or not USGS LOADEST could be used to generate a synthetic period of record accurate enough for computing performance statistics; however, there were not sufficient 
observed data sets to do this. To evaluate model effectiveness, we had to use graphical methods, rather than performance statistics, to evaluate sediment and water quality results.

Finally, while we did perform a cursory field trip to assess watershed features within House Creek watershed, we determined that additional field investigations and surveys may have helped us better characterize key features within the watershed and thus improve model results. We had multiple meetings with Calleguas Creek stakeholders (military and non-military), along with a multi-day field trip with some of the stakeholders to better understand the key features in the watershed. In addition, Mr. Mark George, Naval Facilities Engineering Command (NAVFAC) team member, helped facilitate additional data gathering and coordination activities among the stakeholders.

In regard to lessons learned from the Patuxent River Watershed Demonstration Study, there were a couple of items we identified. The first was investigating the methods for dealing with dry bed conditions in the HECRAS model. While the Patuxent River did not experience dry bed conditions, we do want to discuss one method used by hydraulic engineers. In cases where a stream may be intermittent, one can incorporate a very narrow slot at the low point in the cross-section to numerically keep the channel wet during very low flows. The volume of water in the slot is negligible, but numerically the channel never goes dry, while practically it does. The second lesson learned is that if one wishes to set up the linked model, there needs to be more observed water quality data to better constrain the HSPF output being used as boundary conditions to the HEC-RAS model. Across demonstration studies done as part of this project, that was a continuing data gap that would need to be closed to make full use of this system.

\subsection{Site selection}

The Naval Air Systems Command (NAVAIR) Naval Air Station (NAS) Patuxent River in St. Mary's County, Maryland was selected as the third demonstration location, due to the relatively high abundance of available datasets to support model input development and model calibration activities in the nearby Patuxent River Watershed. St. Mary's County, Maryland is home to the NAVAIR headquarters and NAS Patuxent River, which is located on the mouth of the Patuxent River and Chesapeake Bay (Figure 4- 
1). Located in southcentral Maryland, the Patuxent River Watershed flows south from its headwaters in Montgomery and Howard Counties to its confluence with Chesapeake Bay (Figure 4-1). The HUC-8 watershed" covers over $927 \mathrm{sq} \mathrm{mi}\left(2,400 \mathrm{~km}^{2}\right)$ and is roughly half developed and agricultural land uses and half undeveloped land uses. The river flows between the Washington, DC and Baltimore metro areas, covering the Columbia, Laurel, and Bowie urban areas, and the watershed intersects a total of seven Maryland counties; St. Mary's, Calvert, Charles, Prince George's, Anne Arundel, Montgomery, and Howard.

Figure 4-1. Map of the Patuxent River Watershed.

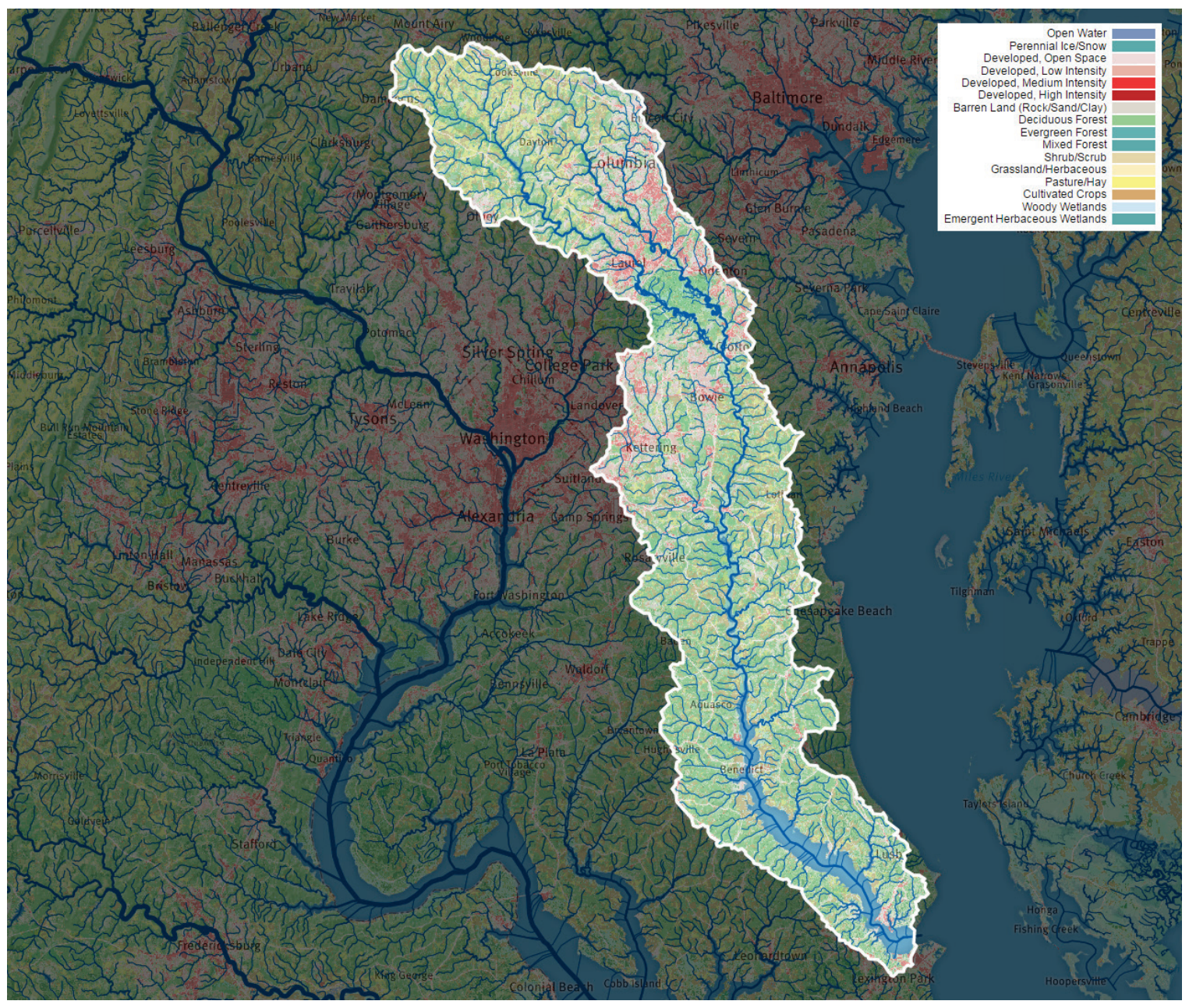

Source: wikiwatershed.org

* HUC: Hydrologic Unit Code 
The Patuxent River Watershed is dominated by forested land uses and is bordered by several water bodies, including the Potomac and Patuxent rivers. Developed and agricultural land uses comprise $14 \%$ and $20 \%$, respectively. Figure 4-2 shows spatial distribution of hydrologic soil group in the Patuxent River Watershed.

Figure 4-2. Map of hydrologic soil groups in the Patuxent River Watershed.

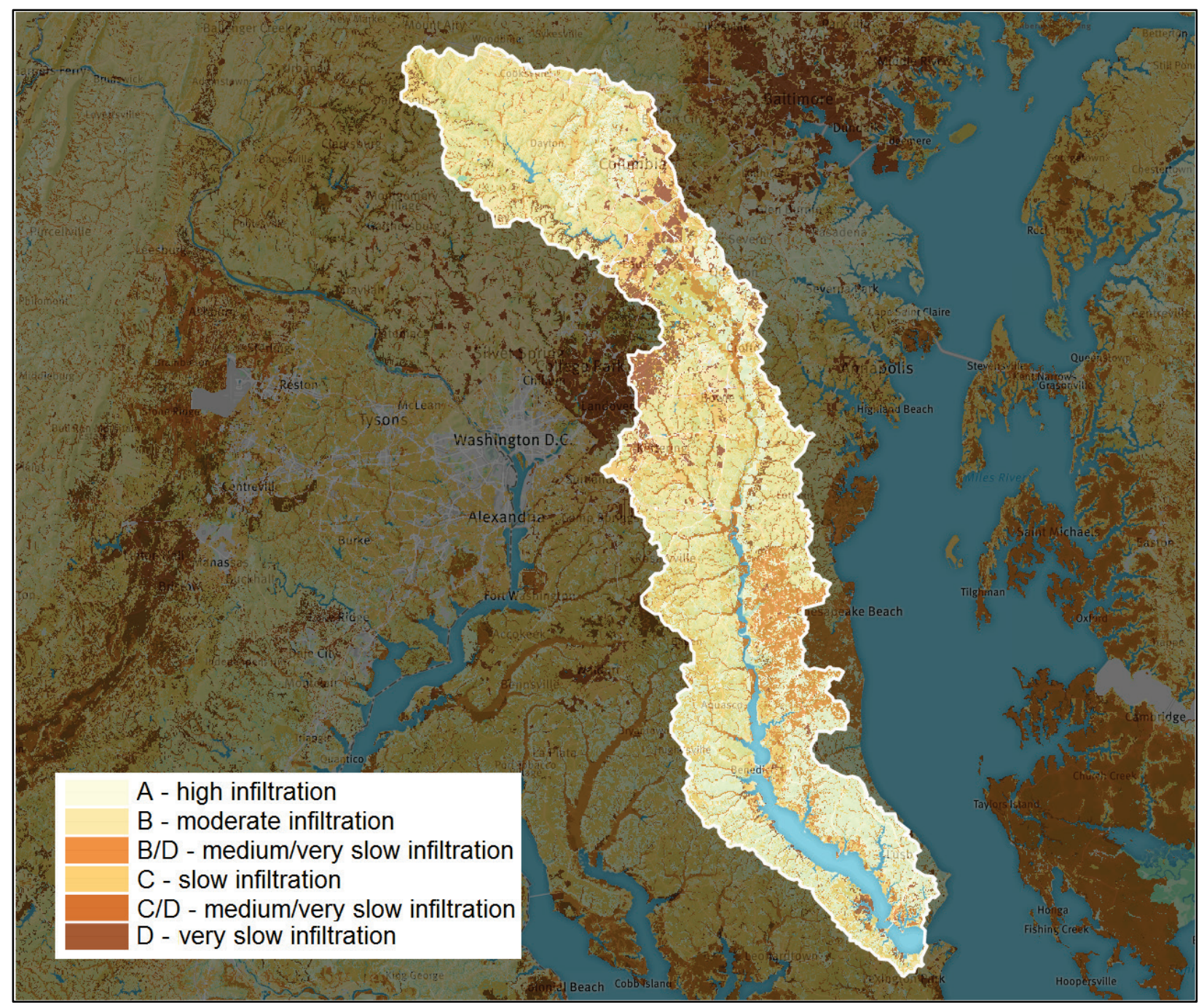

Source: wikiwatershed.org

Observed hydrology and water quality data used for the Phase 5 model calibration were available from the Chesapeake Community Modeling Program website (CCMP 2017b). Figure 4-3 and Table 4-1 show streamflow and water quality sampling station locations and inventories for sites in the Patuxent River Watershed. 
Figure 4-3. Patuxent Watershed flow and water quality gages.

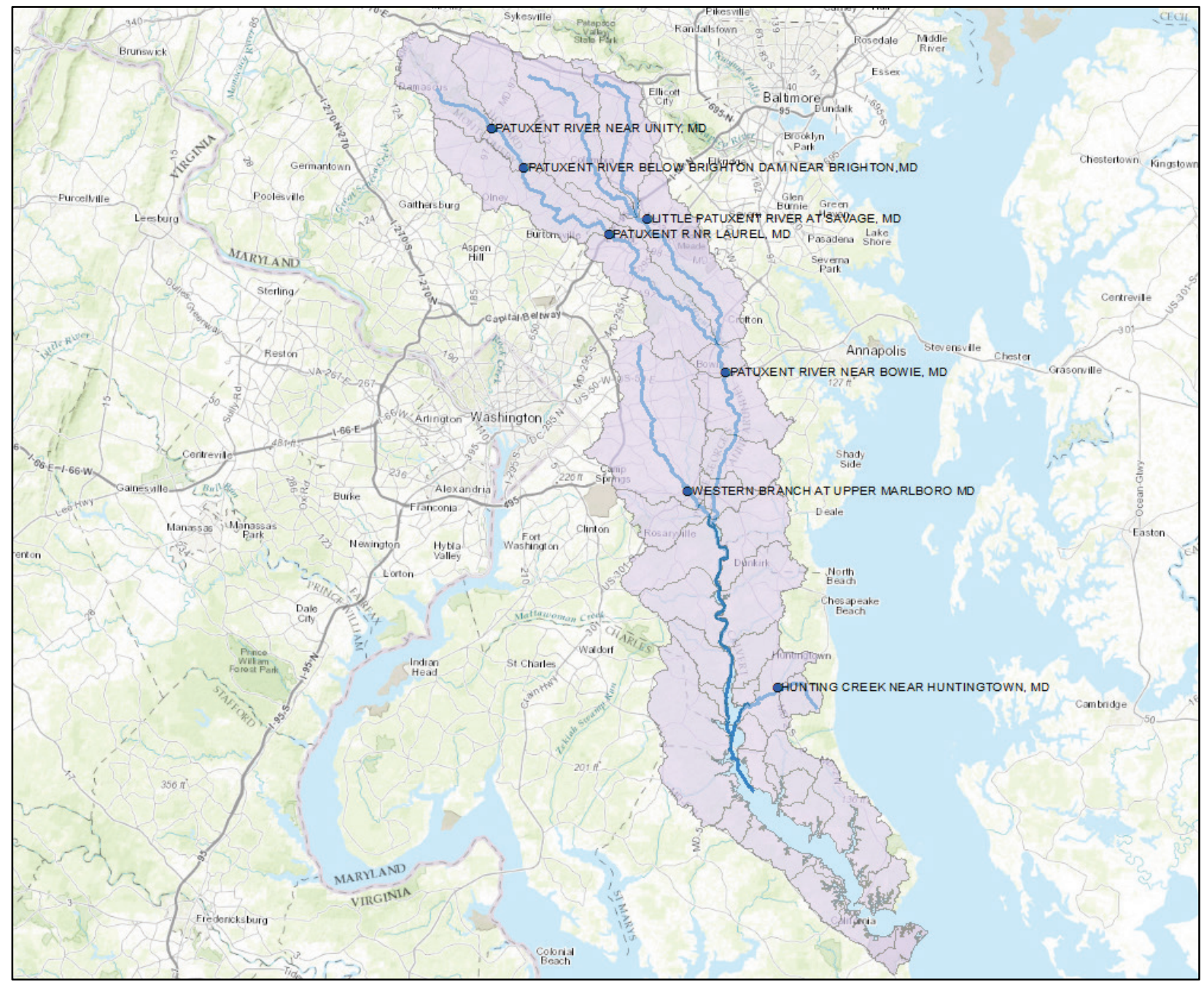

Table 4-1. Inventory (count and start/end years) of streamflow and water quality observations for sampling stations in the Patuxent River Watershed.

\begin{tabular}{|l|c|c|c|c|c|c|c|}
\hline Parameter* & $\begin{array}{c}\text { Hunting Ck near } \\
\text { Huntingtown }\end{array}$ & $\begin{array}{c}\text { W. Branch at } \\
\text { Upper Marlboro }\end{array}$ & $\begin{array}{c}\text { Patuxent } \\
\text { near Unity }\end{array}$ & $\begin{array}{c}\text { Patuxent near } \\
\text { Brighton }\end{array}$ & $\begin{array}{c}\text { Little Patuxent } \\
\text { near Laurel }\end{array}$ & $\begin{array}{c}\text { Patuxent } \\
\text { near Laurel }\end{array}$ & $\begin{array}{c}\text { Patuxent } \\
\text { near Bowie }\end{array}$ \\
\hline Flow & 3533 & 6696 & 8856 & 8850 & 7890 & 8858 & 8858 \\
\hline & $1988-1998$ & $1985-2006$ & $1982-2006$ & $1982-2006$ & $1985-2006$ & $1982-2006$ & $1982-2006$ \\
\hline Water Temp & 130 & 535 & 657 & - & 267 & 269 & 1242 \\
\hline & $1985-1998$ & $1985-2000$ & $1974-2005$ & & $1971-2000$ & $1980-2005$ & $1977-2005$ \\
\hline TSS conc. & 351 & 934 & 874 & - & 531 & 474 & 3381 \\
\hline & $1985-1998$ & $1978-2000$ & $1974-2005$ & & $1971-2000$ & $1974-2005$ & $1974-2005$ \\
\hline PO ${ }_{4}$ conc. & 280 & 788 & 651 & - & 450 & 359 & 1239 \\
\hline & $1985-1998$ & $1977-2000$ & $1974-2005$ & & $1976-2000$ & $1974-2005$ & $1974-2005$ \\
\hline Org P conc. & 261 & 771 & 575 & - & 421 & 255 & 1186 \\
\hline & $1985-1998$ & $1977-2000$ & $1974-2005$ & & $1976-2000$ & $1974-2005$ & $1974-2005$ \\
\hline
\end{tabular}




\begin{tabular}{|c|c|c|c|c|c|c|c|}
\hline Parameter* & $\begin{array}{c}\text { Hunting Ck near } \\
\text { Huntingtown }\end{array}$ & $\begin{array}{l}\text { W. Branch at } \\
\text { Upper Marlboro }\end{array}$ & $\begin{array}{l}\text { Patuxent } \\
\text { near Unity }\end{array}$ & $\begin{array}{c}\text { Patuxent near } \\
\text { Brighton }\end{array}$ & $\begin{array}{c}\text { Little Patuxent } \\
\text { near Laurel }\end{array}$ & $\begin{array}{c}\text { Patuxent } \\
\text { near Laurel }\end{array}$ & $\begin{array}{c}\text { Patuxent } \\
\text { near Bowie }\end{array}$ \\
\hline \multirow[t]{2}{*}{ TP conc. } & 300 & 890 & 804 & - & 464 & 473 & 1521 \\
\hline & $1985-1998$ & $1977-2000$ & $1974-2005$ & & $1971-2000$ & $1974-2005$ & $1974-2005$ \\
\hline \multirow[t]{2}{*}{$\mathrm{NH}_{3}$ conc. } & 282 & 873 & 756 & - & 453 & 464 & 1469 \\
\hline & $1985-1998$ & $1977-2000$ & $1974-2005$ & & $1971-2000$ & $1974-2005$ & $1974-2005$ \\
\hline \multirow[t]{2}{*}{$\mathrm{NO}_{3}$ conc. } & 188 & 685 & 650 & - & 363 & 472 & 1295 \\
\hline & $1985-1998$ & $1977-2000$ & $1974-2005$ & & $1971-2000$ & $1974-2005$ & $1974-2005$ \\
\hline \multirow[t]{2}{*}{ TN conc. } & 207 & 639 & 576 & - & 336 & 242 & 991 \\
\hline & $1985-1998$ & $1985-2000$ & $1985-2005$ & & $1985-2000$ & 1986-2005 & $1978-2005$ \\
\hline \multirow[t]{2}{*}{ DO conc. } & - & 520 & 463 & - & 88 & 365 & 1348 \\
\hline & & $1977-2000$ & $1974-2005$ & & $1971-2000$ & $1974-2005$ & 1974-2005 \\
\hline \multirow[t]{2}{*}{ TOC conc. } & 287 & 690 & 657 & - & 446 & 193 & 941 \\
\hline & $1985-1998$ & $1985-2000$ & $1985-2005$ & & $1973-2000$ & 1986-2005 & 1978-2005 \\
\hline \multirow[t]{2}{*}{ Chlorophyll a } & 2 & 213 & 304 & - & 35 & 316 & 763 \\
\hline & $1997-1997$ & $1977-1997$ & 1976-2005 & & 1976-1997 & 1976-2005 & 1976-2005 \\
\hline \multirow[t]{2}{*}{ TSS load } & - & - & - & - & - & 7305 & 7305 \\
\hline & & & & & & $1985-2004$ & $1985-2004$ \\
\hline \multirow[t]{2}{*}{$\mathrm{PO}_{4}$ load } & - & - & - & - & - & - & 7305 \\
\hline & & & & & & & $1985-2004$ \\
\hline \multirow[t]{2}{*}{ TP load } & - & - & - & - & - & 7305 & 7305 \\
\hline & & & & & & $1985-2004$ & $1985-2004$ \\
\hline \multirow[t]{2}{*}{$\mathrm{NO}_{3}$ load } & - & - & - & - & - & - & 7305 \\
\hline & & & & & & & $1985-2004$ \\
\hline \multirow[t]{2}{*}{ TN load } & - & - & - & - & - & 7305 & 7305 \\
\hline & & & & & & $1985-2004$ & $1985-2004$ \\
\hline
\end{tabular}

Figure 4-4 shows the primary precipitation stations and metrological station in the vicinity of the Patuxent River Watershed that were used to generate hourly precipitation model input time series. The historical data from $1 / 1 / 1984$ to $12 / 31 / 2005$ are available. Table 4-2 lists the site selection criteria for the Patuxent Watershed. 
Figure 4-4. Patuxent Watershed precipitation and meteorological gages.

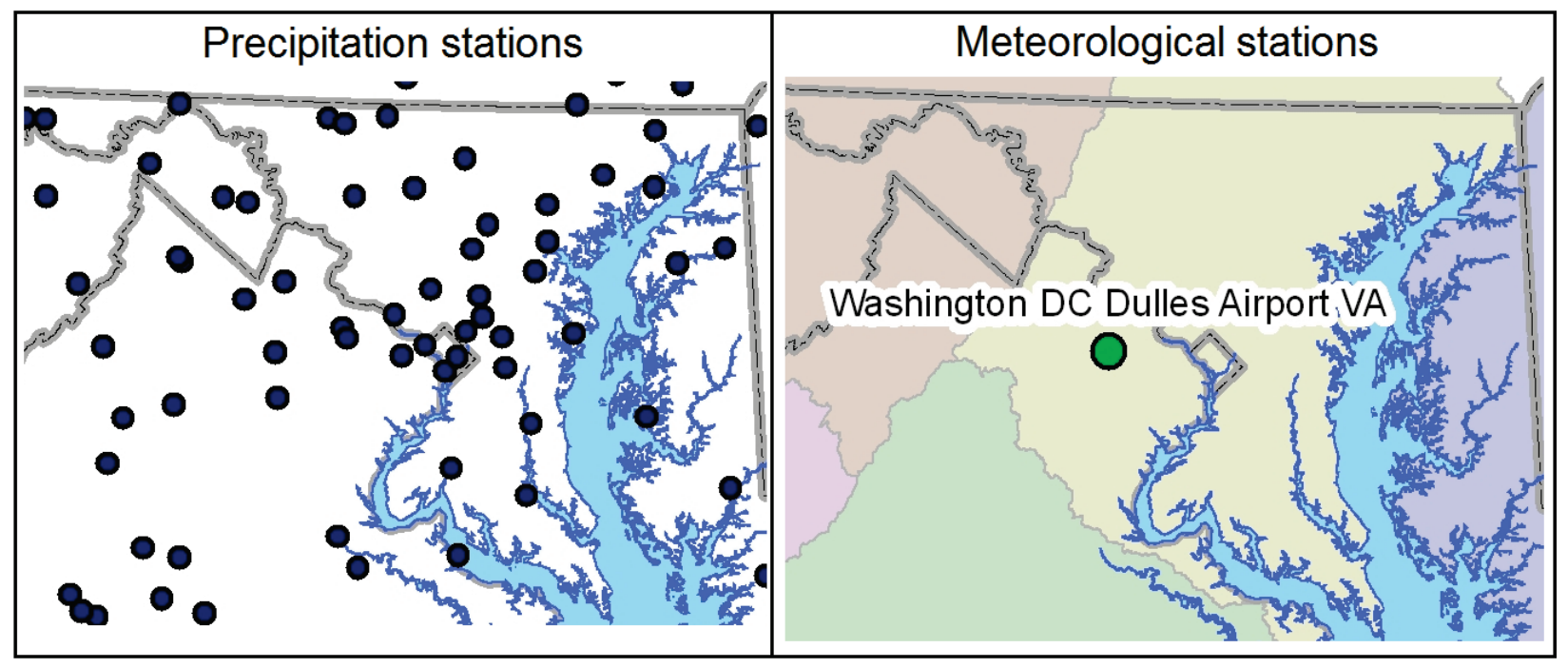

Table 4-2. Site selection criteria for Patuxent Watershed.

\begin{tabular}{|c|c|c|c|}
\hline & & Relative Importance & Patuxent Watershed \\
\hline Parameter & $\begin{array}{l}\text { Avallability or Preterred } \\
\text { Value(s) }\end{array}$ & $\begin{array}{c}\text { (1-5, with } 1 \text { being } \\
\text { highest) }\end{array}$ & Patuxent River \\
\hline Drainage Area $\left(\mathrm{mi}^{2}\right)$ & 10 to 2000 & 5 & 930 \\
\hline Mainstream Length (mi) & 5 to 250 & 4 & 110 \\
\hline $\begin{array}{l}\text { Site Characteristic Data } \\
\text { (Digital Elevation Model [DEM], } \\
\text { Soil, Landuse, Channel } \\
\text { Geometry) Availability }\end{array}$ & Availability & 1 & Yes \\
\hline Annual Precipitation (in) & $>5$ & 3 & $>5$ \\
\hline Number of Precipitation Gages & $>2$ & 2 & $>10$ \\
\hline $\begin{array}{l}\text { Precipitation Data Collection } \\
\text { Frequency }\end{array}$ & Sub-daily & 1 & Hourly/Daily \\
\hline Peak Daily Discharge (cfs) & 100 to 50000 & 1 & Criteria Met \\
\hline Average Annual Discharge (cfs) & 10 to 350 & 1 & Criteria Met \\
\hline Number of Flow Gages & $>1$ & 2 & 6 \\
\hline $\begin{array}{l}\text { Flow Data Collection } \\
\text { Frequency }\end{array}$ & Sub-daily & 1 & Sub-Daily \\
\hline $\begin{array}{l}\text { Average Suspended Sediment } \\
\text { Concentration }(\mathrm{mg} / \mathrm{L})\end{array}$ & $>5 \mathrm{mg} / \mathrm{L}$ & 1 & $>5 \mathrm{mg} / \mathrm{L}$ \\
\hline Number of Sediment Gages & $>1$ & 2 & 6 \\
\hline $\begin{array}{l}\text { Sediment Data Collection } \\
\text { Frequency }\end{array}$ & Event Based & 1 & Discrete \\
\hline $\begin{array}{l}\text { Average Nitrogen }\left(\mathrm{NH}_{4}, \mathrm{NO}_{3} \text {, }\right. \\
\text { Total Kjeldahl Nitrogen }[\mathrm{TKN}]) \\
\text { Concentration (mg/L) }\end{array}$ & $\begin{array}{l}\mathrm{NH}_{4}>0.05 \\
\mathrm{NO}_{3}>0.25 \\
\mathrm{TKN}>0.2\end{array}$ & 2 & $\begin{array}{l}\mathrm{NH}_{4}>0.05 \\
\mathrm{NO}_{3}>0.25 \\
\mathrm{TKN}>0.2\end{array}$ \\
\hline
\end{tabular}




\begin{tabular}{|c|c|c|c|}
\hline \multirow[b]{2}{*}{ Parameter } & \multirow{2}{*}{$\begin{array}{l}\text { Availability or Preferred } \\
\text { Value(s) }\end{array}$} & \multirow{2}{*}{$\begin{array}{l}\text { Relative Importance } \\
\text { (1-5, with } 1 \text { being } \\
\text { highest) }\end{array}$} & \multirow{2}{*}{$\begin{array}{c}\text { Patuxent Watershec } \\
\text { Patuxent River }\end{array}$} \\
\hline & & & \\
\hline $\begin{array}{l}\text { Average Phosphorus }\left(\mathrm{PO}_{4}, \mathrm{TP}\right) \\
\text { Concentration }(\mathrm{mg} / \mathrm{L})\end{array}$ & $\begin{aligned} \mathrm{PO}_{4} & >0.005 \\
\mathrm{TP} & >0.006\end{aligned}$ & 2 & $\begin{array}{l}\mathrm{PO}_{4}>0.005 \\
\mathrm{TP}>0.006\end{array}$ \\
\hline $\begin{array}{l}\text { Average Contaminant } \\
\text { Concentration }(\mathrm{mg} / \mathrm{L})\end{array}$ & $\begin{array}{l}\text { Contaminant Specific } \\
\text { Value }\end{array}$ & 2 & Discrete \\
\hline $\begin{array}{l}\text { Number of Water Quality and } \\
\text { Contaminant Gages }\end{array}$ & $>1$ & 2 & 6 \\
\hline $\begin{array}{l}\text { Water Quality and } \\
\text { Contaminant Data Collection } \\
\text { Frequency }\end{array}$ & Event & 2 & Discrete \\
\hline $\begin{array}{l}\text { Period of Observed Data } \\
\text { (Climate, Flow, Sediment } \\
\text { and/or Water Quality Record) }\end{array}$ & 3 to 5 years & 1 & 21 \\
\hline
\end{tabular}

As referenced in previous sections, the watersheds of the Chesapeake Bay are under a TMDL, as directed by Presidential Executive Order 13508. Development of the Chesapeake Bay TMDL required extensive knowledge of the stream flow characteristics of the watershed, sources of pollution, distribution and acreage of the various land uses, appropriate BMPs, the transport and fate of pollutants, precipitation data and many other factors (USEPA 2010b). The TMDL is informed by a series of models, calibrated to decades of water quality and other data, and refined based on input from dozens of Chesapeake Bay scientists. Modeling, which is an approach that uses observed and simulated data to replicate what is occurring in the environment to make future predictions, was a critical and valuable tool to develop the Chesapeake Bay TMDL.

The development of the TMDL consisted of several steps:

- USEPA provided the jurisdictions with loading allocations for nitrogen, phosphorus, and sediment for the major river basins by jurisdiction.

- Jurisdictions developed draft Phase I Watershed Implementation Plans (WIP) to achieve those basin-jurisdiction allocations. In those draft WIPs, jurisdictions made decisions on how to further sub-allocate the basin-jurisdiction loadings to various individual point sources and a number of point and nonpoint source pollution sectors.

- USEPA evaluated the draft WIPs and, where deficiencies existed, USEPA provided backstop allocations in the draft TMDL that consisted 
of a hybrid of the jurisdiction WIP allocations, modified by USEPA allocations for some source sectors to fill gaps in the WIPs.

- The draft TMDL was published for a 45-day public comment period and USEPA held 18 public meetings in all six states and the District of Columbia. Public comments were received, reviewed, and considered for the final TMDL.

- Jurisdictions, working closely with USEPA, revised, and strengthened Phase I WIPs and submitted final versions to USEPA.

- USEPA evaluated the final WIPs and used them along with public comments to develop the final TMDL.

Since nitrogen and phosphorus loadings from all parts of the Bay watershed have an impact on the impaired tidal segments of the Bay and its rivers, it was necessary for USEPA to allocate the nitrogen and phosphorus loadings in an equitable manner to the states and basins. USEPA used three basic guides to divide these loads:

- Allocated loads should protect living resources of the Bay and its tidal tributaries and should result in all segments of the Bay mainstem, tidal tributaries and embayments meeting water quality standards for dissolved oxygen, chlorophyll a, water clarity and underwater Bay grasses.

- Tributary basins that contribute the most to the Bay water quality problems must do the most to resolve those problems (on a pound-perpound basis).

- All tracked and reported reductions in nitrogen, phosphorus and sediment loads are credited toward achieving final assigned loads.

\subsection{Site location and history}

This section provides a short description of the location, mission, and relevant physical characteristics for Fort Meade and NAS Patuxent River.

\subsubsection{Fort Meade, Maryland}

Fort Meade is located in northwestern Anne Arundel County. It is located between the cities of Baltimore and Washington, DC, and is located approximately 20 minutes from the state capital of Annapolis (Fort Meade 2017). It is bounded on the northwest by the Baltimore-Washington Parkway (Maryland Route 295) and on the south and southwest by the Patuxent Freeway (Maryland Route 32), which leads southeast towards 
Annapolis and northwest to Columbia. The climate in this area is characterized by hot, humid summers and generally mild to cool winters.

Fort Meade is a U.S. Army installation located in Maryland that includes the Defense Information School, the Defense Media Activity, the U.S. Army Field Band, and the headquarters of U.S. Cyber Command, the National Security Agency, the Defense Courier Service, and Defense Information Systems Agency headquarters. Initially called Camp Annapolis Junction, the post was opened as "Camp Admiral" in 1917 on $29.7 \mathrm{sq} \mathrm{mi}\left(77 \mathrm{~km}^{2}\right)$ acquired for a training camp. The post was called Camp Meade Cantonment and Field Signal School by 1918 and in 1919, the Camp Benning tank schoolformed from the World War I Camp Colt and Tobyhanna schools-was transferred to the fort before the Tank Corps was disbanded. During World War II, Fort Meade was used as a recruit training post and prisoner of war camp, in addition to a holding center for approximately 384 Japanese, German, and Italian immigrant residents of the United States arrested as potential fifth columnists. The second U.S. Army Headquarters transferred to the post on June 15, 1947; and in the 1950s, the post became headquarters of the National Security Agency (Fort Meade 2017).

From the 1950s until the 1970s, the Fort Meade radar station had various radar equipment and control systems for air defense (e.g., the 1st Martin AN/FSG-I Antiaircraft Defense System). Fort Meade also had the first Nike Ajax surface-to-air missiles in December 1953 (operational May 1954). In 1977, a merger organized the fort's U.S. Army Intelligence Agency as part of the U.S. Army Intelligence and Security Command. On 1 October 1991, a wing of the Air Force Intelligence Command transferred to Fort Meade, and the organization was replaced by the 7oth Operations Group on May 1, 2005. In the early $1990 \mathrm{~s}, 12.7 \mathrm{sq} \mathrm{mi}\left(33 \mathrm{~km}^{2}\right)$ was transferred from the post to the Patuxent Research Refuge. A planned closure of the post in the $1990 \mathrm{~s}$ was not implemented, and the Defense Information School moved to the fort in 1995. The 311th Signal Command headquarters was at Fort Meade from 1996 - September 2006. The 70th Intelligence Wing headquarters was established at Fort Meade on July 17, 2000, and the Base Realignment and Closure, 2005, designated Fort Meade to gain $\approx 5,700$ positions making it the third largest workforce of any Army installation (Fort Meade 2017)

August 27, 2007, USEPA issued an order to assess the contamination at 14 hazardous waste sites on Fort Meade (e.g., ordnance disposal area, 1940s 
waste dump, closed sanitary landfill). A September 2007 environmental impact report identified adding two golf courses that could be a "significant threat to the biological and territorial integrity of the Patuxent Research Refuge." The Army responded it is taking steps to limit the environmental damage (Fort Meade 2017)

\subsubsection{NAS Patuxent River, Maryland}

NAS Patuxent River is located in St. Mary's County, Maryland, where the waters of the Patuxent River and Chesapeake Bay meet (NAS Patuxent River 2017).

NAS Patuxent River is approximately 90 miles $(145 \mathrm{~km})$ from the Fleet in Norfolk, Virginia, and 65 miles ( $105 \mathrm{~km}$ ) south of the nation's capital; the 14,500-acre (5868-ha) Complex includes the main station in Lexington Park, Webster Outlying Field in St. Inigoes, Navy Recreation Center Solomons in Calvert County, and Bloodsworth Island Range in the Chesapeake Bay (NAS Patuxent River 2017).

NAS Patuxent River was commissioned on April 1, 1943. It was selected to host Naval Air Systems Command (NAVAIR) and Naval Air Warfare Center Aircraft Division (NAWCAD) headquarters, as well as 50 other tenant activities, during a round of Base Realignment and Closures (BRAC) in the mid-1990s; a move that brought more than 20,000 military and civilian employees to the air station (NAS Patuxent River 2017).

\subsection{Site characteristics}

The Patuxent River is the largest river with a watershed located entirely within the state of Maryland, and one of the eight major tributaries to the Chesapeake Bay. The basin includes roughly 64,000 acres (25,900 ha) across seven counties, encompassing one-tenth of the State's total land area. The Patuxent River is 110 miles $(177 \mathrm{~km})$ long, and by the time it reaches the Chesapeake Bay, the Patuxent River is over a miles $(1.6 \mathrm{~km})$ wide and $175 \mathrm{ft}$ (53 $\mathrm{m}$ ) deep, making it the deepest river in Maryland. Roughly half its length is considered tidal (Bevan-Dangel and Tutman 2007).

The headwaters of the river are found near Mt. Airy, where Montgomery, Frederick, and Howard counties meet. Five main tributaries, the Western Branch, Middle Patuxent River, Little Patuxent River, Cabin Branch, and 
Collington Branch, as well as several smaller tributaries, comprise the total drainage of the Patuxent Watershed. Over one-fourth of the watershed, $28 \%$, is in Prince George's County. Howard County is next at $21 \%$, and Calvert County is third with $18 \%$. Anne Arundel County holds 14\%, St Mary's County, 9\%, and Montgomery County, $7 \%$. Charles County contains the smallest part of the watershed with $3 \%$ (Bevan-Dangel and Tutman 2007).

The river provides a diverse and varied habitat for fish, birds, and other animals. There are cold water trout streams in the far north of the River in the State preserved Patuxent River Park, whooping crane breeding grounds in the Patuxent Wildlife Refuge, vast marshlands in the Jug Bay Wetlands sanctuary, and open water fisheries around Solomon's Island at the river's mouth. The river is home to more than 100 species of fish, including bass, catfish, chain pickerel, and bluefish, and provides nesting grounds and habitat for bald eagles, blue herons, osprey, and numerous other bird and animal species (Bevan-Dangel and Tutman 2007).

The human footprint on the river is formidable. There were once great iron foundries in the north, active dams and mills in Savage Falls near Columbia, and industrial sites near Laurel. Two dams were built to create drinking water supply reservoirs between Montgomery and Howard Counties. Surface mining sites pocket Prince George's and Anne Arundel, while major Federal military installations span the river. Sprawling development continues to convert land throughout the watershed, with an immediate increase in housing coming in the next few years as a result of BRAC nationwide. Over 20 major and minor wastewater treatment plants and countless septic systems are spread along the Patuxent's length to support that growth. Current estimates for land cover in the watershed are: $30 \%$ developed, $23 \%$ agriculture, $43 \%$ forest, $3 \%$ water, and $1 \%$ barren. The most urbanized areas include Columbia, Bowie, Laurel, and the southern edges of Ellicott City. The Maryland Department of Planning projects that the population of the Patuxent Watershed will increase by 200,000 people, to nearly 1,200,000 residents from 2007 to 2020. If recent trends continue, the impact of population growth on the watershed will far exceed the actual rise in population, as the amount of land lost to development far outpaced the actual rate of population growth in the past 30 years (BevanDangel and Tutman 2007). 


\subsection{Site-related permits and regulations}

The scope of this project does not require environmental permits for the demonstration to proceed. Conversely, this project will quantify the functional link of streams and rivers to the watershed to better assess sediment, nutrient, and contaminant loading to water systems as a result of landscape activities. The major environmental drivers for Patuxent Watershed are upland erosion, nutrient and contaminant fate, and transport due to a broad range of military, agricultural, and municipal activities, so this demonstration will focus on soil erosion, channel sedimentation, nutrient and contaminant fate, and transport. 


\section{Test Design}

The following section will discuss model conceptualization, data preparation, model setup, model calibration, sampling protocols, and calibration and data quality issues.

\subsection{Watershed and river model conceptualization}

The Chesapeake Bay Watershed HSPF model has a history of development of over 30 years and has been used to simulate hydrology, sediment, and nutrients for the purpose of informing management decisions pertaining to improving water quality and restoration objectives (Shenk et al. 2012). The current version of the model is called Phase 5.3 and included enhancements such as increased segmentation, a longer simulation period, and greater spatial coverage (USEPA 2010a). The Phase 5.3.2 model package was obtained from the Chesapeake Community Modeling Program (CCMP) website in January 2017 (CCMP 2017a).

The Patuxent River Watershed portion of the HSPF model includes simulation of 33 subbasins and 10 reach segments (RCHRES) (Figure 5-1). The model was constructed to simulate point and nonpoint source loading from several dozen landuse types for the 1985-2005 time period (USEPA 2010a), and the full simulation period is 1/1/1984-12/31/2005, with 1984 serving as a warm-up year. 
Figure 5-1. Map of the Patuxent River Watershed HSPF model delineation.

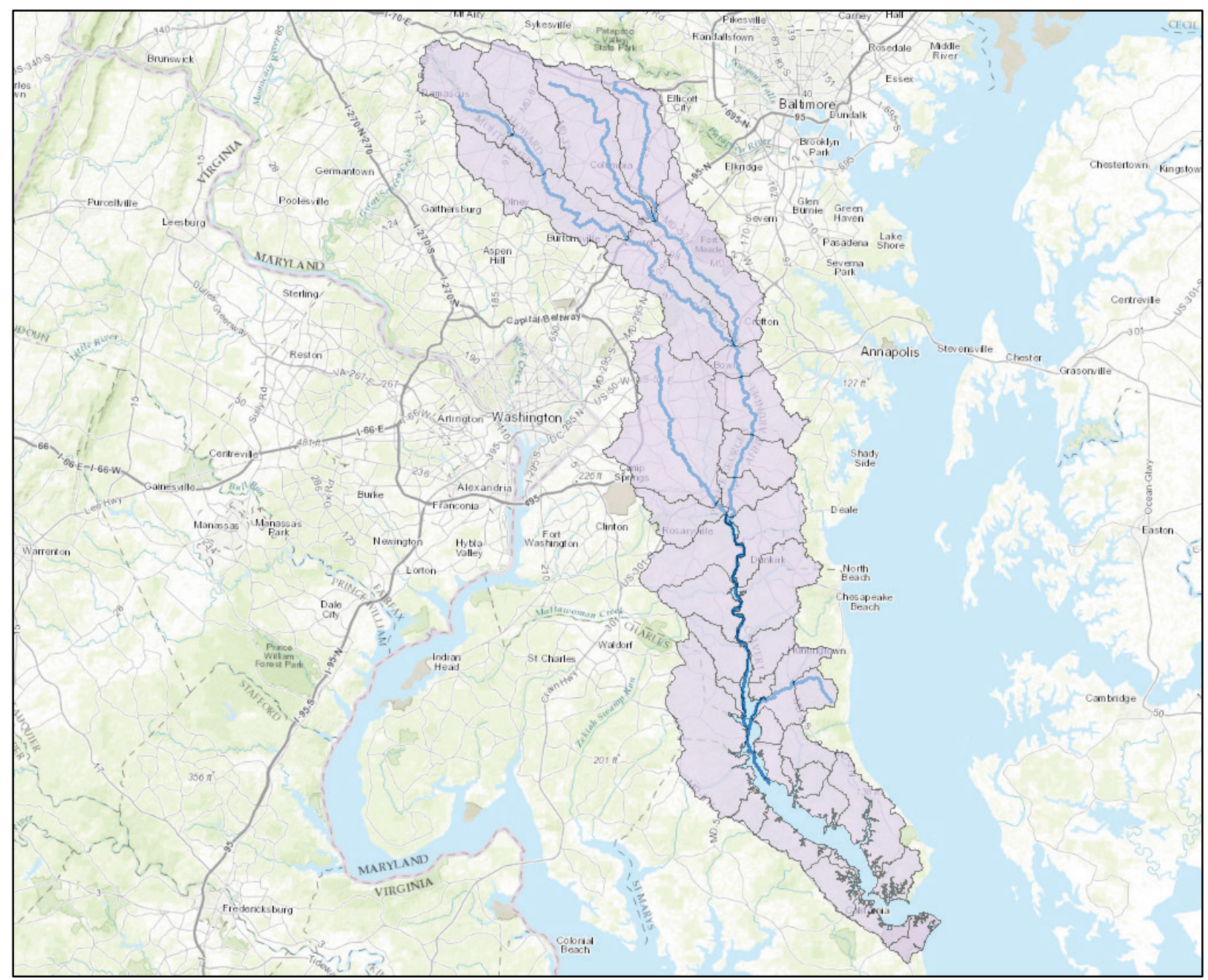

The HEC-RAS model (Figure 5-2) was developed from two separate steady state HEC-RAS models prepared by U.S. Army Corps of Engineers (USACE), Baltimore District. The cross-section geometry for these models was collected through topographic survey. The bank stations, levee locations, roughness coefficients, minimum baseflow, and pilot channel were adjusted as deemed appropriate to the morphology and hydraulics of the system.

In addition to geometric data, the HEC-RAS graphic user interface (GUI) allows for the input of job control, model parameters, meteorological, flow, sediment, and constituent data in support of model simulations. 
Figure 5-2. Patuxent River HEC-RAS model domain.

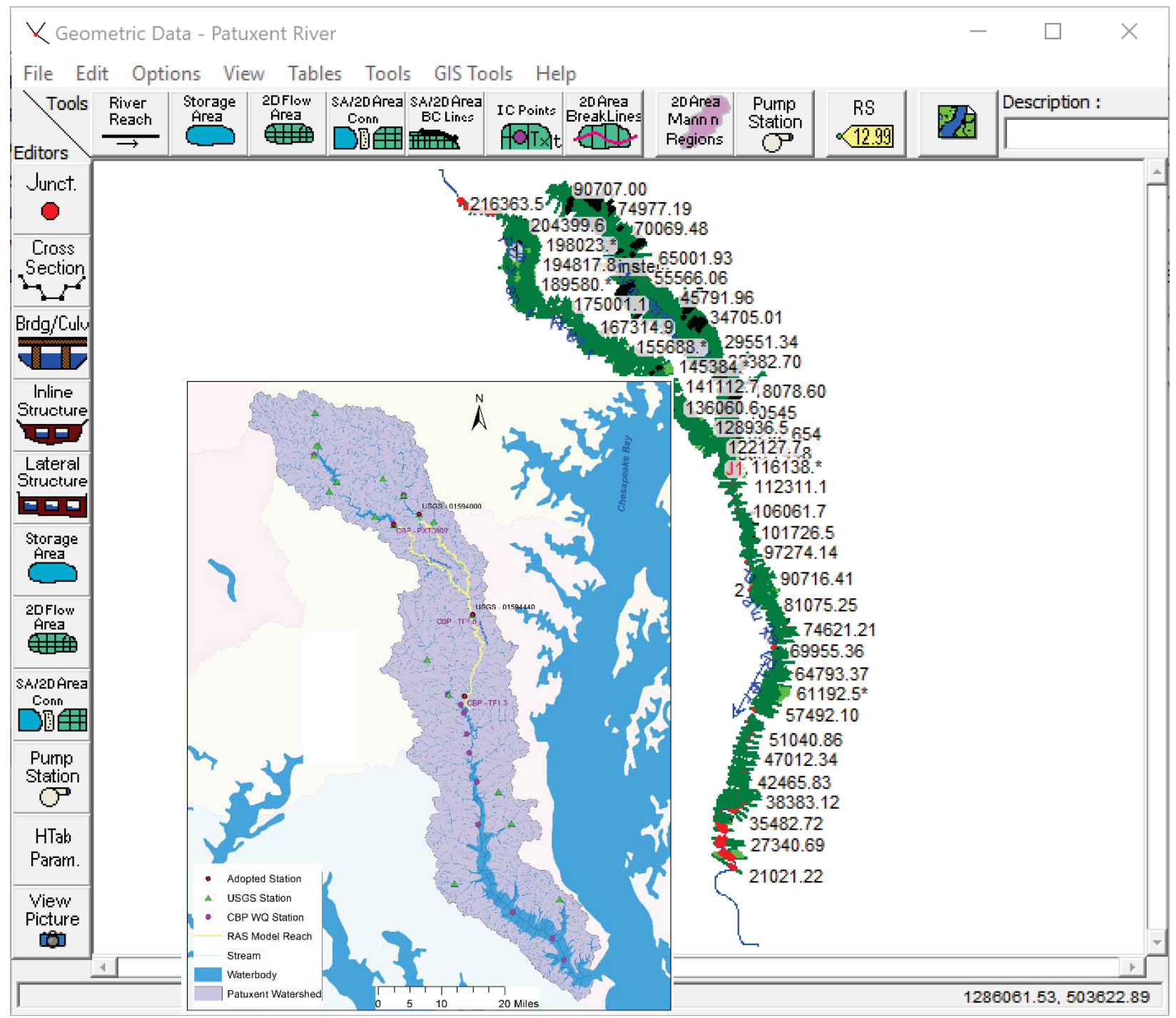

\subsection{Data collection and preparation}

The information used to develop the HSPF model include topography, landuse or vegetative cover, weather, fertilizer and manure applications, crop nutrient uptake, atmospheric deposition, septic loads, point sources, water diversions, stream network, and watershed configuration data (Shenk et al. 2012). Details describing the derivation of these input datasets are described in USEPA (2010a). Figure 4-4 shows the primary precipitation stations and metrological station in the vicinity of the Patuxent River Watershed that were used to generate hourly precipitation model input time series. Figure 4-2 shows hydrologic soil groups represented in the Patuxent River Watershed. 
Observed hydrology and water quality data used for the Phase 5 model calibration were obtained in February 2017 from the CCMP website (CCMP 2017b). Data were processed for entry into a Microsoft Access database to facilitate both visual and statistical comparisons against model output. Figure 4-3 and Table 4-1 show streamflow and water quality sampling station locations and inventories for sites in the Patuxent River Watershed. The USGS ESTIMATOR software program was used to estimate observed water quality loading for two river segments in the Patuxent, as indicated in Table 4-1 (see the columns with data for "Patuxent near Bowie" and "Patuxent near Laurel”) (USEPA 2010a).

\subsection{Watershed and river model setup}

The following section discusses the data used, and discretization, to set up the HSPF (Watershed Model) and HEC-RAS (River Model) models.

\subsubsection{HSPF}

The Patuxent River HSPF model makes full use of most application modules available in HSPF. For pervious land segments (PERLNDs) the air temperature (ATEMP), snow (SNOW), water (PWATER), sediment (SEDMNT), soil temperature (PSTEMP), water temperature and dissolved gas (PWTGAS), quality constituent (PQUAL), soil layer solute transport (MSTLAY), and nitrogen (NITR) sections were all employed. For impervious land segment (IMPLNDs) the air temperature (ATEMP), snow (SNOW), water (IWATER), sediment (SOLIDS), water temperature and dissolved gas (IWTGAS), and quality constituent (IQUAL) sections were employed. For the river segments (RCHRES) the hydraulic behavior (HYDR), advection (ADCALC), heat exchange and water temperature (HTRCH), sediment transport (SEDTRN), (OXRX), nutrient (NUTRX), and plankton (PLANK) sections were employed.

\subsubsection{HEC-RAS}

A cursory comparison was made between the Triangular Irregular Network (TIN) surface, Google image, and the steady state model data provided by the District (Figure 5-3). It was determined that the steady state model data was sufficient for this study. 
Figure 5-3. Sample Google image with cross-section cutlines.

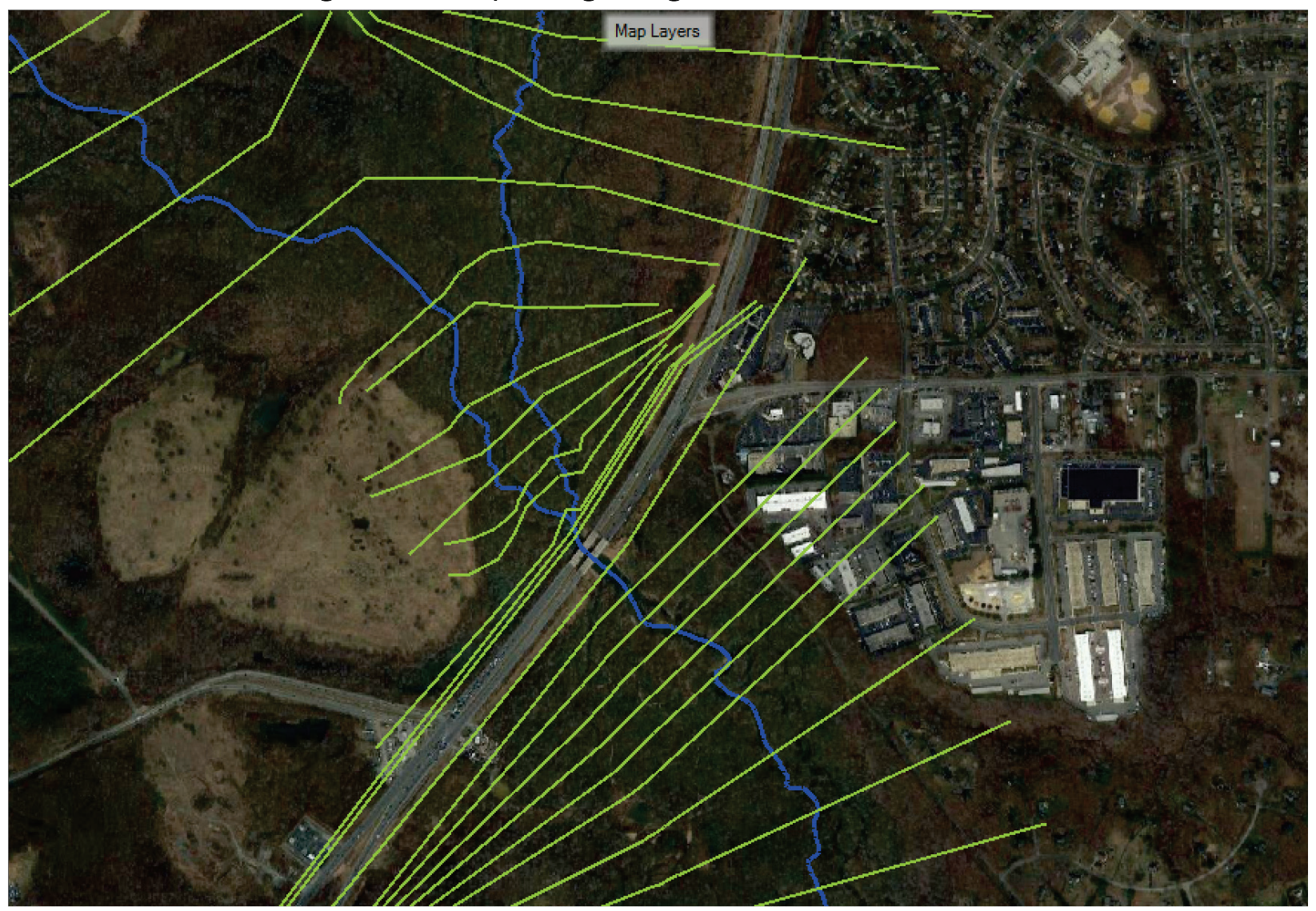

The final HEC-RAS model configuration consisted of three reaches and a junction (Figure 5-4) with interpolated cross-sections between the surveyed cross-sections. The baseline model had stability challenges near the junction and the bridges, which led to fatal model instability. The types of model refinements conducted to stabilize the model are

- Adjust the cross-sections near the junction of the reaches to properly represent the confluence.

- Increase the resolution of cross-sections near abrupt vertical transitions to 100 to $500 \mathrm{ft}$.

- Add ineffective flow areas in areas where the overbank elevation is below the channel bank elevation.

- Add ineffective flow areas near bridges.

- Correct the orientation of select cross-section cutlines.

- Increase Manning's n in areas with steep gradients.

- Increase the overbank Manning's n to select cross-sections. 
- Smooth the transitions into and out of the bridges by moving the internal bridge cross-sections to replace the bridge bounding cross-sections for select bridges.

- Add expansion and contraction coefficients to the bridge bounding cross-sections.

- Smooth abrupt longitudinal transitions by shifting cross-section elevations.

With these refinements, the model was able to run a simulation of $1985^{-}$ 2005 with a 10-minute time step.

Figure 5-4. HEC-RAS model reach representation of Patuxent River.

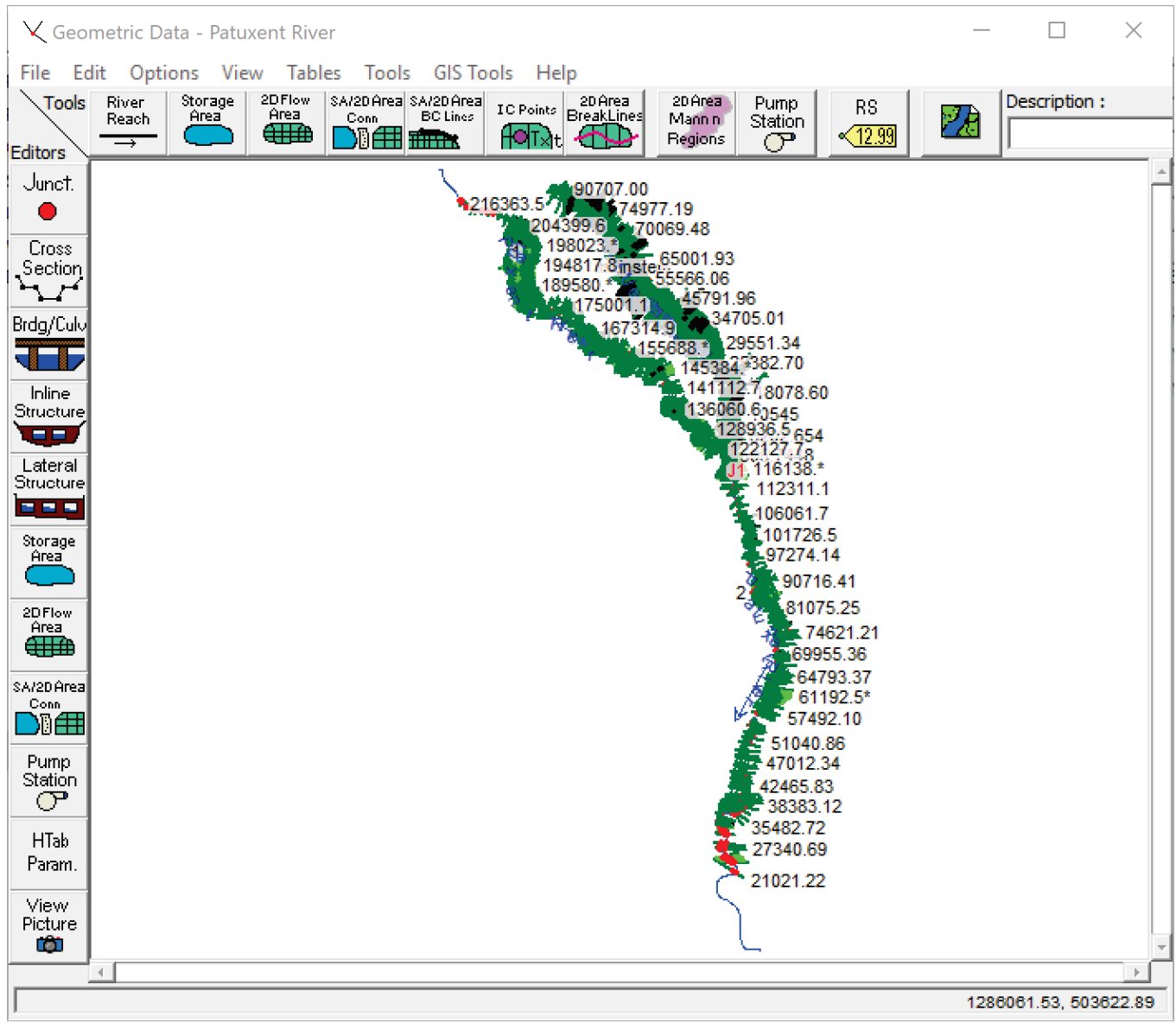

\subsection{Watershed and river model calibration}

Model evaluation provides information to determine when a model, despite its uncertainties, can be appropriately used to inform an environmental decision. This process addresses the soundness of the underlying 
science, the quality and quantity of available data, the degree to which model results correspond to observations, and the appropriateness of a model for a given application. Model evaluation includes qualitative and/or quantitative model calibration, corroboration, and sensitivity and uncertainty analyses. In evaluating performance for model calibration, average daily and average monthly performance for flow, sediment, and nutrients was evaluated for the Patuxent River Watershed. Three statistics, Nash-Sutcliffe Efficiency (NSE), Percent Bias (PBIAS), and Root Mean Square Error-observations standard deviation ratio (RSR), were computed for sites within the watershed for both average daily and average monthly simulations. The model calibration period used in this project's evaluation was 1991-2000 for HSPF model and 1992-2000 for HEC-RAS model. The more recent portion of the simulation period served as a validation period (2001-2005) for both models.

The monitoring stations were screened for observed data availability, length, and coverage of the data record. Table 4-1 lists an inventory of observed data inventories. The primary HSPF calibration stations were Patuxent River near Laurel and Patuxent River near Bowie, as these were the only two locations with estimated daily and monthly sediment and nutrient loads, which is a requirement of the quantitative model evaluation of performance objective criteria. The Patuxent River near Bowie sampling station included load computations for TSS, $\mathrm{PO}_{4}, \mathrm{TP}, \mathrm{NO}_{3}$, and $\mathrm{TN}$. The Patuxent River near Laurel sampling station included load computations for TSS, TP, and TN. Despite having observed sediment and nutrient concentration data, the other stations listed in Table 4-1 were only quantitatively evaluated for calibration of streamflow because these stations did not have sediment and nutrient loading estimates. The HEC-RAS calibration stations were Patuxent River near Bowie and Patuxent River near Jug Bay. Both of these sampling stations included concentrations for water temperature, algae, $\mathrm{DO}, \mathrm{CBOD}$, organic nitrogen ( $\mathrm{OrgN}), \mathrm{NO}_{2}, \mathrm{NO}_{3}, \mathrm{NH}_{4}$, organic phosphorus (OrgP), and $\mathrm{PO}_{4}$. Only the Patuxent River near Bowie sampling station included stream flow and stage.

We did not make changes to the model parameterization/calibration as part of this project. Further details on the calibration process can be found in the report documenting development and calibration of the Phase 5.3 model (USEPA 2010a). The performance analysis in this document serves 
to independently evaluate model hydrology, sediment, and nutrient simulation performance.

\subsubsection{Flow}

Based on comparisons between daily HSPF model results and daily observed values (Table 5-1) and visual inspection of the Figures in Appendix $\mathrm{C}$, the model produced satisfactory results for simulation of streamflow for the calibration period. PBIAS indicates satisfactory performance in replicating daily streamflow at all locations evaluated. NSE indicates satisfactory performance in matching peak daily flows at all locations evaluated. RSR indicates satisfactory correlation between measured and observed values as it relates to minimizing residual error at all locations evaluated. These explanations are confirmed from visual inspection of the simulated and observed time series plots (Figures C-8 to C-14).

Based on comparisons between monthly HSPF model results and monthly observed values (Table 5-1) and visual inspection of the Figures in Appendix $\mathrm{C}$, the model produced very good results for simulation of streamflow for the calibration period. PBIAS indicates very good performance in replicating monthly streamflow volumes at all locations evaluated. NSE indicates very good performance in matching peak monthly flows at all locations evaluated. RSR indicates very good correlation between measured and observed values as it relates to minimizing residual error at all locations evaluated. These explanations are confirmed from visual inspection of the simulated and observed time series plots (Figures C-1 to C-7).

Table 5-1. HSPF Calibration performance objectives for streamflow.

\begin{tabular}{|c|l|c|c|c|c|c|c|}
\hline $\begin{array}{c}\text { Time } \\
\text { Interval }\end{array}$ & Statistic & $\begin{array}{c}\text { Patuxent } \\
\text { near Bowie }\end{array}$ & $\begin{array}{c}\text { Hunting } \\
\text { Creek }\end{array}$ & $\begin{array}{c}\text { W. Branch at } \\
\text { Upper Marlboro }\end{array}$ & $\begin{array}{c}\text { Patuxent } \\
\text { near Unity }\end{array}$ & $\begin{array}{c}\text { Little Patuxent } \\
\text { at Savage }\end{array}$ & $\begin{array}{c}\text { Patuxent } \\
\text { near Laurel }\end{array}$ \\
\hline \multirow{5}{*}{ Daily } & Count & 3652 & 2711 & 3196 & 3652 & 3652 & 3652 \\
\cline { 2 - 9 } & NSE & $0.70(S)$ & $0.62(S)$ & $0.67(S)$ & $0.75(S)$ & $0.83(S)$ & $0.58(S)$ \\
\cline { 2 - 9 } & RSR & $0.55(S)$ & $0.62(S)$ & $0.58(S)$ & $0.50(S)$ & $0.41(S)$ & $0.65(S)$ \\
\cline { 2 - 9 } & PBIAS & $5.8(S)$ & $-3.2(S)$ & $-5.7(S)$ & $8.1(S)$ & $-5.8(S)$ & $5.5(S)$ \\
\hline \multirow{5}{*}{ Monthly } & Count & 120 & 90 & 105 & 120 & 120 & 120 \\
\cline { 2 - 9 } & NSE & $0.92(V G)$ & $0.80(V G)$ & $0.87(V G)$ & $0.90(V G)$ & $0.83(V G)$ & $0.83(V G)$ \\
\cline { 2 - 9 } & RSR & $0.28(V G)$ & $0.45(V G)$ & $0.36(V G)$ & $0.32(V G)$ & $0.41(V G)$ & $0.41(V G)$ \\
\cline { 2 - 9 } & PBIAS & $5.8(V G)$ & $-3.2(V G)$ & $-5.7(V G)$ & $8.1(V G)$ & $-5.8(V G)$ & $5.5(V G)$ \\
\hline
\end{tabular}


Based on comparisons between daily HEC-RAS model results and daily observed values (Table 5-2) and visual inspection of the Figures in Appendix $\mathrm{C}$, the model produced very good results for simulation of streamflow for the calibration period. PBIAS indicates very good performance in replicating daily streamflow at Patuxent River near Bowie (only gage within the HEC-RAS computational domain). NSE indicates very good performance in matching peak daily flows at Patuxent River near Bowie. RSR indicates very good correlation between measured and observed values as it relates to minimizing residual error at Patuxent River near Bowie. These explanations are confirmed from visual inspection of the simulated and observed time series plot (Figure C-16).

Based on comparisons between monthly HEC-RAS model results and monthly observed values (Table 5-2) and visual inspection of the Figures in Appendix C, the model produced very good results for simulation of streamflow for the calibration period. PBIAS indicates very good performance in replicating monthly streamflow at Patuxent River near Bowie. NSE indicates very good performance in matching peak monthly flows at Patuxent River near Bowie. RSR indicates very good correlation between measured and observed values as it relates to minimizing residual error at Patuxent River near Bowie. These explanations are confirmed from visual inspection of the simulated and observed time series plot (Figure C-15).

Table 5-2. HEC-RAS Calibration performance objectives for streamflow.

\begin{tabular}{|c|c|c|}
\hline Time Interval & Statistic & Patuxent near Bowie \\
\hline \multirow{4}{*}{ Daily } & Count & 3193 \\
\hline & NSE & $0.80(\mathrm{~S})$ \\
\hline & RSR & $0.45(\mathrm{~S})$ \\
\hline & PBIAS & $-7.18(\mathrm{~S})$ \\
\hline \multirow{4}{*}{ Monthly } & Count & 105 \\
\hline & NSE & 0.97 (VG) \\
\hline & RSR & $0.16(V G)$ \\
\hline & PBIAS & $-7.28(\mathrm{VG})$ \\
\hline
\end{tabular}

\subsubsection{Sediment}

Based on comparisons between daily HSPF model results and daily observed values (Table 5-3) and visual inspection of the Figures in Appendix C, the 
model produced mixed results for simulation of sediment loads for the calibration period. PBIAS indicates unsatisfactory performance in replicating daily sediment loading at Patuxent near Laurel and satisfactory performance for Patuxent near Bowie. NSE indicates unsatisfactory performance in matching peak daily sediment loads at both locations evaluated. RSR indicates unsatisfactory correlation between measured and observed values as it relates to minimizing residual error at both locations evaluated. The model appears to over-predict sediment loads relative to the estimated/observed loads. These explanations are confirmed from visual inspection of the simulated and observed time series plots (Figures $\mathrm{C}-19$ and $\mathrm{C}-20$ ).

Based on comparisons between monthly HSPF model results and monthly observed values (Table 5-3) and visual inspection of the Figures in Appendix $\mathrm{C}$, the model produced unsatisfactory results for simulation of sediment loads for the calibration period. PBIAS indicates unsatisfactory performance in replicating monthly sediment loading at both locations evaluated. NSE indicates unsatisfactory performance in matching peak monthly sediment loads at both locations evaluated. RSR indicates unsatisfactory correlation between measured and observed values as it relates to minimizing residual error at both locations evaluated. The model appears to over-predict sediment loads relative to the estimated/observed loads. These explanations are confirmed from visual inspection of the simulated and observed time series plots (Figures $\mathrm{C}-17$ and $\mathrm{C}-18$ ).

Table 5-3. HSPF Calibration performance objectives for sediment loading.

\begin{tabular}{|c|c|c|c|}
\hline $\begin{array}{c}\text { Time } \\
\text { Interval }\end{array}$ & Statistic & $\begin{array}{c}\text { Patuxent near } \\
\text { Bowie }\end{array}$ & $\begin{array}{c}\text { Patuxent near } \\
\text { Laurel }\end{array}$ \\
\hline \multirow{4}{*}{ Daily } & Count & 3652 & 3652 \\
\hline & NSE & $-6.30(U)$ & $-17.43(U)$ \\
\hline & RSR & $2.70(\mathrm{U})$ & 4.29 (U) \\
\hline & PBIAS & $-56.0(U)$ & $-251.1(U)$ \\
\hline \multirow{4}{*}{ Monthly } & Count & 120 & 120 \\
\hline & NSE & $-2.36(U)$ & $-24.09(U)$ \\
\hline & RSR & $1.83(\mathrm{U})$ & $5.01(\mathrm{U})$ \\
\hline & PBIAS & $-56.0(U)$ & $-251.1(U)$ \\
\hline \multicolumn{4}{|c|}{$\begin{array}{l}\text { Performance ratings: } \\
\qquad \text { VG = Very Good; } \mathrm{G}=\text { Good; } \mathrm{S}=\text { Satisfactory; } \mathrm{U}=\text { Unsatisfactory }\end{array}$} \\
\hline
\end{tabular}

Based on comparisons between daily HEC-RAS model results and daily observed values (Table 5-4) and visual inspection of the Figures in 
Appendix C, the model produced mixed results for simulation of total suspended solids for the calibration period. PBIAS indicates satisfactory performance in replicating daily total suspended solids at Patuxent River near Bowie. NSE indicates unsatisfactory performance in matching peak daily total suspended solids. RSR indicates unsatisfactory correlation between measured and observed values as it relates to minimizing residual error. These explanations are confirmed from visual inspection of the simulated and observed time series plot (Figure C-22).

Based on comparisons between monthly HEC-RAS model results and monthly observed values (Table 5-4) and visual inspection of the Figures in Appendix C, the model produced mixed results for simulation of total suspended solids for the calibration period. PBIAS indicates good performance in replicating monthly total suspended solids at Patuxent River near Bowie. NSE indicates unsatisfactory performance in matching peak monthly total suspended solids. RSR indicates unsatisfactory correlation between measured and observed values as it relates to minimizing residual error. These explanations are confirmed from visual inspection of the simulated and observed time series plot (Figure C-21).

Table 5-4. EC-RAS Calibration performance objectives for total suspended solids.

\begin{tabular}{|c|c|c|}
\hline Time Interval & Statistic & Patuxent near Bowie \\
\hline \multirow{4}{*}{ Daily } & Count & 273 \\
\hline & NSE & $0.30(U)$ \\
\hline & RSR & $0.84(U)$ \\
\hline & PBIAS & $43.19(\mathrm{U})$ \\
\hline \multirow{4}{*}{ Monthly } & Count & 105 \\
\hline & NSE & $0.12(\mathrm{U})$ \\
\hline & RSR & $0.94(U)$ \\
\hline & PBIAS & $34.98(U)$ \\
\hline
\end{tabular}

\subsubsection{Nutrients}

\subsubsection{Algae}

Based on comparisons between daily HEC-RAS model results and daily observed values (Table 5-5) and visual inspection of the Figures in Appendix $\mathrm{C}$, the model produced mixed results for simulation of algae for the calibration period. PBIAS indicates very good performance in replicating 
daily algae concentration at Patuxent River near Bowie. NSE indicates unsatisfactory performance in matching peak daily algae concentration. RSR indicates unsatisfactory correlation between measured and observed values as it relates to minimizing residual error. These explanations are confirmed from visual inspection of the simulated and observed time series plots (Figure C-36).

Based on comparisons between monthly HEC-RAS model results and monthly observed values (Table 5-5) and visual inspection of the Figures in Appendix C, the model produced mixed results for simulation of algae for the calibration period. PBIAS indicates very good performance in replicating monthly algae concentration at Patuxent River near Bowie. NSE indicates unsatisfactory performance in matching peak monthly algae concentration. RSR indicates unsatisfactory correlation between measured and observed values as it relates to minimizing residual error. These explanations are confirmed from visual inspection of the simulated and observed time series plots (Figure C-35).

\subsubsection{Dissolved oxygen}

Based on comparisons between daily HEC-RAS model results and daily observed values (Table 5-5) and visual inspection of the Figures in Appendix $\mathrm{C}$, the model produced very good results for simulation of dissolved oxygen for the calibration period at Patuxent River near Bowie. PBIAS indicates very good performance in replicating daily DO concentration. NSE indicates very good performance in matching peak daily DO concentration. RSR indicates very good correlation between measured and observed values as it relates to minimizing residual error. These explanations are confirmed from visual inspection of the simulated and observed time series plots (Figure $\mathrm{C}-38$ ).

Based on comparisons between monthly HEC-RAS model results and monthly observed values (Table 5-5) and visual inspection of the Figures in Appendix $\mathrm{C}$, the model produced very good results for simulation of dissolved oxygen for the calibration period at Patuxent River near Bowie. PBIAS indicates very good performance in replicating monthly DO concentration. NSE indicates very good performance in matching peak monthly DO concentration. RSR indicates very good correlation between measured and observed values as it relates to minimizing residual error. 
These explanations are confirmed from visual inspection of the simulated and observed time series plots (Figure C-37).

Table 5-5. HEC-RAS Calibration performance objectives for Algae and DO concentrations.

\begin{tabular}{|l|l|l|l|}
\hline & & \multicolumn{2}{|c|}{ Patuxent near Bowie } \\
\hline Time Interval & Statistic & Algae & DO \\
\hline \multirow{4}{*}{ Daily } & Count & 230 & 272 \\
& NSE & $-0.29(\mathrm{U})$ & $0.76(\mathrm{~S})$ \\
\cline { 2 - 4 } & RSR & $1.14(\mathrm{U})$ & $0.49(\mathrm{~S})$ \\
\cline { 2 - 4 } & PBIAS & $-14.88(\mathrm{~S})$ & $-5.08(\mathrm{~S})$ \\
\hline \multirow{4}{*}{ Monthly } & Count & 99 & 105 \\
& NSE & $-0.36(\mathrm{U})$ & $0.84(\mathrm{~S})$ \\
\cline { 2 - 4 } & RSR & $1.16(\mathrm{U})$ & $0.40(\mathrm{~S})$ \\
\cline { 2 - 4 } & PBIAS & $-18.40(\mathrm{VG})$ & $-4.56(\mathrm{VG})$ \\
\hline Performance ratings: VG & $=$ Very Good; G $=$ Good; S = Satisfactory; U = Unsatisfactory \\
\hline
\end{tabular}

\subsubsection{Nitrogen}

Based on comparisons between daily HSPF model results and daily observed values (Table 5-6) and visual inspection of the Figures in Appendix $\mathrm{C}$, the model produced mixed results for simulation of nitrogen for the calibration period. PBIAS indicates satisfactory performance in replicating daily TN loading at both locations evaluated and $\mathrm{NO}_{3}$ loading at Patuxent near Bowie. NSE indicates satisfactory performance in matching peak daily TN loads at Patuxent near Laurel and peak daily $\mathrm{NO}_{3}$ loads at Patuxent near Bowie, but NSE indicates unsatisfactory performance for TN for Patuxent near Bowie. RSR indicates satisfactory correlation between measured and observed values as it relates to minimizing residual error for TN loads at Patuxent near Laurel and $\mathrm{NO}_{3}$ loads at Patuxent near Bowie, but RSR indicates unsatisfactory performance for TN for Patuxent near Bowie. These explanations are confirmed from visual inspection of the simulated and observed time series plots (Figures C-25, C-26, and C-28).

Based on comparisons between monthly HSPF model results and monthly observed values (Table 5-6) and visual inspection of the Figures in Appendix $\mathrm{C}$, the model produced satisfactory results for simulation of nitrogen for the calibration period. PBIAS indicates satisfactory performance in replicating monthly $\mathrm{TN}$ loading at both locations and $\mathrm{NO}_{3}$ loading at Patuxent near Bowie. NSE indicates satisfactory performance in matching peak monthly $\mathrm{TN}$ and/or $\mathrm{NO}_{3}$ loads. RSR indicates satisfactory correlation 
between measured and observed values as it relates to minimizing residual error at both locations. These explanations are confirmed from visual inspection of the simulated and observed time series plots (Figures C-23, C24, and C-27).

Based on comparisons between daily HEC-RAS model results and daily observed values (Table 5-7) and visual inspection of the Figures in Appendix $\mathrm{C}$, the model produced mixed results for simulation of nitrogen for the calibration period. PBIAS indicates very good performance in replicating daily OrgN concentration at Patuxent River near Bowie. PBIAS indicates very good performance in replicating daily $\mathrm{NH}_{4}$, and $\mathrm{NO}_{3}$ concentration. NSE indicates unsatisfactory performance in matching peak daily OrgN, $\mathrm{NH}_{4}$, and $\mathrm{NO}_{3}$ concentration. RSR indicates unsatisfactory correlation between measured and observed values as it relates to minimizing residual error. These explanations are confirmed from visual inspection of the simulated and observed time series plots (Figures C-40, C-42, C-44).

Based on comparisons between monthly HEC-RAS model results and monthly observed values (Table 5-7) and visual inspection of the Figures in Appendix C, the model produced mixed results for simulation of nitrogen for the calibration period at Patuxent River near Bowie. PBIAS indicates very good performance in replicating monthly $\mathrm{OrgN}$ and $\mathrm{NO}_{3}$ concentration. PBIAS indicates good performance in replicating monthly $\mathrm{NH}_{4}$ concentration. NSE indicates unsatisfactory performance in matching peak monthly OrgN and $\mathrm{NO}_{3}$ concentration. NSE indicates unsatisfactory performance in matching peak monthly $\mathrm{NH}_{4}$ concentration. RSR indicates unsatisfactory correlation between measured and observed values as it relates to minimizing residual error. These explanations are confirmed from visual inspection of the simulated and observed time series plots (Figures C-39, C-41, C-43).

\subsubsection{Phosphorus}

Based on comparisons between daily HSPF model results and daily observed values (Table 5-6) and visual inspection of the Figures in Appendix $\mathrm{C}$, the model produced mixed results for simulation of phosphorus the for the calibration period. PBIAS indicates unsatisfactory performance in replicating daily TP loading at Patuxent near Laurel and satisfactory performance in replicating daily TP and $\mathrm{PO}_{4}$ (Dissolved) loading at Patuxent 
near Bowie. NSE indicates unsatisfactory performance in matching peak daily TP and $\mathrm{PO}_{4}$ loads at Patuxent near Bowie. RSR indicates unsatisfactory correlation between measured and observed values as it relates to minimizing residual error at Patuxent near Bowie. These explanations are confirmed from visual inspection of the simulated and observed time series plots (Figures $\mathrm{C}-31, \mathrm{C}-32$, and $\mathrm{C}-34$ ).

Based on comparisons between monthly HSPF model results and monthly observed values(Table 5-6) and visual inspection of the Figures in Appendix $\mathrm{C}$, the model produced mixed results for simulation of phosphorus for the calibration period. PBIAS indicates unsatisfactory performance in replicating monthly TP loading at Patuxent near Laurel and very good performance in replicating monthly $\mathrm{TP}$ and $\mathrm{PO}_{4}$ loading at Patuxent near Bowie. NSE indicates unsatisfactory performance in matching peak monthly TP and $\mathrm{PO}_{4}$ loads at Patuxent near Bowie. RSR indicates unsatisfactory correlation between measured and observed values as it relates to minimizing residual error at Patuxent near Bowie. These explanations are confirmed from visual inspection of the simulated and observed time series plots (Figures C-29, C-30, and C-32).

Based on comparisons between daily HEC-RAS model results and daily observed values (Table 5-7) and visual inspection of the Figures in Appendix $\mathrm{C}$, the model produced mixed results for simulation of phosphorus for the calibration period. PBIAS indicates unsatisfactory performance in replicating daily OrgP concentration at Patuxent River near Bowie. PBIAS indicates satisfactory performance in replicating daily $\mathrm{PO}_{4}$ concentration. NSE indicates unsatisfactory performance in matching peak daily OrgP and $\mathrm{PO}_{4}$ concentration. RSR indicates unsatisfactory correlation between measured and observed values as it relates to minimizing residual error. These explanations are confirmed from visual inspection of the simulated and observed time series plots (Figures C-46 and C-48).

Based on comparisons between monthly HEC-RAS model results and monthly observed values (Table 5-7) and visual inspection of the Figures in Appendix C, the model produced mixed results for simulation of phosphorus for the calibration period. PBIAS indicates unsatisfactory performance in replicating monthly OrgP concentration at Patuxent River near Bowie. PBIAS indicates satisfactory performance in replicating monthly $\mathrm{PO} 4$ concentration. NSE indicates unsatisfactory performance in matching peak 
monthly OrgP and $\mathrm{PO}_{4}$ concentration. RSR indicates unsatisfactory correlation between measured and observed values as it relates to minimizing residual error. These explanations are confirmed from visual inspection of the simulated and observed time series plots (Figures C-45 and C-47).

Table 5-6. HSPF Calibration performance objectives for nutrient loading.

\begin{tabular}{|c|c|c|c|c|c|c|c|}
\hline \multirow[b]{2}{*}{ Time Interval } & \multirow[b]{2}{*}{ Statistic } & \multicolumn{4}{|c|}{ Patuxent near Bowie } & \multicolumn{2}{|c|}{ Patuxent near Laure } \\
\hline & & TN load & $\mathrm{NO}_{3}$ load & TP load & $\mathrm{PO}_{4}$ load & TN load & TP load \\
\hline \multirow{4}{*}{ Daily } & Count & 3652 & 3652 & 3652 & 3652 & 3652 & 3652 \\
\hline & NSE & $-0.20(U)$ & $0.51(\mathrm{~S})$ & $-1.08(U)$ & $-14.48(U)$ & $0.52(\mathrm{~S})$ & $-6.26(U)$ \\
\hline & RSR & $1.09(\mathrm{U})$ & $0.70(\mathrm{~S})$ & $1.44(U)$ & $3.93(U)$ & $0.70(\mathrm{~S})$ & $2.69(U)$ \\
\hline & PBIAS & $-5.4(\mathrm{~S})$ & $26.4(\mathrm{~S})$ & $-3.0(\mathrm{~S})$ & $-17.2(\mathrm{~S})$ & $38.9(\mathrm{~S})$ & $-138.0(U)$ \\
\hline \multirow{4}{*}{ Monthly } & Count & 120 & 120 & 120 & 120 & 120 & 120 \\
\hline & NSE & $0.73(\mathrm{~S})$ & $0.56(\mathrm{~S})$ & $0.48(U)$ & $-5.48(U)$ & 0.69 (S) & $-7.67(U)$ \\
\hline & RSR & $0.52(\mathrm{~S})$ & $0.66(\mathrm{~S})$ & $0.72(U)$ & $2.55(U)$ & $0.55(\mathrm{~S})$ & $2.95(U)$ \\
\hline & PBIAS & -5.4 (VG) & $26.4(G)$ & $-3.0(V G)$ & $-17.2(V G)$ & $38.9(G)$ & $-138.0(U)$ \\
\hline
\end{tabular}

Table 5-7. HEC-RAS Calibration performance objectives for nutrient concentration.

\begin{tabular}{|c|c|c|c|c|c|c|}
\hline \multirow[b]{2}{*}{$\begin{array}{c}\text { Time } \\
\text { Interval }\end{array}$} & \multirow[b]{2}{*}{ Statistic } & \multicolumn{5}{|c|}{ Patuxent near Bowie } \\
\hline & & OrgN & $\mathrm{NH}_{4}$ & $\mathrm{NO}_{3}$ & OrgP & $\mathrm{PO}_{4}$ \\
\hline \multirow{4}{*}{ Daily } & Count & 168 & 173 & 172 & 103 & 172 \\
\hline & NSE & $-1.63(U)$ & $0.43(U)$ & $-0.09(U)$ & $-20.37(U)$ & $-1.71(U)$ \\
\hline & RSR & $1.62(U)$ & $0.75(U)$ & $1.04(\mathrm{U})$ & $4.62(U)$ & $1.65(U)$ \\
\hline & PBIAS & $11.66(\mathrm{~S})$ & $22.23(\mathrm{~S})$ & $-5.73(S)$ & $-95.92(U)$ & $-41.58(S)$ \\
\hline \multirow{4}{*}{ Monthly } & Count & 103 & 103 & 103 & 103 & 103 \\
\hline & NSE & $-2.46(U)$ & $0.48(U)$ & $-0.02(\mathrm{U})$ & $-20.37(U)$ & $-1.61(U)$ \\
\hline & RSR & $1.86(U)$ & $0.72(U)$ & $1.01(U)$ & $4.62(U)$ & $1.62(\mathrm{U})$ \\
\hline & PBIAS & 7.99 (VG) & $26.81(\mathrm{G})$ & -4.84 (VG) & -95.92 (U) & $-43.14(\mathrm{~S})$ \\
\hline
\end{tabular}

Table 5-8 lists HSPF calibrated values for key hydrology, sediment, and nutrient parameters and Table 5-9 lists HEC-RAS calibrated parameter values for nutrients and sediment. 


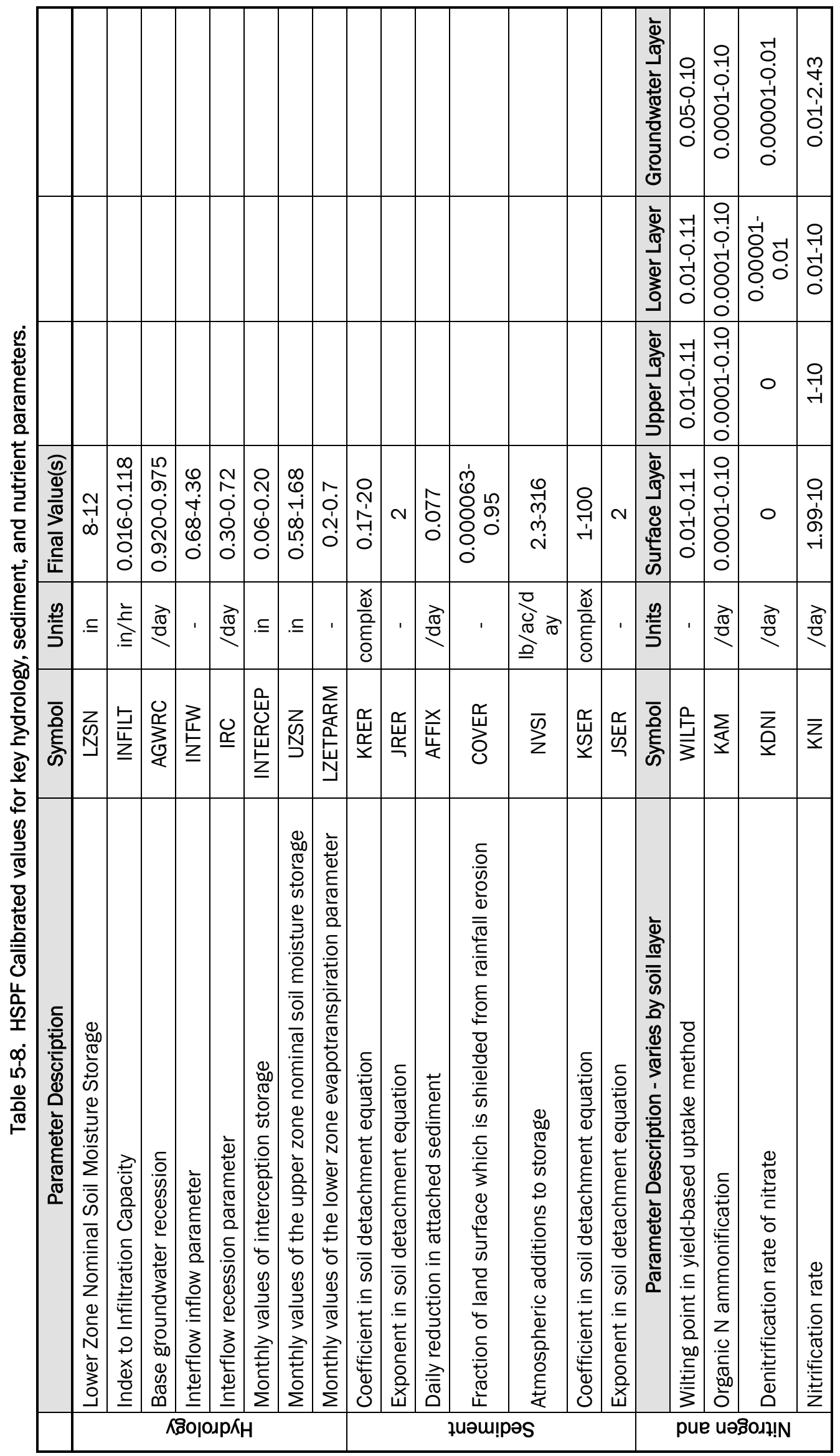




\begin{tabular}{|c|c|c|c|c|c|c|}
\hline $\begin{array}{l}\text { - } \\
8 \\
\circ \\
\circ\end{array}$ & $\begin{array}{l}-1 \\
8 \\
8 \\
\circ \\
\circ\end{array}$ & 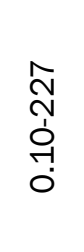 & 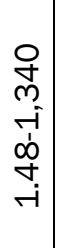 & $\begin{array}{l} \\
\stackrel{0}{\circ} \\
\circ \\
0\end{array}$ & $\begin{array}{l}10 \\
8 \\
0 \\
0 \\
0 \\
0 \\
0 \\
8 \\
8 \\
0 \\
0\end{array}$ & 웅 \\
\hline 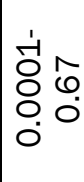 & 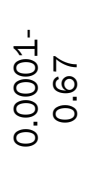 & 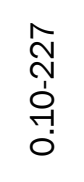 & 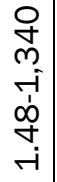 & $\begin{array}{l} \\
\stackrel{0}{\circ} \\
\stackrel{0}{0}\end{array}$ & 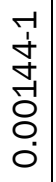 & 웅 \\
\hline $\begin{array}{l}\stackrel{-}{4} \\
\stackrel{+}{8} \\
8 \\
0 \\
0\end{array}$ & $\begin{array}{l}\stackrel{-}{1} \\
\stackrel{-}{8} \\
8 \\
0 \\
0\end{array}$ & 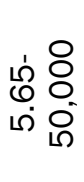 & 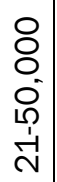 & 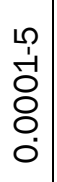 & 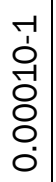 & 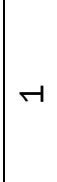 \\
\hline $\begin{array}{l}\stackrel{-}{+} \\
\text { - } \\
8 \\
\circ \\
0\end{array}$ & $\begin{array}{l}\stackrel{-}{1} \\
\dot{1} \\
\stackrel{8}{8} \\
\varnothing \\
\circ\end{array}$ & \begin{tabular}{l}
8 \\
8 \\
0 \\
0 \\
1 \\
0 \\
\multirow{1}{0}{} \\
0
\end{tabular} & 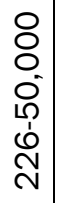 & $\begin{array}{l}0 \\
\dot{1} \\
\stackrel{+}{8} \\
8 \\
0 \\
0\end{array}$ & 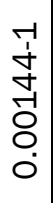 & -1 \\
\hline$\frac{\pi}{0}$ & $\frac{\pi}{0}$ & ' & ' & $\frac{\pi}{0}$ & $\vec{\pi}$ & ' \\
\hline$\sum_{\Sigma}$ & $\sum_{\Sigma}$ & $\begin{array}{l}z \\
\text { 올 }\end{array}$ & $\begin{array}{l}z \\
\text { ơ } \\
\underline{x} \\
\underline{x}\end{array}$ & $\sum_{\Sigma}^{n}$ & $\sum_{\Sigma}^{q}$ & $\vec{x}$ \\
\hline 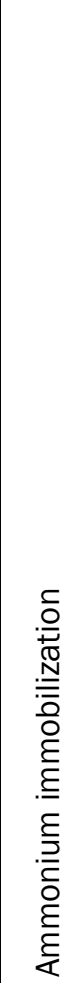 & 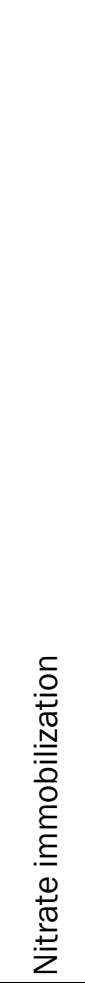 & 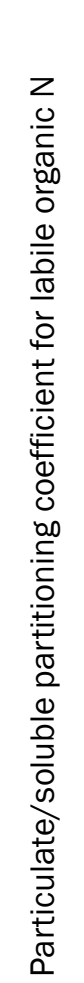 & 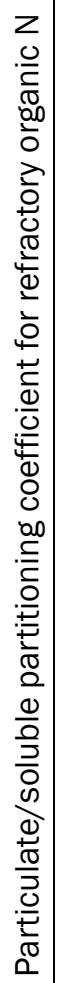 & 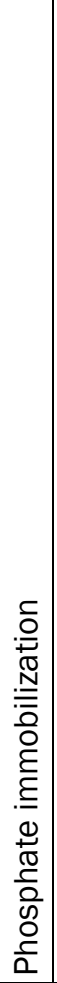 & 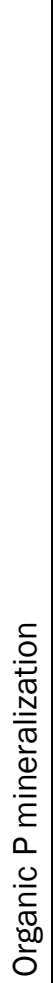 & 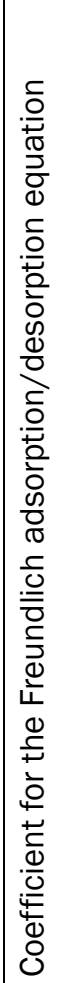 \\
\hline
\end{tabular}


Table 5-9. HEC-RAS Calibrated parameter values for nutrients and sediment.

\begin{tabular}{|c|c|c|c|}
\hline Parameter Description & Symbol & Units & $\begin{array}{c}\text { Final Value(s) (temperature } \\
\text { correction) }\end{array}$ \\
\hline \multicolumn{4}{|l|}{ Algae } \\
\hline Biomass Chl-a ratio & $\alpha_{0}$ & ugCha/mgA & 7.72 \\
\hline Biomass Nitrogen Fraction & $\alpha_{1}$ & mgN/mgA & 0.08 \\
\hline Biomass Phosphorus Fraction & $\alpha_{2}$ & $\mathrm{mgP} / \mathrm{mgA}$ & 0.01 \\
\hline Maximum Growth Rate & $\mu_{\max }$ & day $^{-1}$ & $1(1.047)$ \\
\hline $\begin{array}{l}\text { Maximum Growth Rate } \\
\text { Formulation }\end{array}$ & - & - & Multiplicative \\
\hline Growth Limitation (light) & $K_{L}$ & $\mathrm{~W} \mathrm{~m} \mathrm{~m}^{-2}$ & 4 \\
\hline Growth Limitation (N) & $\mathrm{K}_{\mathrm{N}}$ & mgN/L & 0.01 \\
\hline Growth Limitation $(P)$ & $K_{P}$ & $\mathrm{mgP} / \mathrm{L}$ & 0.001 \\
\hline Light Limitation Formulation & - & - & Half Saturation \\
\hline Light Extinction (non-algal) & $\lambda_{0}$ & $m^{-1}$ & 0.03 \\
\hline Light Extinction (linear algal) & $\lambda_{1}$ & $\mathrm{~m}^{-1}(\text { ugCha/L) })^{-1}$ & 0.007 \\
\hline Light Extinction (non-linear algal) & $\lambda_{2}$ & $\begin{array}{l}\mathrm{m}^{-1}(\text { ugCha/L) } \\
2 / 3\end{array}$ & 0.05 \\
\hline Respiration Rate & $\rho$ & day $^{-1}$ & $0.05(1.047)$ \\
\hline Nitrogen Preference & $P_{N}$ & - & 1 \\
\hline Settling Rate & $\sigma_{1}$ & m day ${ }^{-1}$ & $0.1(1.024)$ \\
\hline Dissolved Oxygen & Symbol & Units & $\begin{array}{l}\text { Final Value(s) (temperature } \\
\text { correction) }\end{array}$ \\
\hline Production per unit algal growth & $\alpha_{3}$ & mgO/mgAp & 1.4 \\
\hline Uptake per unit algal respired & $\alpha_{4}$ & $\mathrm{mgO} / \mathrm{mgAp}$ & 1.6 \\
\hline $\begin{array}{l}\text { Production per unit benthic algal } \\
\text { growth }\end{array}$ & $\alpha_{3 b}$ & mgO/mgAb & 1.4 \\
\hline $\begin{array}{l}\text { Uptake per unit benthic algal } \\
\text { respired }\end{array}$ & $\alpha_{4 b}$ & $\mathrm{mgO} / \mathrm{mgAb}$ & 1.6 \\
\hline Uptake per unit NH4 oxidized & $\alpha_{5}$ & $\mathrm{mgO} / \mathrm{mgN}$ & 3 \\
\hline Uptake per unit $\mathrm{NO}_{2}$ oxidized & $\alpha_{6}$ & $\mathrm{mgO} / \mathrm{mgN}$ & 1 \\
\hline Atmospheric Reaeration & $\mathrm{K}_{2}$ & day ${ }^{-1}$ & $1(1.024)$ \\
\hline Sediment Demand & $\mathrm{K}_{4}$ & day $^{-1}$ & $0(1.06)$ \\
\hline CBOD & Symbol & Units & $\begin{array}{l}\text { Final Value(s) (temperature } \\
\text { correction) }\end{array}$ \\
\hline Decay Rate & $\mathrm{K}_{1}$ & day $^{-1}$ & $0.02(1.047)$ \\
\hline Settling Rate & $\mathrm{K}_{3}$ & day $^{-1}$ & $0(1.024)$ \\
\hline Nitrogen & Symbol & Units & $\begin{array}{l}\text { Final Value(s) (temperature } \\
\text { correction) }\end{array}$ \\
\hline OrgN -> NH4 & $\beta_{3}$ & day $^{-1}$ & 0.02 (1.047) \\
\hline $\mathrm{NH} 4->\mathrm{NO}_{2}$ & $\beta_{1}$ & day $^{-1}$ & 0.1 (1.083) \\
\hline $\mathrm{NO}_{2}->\mathrm{NO} 3$ & $\beta_{2}$ & day $^{-1}$ & $0.2(1.047)$ \\
\hline
\end{tabular}




\begin{tabular}{|c|c|c|c|}
\hline Parameter Description & Symbol & Units & $\begin{array}{c}\text { Final Value(s) (temperature } \\
\text { correction) }\end{array}$ \\
\hline OrgN Settling Rate & $\sigma_{4}$ & day $^{-1}$ & $0.001(1.024)$ \\
\hline NH4 Benthos Source Rate & 03 & mgN m-2 day $^{-1}$ & $0(1.074)$ \\
\hline Nitrification Inhibition Factor & KNR & $\mathrm{Mg} / \mathrm{L}$ & 0.6 \\
\hline Phosphorus & Symbol & Units & $\begin{array}{l}\text { Final Value(s) (temperature } \\
\text { correction) }\end{array}$ \\
\hline OrgP -> InorgP & $\beta_{4}$ & day $^{-1}$ & $0.01(1.047)$ \\
\hline OrgP Settling Rate & $\sigma_{5}$ & day $^{-1}$ & $0.001(1.024)$ \\
\hline Benthos Source Rate & $\sigma_{2}$ & mgP m ${ }^{-2}$ day $^{-1}$ & $0.001(1.074)$ \\
\hline Benthic Algae & Symbol & Units & $\begin{array}{l}\text { Final Value(s) (temperature } \\
\text { correction) }\end{array}$ \\
\hline Biomass (Chl-a ratio) & $\alpha_{0 b}$ & ugChab/mgAb & 5 \\
\hline Biomass (Nitrogen Fraction) & $\alpha_{1 b}$ & mgN/mgAb & 0.07 \\
\hline Biomass (Phosphorus Fraction) & $\alpha_{2 b}$ & $\mathrm{mgP} / \mathrm{mgAb}$ & 0.01 \\
\hline Maximum Growth Rate & $\mu_{\mathrm{bmax}}$ & day $^{-1}$ & $0.3(1.047)$ \\
\hline $\begin{array}{l}\text { Maximum Benthic Growth Rate } \\
\text { Formulation }\end{array}$ & - & - & Multiplicative \\
\hline Growth Limitation (light) & KLb & $\mathrm{W} \mathrm{m}^{-2}$ & 6276 \\
\hline Growth Limitation (N) & $K_{N b}$ & mgN/L & 0.01 \\
\hline Growth Limitation $(\mathrm{P})$ & $\mathrm{K}_{\mathrm{Pb}}$ & $\mathrm{mgP} / \mathrm{L}$ & 0.001 \\
\hline $\begin{array}{l}\text { Benthic Light Limitation } \\
\text { Formulation }\end{array}$ & & & Half Saturation \\
\hline Respiration Rate & $\rho_{b}$ & day $^{-1}$ & $0.01(1.047)$ \\
\hline Death Rate & $K_{d b}$ & day $^{-1}$ & $0(1.047)$ \\
\hline Nitrogen Preference & $P_{\mathrm{Nb}}$ & - & 0 \\
\hline Bottom Area Fraction & $F_{b}$ & - & 0 \\
\hline TSS & Symbol & Units & $\begin{array}{l}\text { Final Value(s) (temperature } \\
\text { correction) }\end{array}$ \\
\hline Decay Rate & $\mathrm{K}_{1 \mathrm{~s}}$ & day $^{-1}$ & 0 \\
\hline Settling Rate & $\mathrm{K}_{3 \mathrm{~s}}$ & day $^{-1}$ & $3(1.024)$ \\
\hline
\end{tabular}

\subsection{Sampling protocol}

There were no field samples collected as a part of this demonstration study.

\subsection{Equipment calibration and data quality issues}

There were no field samples collected as a part of this demonstration study. 


\section{Performance Assessment}

In evaluating performance for model validation, average daily and average monthly performance for streamflow, sediment, and nutrients were evaluated for Patuxent River Watershed. Three statistics, NSE, Percent Bias (PBIAS), and RMSE-observations standard deviation ratio (RSR), were computed for sites within the watershed for both average daily and average monthly simulations.

\subsection{Watershed and river model validation}

The validation is used to evaluate the reliability of a calibrated model. The HSPF model for the Patuxent River Watershed was run for an additional 17-year period without adjusting calibrated parameters. The period of record for validating streamflow, sediment, and nutrients for HSPF-only and integrated model was set from 2001-2005.

Validation is used to evaluate the reliability of a calibrated model. The Patuxent River HSPF model and HEC-RAS model was run for an additional 5 -year period without adjusting calibrated parameters. The period of record for validating streamflow was 2001-2005 and 2001-2004 for validating sediment and nutrients, as load estimates were not available for 2005 .

\subsubsection{Flow}

Based on comparisons between daily HSPF model results and daily observed values (Table 6-1) and visual inspection of the Figures in Appendix $\mathrm{D}$, the model produced satisfactory results for simulation of streamflow for the validation period. PBIAS indicates satisfactory performance in replicating daily streamflow at all locations evaluated. NSE indicates satisfactory performance in matching peak daily flows at nearly all locations evaluated; the only location not meeting the NSE threshold was Patuxent near Laurel. RSR indicates satisfactory correlation between measured and observed values as it relates to minimizing residual error at all locations evaluated. These explanations are confirmed from visual inspection of the simulated and observed time series plots (Figures D-7to D-12).

Based on comparisons between monthly HSPF model results and monthly observed values (Table 6-1) and visual inspection of the Figures in Appendix D, the model produced very good results for simulation of streamflow 
for the validation period. PBIAS indicates satisfactory to very good performance in replicating monthly streamflow volumes at all locations evaluated. NSE indicates satisfactory to very good performance in matching peak monthly flows at all locations evaluated. RSR indicates satisfactory to very good correlation between measured and observed values as it relates to minimizing residual error at all locations evaluated. These explanations are confirmed from visual inspection of the simulated and observed time series plots (Figures D-1 to D-6).

Table 6-1. HSPF Validation performance objectives for streamflow.

\begin{tabular}{|c|c|c|c|c|c|c|c|}
\hline $\begin{array}{c}\text { Time } \\
\text { Interval }\end{array}$ & Statistic & $\begin{array}{c}\text { Patuxent } \\
\text { near Bowie }\end{array}$ & $\begin{array}{l}\text { Patuxent } \\
\text { near } \\
\text { Brighton }\end{array}$ & $\begin{array}{l}\text { W. Branch at } \\
\text { Upper } \\
\text { Marlboro }\end{array}$ & $\begin{array}{c}\text { Patuxent } \\
\text { near Unity }\end{array}$ & $\begin{array}{c}\text { Little } \\
\text { Patuxent at } \\
\text { Savage }\end{array}$ & $\begin{array}{c}\text { Patuxent } \\
\text { near Laurel }\end{array}$ \\
\hline \multirow{4}{*}{ Daily } & Count & 1824 & 1824 & 1824 & 1824 & 1824 & 1824 \\
\hline & NSE & $0.63(\mathrm{~S})$ & $0.33(U)$ & $0.60(\mathrm{~S})$ & $0.52(\mathrm{~S})$ & $0.76(\mathrm{~S})$ & $0.44(U)$ \\
\hline & RSR & $0.61(\mathrm{~S})$ & $0.82(U)$ & $0.63(\mathrm{~S})$ & $0.69(\mathrm{~S})$ & 0.49 (S) & $0.75(\mathrm{~S})$ \\
\hline & PBIAS & $0.6(S)$ & $1.8(\mathrm{~S})$ & $-5.3(\mathrm{~S})$ & $11.1(\mathrm{~S})$ & $-0.2(\mathrm{~S})$ & $-19.8(\mathrm{~S})$ \\
\hline \multirow{4}{*}{ Monthly } & Count & $\mathrm{E}$ & 60 & 60 & 60 & 60 & 60 \\
\hline & NSE & $0.90(\mathrm{VG})$ & $0.69(\mathrm{G})$ & 0.84 (VG) & $0.74(\mathrm{G})$ & 0.89 (VG) & $0.63(\mathrm{~S})$ \\
\hline & RSR & $0.31(\mathrm{VG})$ & $0.56(\mathrm{G})$ & 0.40 (VG) & $0.51(G)$ & 0.34 (VG) & $0.61(\mathrm{~S})$ \\
\hline & PBIAS & 0.6 (VG) & $1.8(\mathrm{VG})$ & $-5.3(V G)$ & $11.1(\mathrm{G})$ & $-0.2(\mathrm{VG})$ & $-19.8(\mathrm{~S})$ \\
\hline
\end{tabular}

Based on comparisons between daily HEC-RAS model results and daily observed values (Table 6-2) and visual inspection of the Figures in Appendix $\mathrm{D}$, the model produced very good results for simulation of streamflow for the validation period. PBIAS indicates very good performance in replicating daily streamflow at Patuxent River near Bowie. NSE indicates very good performance in matching peak daily flows at Patuxent River near Bowie. RSR indicates very good correlation between measured and observed values as it relates to minimizing residual error at Patuxent River near Bowie. These explanations are confirmed from visual inspection of the simulated and observed time series plot (Figure D-14).

Based on comparisons between monthly HEC-RAS model results and monthly observed values (Table 6-2) and visual inspection of the Figures in Appendix D, the model produced very good results for simulation of streamflow for the validation period. PBIAS indicates very good performance in replicating monthly streamflow at Patuxent River near Bowie. NSE indicates very good performance in matching peak monthly flows at Patuxent River near Bowie. RSR indicates very good correlation between 
measured and observed values as it relates to minimizing residual error at Patuxent River near Bowie. These explanations are confirmed from visual inspection of the simulated and observed time series plot (Figure D-13).

Table 6-2. HEC-RAS Validation performance objectives for streamflow.

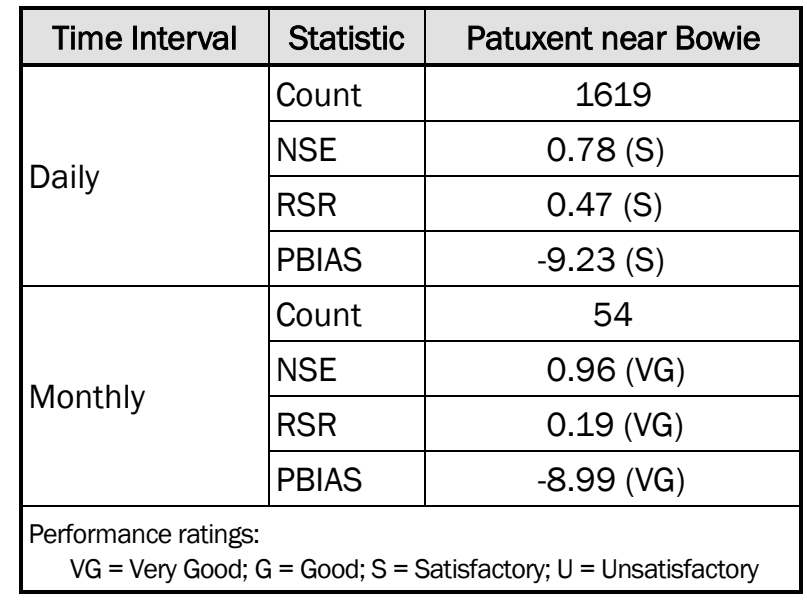

\subsubsection{Sediment}

Based on comparisons between daily HSPF model results and daily observed values (Table 6-3) and visual inspection of the Figures in Appendix D, the model produced mixed results for simulation of sediment loading for the validation period. PBIAS indicates unsatisfactory performance in replicating daily sediment loading at Patuxent near Laurel and satisfactory performance for Patuxent near Bowie. NSE indicates unsatisfactory performance in matching peak daily sediment loads at both locations evaluated. RSR indicates unsatisfactory correlation between measured and observed values as it relates to minimizing residual error at both locations evaluated. The model appears to over-predict sediment loads relative to the estimated/observed loads. These explanations are confirmed from visual inspection of the simulated and observed time series plots (Figures D-17 and D-18).

Based on comparisons between monthly HSPF model results and monthly observed values(Table 6-3) and visual inspection of the Figures in Appendix D, the model produced satisfactory results for simulation of sediment loading for the validation period. PBIAS indicates very good performance in replicating monthly sediment loading at Patuxent near Bowie. NSE indicates satisfactory performance in matching peak monthly sediment loads at Patuxent near Bowie. RSR indicates satisfactory correlation between measured and observed values as it relates to minimizing residual error at Patuxent near Bowie. Although the model produced unsatisfactory performance for all three metrics for simulating sediment at Patuxent near Laurel, 
greater confidence was given in the estimated loads for Patuxent near Bowie in determining overall satisfaction in model predictions of monthly sediment loading. These explanations are confirmed from visual inspection of the simulated and observed time series plots (Figures D-15 and D-16).

\begin{tabular}{|c|c|c|c|}
\hline $\begin{array}{c}\text { Time } \\
\text { Interval }\end{array}$ & Statistic & $\begin{array}{l}\text { Patuxent near } \\
\text { Bowie }\end{array}$ & $\begin{array}{c}\text { Patuxent near } \\
\text { Laurel }\end{array}$ \\
\hline \multirow{4}{*}{ Daily } & Count & 1459 & 1460 \\
\hline & NSE & $-1.81(U)$ & $-22.50(U)$ \\
\hline & RSR & $1.68(\mathrm{U})$ & $4.85(U)$ \\
\hline & PBIAS & $5.3(\mathrm{~S})$ & $-302.3(\mathrm{U})$ \\
\hline \multirow{4}{*}{ Monthly } & Count & 48 & 48 \\
\hline & NSE & $0.52(\mathrm{~S})$ & $-41.52(U)$ \\
\hline & RSR & $0.69(\mathrm{~S})$ & $6.52(\mathrm{U})$ \\
\hline & PBIAS & $5.3(\mathrm{VG})$ & $-302.3(\mathrm{U})$ \\
\hline $\begin{array}{r}\text { Performance } \\
\text { VG }=\text { Very }\end{array}$ & $\begin{array}{l}\text { ratings: } \\
\text { Good; } G=G\end{array}$ & $=$ Satisfactory; $U=$ & satisfactory \\
\hline
\end{tabular}

Based on comparisons between daily HEC-RAS model results and daily observed values (Table 6-4) and visual inspection of the Figures in Appendix $\mathrm{D}$, the model produced unsatisfactory results for simulation of total suspended solids for the validation period at Patuxent River near Bowie. PBIAS indicates unsatisfactory performance in replicating daily total suspended solids. NSE indicates unsatisfactory performance in matching peak daily total suspended solids. RSR indicates unsatisfactory correlation between measured and observed values as it relates to minimizing residual error. These explanations are confirmed from visual inspection of the simulated and observed time series plot (Figure D-20).

Based on comparisons between monthly HEC-RAS model results and monthly observed values (Table 6-4) and visual inspection of the Figures in Appendix D, the model produced unsatisfactory results for simulation of total suspended solids for the validation period at Patuxent River near Bowie. PBIAS indicates unsatisfactory performance in replicating monthly total suspended solids. NSE indicates unsatisfactory performance in matching peak monthly total suspended solids. RSR indicates unsatisfactory correlation between measured and observed values as it relates to minimizing residual error. These explanations are confirmed from visual inspection of the simulated and observed time series plot (Figure D-19). 
Table 6-4. HEC-RAS validation performance objectives for total suspended solids.

\begin{tabular}{|c|c|c|}
\hline Time Interval & Statistic & Patuxent near Bowie \\
\hline \multirow{4}{*}{ Daily } & Count & 139 \\
\hline & NSE & $-0.18(U)$ \\
\hline & RSR & $1.09(\mathrm{U})$ \\
\hline & PBIAS & $82.55(U)$ \\
\hline \multirow{4}{*}{ Monthly } & Count & 54 \\
\hline & NSE & $-0.50(U)$ \\
\hline & RSR & $1.23(U)$ \\
\hline & PBIAS & $81.25(\mathrm{U})$ \\
\hline
\end{tabular}

\subsubsection{Nutrients}

\subsubsection{Algae}

Based on comparisons between daily HEC-RAS model results and daily observed values (Table 6-5) and visual inspection of the Figures in Appendix $\mathrm{D}$, the model produced unsatisfactory results for simulation of algae for the validation period. PBIAS indicates unsatisfactory performance in replicating daily algae concentration at Patuxent River near Bowie. NSE indicates unsatisfactory performance in matching peak daily algae concentration. RSR indicates unsatisfactory correlation between measured and observed values as it relates to minimizing residual error. These explanations are confirmed from visual inspection of the simulated and observed time series plots (Figure D-34).

Based on comparisons between monthly HEC-RAS model results and monthly observed values (Table 6-5) and visual inspection of the Figures in Appendix D, the model produced unsatisfactory results for simulation of algae for the validation period. PBIAS indicates unsatisfactory performance in replicating monthly algae concentration at Patuxent River near Bowie. NSE indicates unsatisfactory performance in matching peak monthly algae concentration. RSR indicates unsatisfactory correlation between measured and observed values as it relates to minimizing residual error. These explanations are confirmed from visual inspection of the simulated and observed time series plots (Figure D-33). 


\subsubsection{Dissolved oxygen}

Based on comparisons between daily HEC-RAS model results and daily observed values (Table 6-5) and visual inspection of the Figures in Appendix D, the model produced very good results for simulation of dissolved oxygen for the validation period at Patuxent River near Bowie. PBIAS indicates very good performance in replicating daily DO concentration. NSE indicates very good performance in matching peak daily DO concentration. RSR indicates very good correlation between measured and observed values as it relates to minimizing residual error. These explanations are confirmed from visual inspection of the simulated and observed time series plots (Figure D-36).

Based on comparisons between monthly HEC-RAS model results and monthly observed values (Table 6-5) and visual inspection of the Figures in Appendix D, the model produced very good results for simulation of dissolved oxygen for the validation period at Patuxent River near Bowie. PBIAS indicates very good performance in replicating monthly DO concentration. NSE indicates very good performance in matching peak monthly DO concentration. RSR indicates very good correlation between measured and observed values as it relates to minimizing residual error. These explanations are confirmed from visual inspection of the simulated and observed time series plots (Figure D-35).

Table 6-5. HEC-RAS validation performance objectives for Algae, DO and CBOD concentrations.

\begin{tabular}{|c|c|c|c|}
\hline \multirow[b]{2}{*}{ Time Interval } & \multirow[b]{2}{*}{ Statistic } & \multicolumn{2}{|c|}{ Patuxent near Bowie } \\
\hline & & Algae & DO \\
\hline \multirow{4}{*}{ Daily } & Count & 124 & 140 \\
\hline & NSE & $-3.96(U)$ & $0.77(\mathrm{~S})$ \\
\hline & RSR & $2.23(\mathrm{U})$ & $0.47(\mathrm{~S})$ \\
\hline & PBIAS & $-97.46(U)$ & $-4.61(\mathrm{~S})$ \\
\hline \multirow{4}{*}{ Monthly } & Count & 50 & 54 \\
\hline & NSE & $-4.83(U)$ & $0.84(\mathrm{~S})$ \\
\hline & RSR & $2.41(U)$ & $0.40(\mathrm{~S})$ \\
\hline & PBIAS & $-93.87(U)$ & $\begin{array}{l}-3.71 \\
\text { (VG) }\end{array}$ \\
\hline \multicolumn{4}{|c|}{$\begin{array}{l}\text { Performance ratings: } \\
\qquad V G=\text { Very Good; } G \text { = Good; S = Satisfactory; U = Unsatisfactory }\end{array}$} \\
\hline
\end{tabular}




\section{Nitrogen}

Based on comparisons between daily HSPF model results and daily observed values (Table 6-6) and visual inspection of the Figures in Appendix D, the model produced mixed results for simulation of TN loads and satisfactory simulation of $\mathrm{NO}_{3}$ loads for the validation period. PBIAS indicates satisfactory performance in replicating daily $\mathrm{TN}$ loading at both locations. NSE indicates unsatisfactory performance in matching peak daily TN loads at Patuxent near Bowie, but NSE is satisfactory for Patuxent near Laurel. RSR indicates unsatisfactory correlation between measured and observed values as it relates to minimizing residual error for TN at Patuxent near Bowie, but RSR is satisfactory for Patuxent near Laurel. PBIAS indicates satisfactory performance in replicating daily $\mathrm{NO}_{3}$ loading at Patuxent near Bowie. NSE indicates satisfactory performance in matching peak daily $\mathrm{NO}_{3}$ loads at Patuxent near Bowie. RSR indicates satisfactory correlation between measured and observed values as it relates to minimizing residual error for $\mathrm{NO}_{3}$ at Patuxent near Bowie. These explanations are confirmed from visual inspection of the simulated and observed time series plots (Figures D-23, D-24, and D-26).

Based on comparisons between monthly HSPF model results and monthly observed values (Table 6-6) and visual inspection of the Figures in Appendix D, the model produced satisfactory results for simulation of TN loads and mixed simulation of $\mathrm{NO}_{3}$ loads for the validation period at Patuxent River near Bowie. PBIAS indicates very good performance in replicating monthly TN loading. NSE indicates satisfactory performance in matching peak monthly TN loads. RSR indicates satisfactory correlation between measured and observed values as it relates to minimizing residual error. PBIAS indicates good performance in replicating monthly $\mathrm{NO}_{3}$ loading. NSE indicates unsatisfactory performance in matching peak monthly $\mathrm{NO}_{3}$ loads. RSR indicates unsatisfactory correlation between measured and observed values as it relates to minimizing residual error for $\mathrm{NO}_{3}$. These explanations are confirmed from visual inspection of the simulated and observed time series plots (Figures D-21, D-22, and D-25).

Based on comparisons between daily HEC-RAS model results and daily observed values (Table 6-7) and visual inspection of the Figures in Appendix D, the model produced mixed results for simulation of nitrogen for the validation period at Patuxent River near Bowie. PBIAS indicates very good performance in replicating daily $\mathrm{OrgN}$ and $\mathrm{NO}_{3}$ concentration. PBIAS indicates good performance in replicating daily $\mathrm{NH}_{4}$ concentration. NSE 
indicates unsatisfactory performance in matching peak daily $\operatorname{OrgN}, \mathrm{NH}_{4}$, and $\mathrm{NO}_{3}$ concentration. RSR indicates unsatisfactory correlation between measured and observed values as it relates to minimizing residual error. These explanations are confirmed from visual inspection of the simulated and observed time series plots (Figures D-38, D-40, and D-42).

Based on comparisons between monthly HEC-RAS model results and monthly observed values (Table 6-7) and visual inspection of the Figures in Appendix D, the model produced unsatisfactory results for simulation of nitrogen for the validation period at Patuxent River near Bowie. PBIAS indicates very good performance in replicating monthly $\mathrm{OrgN}$ and $\mathrm{NO}_{3}$ concentration. PBIAS indicates good performance in replicating monthly $\mathrm{NH}_{4}$ concentration. NSE indicates unsatisfactory performance in matching peak monthly OrgN, $\mathrm{NH}_{4}$ and $\mathrm{NO}_{3}$ concentration. RSR indicates unsatisfactory correlation between measured and observed values as it relates to minimizing residual error. These explanations are confirmed from visual inspection of the simulated and observed time series plots (Figures D-37, D-39, and D-41).

\subsubsection{Phosphorus}

Based on comparisons between daily HSPF model results and daily observed values (Table 6-6) and visual inspection of the Figures in Appendix $\mathrm{D}$, the model produced mixed results for simulation of phosphorus for the validation period. PBIAS indicates unsatisfactory performance in replicating daily TP loading at Patuxent near Laurel and satisfactory performance in replicating daily TP and $\mathrm{PO}_{4}$ (Dissolved) loading at Patuxent near Bowie. NSE indicates unsatisfactory performance in matching peak daily $\mathrm{TP}$ and $\mathrm{PO}_{4}$ loads at Patuxent near Bowie. RSR indicates unsatisfactory correlation between measured and observed values as it relates to minimizing residual error at Patuxent near Bowie. These explanations are confirmed from visual inspection of the simulated and observed time series plots (Figures D-29, D-30, and D-32).

Based on comparisons between monthly HSPF model results and monthly observed values (Table 6-6) and visual inspection of the Figures in Appendix D, the model produced unsatisfactory results for simulation of phosphorus for the validation period. PBIAS indicates mixed performance in replicating monthly TP loading at Patuxent near Laurel and good performance in replicating monthly TP and $\mathrm{PO}_{4}$ loading at Patuxent near Bowie. NSE indicates satisfactory performance in matching peak monthly TP loads and unsatisfactory performance in matching peak monthly $\mathrm{PO}_{4}$ loads at 
Patuxent near Bowie. RSR indicates satisfactory correlation between measured and observed values as it relates to minimizing residual error for TP and unsatisfactory correlation for $\mathrm{PO}_{4}$ at Patuxent near Bowie. These explanations are confirmed from visual inspection of the simulated and observed time series plots (Figures D-27, D-28, and D-31).

Based on comparisons between daily HEC-RAS model results and daily observed values (Table 6-7) and visual inspection of the Figures in Appendix $\mathrm{D}$, the model produced mixed results for simulation of phosphorus for the validation period. PBIAS indicates good performance in replicating daily OrgP concentration at Patuxent River near Bowie. PBIAS indicates unsatisfactory performance in replicating daily $\mathrm{PO}_{4}$ concentration. NSE indicates unsatisfactory performance in matching peak daily OrgP and $\mathrm{PO}_{4}$ concentration. RSR indicates unsatisfactory correlation between measured and observed values as it relates to minimizing residual error. These explanations are confirmed from visual inspection of the simulated and observed time series plots (Figures D-44 and D-46).

Based on comparisons between monthly HEC-RAS model results and monthly observed values (Table 6-7) and visual inspection of the Figures in Appendix D, the model produced mixed results for simulation of phosphorus for the validation period. PBIAS indicates good performance in replicating monthly OrgP concentration at Patuxent River near Bowie. PBIAS indicates unsatisfactory performance in replicating monthly $\mathrm{PO}_{4}$ concentration. NSE indicates unsatisfactory performance in matching peak monthly OrgP and $\mathrm{PO}_{4}$ concentration. RSR indicates unsatisfactory correlation between measured and observed values as it relates to minimizing residual error. These explanations are confirmed from visual inspection of the simulated and observed time series plots (Figures D-43 and D-45).

Table 6-6. HSPF Validation performance objectives for nutrient loading.

\begin{tabular}{|l|l|c|c|c|c|c|c|}
\hline \multirow{3}{*}{ Time Interval } & & \multicolumn{4}{|c|}{ Patuxent near Bowie } & \multicolumn{2}{c|}{ Patuxent near Laurel } \\
\cline { 2 - 8 } & Statistic & TN load & NO3 load & TP load & PO4 load & TN load & TP load \\
\hline \multirow{5}{*}{ Daily } & Count & 1459 & 1459 & 1459 & 1459 & 1460 & 1460 \\
\cline { 2 - 8 } & NSE & $0.17(\mathrm{U})$ & $0.40(\mathrm{U})$ & $-0.02(\mathrm{U})$ & $-14.26(\mathrm{U})$ & $0.38(\mathrm{U})$ & $-6.97(\mathrm{U})$ \\
\cline { 2 - 8 } & RSR & $0.91(\mathrm{U})$ & $0.77(\mathrm{U})$ & $1.01(\mathrm{U})$ & $3.91(\mathrm{U})$ & $0.79(\mathrm{U})$ & $2.82(\mathrm{U})$ \\
\cline { 2 - 8 } & PBIAS & $-1.1(\mathrm{~S})$ & $33.9(\mathrm{~S})$ & $23.8(\mathrm{~S})$ & $-31.2(\mathrm{~S})$ & $21.3(\mathrm{~S})$ & $-152.0(\mathrm{U})$ \\
\hline \multirow{5}{*}{ Monthly } & Count & 48 & 48 & 48 & 48 & 48 & 48 \\
\cline { 2 - 8 } & NSE & $0.85(\mathrm{~S})$ & $0.14(\mathrm{U})$ & $0.69(\mathrm{~S})$ & $-1.79(\mathrm{U})$ & $0.58(\mathrm{~S})$ & $-12.42(\mathrm{U})$ \\
\cline { 2 - 8 } & RSR & $0.39(\mathrm{~S})$ & $0.93(\mathrm{U})$ & $0.55(\mathrm{~S})$ & $1.67(\mathrm{U})$ & $0.65(\mathrm{~S})$ & $3.66(\mathrm{U})$ \\
\cline { 2 - 8 } & PBIAS & $-1.1(\mathrm{VG})$ & $33.9(\mathrm{G})$ & $23.8(\mathrm{VG})$ & $-31.2(\mathrm{G})$ & $21.3(\mathrm{VG})$ & $-152.0(\mathrm{U})$ \\
\hline \multirow{5}{*}{ Performance ratings: VG = Very Good; G = Good; S = Satisfactory; U = Unsatisfactory } \\
\hline
\end{tabular}


Table 6-7. HEC-RAS validation performance objectives for nutrient concentration.

\begin{tabular}{|c|c|c|c|c|c|c|}
\hline \multirow{2}{*}{$\begin{array}{c}\text { Time } \\
\text { Interval }\end{array}$} & \multirow[b]{2}{*}{ Statistic } & \multicolumn{5}{|c|}{ Patuxent near Bowie } \\
\hline & & OrgN & $\mathrm{NH}_{4}$ & $\mathrm{NO}_{2}+\mathrm{NO}_{3}$ & OrgP & $\mathrm{PO}_{4}$ \\
\hline \multirow{4}{*}{ Daily } & Count & 86 & 91 & 89 & 50 & 91 \\
\hline & NSE & $-0.56(U)$ & $-0.39(U)$ & $-1.31(U)$ & $-0.12(U)$ & $-3.41(U)$ \\
\hline & RSR & $1.25(\mathrm{U})$ & $1.18(U)$ & $1.52(\mathrm{U})$ & $1.06(\mathrm{U})$ & $2.10(U)$ \\
\hline & PBIAS & $-0.75(\mathrm{~S})$ & $-33.71(\mathrm{~S})$ & $2.56(\mathrm{~S})$ & $36.57(\mathrm{~S})$ & $-101.41(U)$ \\
\hline \multirow{4}{*}{ Monthly } & Count & 53 & 54 & 53 & 50 & 54 \\
\hline & NSE & $-0.88(U)$ & $0.28(U)$ & $-1.55(U)$ & $-0.12(U)$ & $-4.16(U)$ \\
\hline & RSR & $1.37(\mathrm{U})$ & $0.85(U)$ & $1.60(\mathrm{U})$ & $1.06(\mathrm{U})$ & $2.27(\mathrm{U})$ \\
\hline & PBIAS & $-3.74(V G)$ & $-26.20(G)$ & 4.58 (VG) & $36.57(\mathrm{G})$ & $-115.41(U)$ \\
\hline
\end{tabular}

\subsection{Modeling best management practices (management scenarios)}

\subsubsection{Fort Meade management practice descriptions}

A scenario was implemented to evaluate the impacts of management practices implemented on the Fort Meade, Maryland military installation. Construction plan documents for six project sites were received from the USACE Baltimore District. The practices implemented across the six project sites included four bioretention cells, two pavement removal areas, one infiltration trench, and one infiltration basin.

The construction documents included survey information, demolition plans, site plans, and landscape plans for each practice. Practice surface areas/footprints and drainage areas were not included. Practice surface areas were estimated from the construction documents and satellite imagery that captured the construction phases of these projects (CAST 2018a). Drainage areas and percent imperviousness were estimated from a combination of survey information in the construction documents, a geospatial elevation layer, and typical surface area to drainage area ratios for bioretention and infiltration practices. A $4 \%$ surface area to drainage area ratio was assumed for the bioretention and infiltration practices. The pavement removal areas were assumed to have no additional area draining to them; therefore a 1-to1 surface area to drainage area ratio was assumed for these practices. Table 6-8 lists the project sites, practices, surface areas, drainage areas, and imperviousness. Figures 6-1 through 6-6 show the six project sites, including screenshots from the construction plans and satellite imagery. 
Table 6-8. Project sites, practices, surface areas, drainage areas, and imperviousness.

\begin{tabular}{|l|l|c|c|c|}
\hline Project Site & Practice & $\begin{array}{c}\text { Estimated Surface } \\
\text { Area (acres) }\end{array}$ & $\begin{array}{c}\text { Estimated Drainage } \\
\text { Area (acres) }\end{array}$ & $\begin{array}{c}\text { Estimated } \\
\text { Imperviousness }\end{array}$ \\
\hline Club Meade & Bioretention 1 & 0.035 & 0.875 & $100 \%$ \\
\hline Gym \& Chapel & Bioretention 2 & 0.035 & 0.875 & $100 \%$ \\
\hline 8500 Area & Bioretention 3 & 0.080 & 2.000 & $50 \%$ \\
\hline Donohue Field & Infiltration Trench 1 & 0.032 & 0.800 & $100 \%$ \\
\hline & Bioretention 4 & 1.100 & 1.100 & $100 \%$ \\
\hline Building 6300 & Infiltration Basin 1 & 0.095 & 2.375 & $50 \%$ \\
\hline Division Hill & Pavement Removal 1 & 0.032 & 0.800 & $75 \%$ \\
\hline
\end{tabular}

Figure 6-1. Club Meade bioretention practices depicted on construction plan documents and before and after satellite imagery.

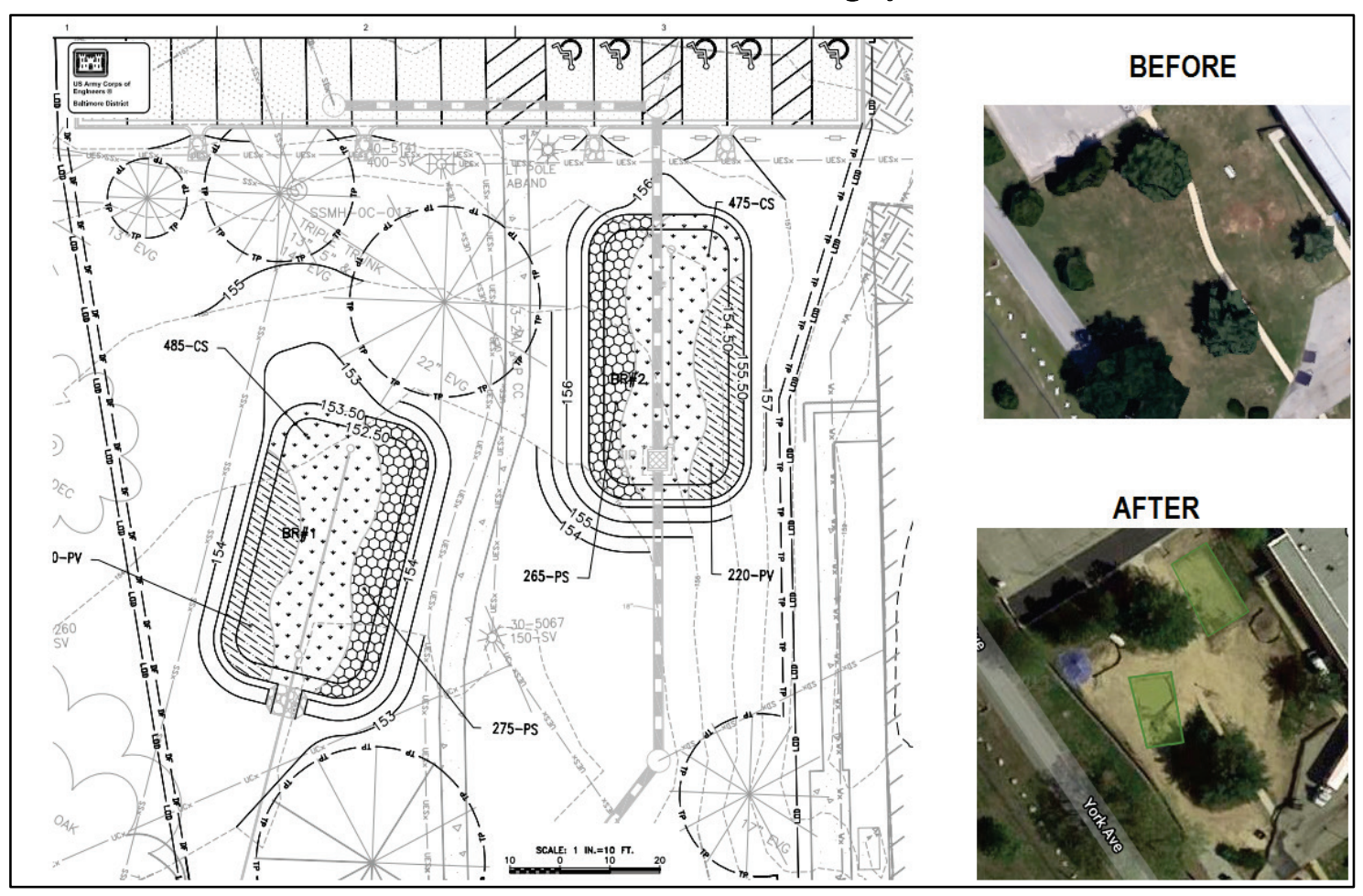


Figure 6-2. Gym and Chapel bioretention practice depicted on construction plan documents and before and after satellite imagery.

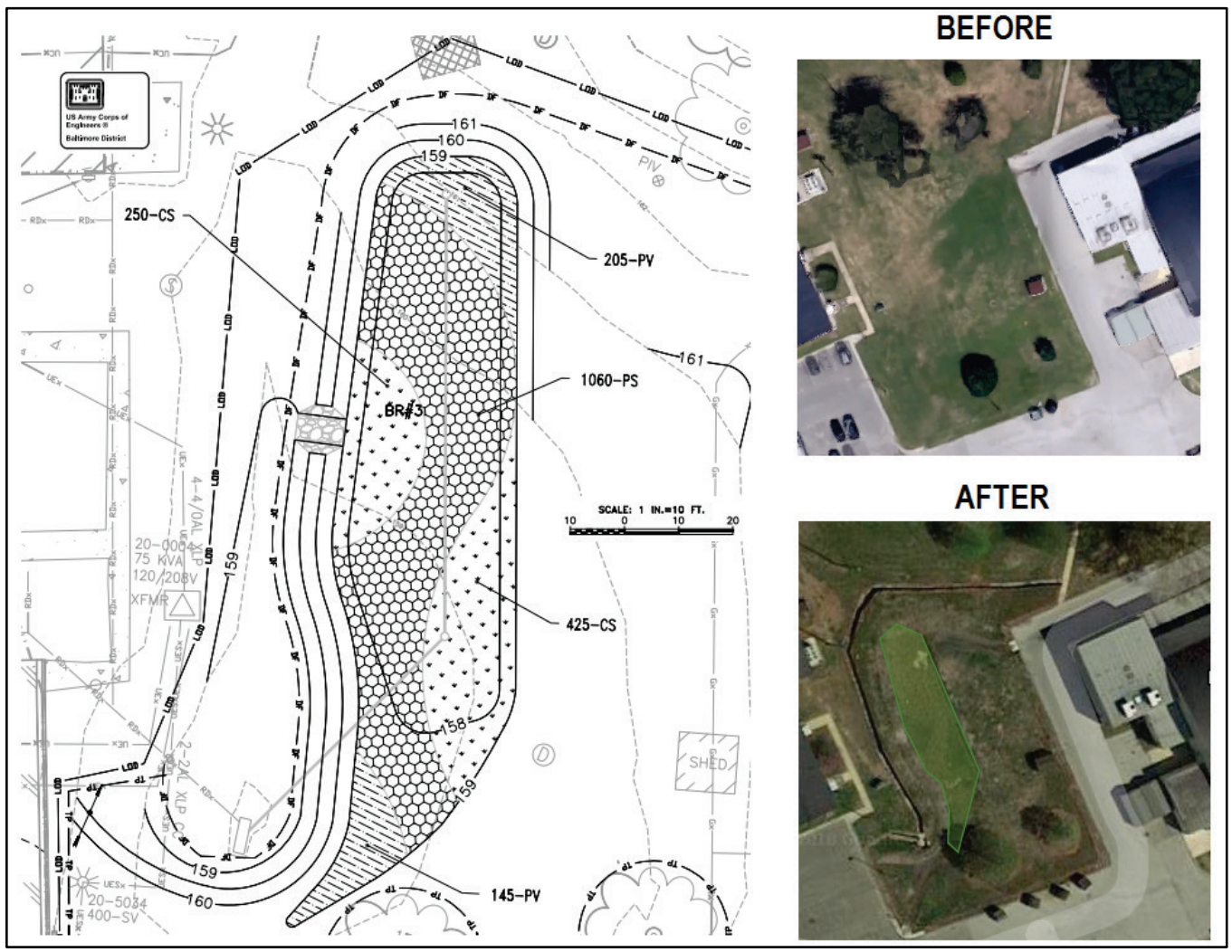

Figure 6-3. 8500 Area infiltration trench depicted on construction plan documents and before and after satellite imagery,

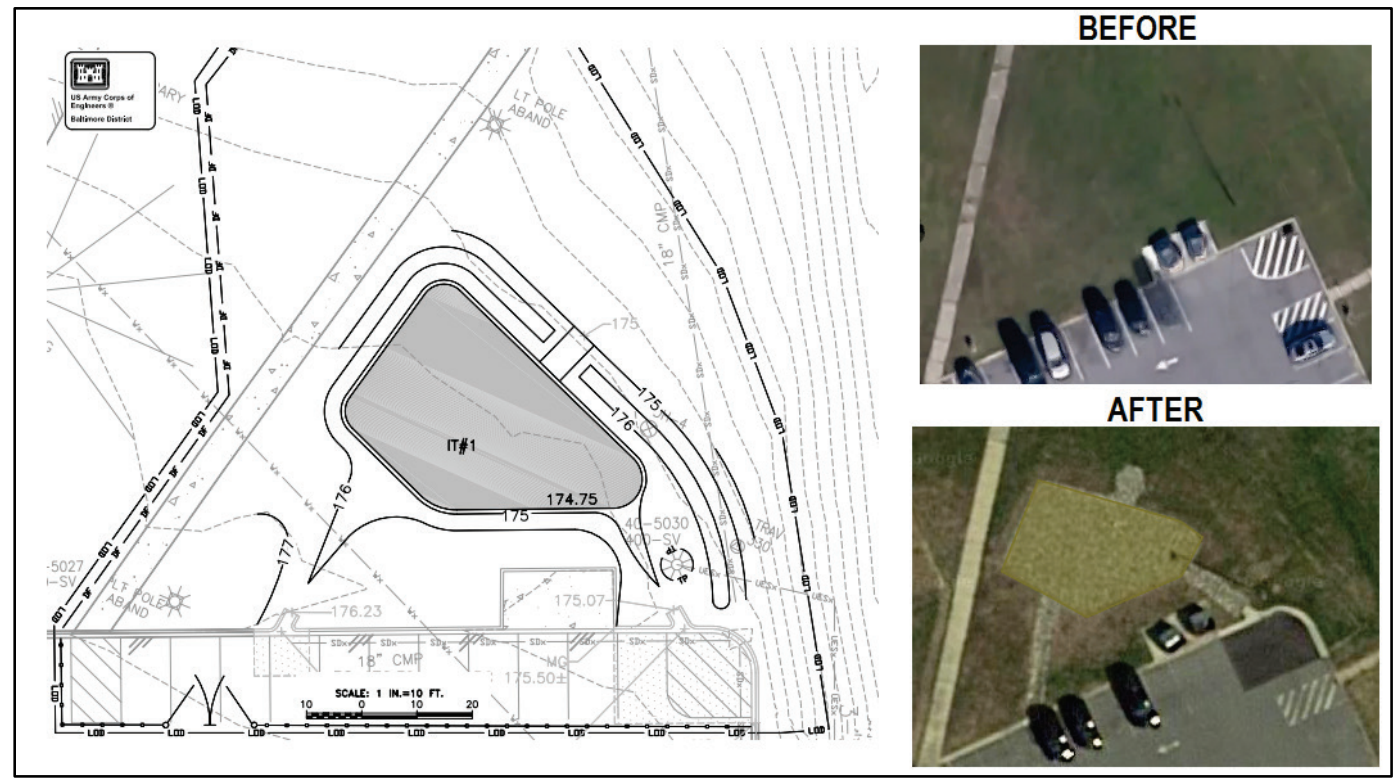


Figure 6-4. Donohue Field area practices - bioretention and pavement removal depicted on construction plan documents and before and after satellite imagery.

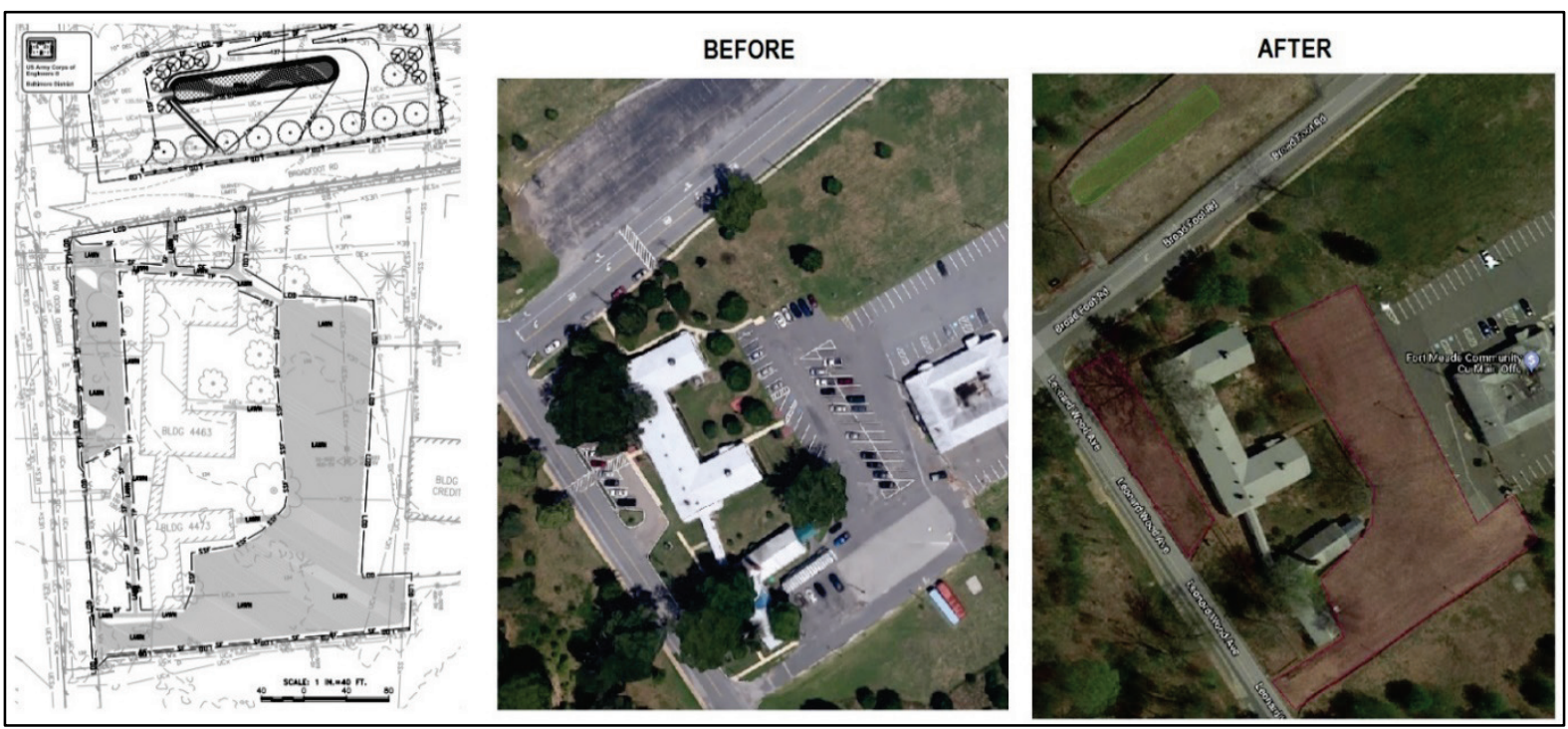

Figure 6-5. Building 6300 infiltration basin depicted on construction plan documents and before and after satellite imagery.

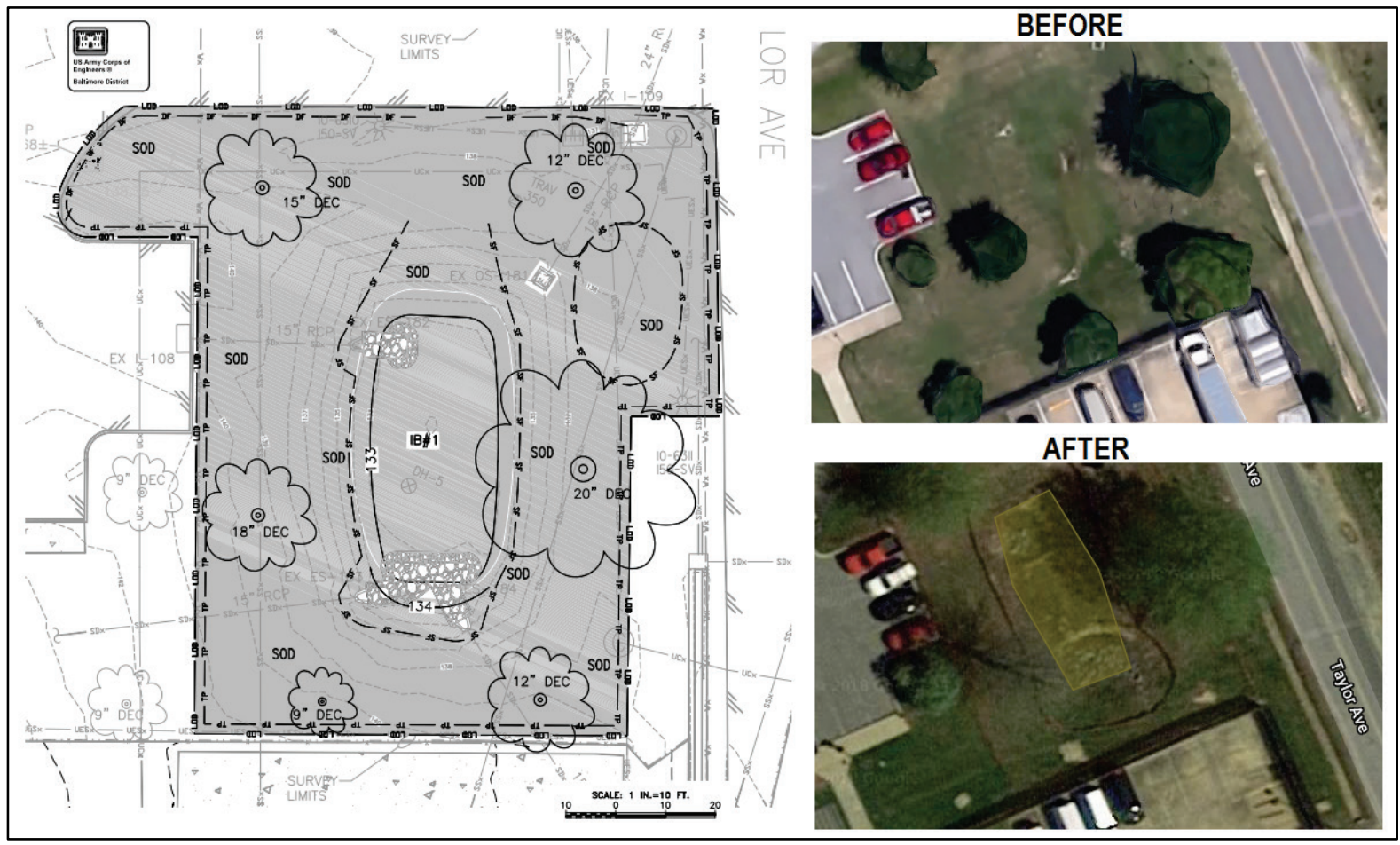


Figure 6-6. Division Hill pavement removal depicted on construction plan documents and before and after satellite imagery.

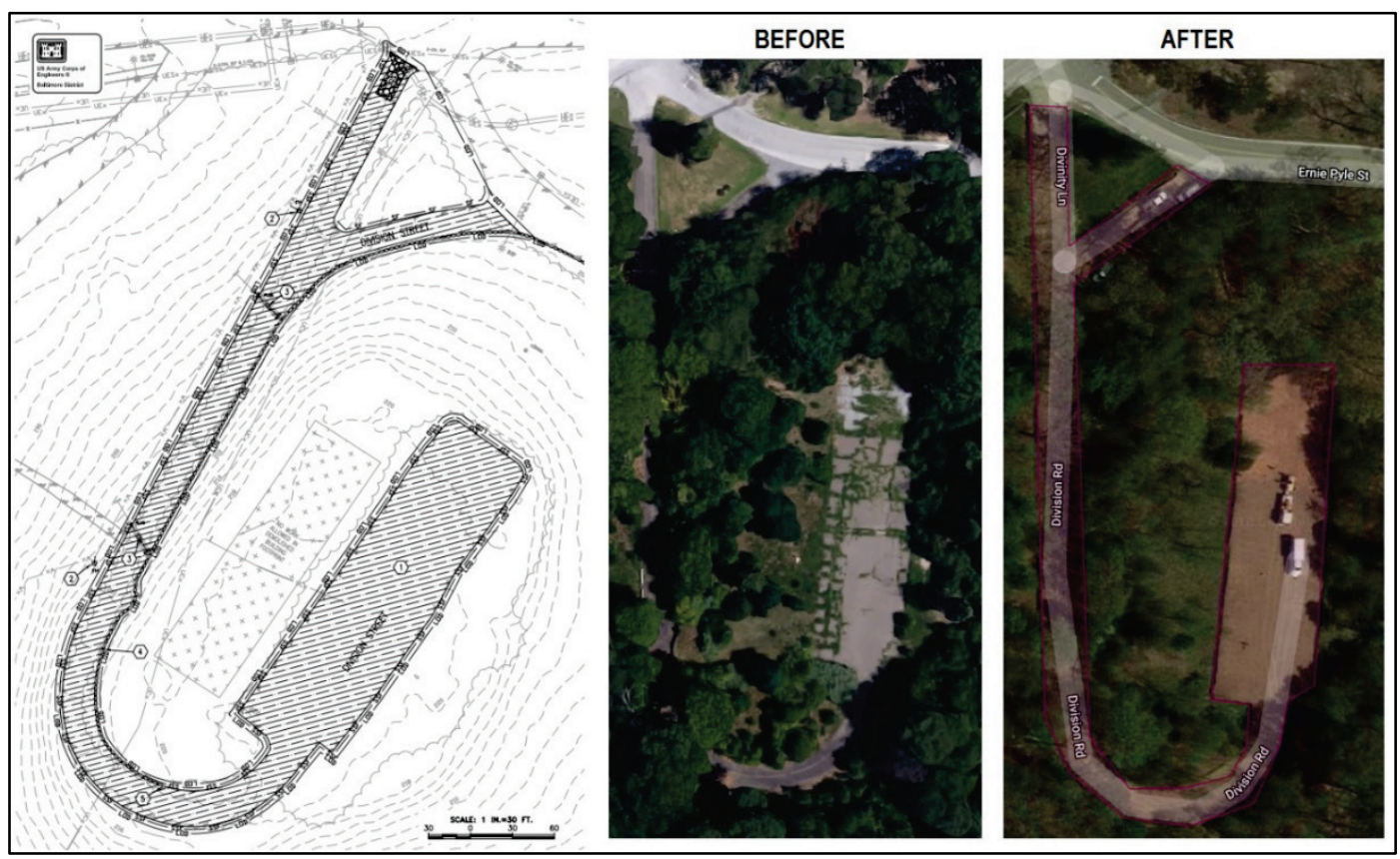

\subsubsection{Load reduction estimation approach}

The approach outlined in the "Protocol for Setting Targets, Planning BMPs and Reporting Progress for Federal Facilities and Lands" (CAST 2015) was used to estimate annual baseline loading and load reductions associated with the practices. Federal facility loading rates for untreated impervious and untreated pervious as described in the Maryland section of the Federal Targets Protocol (CAST 2015) were used to compute baseline loading for the drainage area associated with each practice (Table 6-9). Assumed nitrogen $(\mathrm{N})$, phosphorus $(\mathrm{P})$, and sediment removal efficiencies for bioretention and infiltration practices from the Chesapeake Assessment Scenario Tool (CAST) Phase 6 Source Data Tables (CAST 2018b) were used in this analysis (Table 6-10). Efficiencies for the pavement removal projects were estimated by computing the percent load reduction associated with conversion from untreated impervious to untreated pervious (Table 6-10).

Table 6-9. Federal facility loading rates.

\begin{tabular}{|l|c|c|c|}
\hline \multirow{2}{*}{ Land Type } & \multicolumn{3}{|c|}{ Assumed Baseline Load (Ibs/acre/year) } \\
\cline { 2 - 4 } & $\mathbf{N}$ & $\mathbf{P}$ & Sediment \\
\hline Impervious & 15.3 & 1.7 & 1117.7 \\
\hline Pervious & 10.8 & 0.4 & 175.6 \\
\hline Source: CAST 2015 \\
\hline
\end{tabular}


Table 6-10. Assumed load removal efficiencies

\begin{tabular}{|c|c|c|c|}
\hline \multirow[b]{2}{*}{ Practice } & \multicolumn{3}{|c|}{ Assumed Removal Efficiencies (\%) } \\
\hline & $\mathbf{N}$ & $\mathbf{P}$ & Sediment \\
\hline Bioretention ${ }^{1}$ & 70 & 75 & 80 \\
\hline Infiltration Trench/Basin ${ }^{2}$ & 85 & 85 & 95 \\
\hline Pavement Removal 3 & 29 & 76 & 84 \\
\hline \multicolumn{4}{|c|}{$\begin{array}{l}\text { Notes: } \\
1 \text { - Assumed “Bioretention/raingardens - A/B soils, underdrain” from CAST (2018b) } \\
2 \text { - Assumed “Infiltration Practices w/ Sand, Veg. - A/B soils, no underdrain” from CAST (2018b) } \\
3 \text { - Computed from CAST (2015) assuming conversion from impervious to pervious unit area loading } \\
\quad \text { rate }\end{array}$} \\
\hline
\end{tabular}

\subsubsection{Load reduction estimation results}

The combined annual load reduction associated with the six project sites was estimated to be $88.3 \mathrm{lbs} \mathrm{N}, 10.5 \mathrm{lbs} \mathrm{P}$, and $7367 \mathrm{lbs}$ sediment (Table 611). These load reductions were then applied to the HSPF model as described below. The edge-of-stream (EOS) loadings for the HSPF catchment where Fort Meade is located (XU2_4270_4650) were reduced on days when simulated flows were between the $80^{\text {th }}$ and $95^{\text {th }}$ percentile to replicate wet weather load reductions from these stormwater BMPs. The annual reductions were applied equally for each year of the simulation period, but the daily loading reduction rate varied by year, depending on how many days fell into the selected wet weather threshold (i.e., flows between the $80^{\text {th }}$ and $95^{\text {th }}$ percentile). The HSPF EOS loadings were used as boundary conditions for the HEC-RAS model to determine the in-stream impact of the six project sites.

Table 6-11. Estimated annual N, P, and sediment load reductions associated with the six project sites.

\begin{tabular}{|l|l|c|c|c|}
\hline \multirow{2}{*}{ Project Site } & \multirow{2}{*}{ Practice } & \multicolumn{2}{|c|}{ Annual Load Reduction (Ibs/year) } \\
\cline { 2 - 4 } & Club Meade & N & P & Sediment \\
\hline & Bioretention 1 & 9.4 & 1.1 & 782 \\
\hline Gym \& Chapel & Bioretention 3 & 9.4 & 1.1 & 782 \\
\hline 8500 Area & Infiltration Trench 1 & 18.3 & 1.6 & 1035 \\
\hline Donohue Field & Pavement Removal 1 & 4.9 & 1.2 & 849 \\
\hline & Bioretention 4 & 21.7 & 1.4 & 1033 \\
\hline Building 6300 & Infiltration Basin 1 & 9.6 & 1.9 & 1229 \\
\hline Division Hill & Pavement Removal 1 & 4.7 & 0.9 & 670 \\
\hline TOTAL & & 88.3 & 1.4 & 986 \\
\hline
\end{tabular}


Based on the Fort Meade management practice scenario discussed above, the linked HSPF and HEC-RAS modeling system was used to assess the reduction in sediment and nutrient loads to the Patuxent River. The baseline linked HSPF and HEC-RAS model was run using updated loadings created from the HSPF model. There were slightly changes of loadings for segment XU2_4270_4650 (Figure 6-7). The impacts of the management practice on the Patuxent River downstream water quality near Laurel, Maryland are not noticeable. Since the management practices implemented across the six project sites included were relatively small and less than 10 acres (4 ha). The reduced loading from these practices really did not affect the downstream and Chesapeake Bay water quality.

\subsection{Summary and conclusions}

The objective of this project was to evaluate a linked watershed and riverine modeling system for Patuxent River Watershed, Maryland against observed field data, as well as against model output from only the watershed model (HSPF-only). The model evaluation consisted of calibrating the models for the period of record from 1991 to 2000 (HSPF-only) and 1992 to 2000 (linked models), and validating the models for 2001 to 2005 (HSPF-only) and 2001 to 2005 (linked models). The performance objectives (NSE, PBIAS, and RSR) were computed for streamflow, sediment, total phosphorus, orthophosphorus, total nitrogen, ammonium, and nitrate using both daily and monthly average model predictions and measured data.

There were sufficient daily streamflow records to compute the required statistics for the three time periods mentioned above. For sediment and the various other water quality constituents, the availability of samples was sparse relative to the time period over which sampling was completed. Although performance statistics were computed for the water quality parameters, the sampling frequency (approximately two samples per month for most parameters) must be considered when evaluating model performance against prescribed thresholds. 
Figure 6-7. Linked HSPF and HEC-RAS model domain.

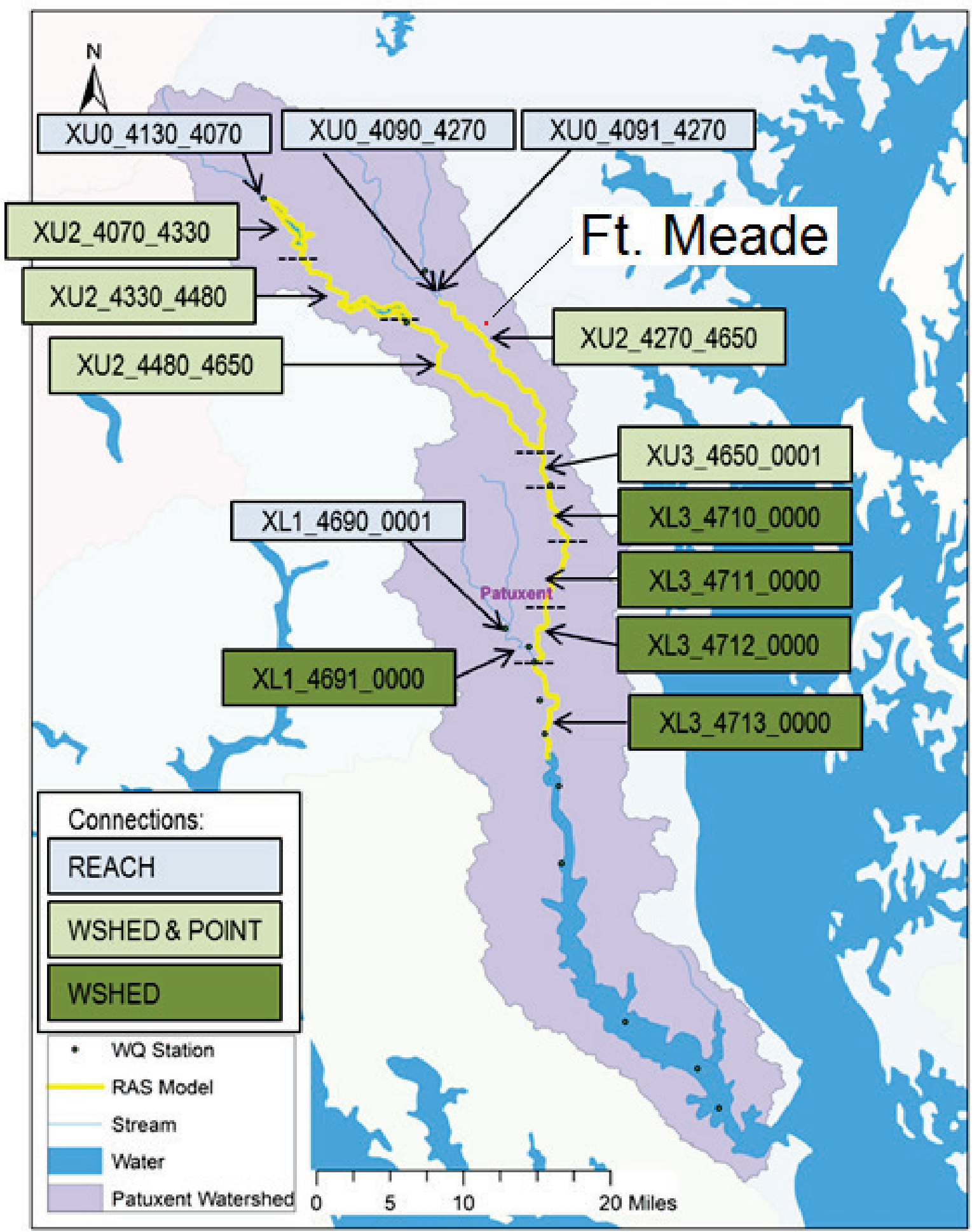




\subsection{Model performance as related to the performance objectives}

\subsubsection{Performance Objective 1 - Linked model accurately simulates major components of hydrologic cycle and stream flow}

Sections 5.4.1 and 6.1.1 describe the performance of HSPF-only and the linked model for the calibration and validation of daily average and monthly flows. Based on the performance ratings, the HSPF-only model was able to produce satisfactory daily streamflow results for the model calibration period and produced "very good" monthly streamflow results for nearly all statistics and locations. In general, shorter temporal scales produce poorer model simulations than longer temporal scales (e.g., daily versus monthly or yearly) (Engel et al. 2007). When visually comparing daily flow results, the HSPF-only model as a whole represented the overall hydrograph shape and timing within reasonable limits. Based on the performance ratings and visual comparison of modeled and observed hydrographs, the linked model was able to produce satisfactory daily and monthly flow results for its calibration period.

Based on the performance statistics and visual comparisons of hydrographs, the HSPF-only model was able to produce satisfactory flow results during the validation period for both daily and monthly streamflow simulation. The linked model was also able to produce satisfactory monthly flow results when compared to the performance statistics and hydrograph plots.

In conclusion, the HSPF-only model and the linked model performed equally well during the validation and calibration for daily streamflow simulation. In addition, HSPF-only and the linked model performed equally well for both the calibration and validation periods for monthly streamflow simulation.

\subsubsection{Performance Objective 2 - Linked model accurately simulates soil erosion and sediment transport}

Sections 5.4.2 and 6.1.2 describe the performance of HSPF-only and the linked model for the calibration and validation of daily average and monthly sediment simulation. The statistical performance evaluations were based on observed concentrations, not loads. The HSPF-only model produced mixed daily average results for all three metrics for both the calibration and validation periods for simulation of TSS concentrations. The HSPF-only model produced unsatisfactory monthly average results during calibration; however, the monthly results during the validation period 
were satisfactory. Visual inspection of simulated concentration time series indicates the HSPF-only model accurately simulates baseflow and storm flow TSS concentrations.

From reviewing the daily calibration performance statistics for the linked model, it was possible to produce mixed daily results for TSS. For the validation period, the results were unsatisfactory. The visual plots indicate that the linked model was able to capture the temporal variation of observed TSS as well as accurately simulate baseflow TSS and storm flow TSS.

In summary, the HSPF-only and linked models were judged to produce mixed results when simulating sediment in the watershed and riverine environments.

\subsubsection{Performance Objective 3 - Linked model accurately simulates contaminant fate and transport}

There were no contaminants simulated for the Patuxent River Watershed due to lack of observed data.

\subsubsection{Performance Objective 4 - Linked model accurately simulates nutrient fate and transport}

Sections 5.4.3 and 6.1.3 describe the performance of HSPF-only and the linked model for the calibration and validation of daily average and monthly nutrient simulation. The statistical performance evaluations were based on observed concentrations, not loads. The HSPF-only model met PBIAS targets for all nutrient species evaluated (total phosphorus, orthophosphate, total nitrogen, and nitrate) for simulation of both daily and monthly averages for both the calibration and validation periods. The HSPF-only model did not meet NSE and RSR thresholds for simulation of both daily and monthly averages for both the calibration and validation periods.

From reviewing the daily calibration performance statistics for the linked model, it was able to produce mixed daily results for $\mathrm{TP}, \mathrm{TN}, \mathrm{NH}_{4}$ and $\mathrm{NO}_{3}$. PBIAS indicated very good results with these constituents in streamflow. These constituents had unsatisfactory daily NSE and RSR, The visual plots shown indicate that the linked model was able to capture the temporal variation of observed data. From reviewing the daily validation performance statistics for the linked model, it was able to produce mixed daily results for TP, TN, $\mathrm{NH}_{4}$ and $\mathrm{NO}_{3}$. PBIAS indicated overall satisfactory 
results with these constituents in streamflow. Monthly validation results for the linked model were deemed to be unsatisfactory based upon the performance statistics.

In summary, the HSPF-only and linked models were judged successful in their ability to simulate observed nutrient concentrations. To improve the models and the evaluation of their performance, more nutrient samples need to be taken.

\subsubsection{Performance Objective 5 - Management scenarios}

Section 6.2 describes the performance of HSPF-only and the linked model in being able to simulate the effect of management scenarios. The scenario simulated was a representation of several actual stormwater BMPs implemented on the Fort Meade, Maryland military installation, including four bioretention cells, two pavement removal areas, one infiltration trench, and one infiltration basin. Using information contained in construction plan documents received from the USACE Baltimore District and sediment and nutrient load removal efficiencies from the CAST, we were able to successfully estimate annual load reductions associated with the Fort Meade management practices.

\subsubsection{Performance Objective 6 - Data availability}

USEPA Chesapeake Bay Office and USACE Baltimore District personnel served as local resources to assist in the data gathering and model conceptualization. There were sufficient national and local datasets available to develop the needed model inputs for both HSPF and HEC-RAS.

In regard to field data collection, there were sufficient streamflow data to perform model calibration and validation and generate the required statistics for storm event periods. There were sufficient observed water quality data to perform statistical evaluations at various locations in the watershed for simulation of daily average concentrations. The sampling frequency for the various water quality parameters was approximately two per month, however, and therefore many "monthly average" observations represented just a few samples. The USGS ESTIMATOR software program was used to estimate observed water quality loading for two river segments. These load estimates served as the basis for visual and statistical performance evaluations of the HSPF model sediment and nutrient predictions. 
Therefore, for Performance Objectives 6.1 to 6.3, we judge the demonstration to be successful.

\subsubsection{Performance Objective 7 - Ease of use}

Summarizing ease of use, both models had mature graphical user interfaces, thus facilitating the set up and simulation of the models. Two professional engineers with master's degrees and 7 to 15 years of work experience were used to initialize the watershed model and generate output needed for the independent performance analysis and linkage to the riverine model. Calibration and validation of the riverine model was performed by a senior level engineer, $\mathrm{PhD}$ with $20+$ years of experience. Thus, there were sufficient resources and personnel to run the HSPF-only and linked models. The initial set up of the models took a total of 2 weeks for the HSPF watershed model and 2 weeks for the HEC-RAS riverine model. The independent calibration and validation performance analysis phase took approximately 2 months, and the management scenario evaluations took approximately one month. Based on experience in performing these types of studies in the past, the goals we set in Performance Objectives 7.1 to 7.4 were met and thus successful.

\subsubsection{Lessons learned}

In regard to lessons learned from the Patuxent River Watershed Demonstration Study, there were a couple of items we identified. The first was investigating the methods for dealing with dry bed conditions in the HECRAS model. While the Patuxent River did not experience dry bed conditions, we do want to discuss one method used by hydraulic engineers. In cases where a stream may be intermittent, one can incorporate a very narrow slot at the low point in the cross-section to numerically keep the channel wet during very low flows. The volume of water in the slot is negligible, but numerically the channel never goes dry, while practically it does.

The second lesson learned is that, if one wishes to set up the linked model, there needs to be more observed water quality data to better constrain the HSPF output being used as boundary conditions to the HEC-RAS model. Across demonstration studies done as part of this project, that was a continuing data gap that would need to be closed to make full use of this system. 


\section{References}

ASCE (American Society of Civil Engineers). 1993. "Criteria for Evaluation of Watershed Models.” Journal of Irrigation Drainage Engineering 119(3):429-442.

Barkau, Robert L. 1992. UNET, One-Dimensional Unsteady Flow Through a Full Network of Open Channels: User's Manual. St. Louis, MO: The Center.

Bevan-Dangel, J., and F. Tutman. 2007. "Patuxent River 20/20. The Need for Effective Action and Effective Solutions." Patuxent Riverkeeper December 2007.

Bicknell, Brian R., John C. Imhoff, John L. Kittle Jr., Thomas H. Jobes, and Anthony S. Donigian, Jr. 2005. HSPF Version 12.2 User's Manual. Mountain View, CA: Aqua Verra Consultants.

CAST (Chesapeake Assessment Scenario Tool). 2015. Federal Targets Protocol. https://cast.chesapeakebay.net/Documentation/FederalFacilitylnformation.

2018a. Measure Polygon Area and Perimeter Utility. http://gis.chesapeakebay.net/utilities/measure.htm.

2018b. Phase 6 Source Data. https://cast.chesapeakebay.net/Home/SourceData.

CCMP (Chesapeake Community Modeling Program). 2017a. Chesapeake Bay Watershed Phase 5.3 Model. http://ches.communitymodeling.org/models/CBPhase5/index.php\#links.

- 2017b. Watershed Data Library. http://ches.communitymodeling.org/models/CBPhase5/datalibrary/observed-data.php.

CEQ (Council on Environmental Quality). 2005. 40 CFR 1500-1508: CEQ Regulations for Implementing the Procedural Provisions of NEPA. Washington, DC: CEQ, Executive Office of the President. https://www.energy.gov/sites/prod/files/NEPA40CFR1500_1508.pdf

Engel, B., D. Storm, M. White, J. Arnold, and M. Arabi. 2007. "A Hydrologic/Water Quality Model Application Protocol." Journal of the American Water Resources Association 43(5):1223-1236.

Fort Meade. 2017. www.FtMeade.Army.mil.

HEC (Hydrologic Engineering Center), 1997. UNET, One-Dimensional Unsteady Flow Through a Full Network Open Channels, User's Manual. Davis, CA: U.S. Army Corps of Engineers, HEC.

Legates, D. R., and G. J. McCabe Jr. 1999. "Evaluating the Use of "Goodness-of-Fit" Measures in Hydrologic and Hydroclimatic Model Validation." Water Resources Research 35:233-241.

Mashriqui, H., S. Reed, and C. Aschwanden. 2010. "Toward Modeling of River-EstuaryOcean Interactions to Enhance Operational River Forecasting in the NOAA National Weather Service." Las Vegas, NV: 2nd Joint Federal Interagency Conference. 
Milchunas, D. G., K. A. Schultz, and R. B. Shaw. 1999. "Plant Community Response to Disturbance by Mechanized Military Maneuvers.” Journal of Environmental Quality 28:1533-1547.

Moriasi, D. N., J. G. Arnold, M. W. Van Liew, R. L. Bingner, R. D. Harmel, and T. L. Veith. 2007. "Model Evaluation Guidelines for Systematic Quantification of Accuracy in Watershed Simulations." Transactions of the ASABE. 5O(3):885900.

NEPA National Environmental Policy Act). 1970 (as amended). Pub. L. 91-190, 42 U.S.C. 4321-4347, January 1, 1970, as amended by Pub. L. 94-52, July 3, 1975, Pub. L. 94-83, August 9, 1975, and Pub. L. 97-258, § 4(b), Sept. 13, 1982). https://www.whitehouse.gov/sites/whitehouse.gov/files/ceq/NEPA_full_text.pdf.

NAS (Naval Air Station) Patuxent River. 2017. Installation Information. https://www.cnic.navy.mil/regions/ndw/installations/nas_patuxent_river.html.

Quist M. C., P. A. Fay, C. S. Guy, A. K. Knapp, and B. N. Rubenstein. 2003. "Military Training Effects on Terrestrial and Aquatic Communities on a Grassland Military Installation.” Ecological Applications 13(2):432-442.

Shaw R. B., and V. E. Diersing. 1989. "Allowable Use Estimates for Tracked Vehicular Training on Pinon Canyon Maneuver Site, Colorado, USA.” Environmental Management 13:773-782.

Shenk, G. W., J. Wu, and L. C. Linker. 2012. "Enhanced HSPF Model Structure for Chesapeake Bay Watershed Simulation.” Journal of Environmental Engineering 138:949-957.

USEPA (U.S. Environmental Protection Agency). 2010a. Chesapeake Bay Phase 5.3 Community Watershed Model. EPA 903S10002-CBP/TRS-303-10. Annapolis MD: USEPA, Chesapeake Bay Program Office.

- 2010b. Chesapeake Bay TMDL Executive Summary. https://www.epa.gov/sites/production/files/201412/documents/bay_tmdl_executive_summary_final_12.29.10_final_1.pdf.

White House, The. 2009. Chesapeake Bay Protection and Restoration Section 203 Final Coordinated Implementation Strategy. Executive Order (EO) 13508. Washington, DC: The White House. https://www.govinfo.gov/app/details/CFR-2010title3-vol1/CFR-2010-title3-vol1-e013508. 


\section{Acronyms and Abbreviations}

\begin{tabular}{|c|c|}
\hline Abbreviation & Term \\
\hline ADCALC & advection (HSPF model application modules) \\
\hline ATEMP & air temperature (HSPF model application modules) \\
\hline BASINS & Better Assessment Science Integrating Point and Non-point Sources \\
\hline BMP & Best Management Practice \\
\hline BRAC & Base Realignment and Closures \\
\hline CBOD & Carbonaceous Biochemical Oxygen Demand \\
\hline CCMP & Chesapeake Community Modeling Program \\
\hline CEQ & Council on Environmental Quality \\
\hline CSM & Contaminant Simulation Module \\
\hline CTT\&F & Contaminant Transport, Transformation, and Fate \\
\hline CWA & Clean Water Act \\
\hline DEM & Digital Elevation Map \\
\hline DO & Dissolved Oxygen \\
\hline DOC & Dissolved Organic Carbon \\
\hline DoD & Department of Defense \\
\hline EOS & Edge-of-Stream \\
\hline USEPA & U.S. Environmental Protection Agency \\
\hline ERDC & Engineer Research and Development Center \\
\hline ESTCP & Environmental Security Technology Certification Program \\
\hline FTABLE & Hydraulic Function Table \\
\hline GUI & Graphic User Interface \\
\hline HEC-DSS & Hydrologic Engineer Center - Data Storage System \\
\hline HEC-RAS & Hydrologic Engineer Center - River Analysis System \\
\hline HSPF & Hydrological Simulation Program Fortran \\
\hline $\mathrm{HTRCH}$ & $\begin{array}{l}\text { heat exchange and water temperature (HSPF model application } \\
\text { modules) }\end{array}$ \\
\hline HUC & Hydrologic Unit Code \\
\hline HYDR & hydraulic behavior (HSPF model application modules) \\
\hline IMPLND & impervious land segment (HSPF model application modules) \\
\hline IQUAL & quality constituent (HSPF model application modules) \\
\hline IWATER & water (HSPF model application modules) \\
\hline IWTGAS & water temperature and dissolved (HSPF model application modules) \\
\hline
\end{tabular}




\begin{tabular}{|c|c|}
\hline Abbreviation & Term \\
\hline LOADEST & Load Estimator \\
\hline MSTLAY & soil layer solute transport (HSPF model application modules) \\
\hline MV & Modeled Value \\
\hline NAS & Naval Air Station \\
\hline NAVAIR & Naval Air Systems Command \\
\hline NAVFAC & Naval Facilities Engineering Command \\
\hline NAWCAD & Naval Air Warfare Center Aircraft Division \\
\hline NEPA & National Environmental Policy Act \\
\hline $\mathrm{NH}_{4}$ & Ammonium \\
\hline NITR & nitrogen (HSPF model application modules) \\
\hline $\mathrm{NO}_{2}$ & Nitrite \\
\hline $\mathrm{NO}_{3}$ & Nitrate \\
\hline NPDES & National Pollutant Discharge Elimination System \\
\hline NSE & Nash-Sutcliffe Efficiency \\
\hline NSM & Nutrient Simulation Module \\
\hline NUTRX & nutrient (HSPF model application modules) \\
\hline OrgN & Organic Nitrogen \\
\hline OrgP & Organic Phosphorus \\
\hline OV & Observed Value \\
\hline OXRX & oxygen (HSPF model application modules) \\
\hline PBIAS & Percent Bias \\
\hline PERLND & pervious land segments (HSPF model application modules) \\
\hline PLANK & plankton (HSPF model application modules) \\
\hline $\mathrm{PO}_{4}$ & Phosphate \\
\hline PQUAL & quality constituent (HSPF model application modules) \\
\hline PSTEMP & soil temperature (HSPF model application modules) \\
\hline PWATER & water (HSPF model application modules) \\
\hline PWTGAS & $\begin{array}{l}\text { water temperature and dissolved gas (HSPF model application } \\
\text { modules) }\end{array}$ \\
\hline RCHRES & reach reservoir (HSPF model application modules) \\
\hline RMSE & Root mean square error \\
\hline RSR & RMSE-observations standard deviation ratio \\
\hline SEDMNT & sediment (HSPF model application modules) \\
\hline SEDTRN & sediment transport (HSPF model application modules) \\
\hline
\end{tabular}




\begin{tabular}{|l|l|}
\hline Abbreviation & Term \\
\hline SNOW & snow (HSPF model application modules) \\
\hline SOLIDS & sediment (HSPF model application modules) \\
\hline TIN & Triangular Irregular Network \\
\hline TKN & Total Kjeldahl Nitrogen \\
\hline TMDL & Total Maximum Daily Load \\
\hline TN & Total Nitrogen \\
\hline TP & Total Phosphorus \\
\hline TSS & Total Suspended Sediment \\
\hline UNET & Unsteady Network \\
\hline USACE & United States Army Corps of Engineers \\
\hline USEPA & United States Environmental Protection Agency \\
\hline USGS & United States Geological Survey \\
\hline WDM & Water Data Management \\
\hline WIP & Watershed Implementation Plans \\
\hline
\end{tabular}




\section{Appendix A: Health and Safety Plan (HASP)}

HASP applies to exposure to chemical and hazardous materials. This ESTCP project does not require exposure to chemical and hazardous materials. We are currently working with the ERDC Safety Office in developing a plan and will submit a signed copy once it has been approved.

POSITION HAZARD ANALYSIS

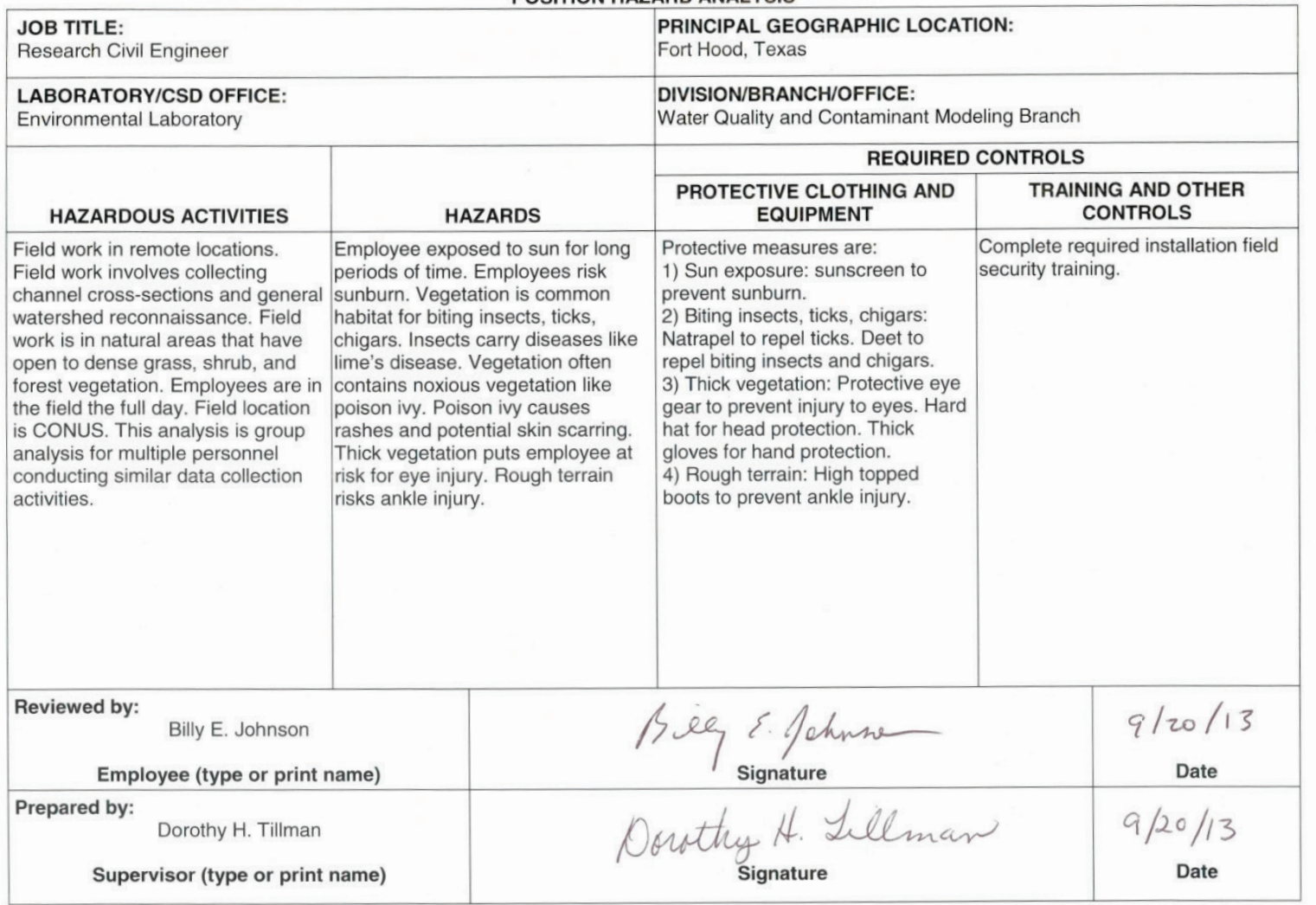




\section{Appendix B: Points of Contact}

\begin{tabular}{|c|c|c|c|}
\hline $\begin{array}{l}\text { Point of } \\
\text { Contact }\end{array}$ & Organization & Phone, Fax, Email & Role in Project \\
\hline Billy Johnson & $\begin{array}{l}\text { ERDC-EL, } 3909 \\
\text { Halls Ferry Road, } \\
\text { Vicksburg, MS, } \\
39180\end{array}$ & $\begin{array}{l}\text { Phone: 601-634-3714 } \\
\text { Fax: 601-634-3129 } \\
\text { Email: } \\
\text { billy.e.johnson@usace.army.mil }\end{array}$ & $\begin{array}{l}\text { Project Coordinator, } \\
\text { ERDC } \\
\text { Demonstration } \\
\text { Lead }\end{array}$ \\
\hline Heidi Howard & $\begin{array}{l}\text { ERDC-CERL, } 2902 \\
\text { Newmark Dr. } \\
\text { Champaign IL, } \\
61822-1076\end{array}$ & $\begin{array}{l}\text { Phone: 217-373-5865 } \\
\text { Fax: 217-373-7266 } \\
\text { Email: } \\
\text { heidi.r.howard@usace.army.mil }\end{array}$ & $\begin{array}{l}\text { Installation } \\
\text { Coordinator }\end{array}$ \\
\hline $\begin{array}{l}\text { Zhonglong } \\
\text { Zhang }\end{array}$ & $\begin{array}{l}\text { LimnoTech, } 3909 \\
\text { Halls Ferry Road, } \\
\text { Vicksburg, MS, } \\
39180\end{array}$ & $\begin{array}{l}\text { Phone: 601-634-3337 } \\
\text { Fax: 601-634-3129 } \\
\text { Email: } \\
\text { zhonglong.zhang@usace.army.mil }\end{array}$ & $\begin{array}{l}\text { Model application } \\
\text { and development }\end{array}$ \\
\hline Jeffrey Gerald & $\begin{array}{l}\text { ERDC-EL, } 3909 \\
\text { Halls Ferry Road, } \\
\text { Vicksburg, MS, } \\
39180\end{array}$ & $\begin{array}{l}\text { Phone: 601-634-3590 } \\
\text { Fax: 601-634-3129 } \\
\text { Email: jeff.gerald@usace.army.mil }\end{array}$ & Model Linkage \\
\hline Mark George & $\begin{array}{l}\text { Environmental } \\
\text { Department (EV14) } \\
\text { Naval Facilities } \\
\text { Engineering Service } \\
\text { Center } \\
110023^{\text {rd }} \text { Avenue, } \\
\text { Port Hueneme, CA } \\
93043\end{array}$ & $\begin{array}{l}\text { Phone: (805)982-3110; } \\
\text { Fax: (805)982-4832 } \\
\text { Email: mark.s.george@navy.mil }\end{array}$ & $\begin{array}{l}\text { Data Collector and } \\
\text { Installation } \\
\text { Coordinator }\end{array}$ \\
\hline Kurt Preston & $\begin{array}{l}\text { ESTCP, } 901 \text { N. } \\
\text { Stuart St., Suite } \\
\text { 303, Arlington, VA, } \\
\text { 22203-1853 }\end{array}$ & $\begin{array}{l}\text { Phone - 703-697-0487 } \\
\text { Email: } \\
\text { Kurt.T.Preston@usace.army.mil }\end{array}$ & $\begin{array}{l}\text { Resource } \\
\text { Conservation } \\
\text { Program Manager }\end{array}$ \\
\hline $\begin{array}{l}\text { Cassandra } \\
\text { Bergstedt }\end{array}$ & $\begin{array}{l}\text { ESTCP/Noblis; } \\
16414 \text { San Pedro } \\
\text { Avenue, Suite 400, } \\
\text { San Antonio, TX } \\
78232\end{array}$ & $\begin{array}{l}\text { Phone - 210-403-5409 } \\
\text { Email: } \\
\text { Cassandra.A.Bergstedt@noblis.org }\end{array}$ & Project reporting \\
\hline $\begin{array}{l}\text { Stephanie } \\
\text { Lawless }\end{array}$ & $\begin{array}{l}\text { ESTCP/Noblis; } 3150 \\
\text { Fairview Park Drive, } \\
\text { Falls Church, VA } \\
2204\end{array}$ & $\begin{array}{l}\text { Phone - 703-610-2817 } \\
\text { Email: } \\
\text { Stephanie.Lawless@noblis.org }\end{array}$ & Project reporting \\
\hline
\end{tabular}




\section{Appendix C: Calibration Model Results}

Figure C-1. Monthly Streamflow Volume Time Series for Hunting Creek near Huntingtown, Maryland (Segment: XLO_5320_0001).

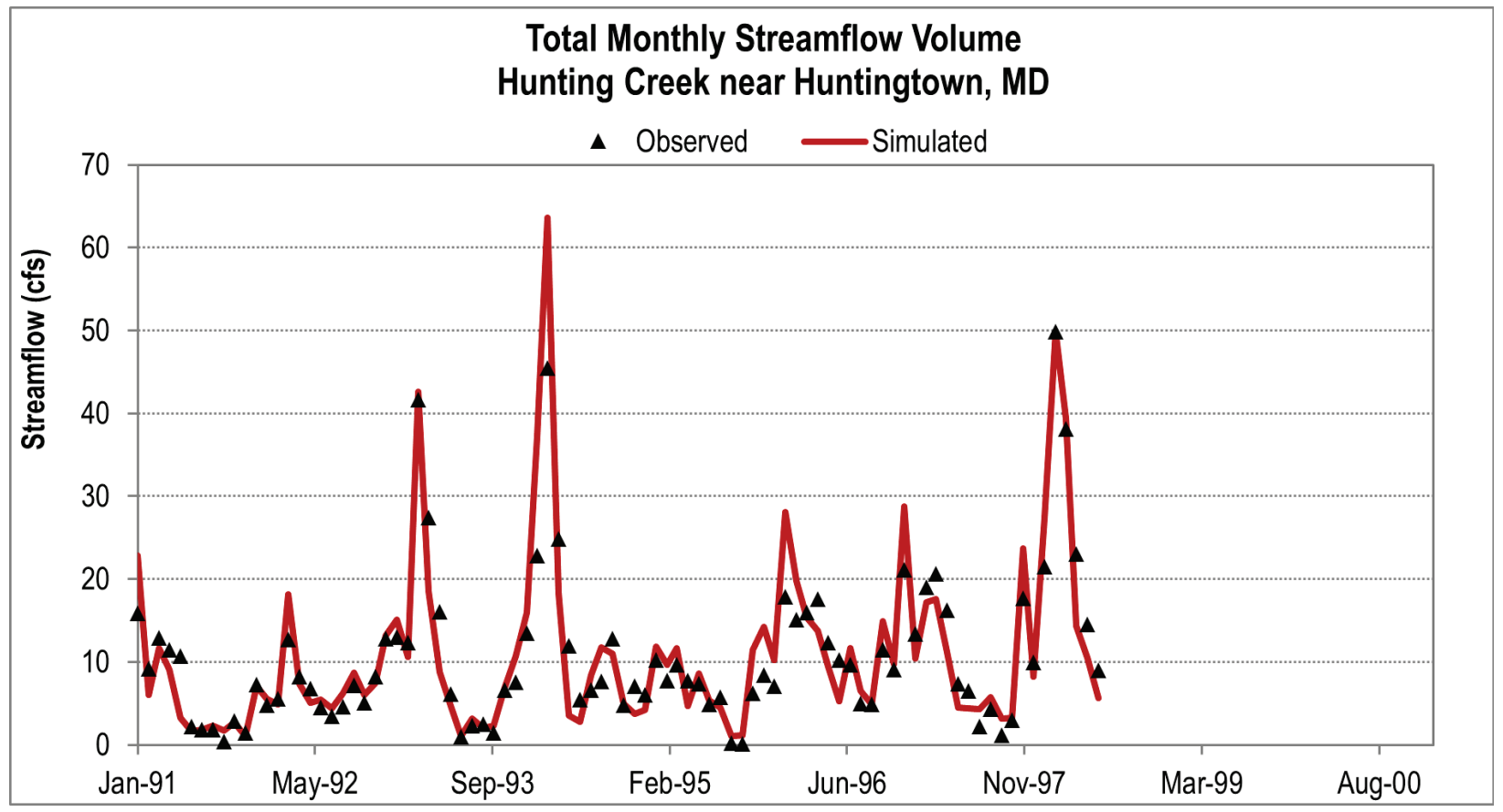

Figure C-2. Monthly Streamflow Volume Time Series for Western Branch at Upper Marlboro MD (Segment: XL1_4690_0001).

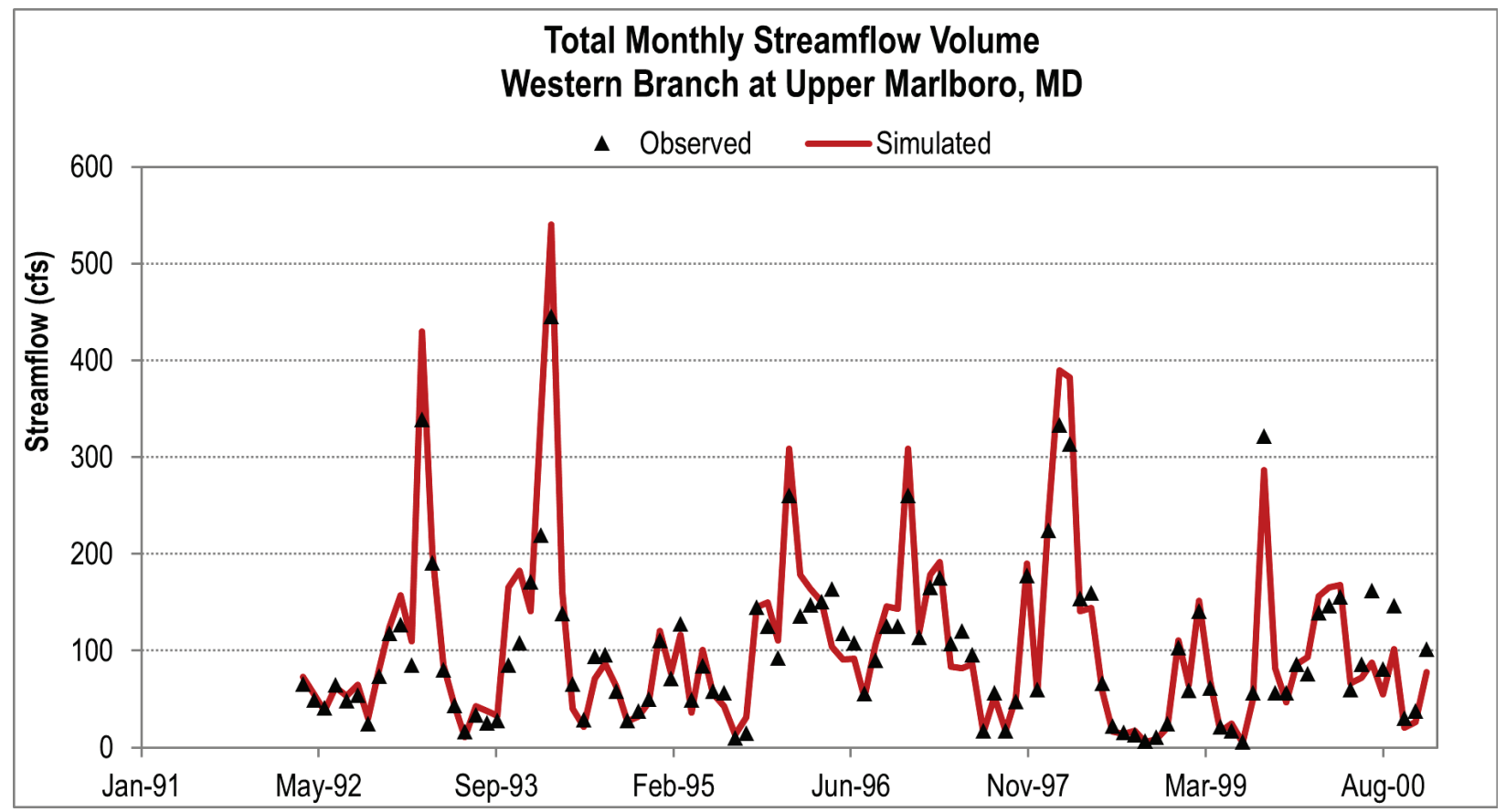


Figure C-3. Monthly Streamflow Volume Time Series for Patuxent River near Unity, Maryland (Segment: XUO_4130_4070).

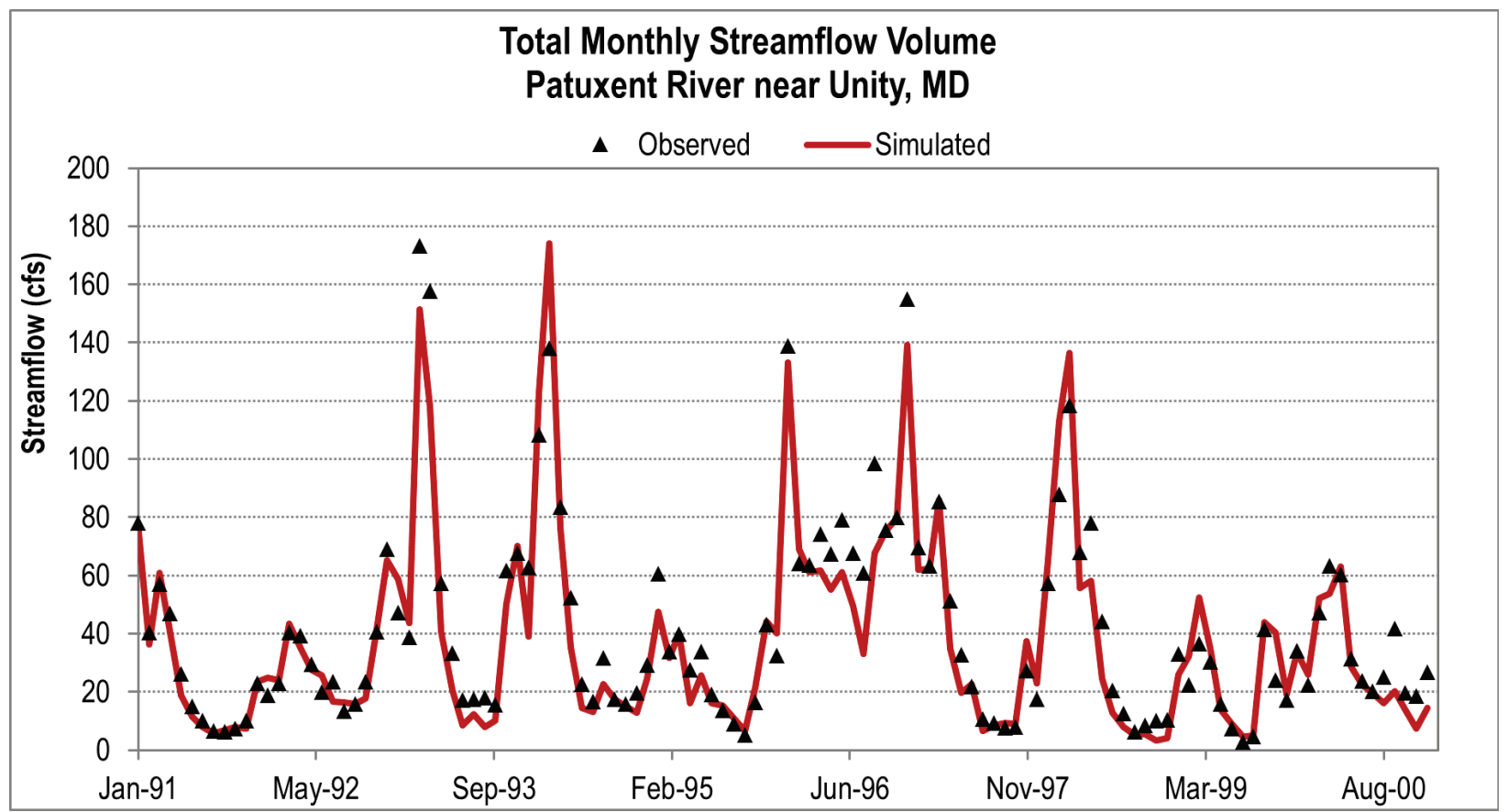

Figure C-4. Monthly Streamflow Volume Time Series for Patuxent River near Brighton, Maryland (Segment: XU2_4070_4330).

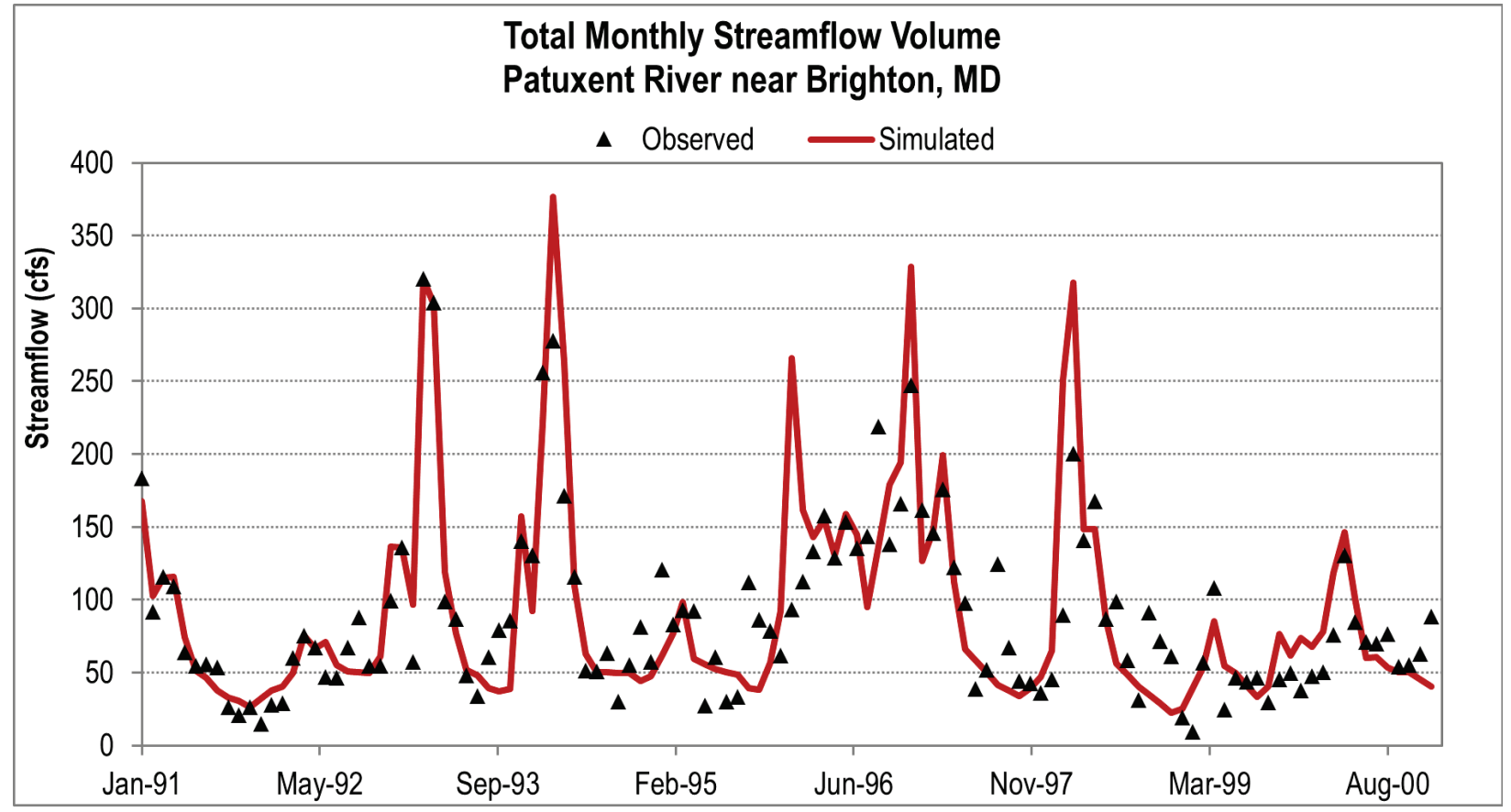


Figure C-5. Monthly Streamflow Volume Time Series for Little Patuxent River at Savage, Maryland (Segment: XU2_4270_0003),

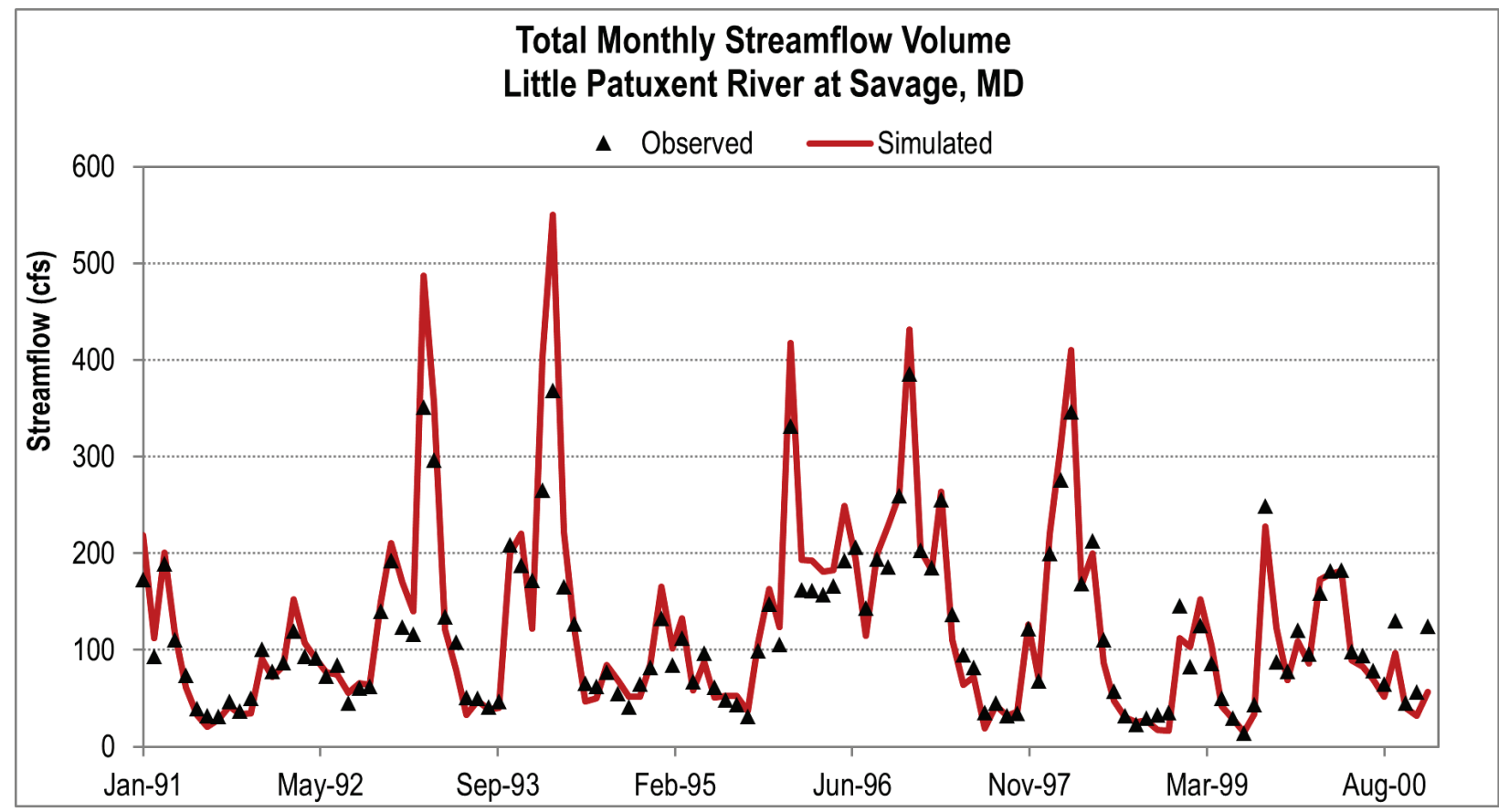

Figure C-6. Monthly Streamflow Volume Time Series for Patuxent River near Laurel, Maryland (Segment: XU2_4330_4480).

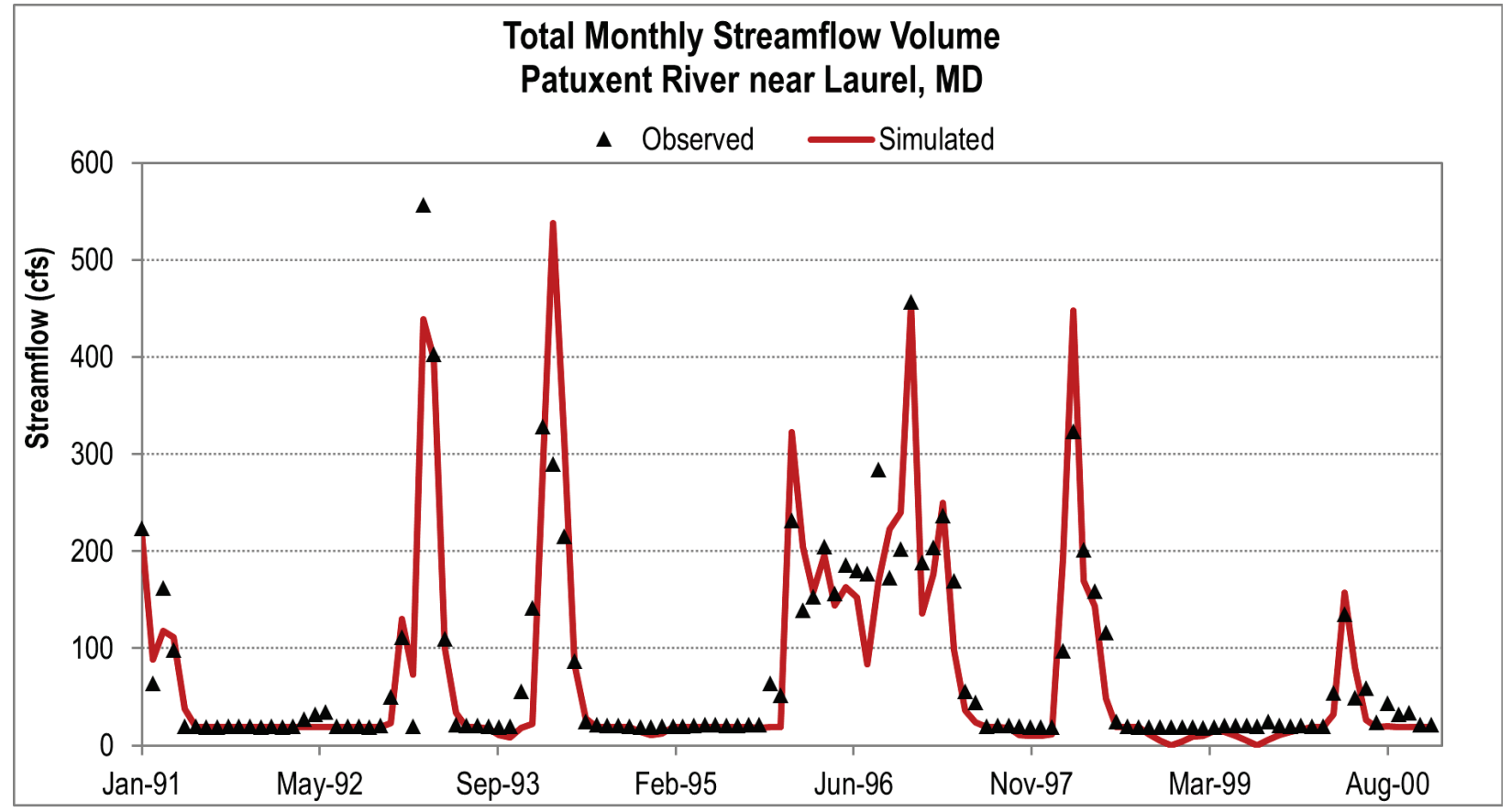


Figure C-7. Monthly Streamflow Volume Time Series for Patuxent River near Bowie, Maryland (Segment: XU3_4650_0001).

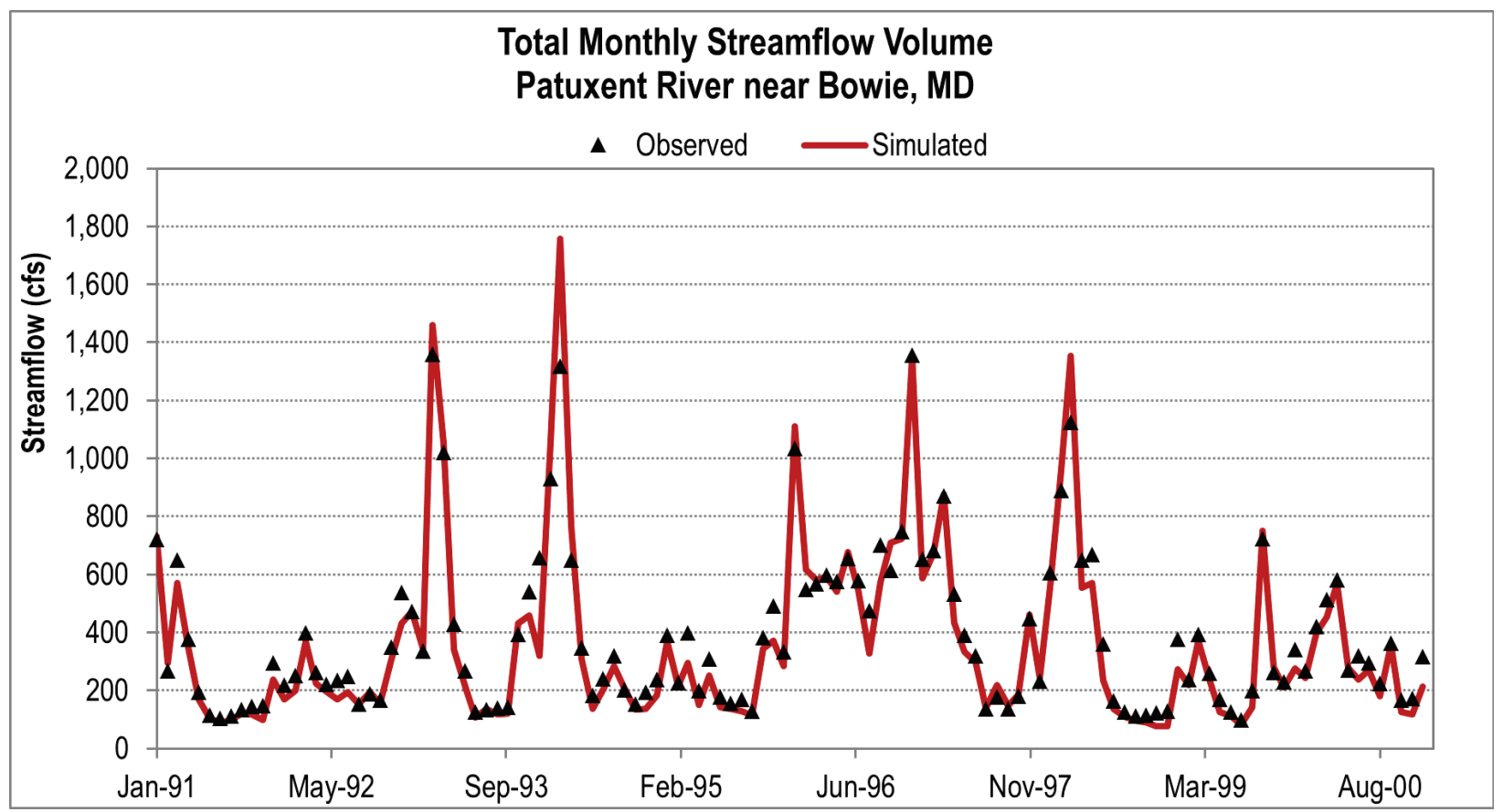

Figure C-8. Daily Average Streamflow Time Series for Hunting Creek near Huntingtown, Maryland (Segment: XL0_5320_0001).

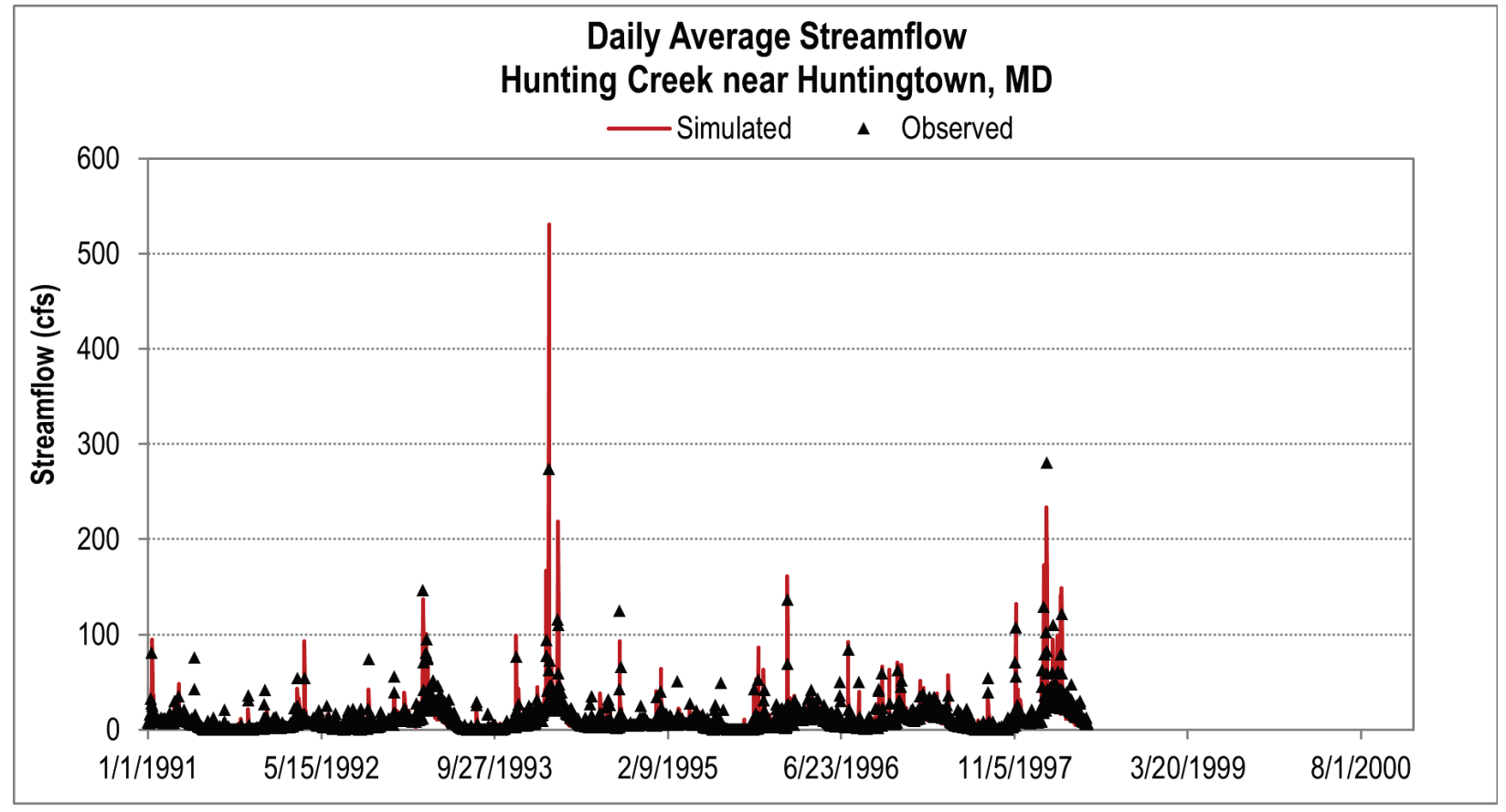


Figure C-9. Daily Average Streamflow Time Series for Western Branch at Upper Marlboro MD (Segment: XL1_4690_0001).

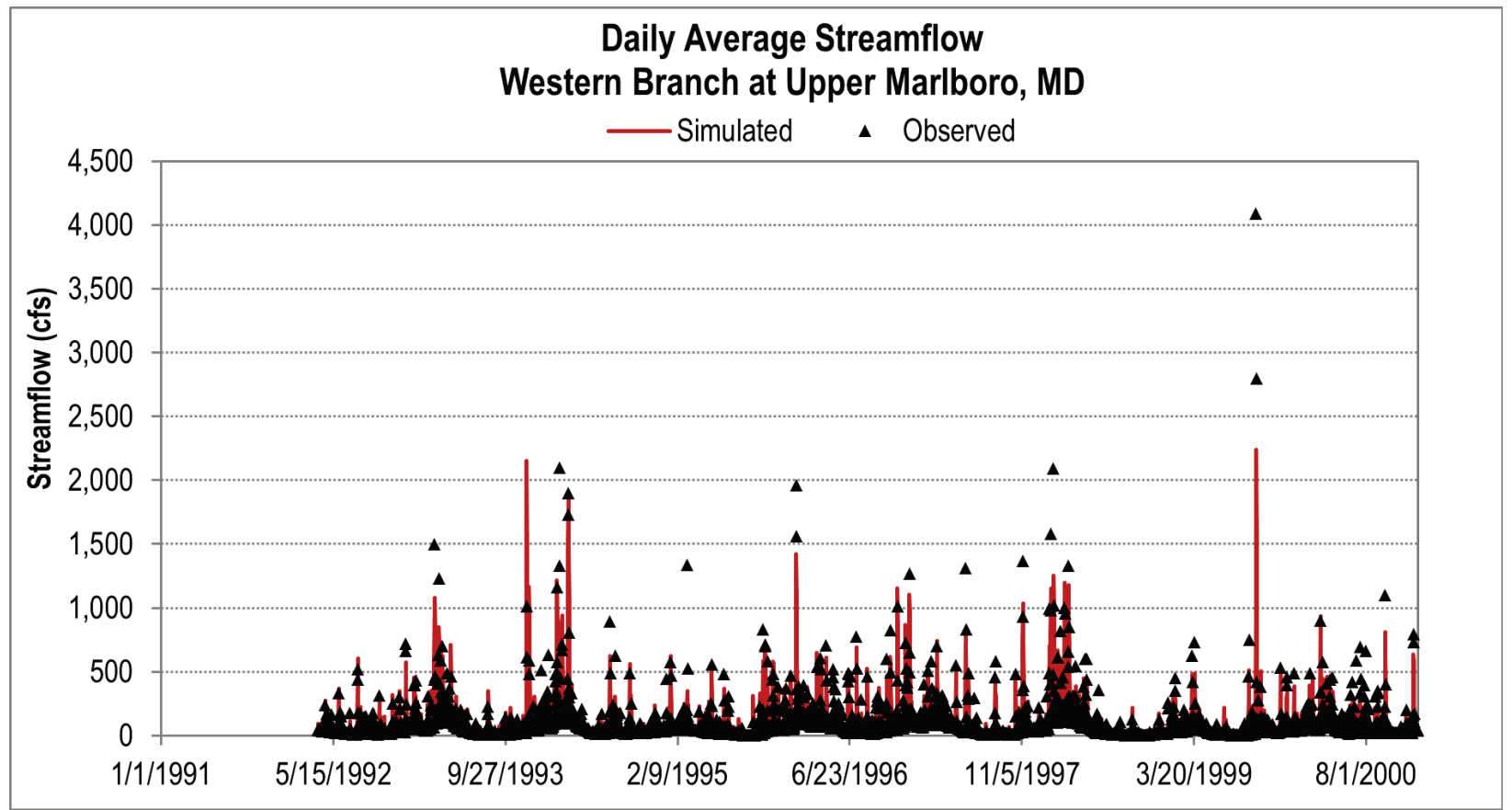

Figure C-10. Daily Average Streamflow Time Series for Patuxent River near Unity, Maryland (Segment: XUO_4130_4070).

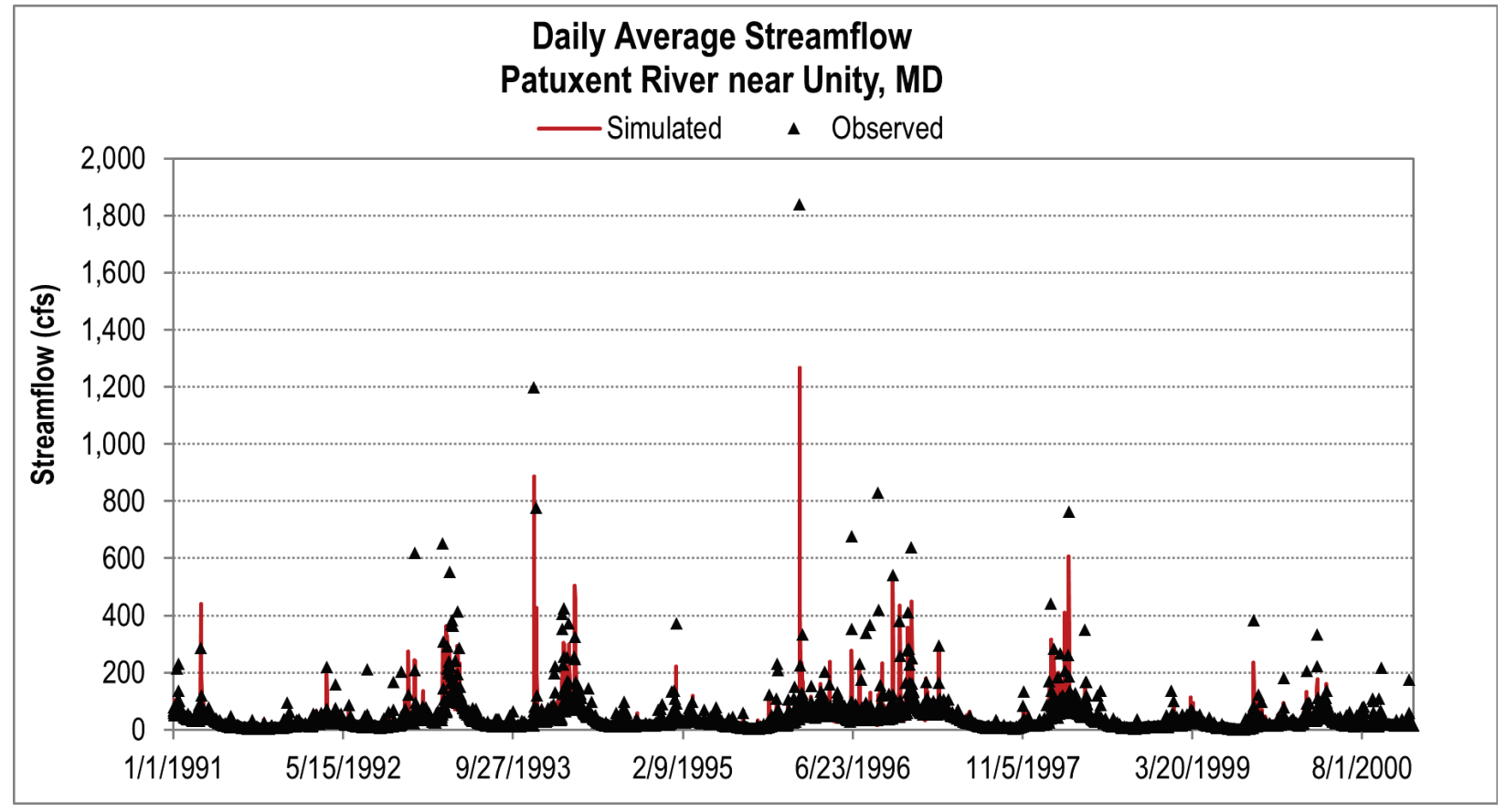


Figure C-11. Daily Average Streamflow Time Series for Patuxent River near Brighton, Maryland (Segment: XU2_4070_4330).

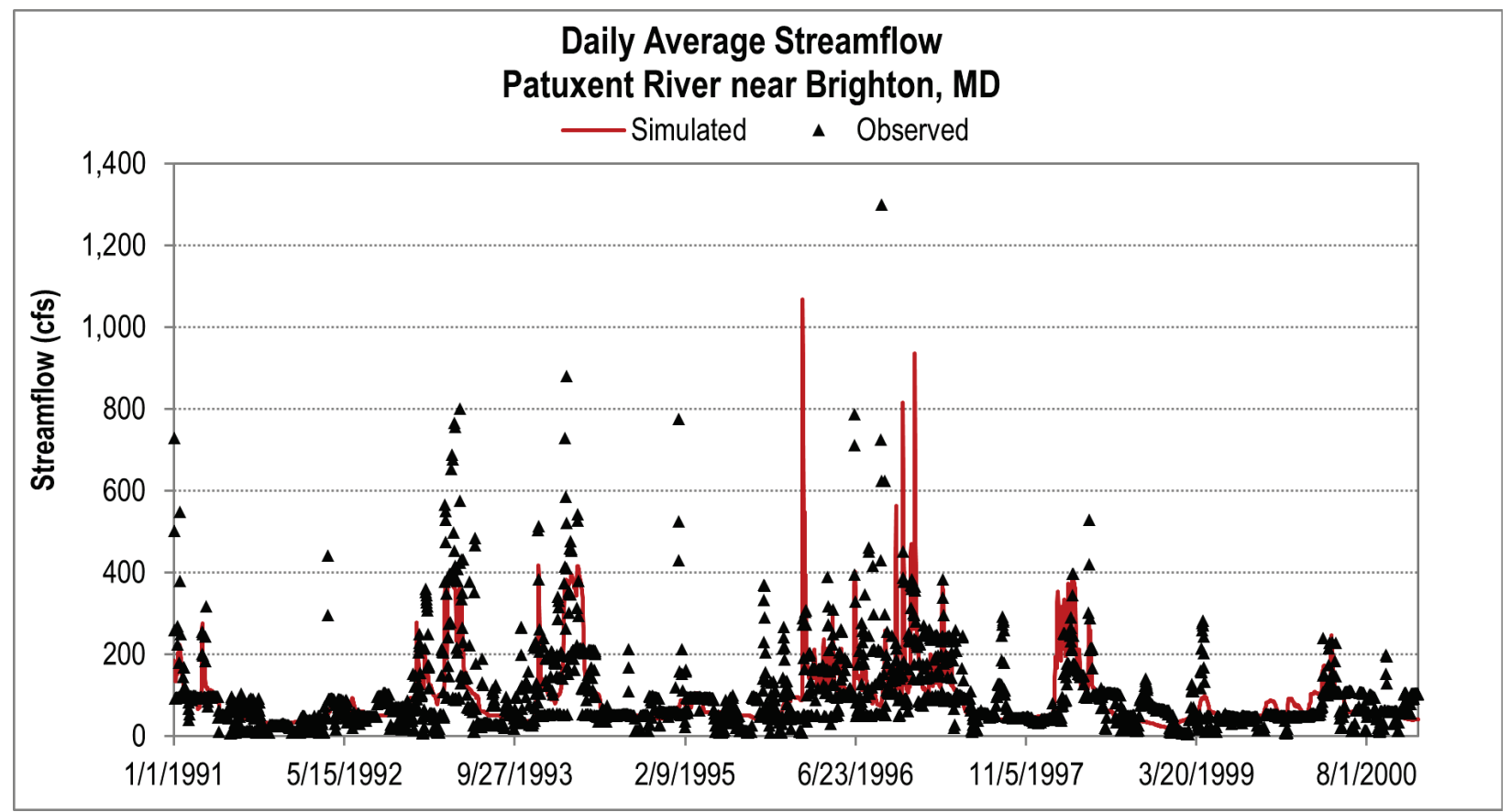

Figure C-12. Daily Average Streamflow Time Series for Little Patuxent River at Savage, Maryland (Segment: XU2_4270_0003).

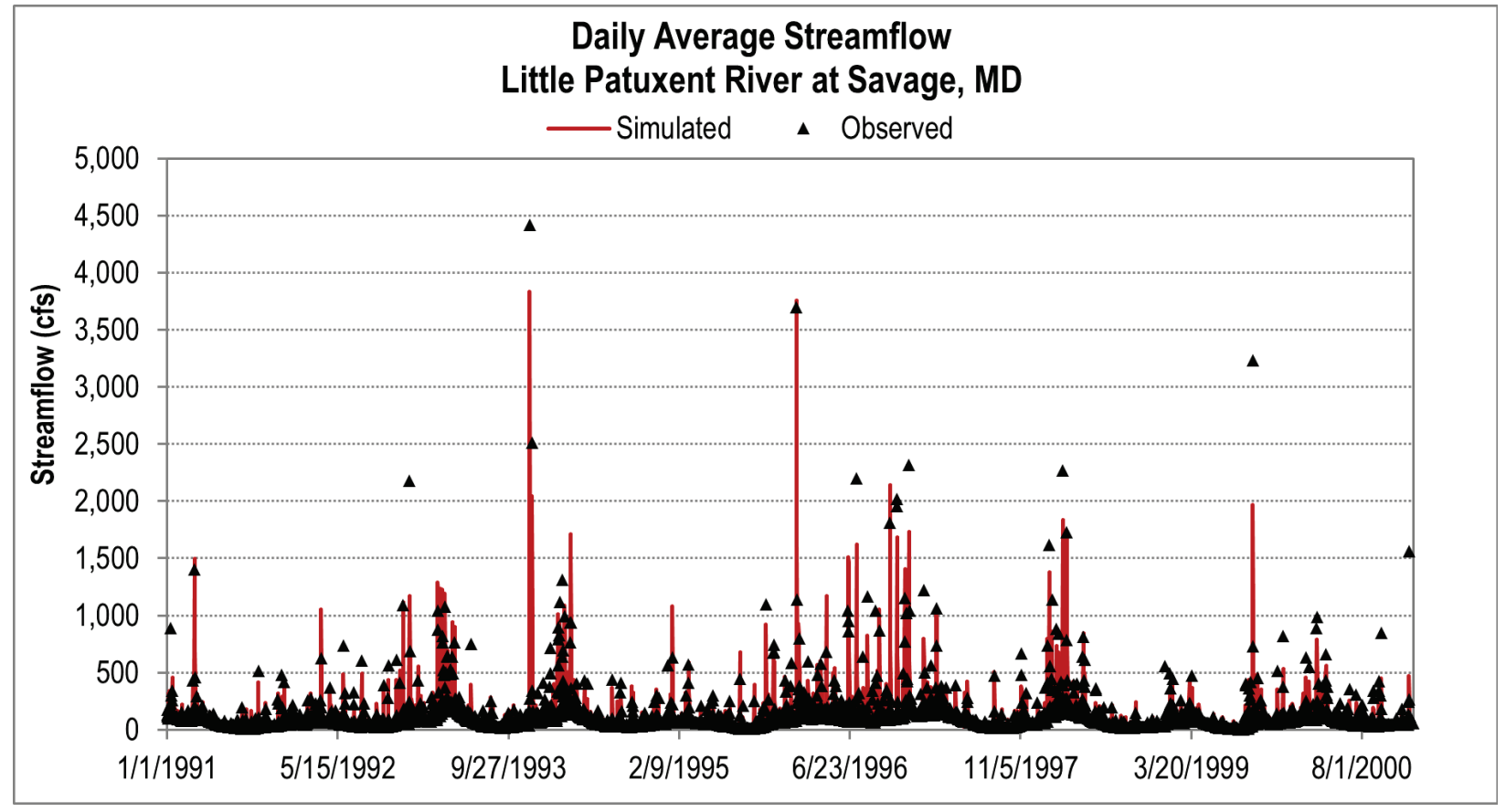


Figure C-13. Daily Average Streamflow Time Series for Patuxent River near Laurel, Maryland (Segment: XU2_4330_4480).

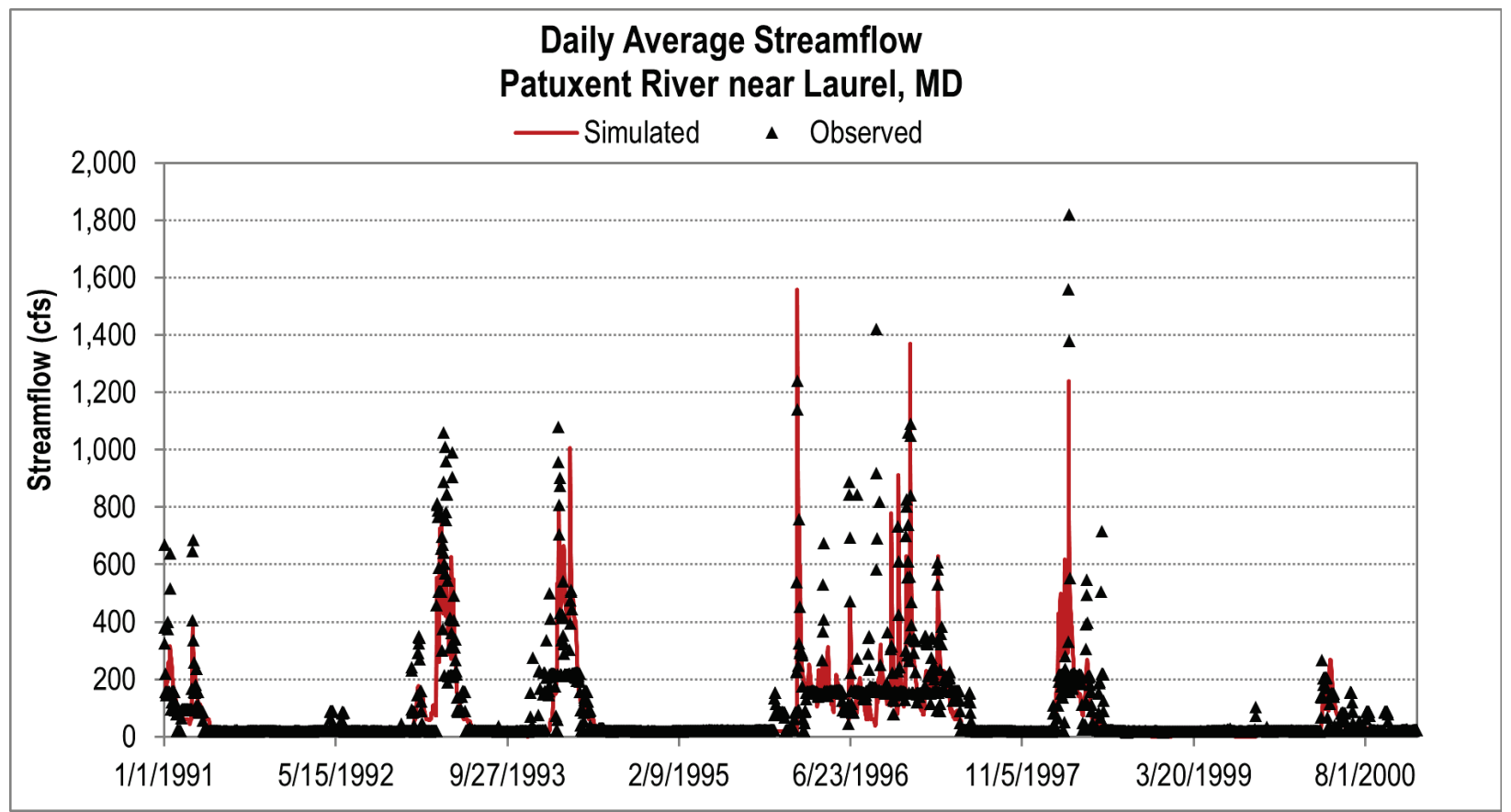

Figure C-14. Daily Average Streamflow Time Series for Patuxent River near Bowie, Maryland (Segment: XU3_4650_0001).

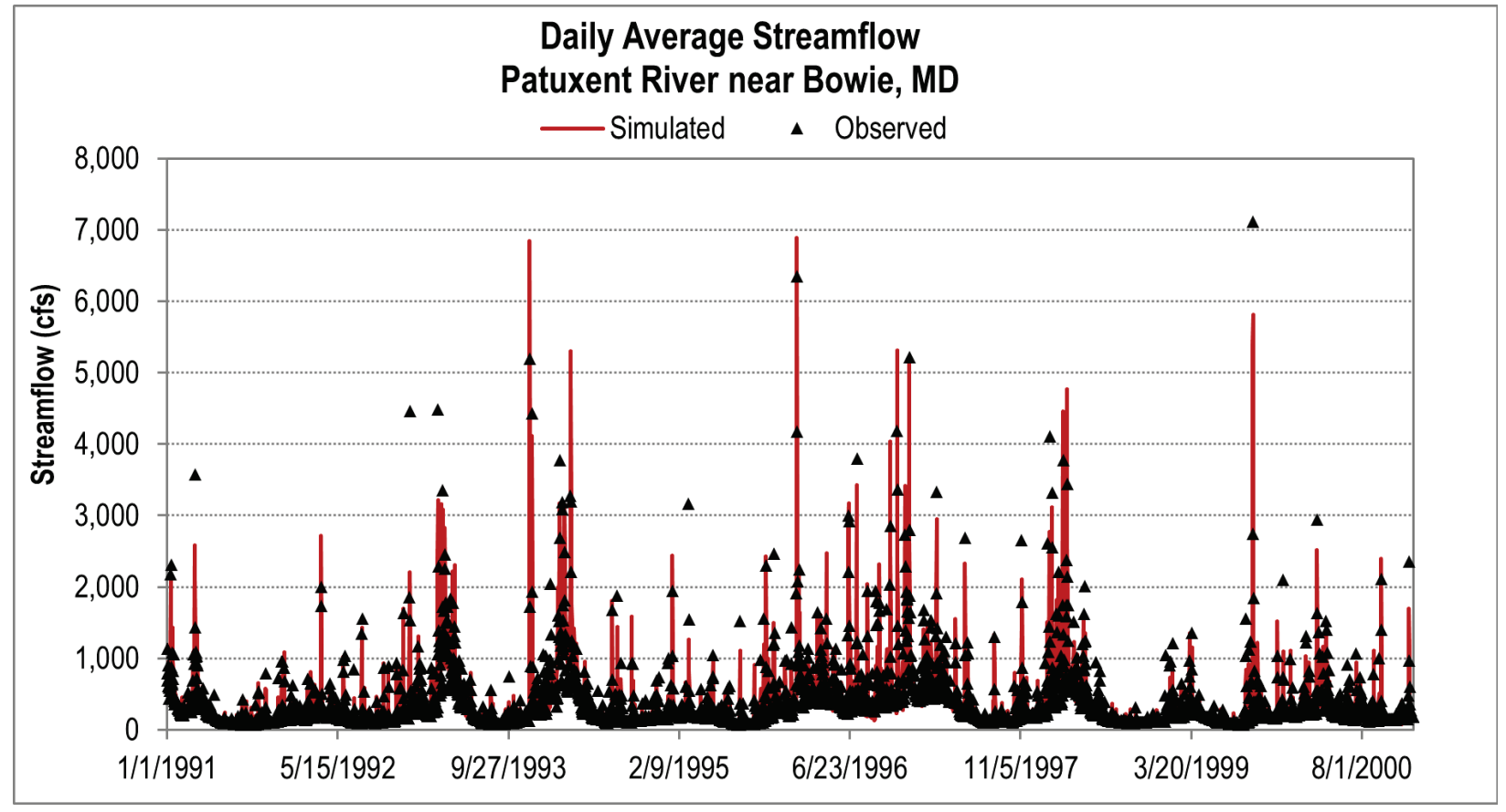


Figure C-15. Monthly average observed versus linked HSPF/HEC-RAS modeled streamflow near Bowie, Maryland for the calibration period.

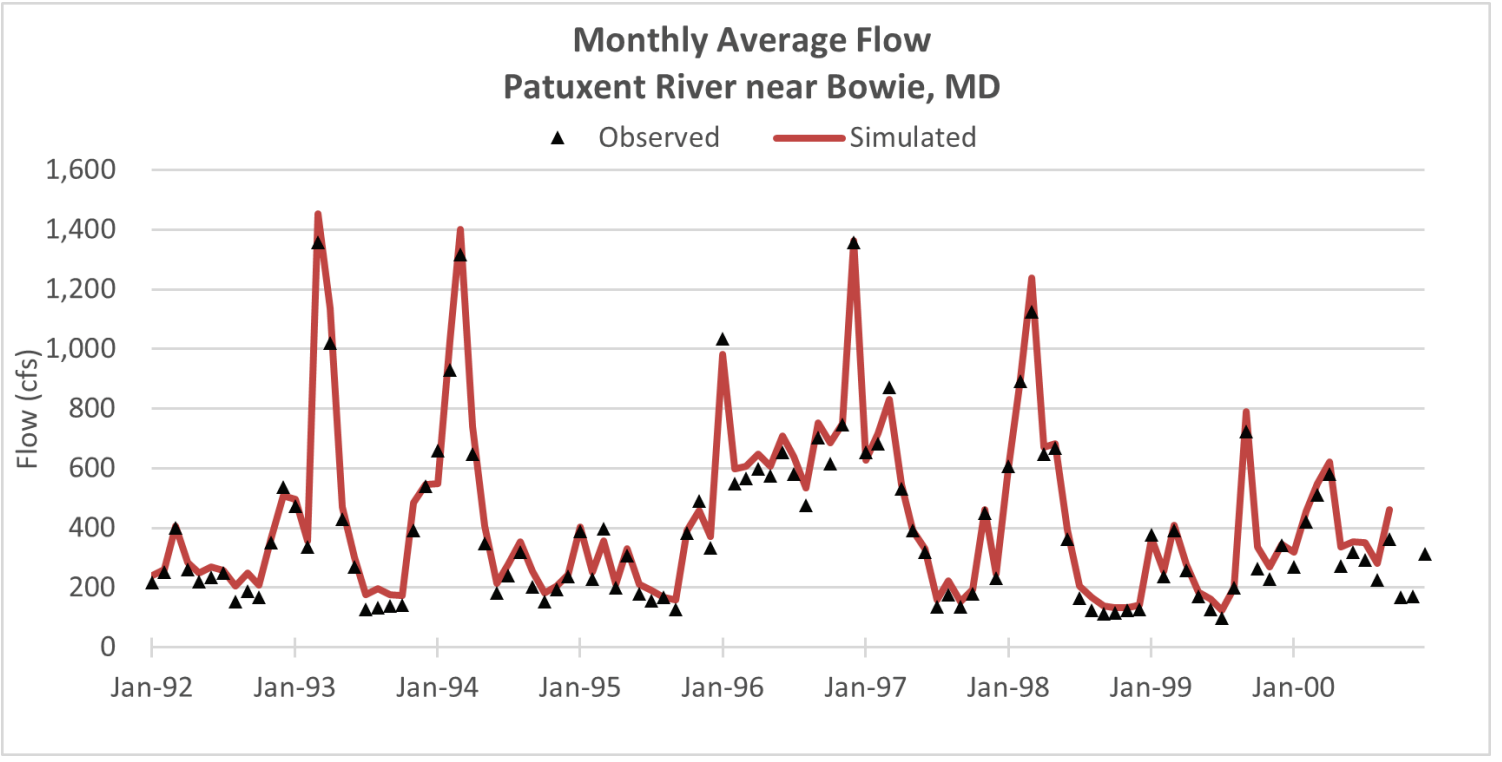

Figure C-16. Daily average observed versus linked HSPF/HEC-RAS modeled streamflow near Bowie, Maryland for the calibration period.

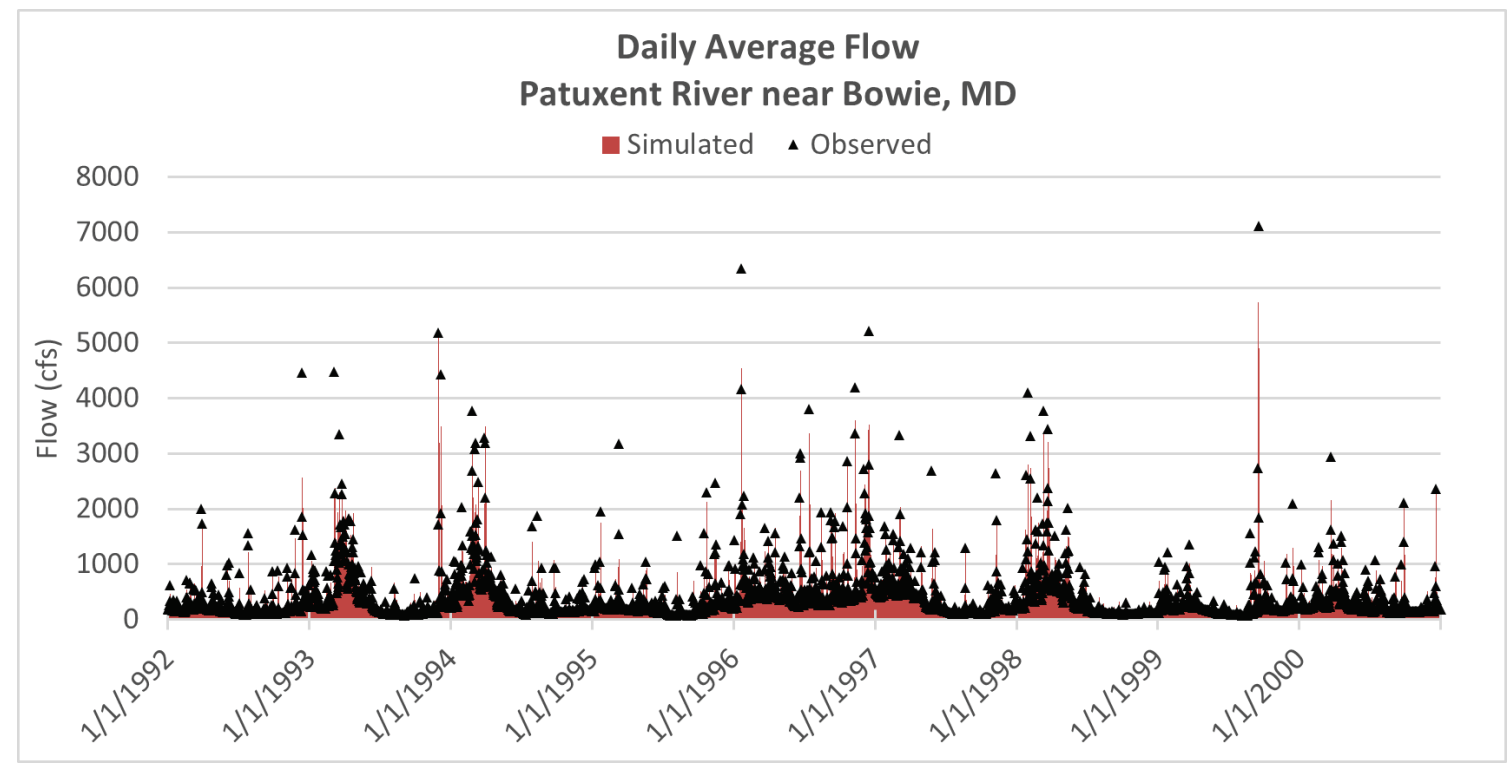


Figure C-17. Monthly Sediment Load Time Series for Patuxent River near Laurel, Maryland (Segment: XU2_4330_4480).

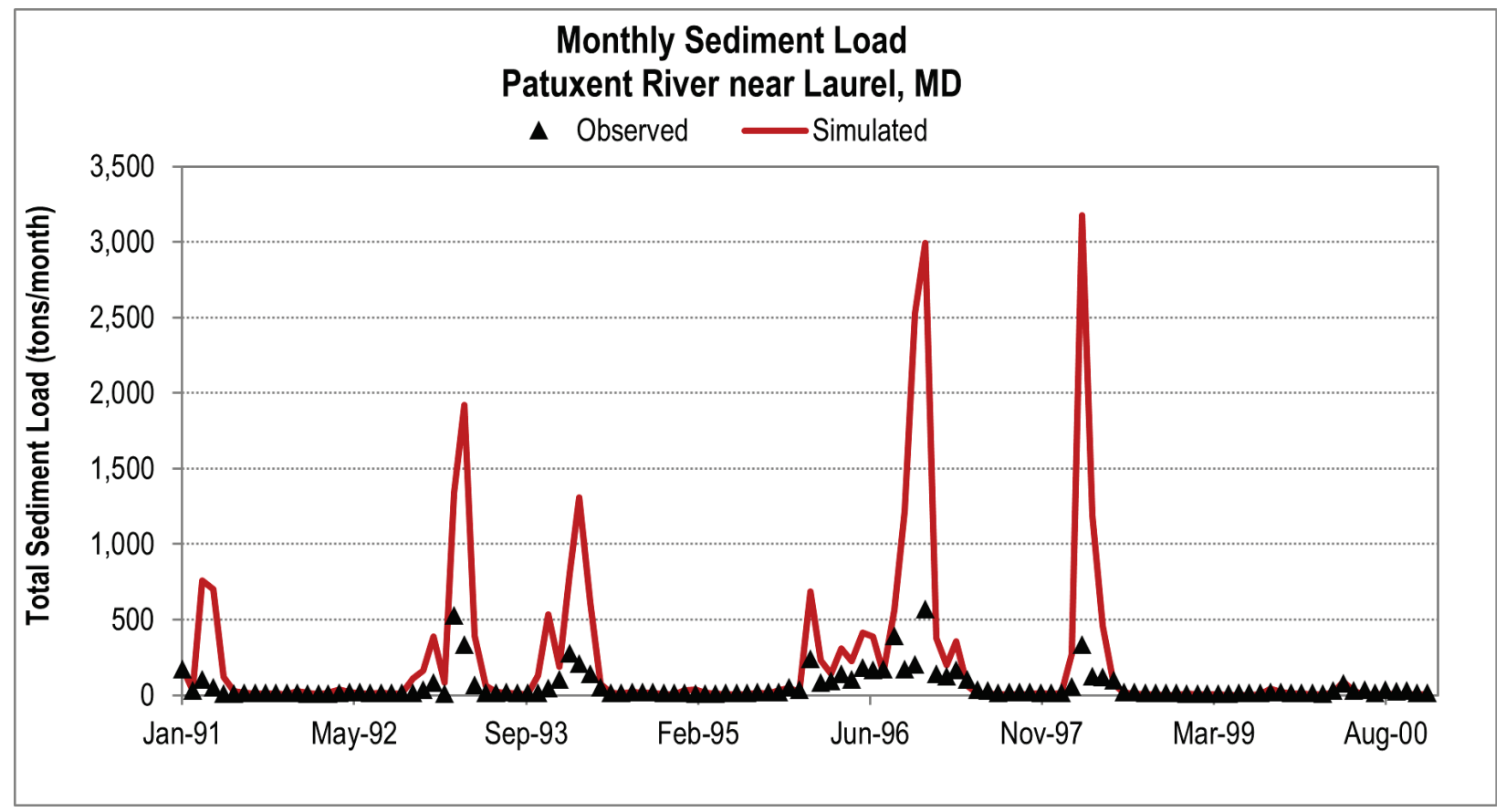

Figure C-18. Monthly Sediment Load Time Series for Patuxent River near Bowie, Maryland (Segment: XU3_4650_0001).

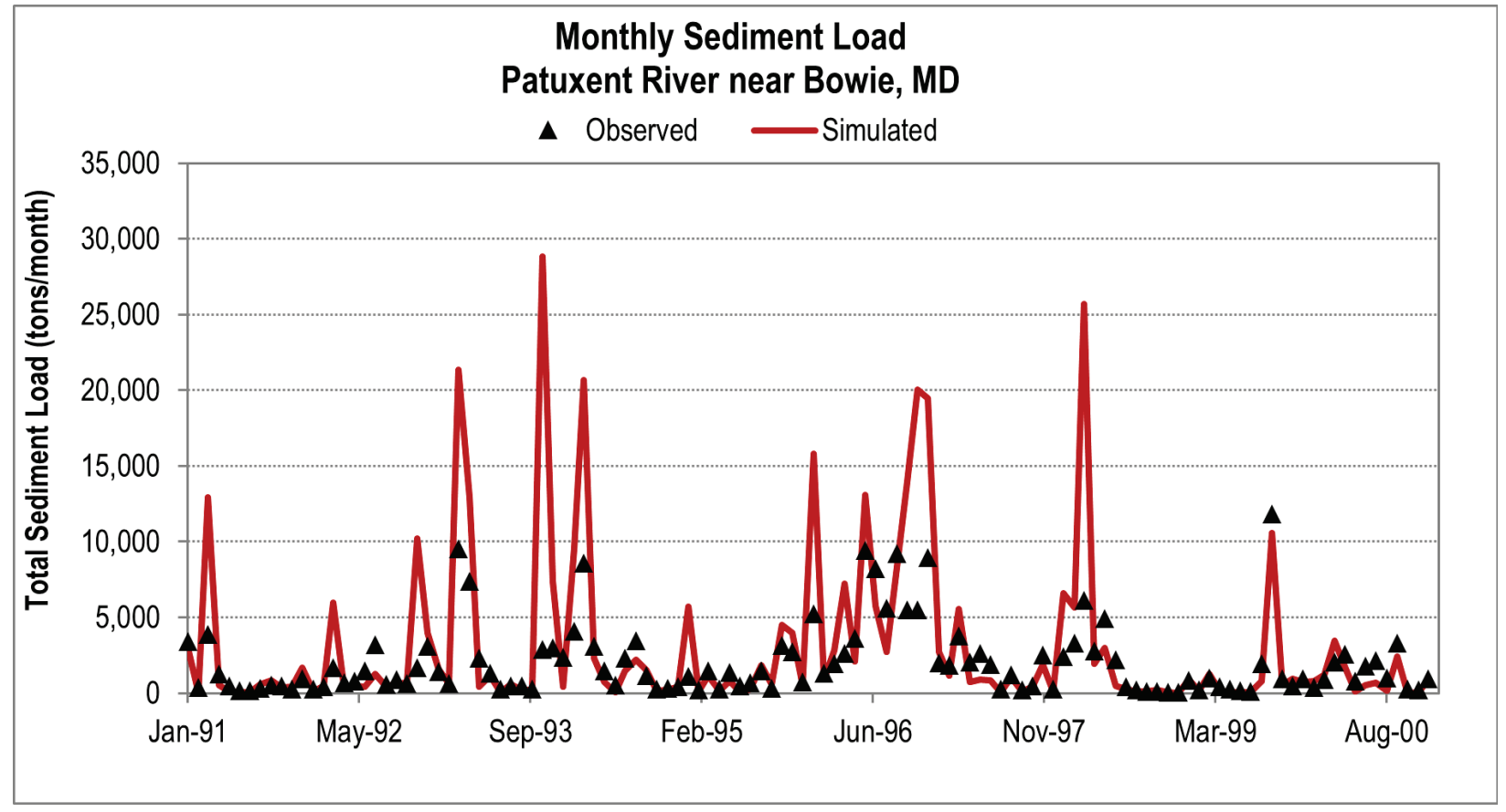


Figure C-19. Daily Sediment Load Time Series for Patuxent River near Laurel, Maryland (Segment: XU2_4330_4480).

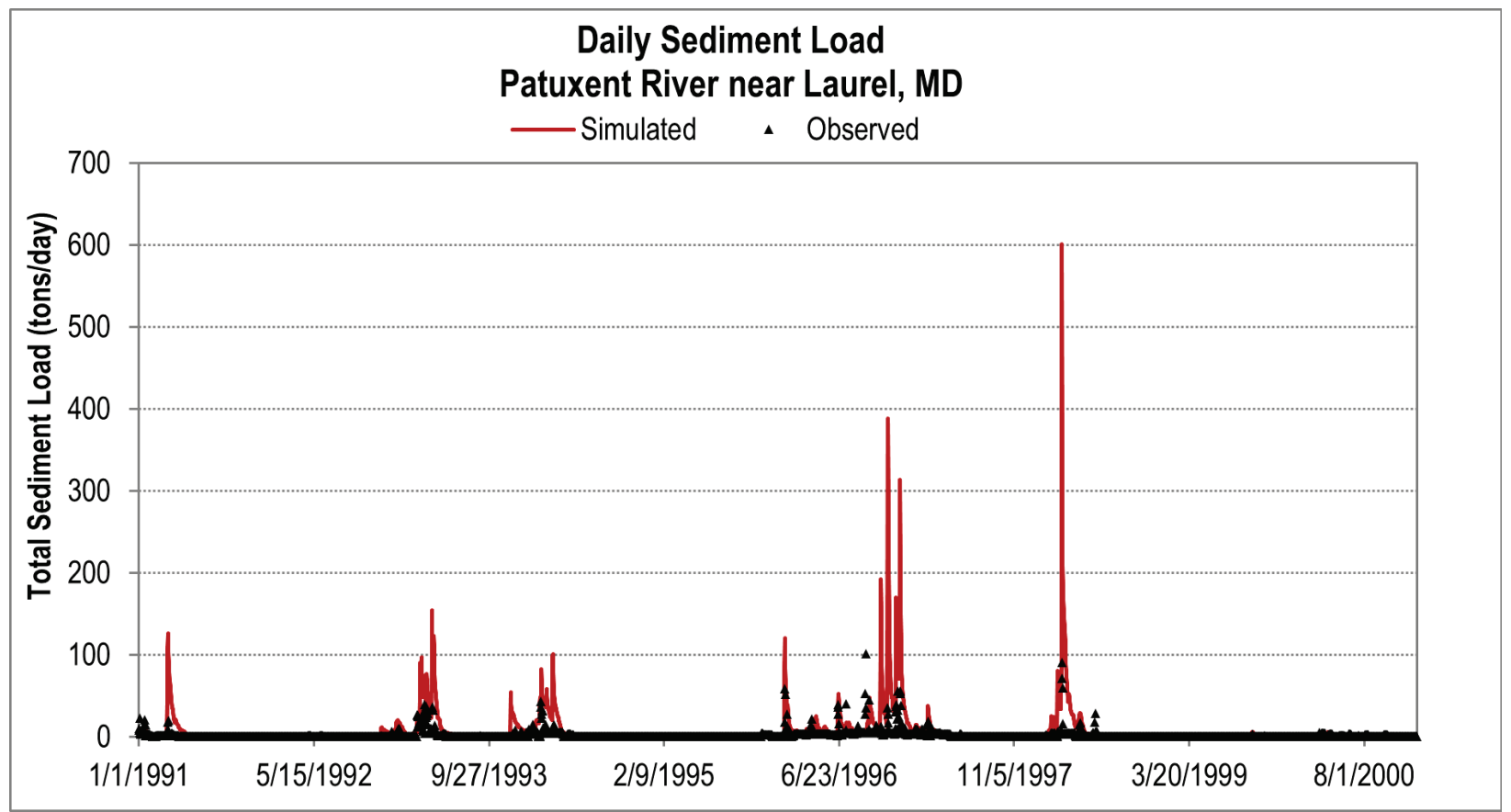

Figure C-20. Daily Sediment Load Time Series for Patuxent River near Bowie, Maryland (Segment: XU3_4650_0001).

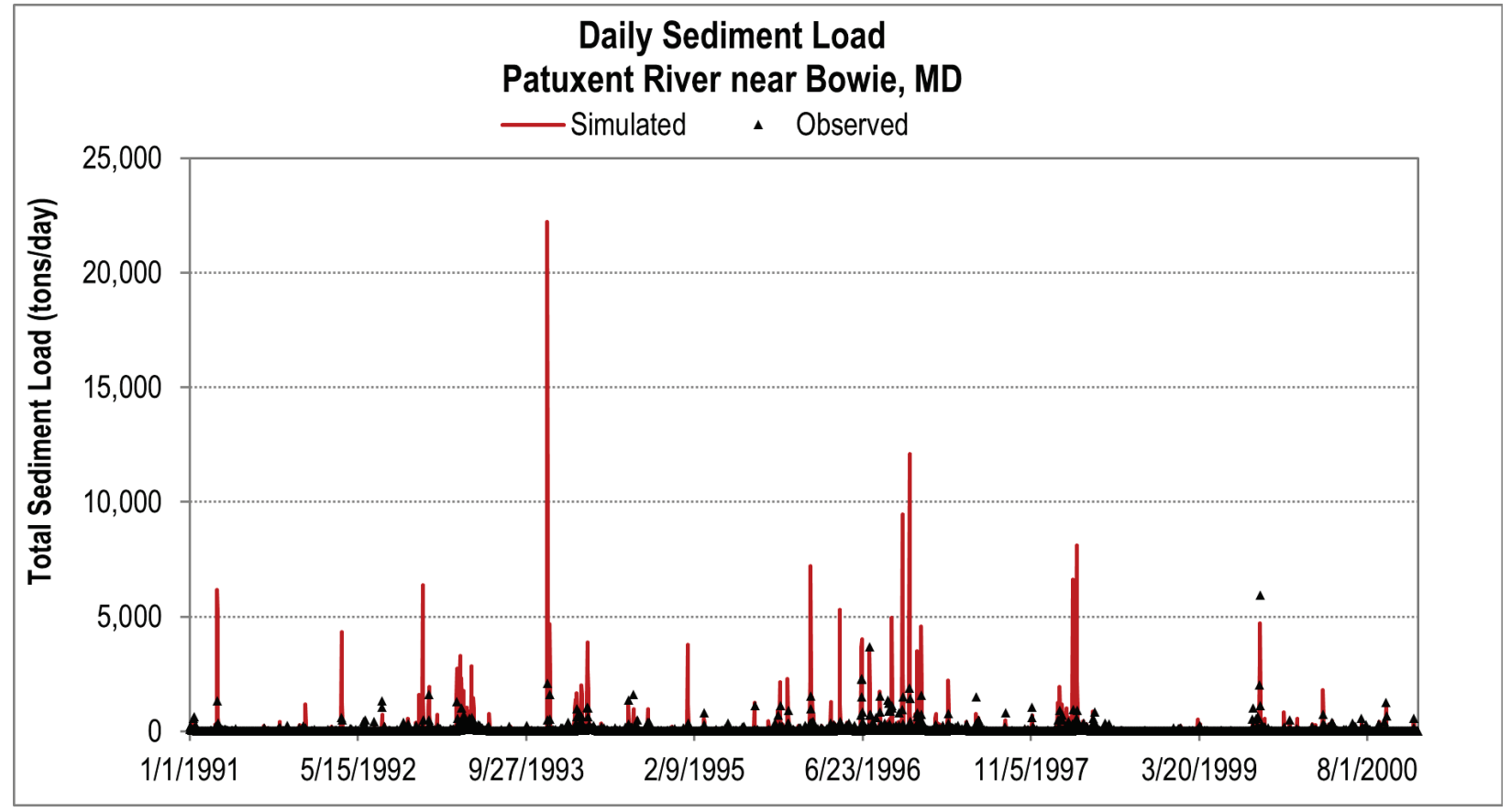


Figure C-21. Monthly average observed versus linked HSPF/HEC-RAS modeled TSS concentrations near Bowie, Maryland for the calibration period.

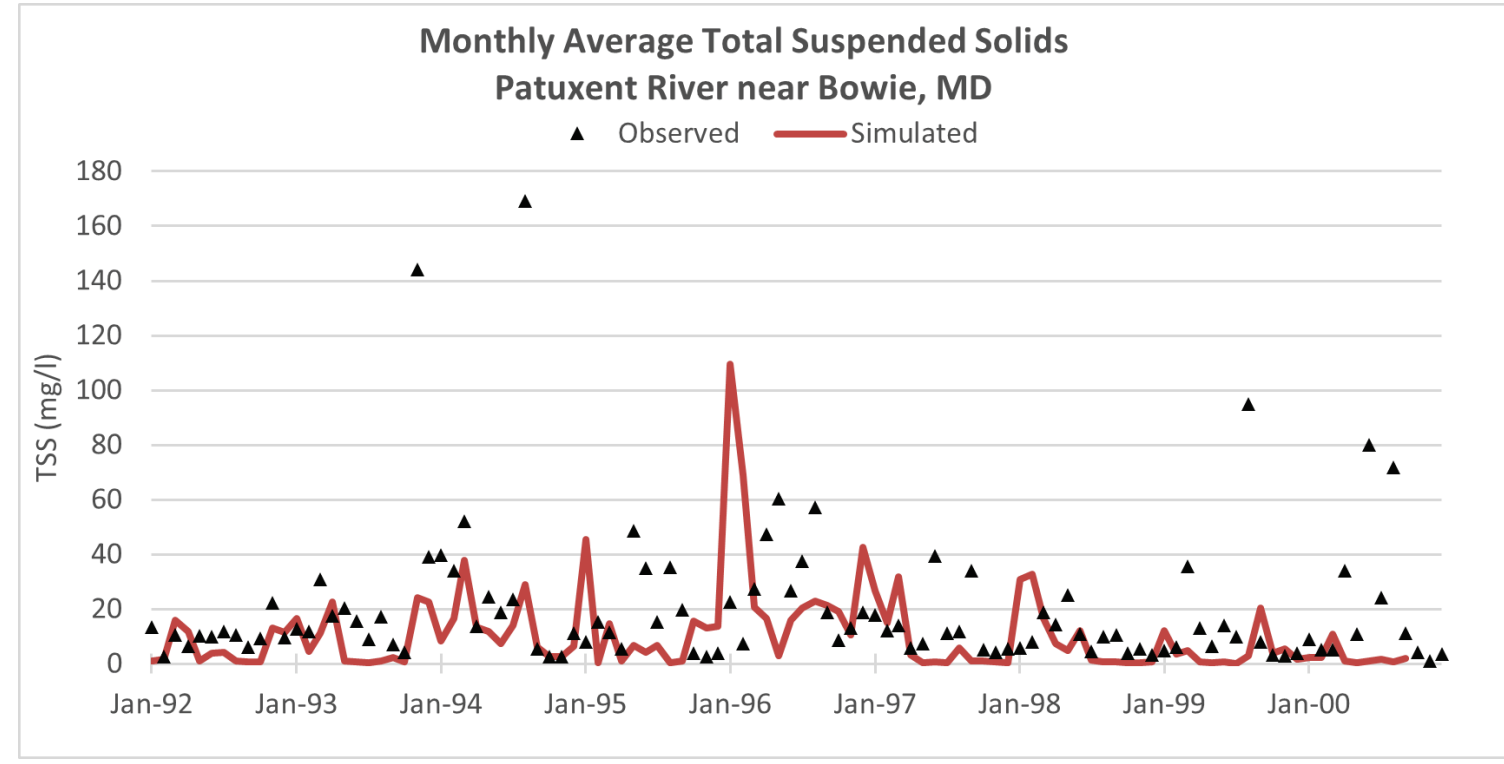

Figure C-22. Daily average observed versus linked HSPF/HEC-RAS modeled TSS concentrations near Bowie, Maryland for the calibration period.

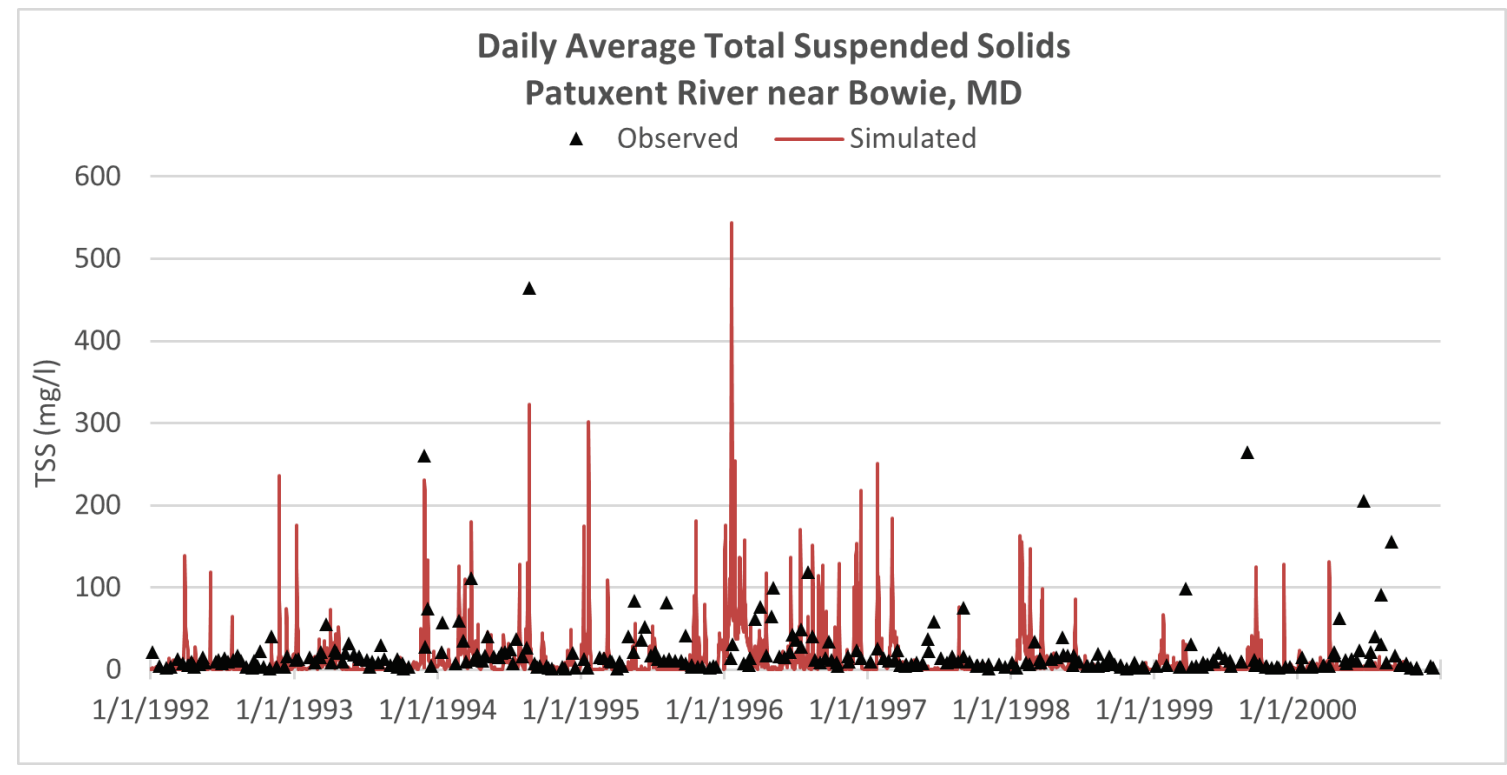


Figure C-23. Monthly Total Nitrogen Load Time Series for Patuxent River near Laurel, Maryland (Segment: XU2_4330_4480).

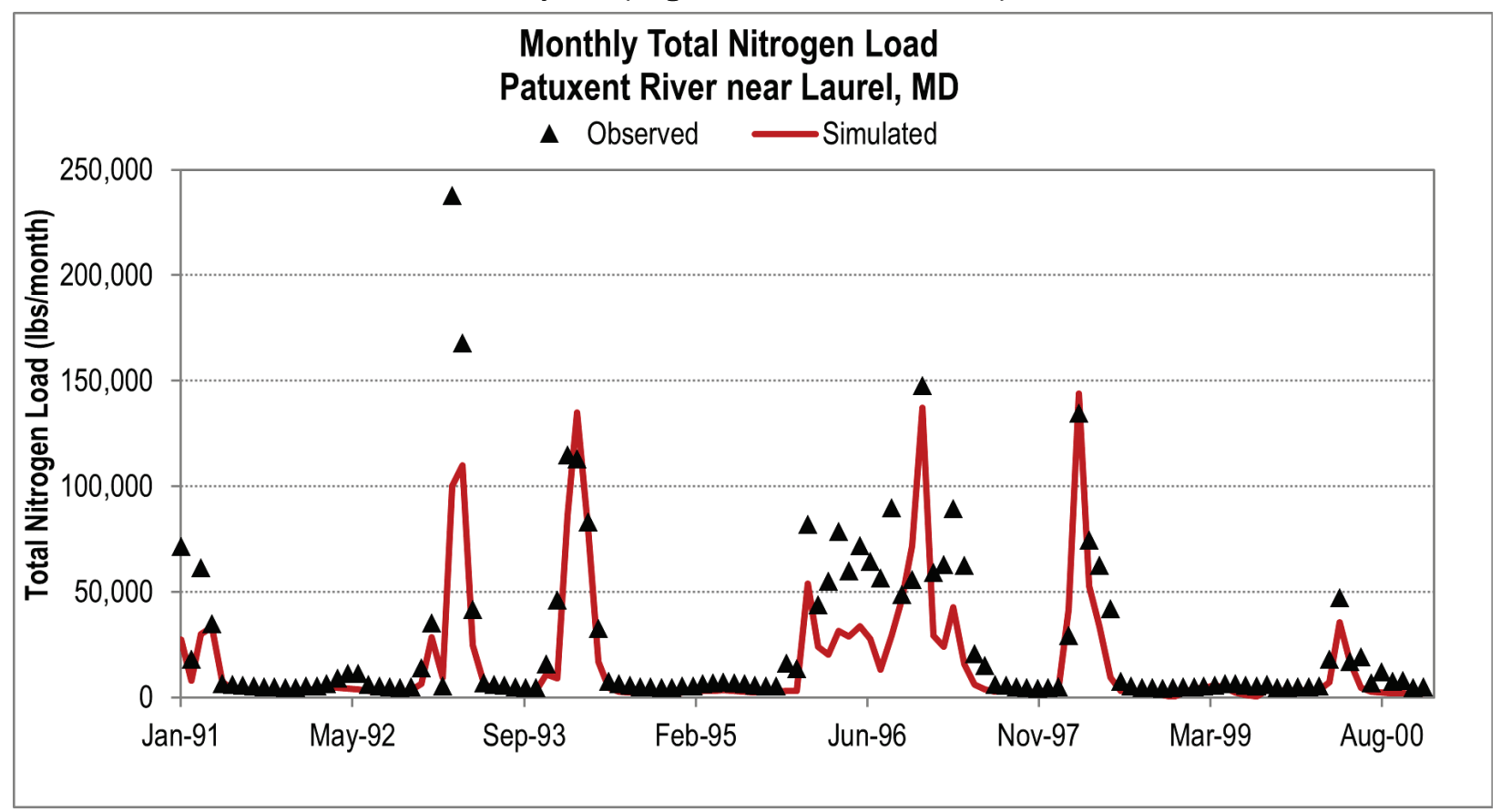

Figure C-24. Monthly Total Nitrogen Load Time Series for Patuxent River near Bowie, Maryland (Segment: XU3_4650_0001).

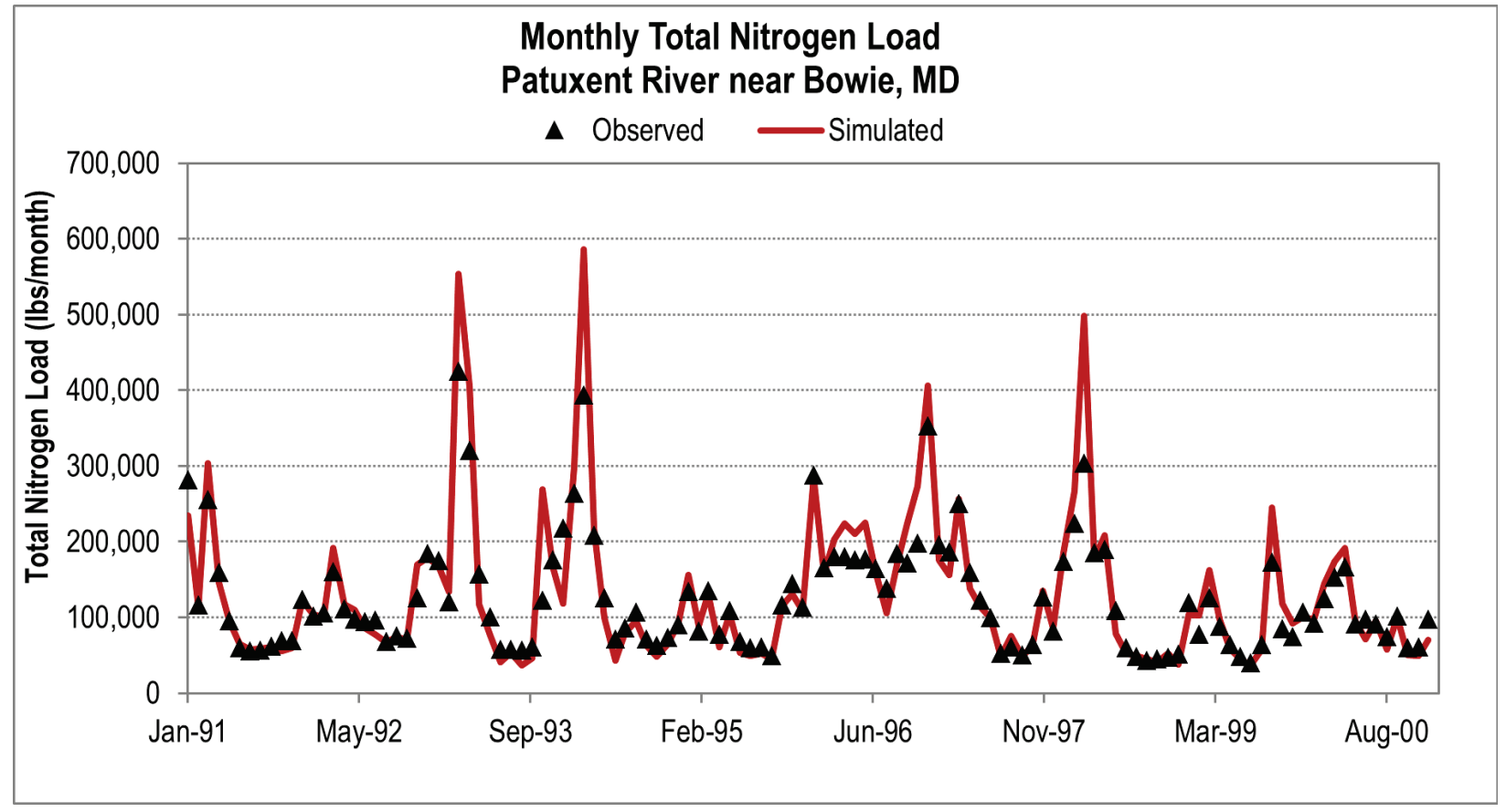


Figure C-25. Daily Total Nitrogen Load Time Series for Patuxent River near Laurel, Maryland (Segment: XU2_4330_4480).

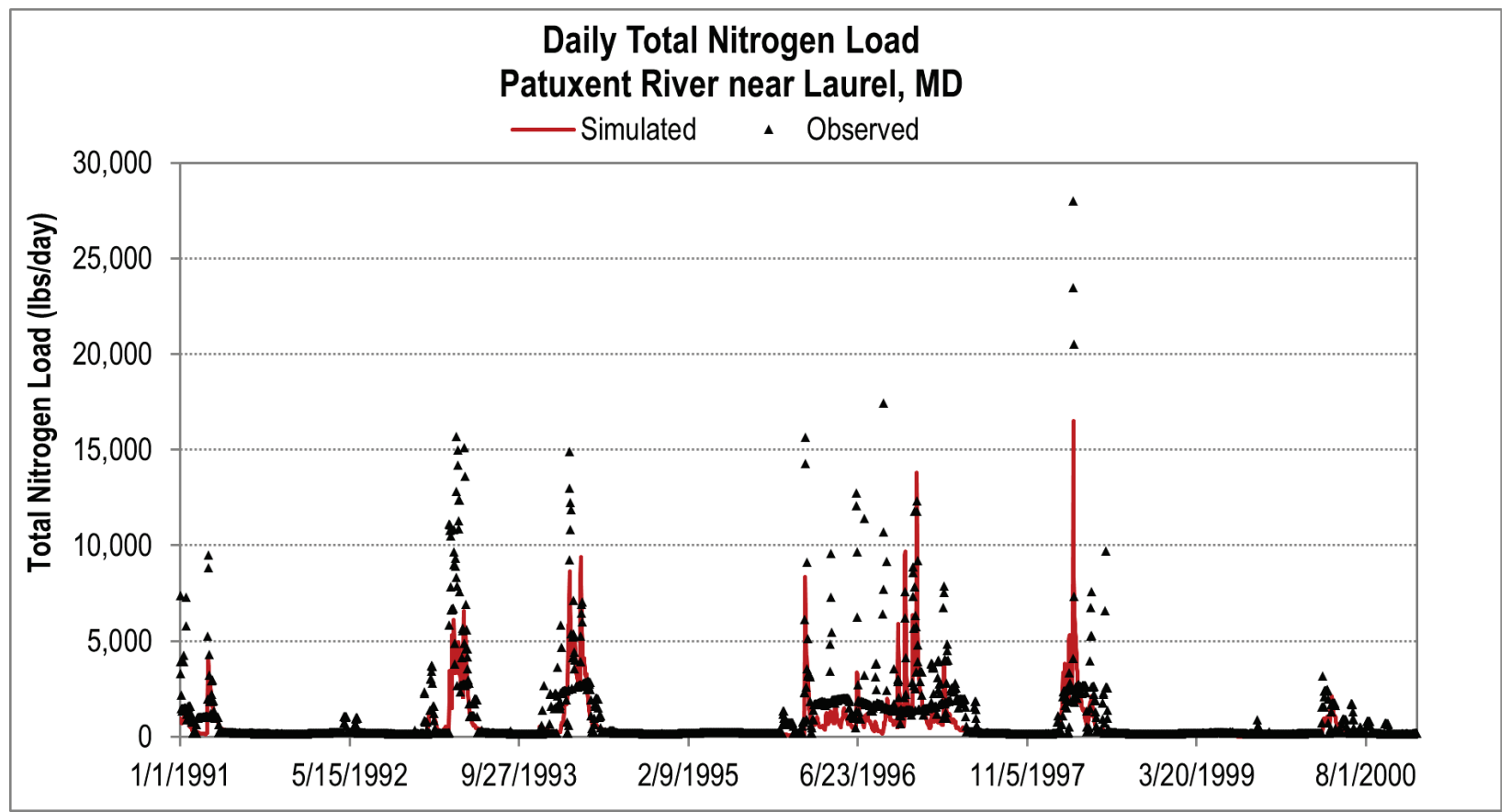

Figure C-26. Daily Total Nitrogen Load Time Series for Patuxent River near Bowie, Maryland (Segment: XU3_4650_0001).

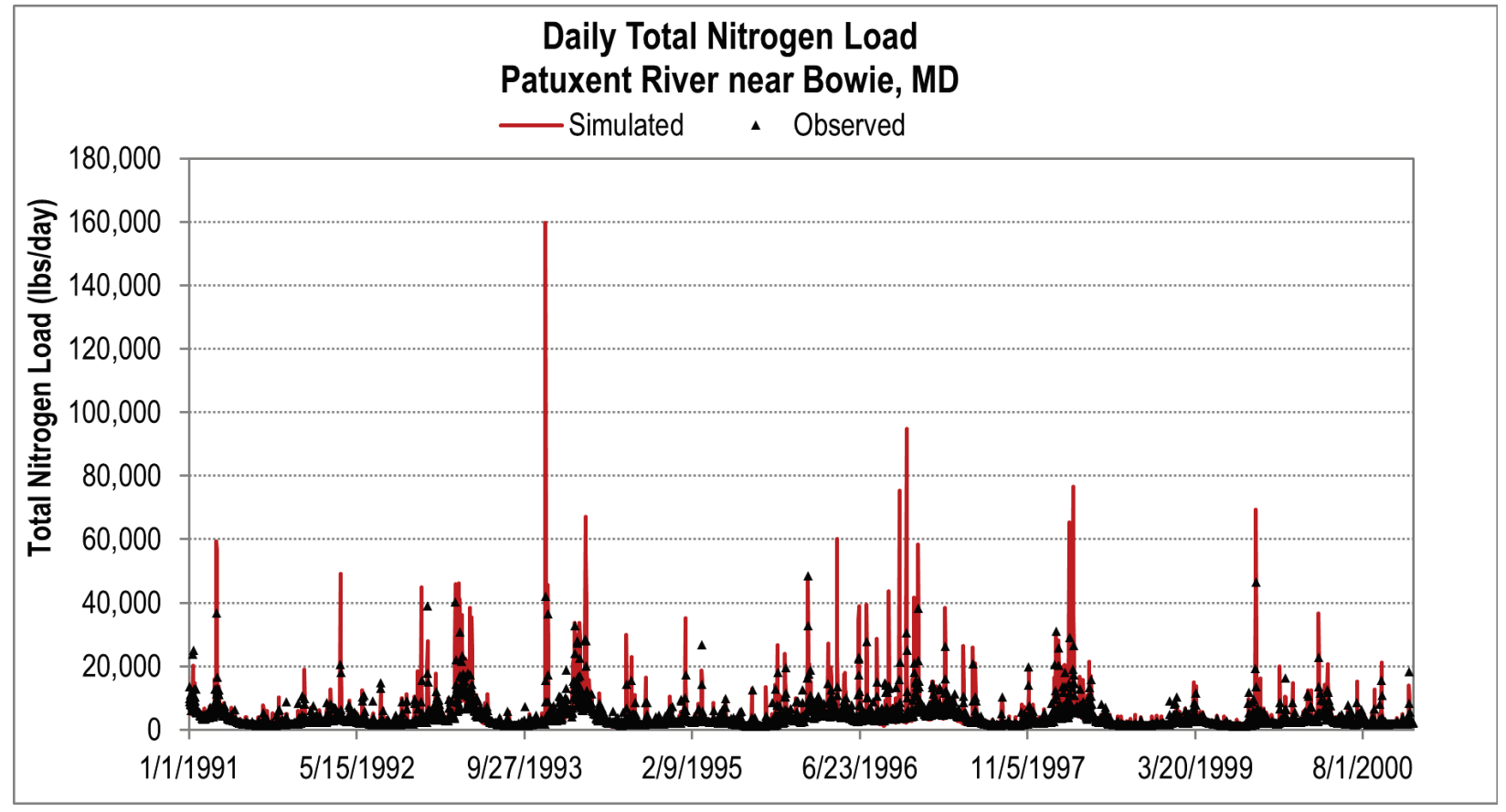


Figure C-27. Monthly Nitrate-Nitrogen Load Time Series for Patuxent River near Bowie, Maryland (Segment: XU3_4650_0001).

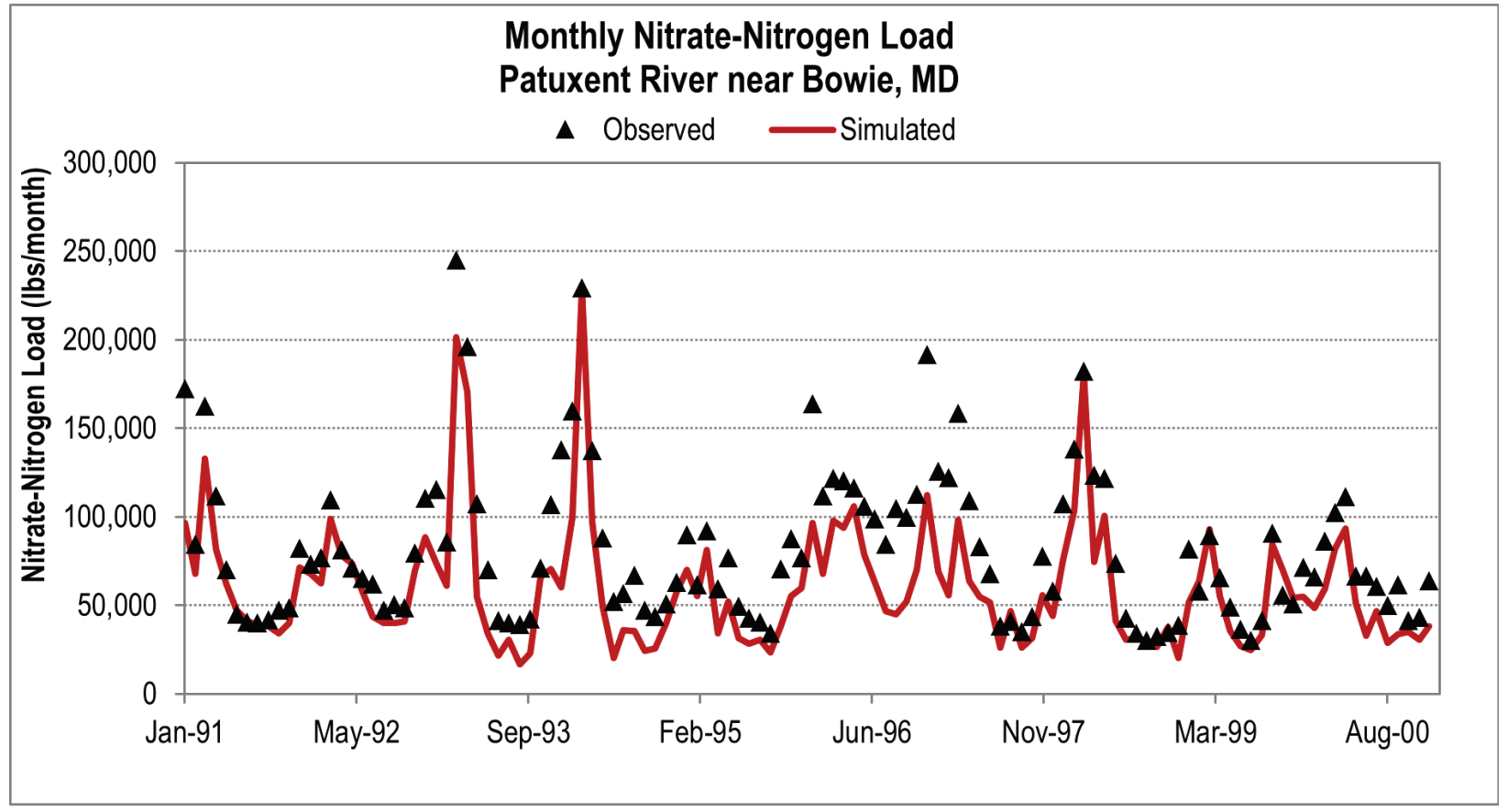

Figure C-28. Daily Nitrate-Nitrogen Load Time Series for Patuxent River near Bowie, Maryland (Segment: XU3_4650_0001).

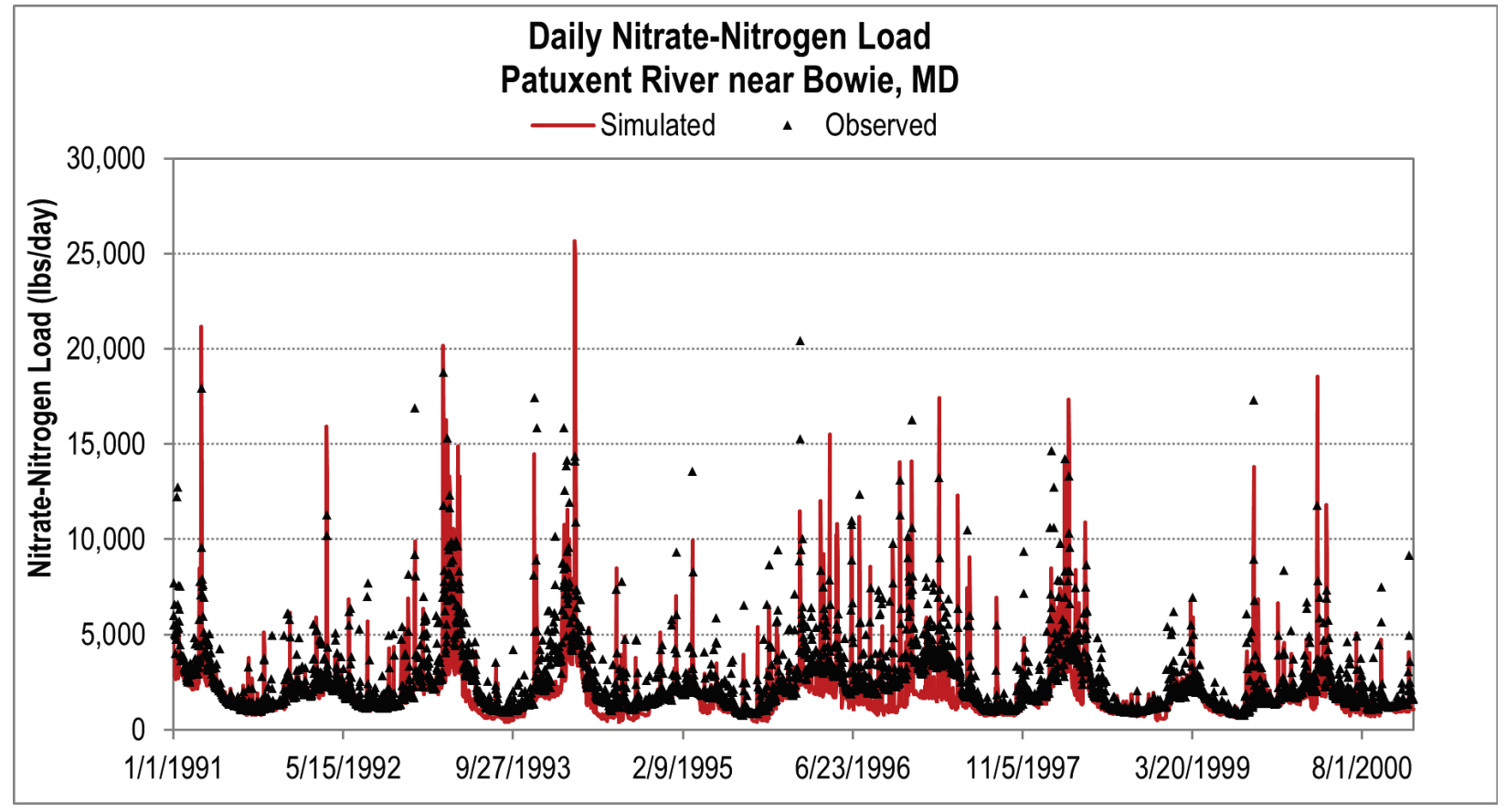


Figure C-29. Monthly Total Phosphorus Load Time Series for Patuxent River near Laurel, Maryland (Segment: XU2_4330_4480).

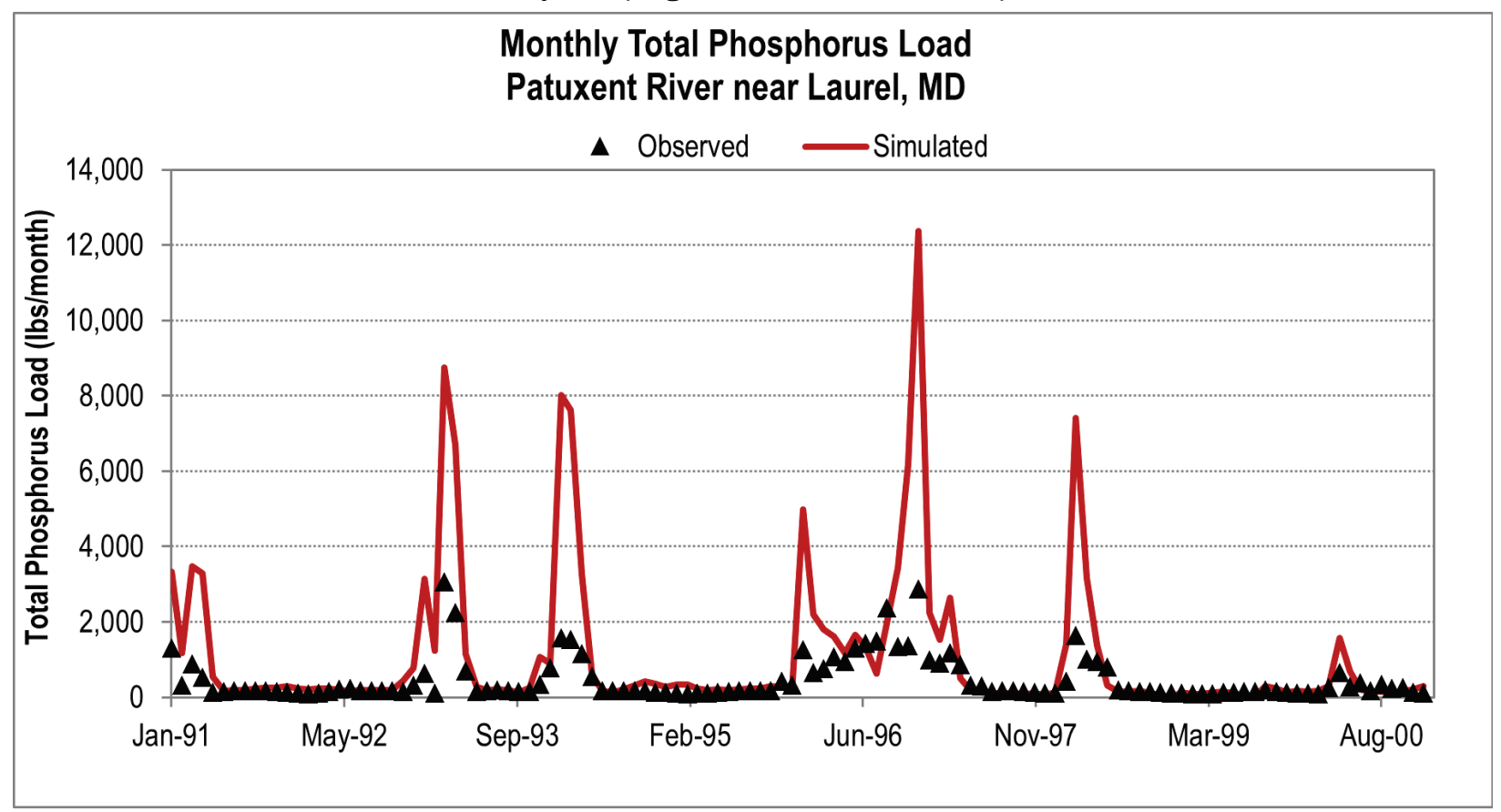

Figure C-30. Monthly Total Phosphorus Load Time Series for Patuxent River near Bowie, Maryland (Segment: XU3_4650_0001).

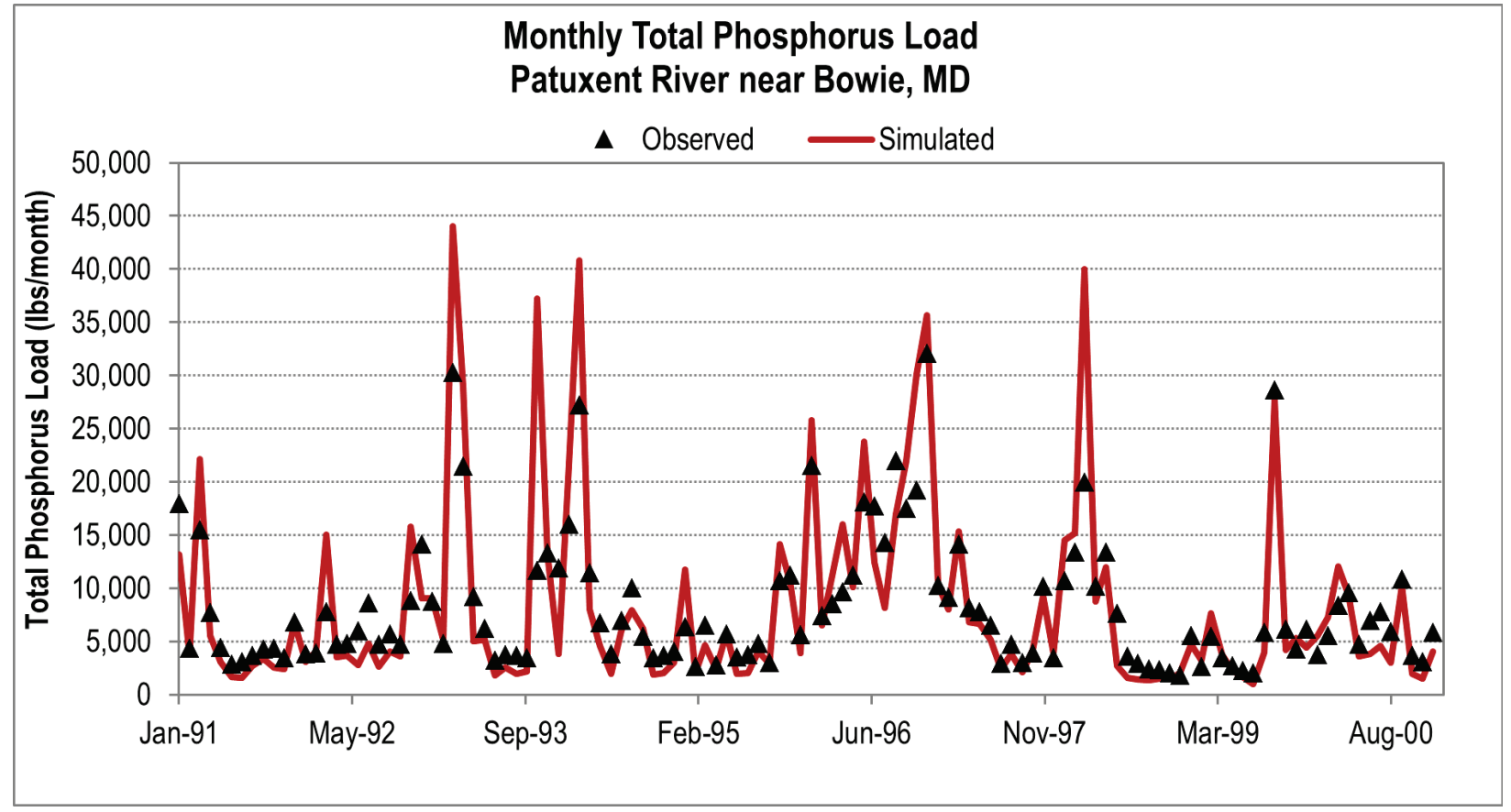


Figure C-31. Daily Total Phosphorus Load Time Series for Patuxent River near Laurel, Maryland (Segment: XU2_4330_4480).

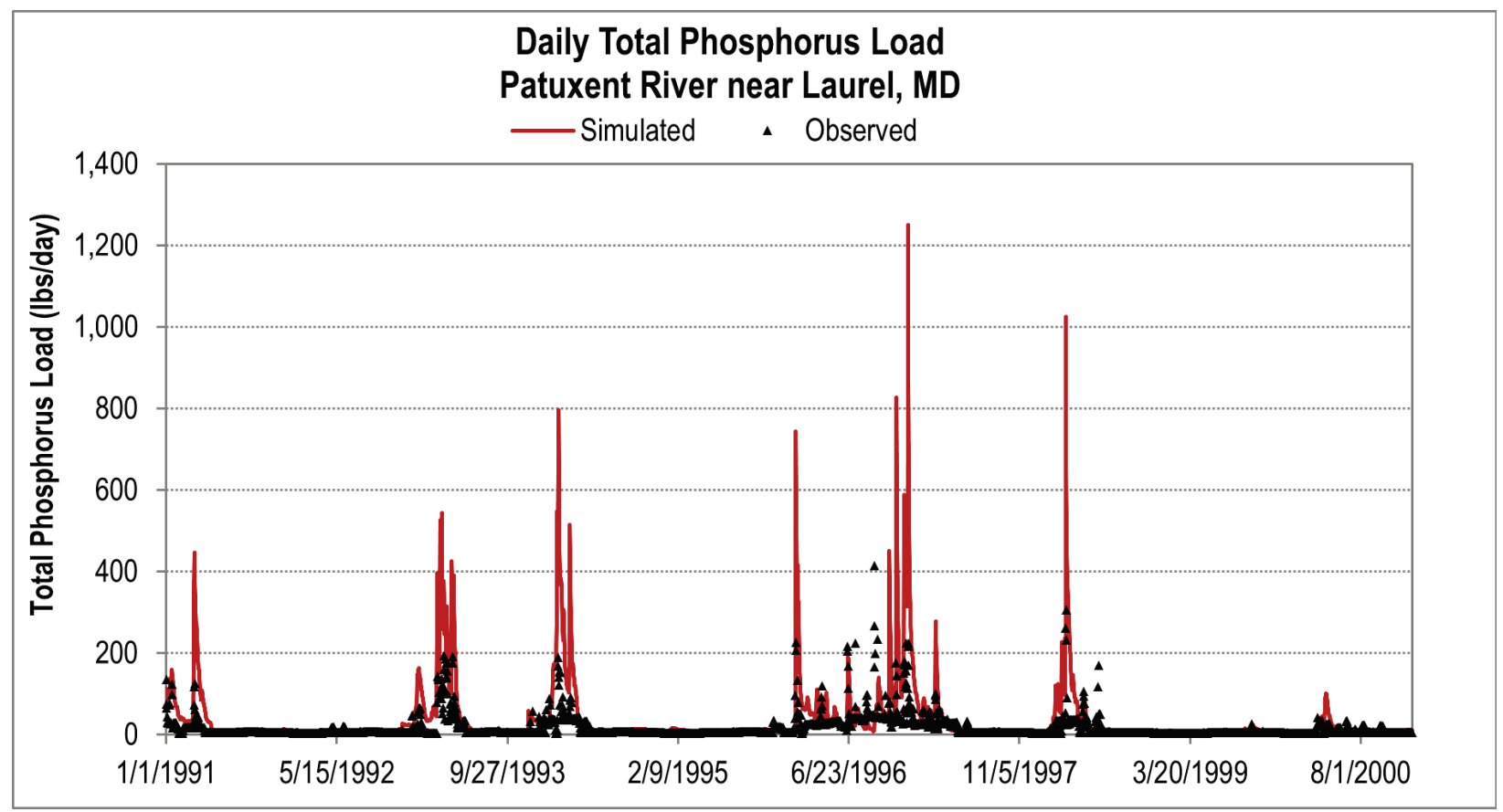

Figure C-32. Daily Total Phosphorus Load Time Series for Patuxent River near Bowie, Maryland (Segment: XU3_4650_0001).

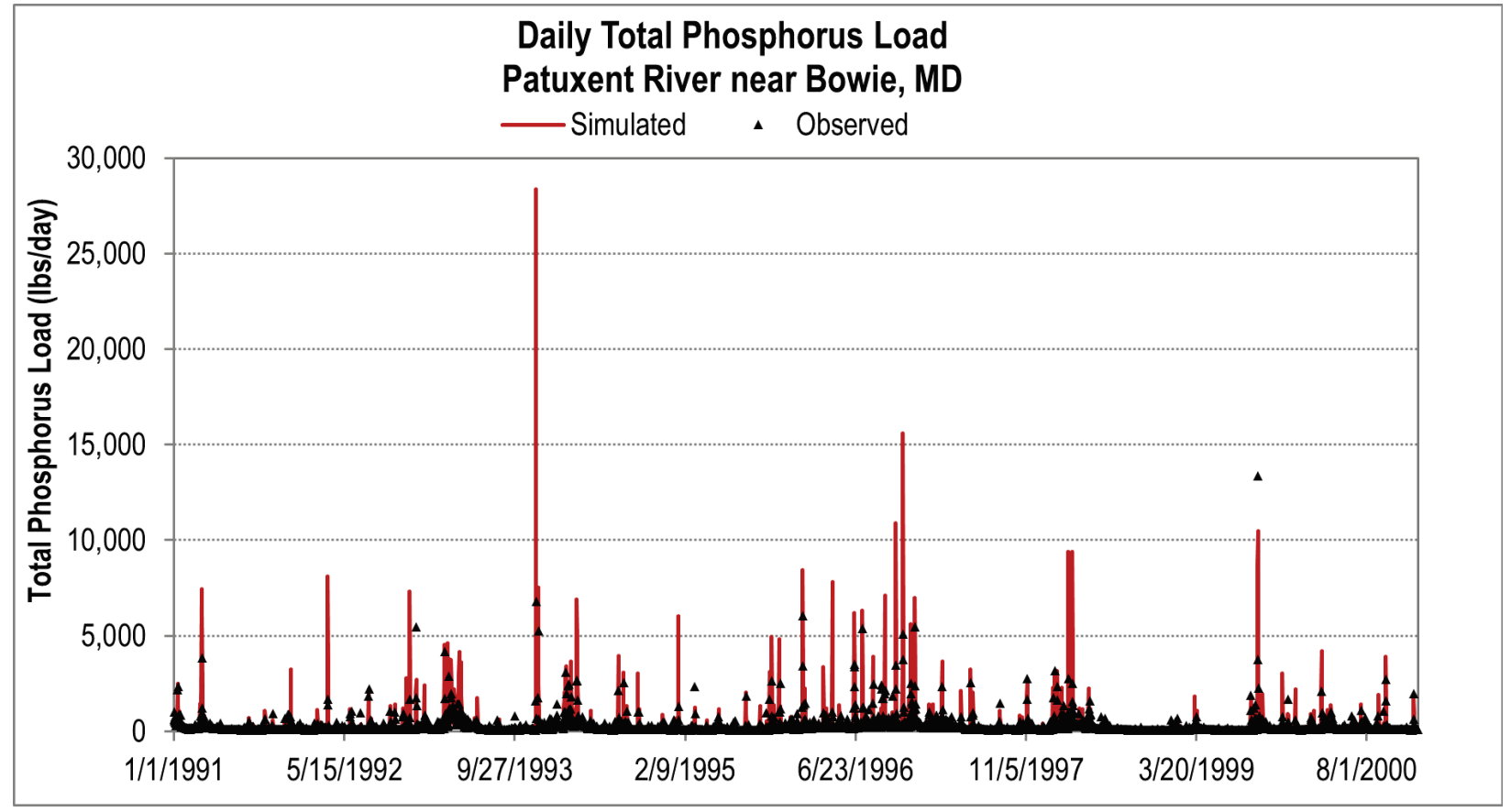


Figure C-33. Monthly Dissolved Phosphate Load Time Series for Patuxent River near Bowie, Maryland (Segment: XU3_4650_0001).

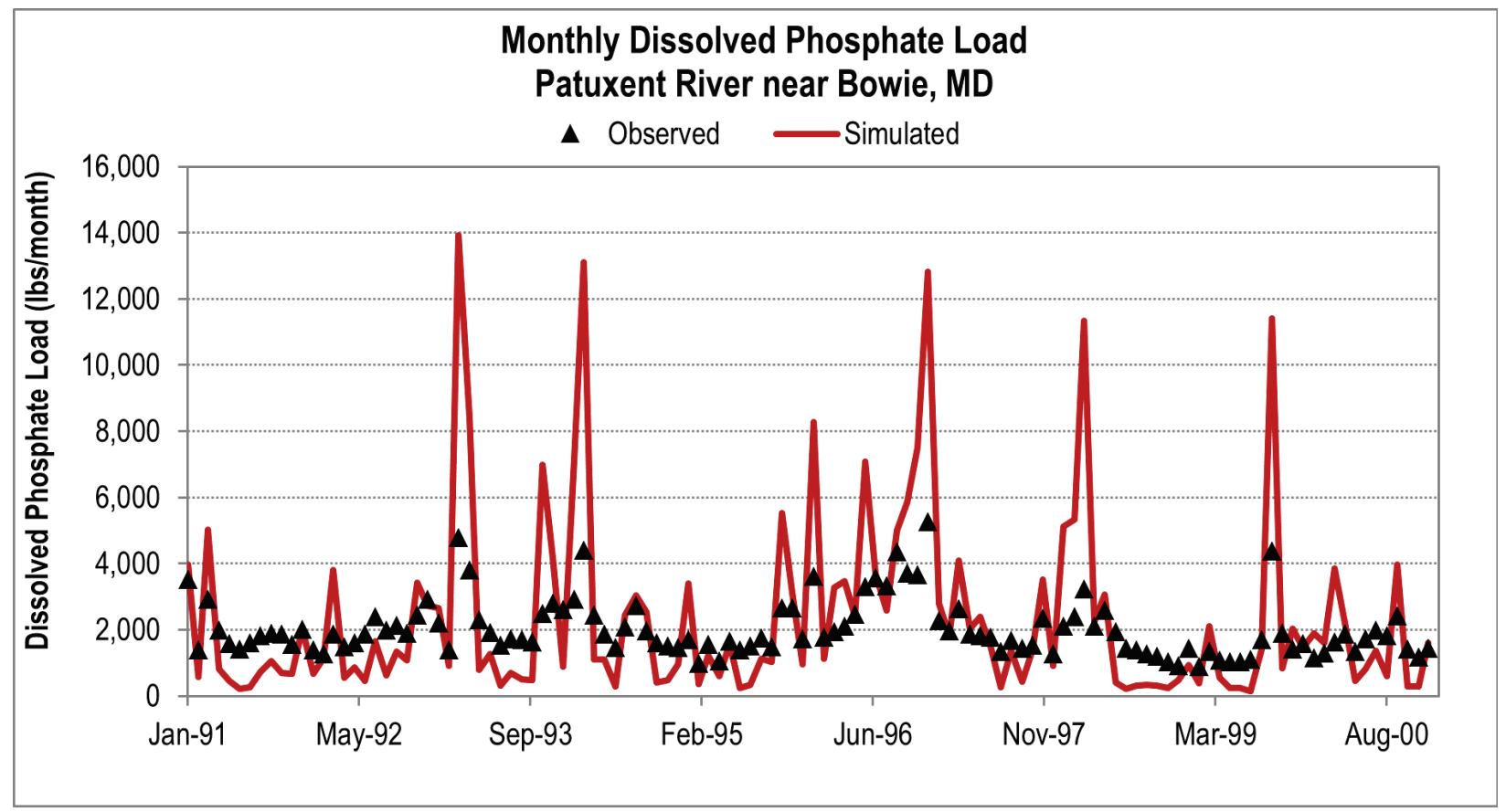

Figure C-34. Daily Dissolved Phosphate Load Time Series for Patuxent River near Bowie, Maryland (Segment: XU3_4650_0001).

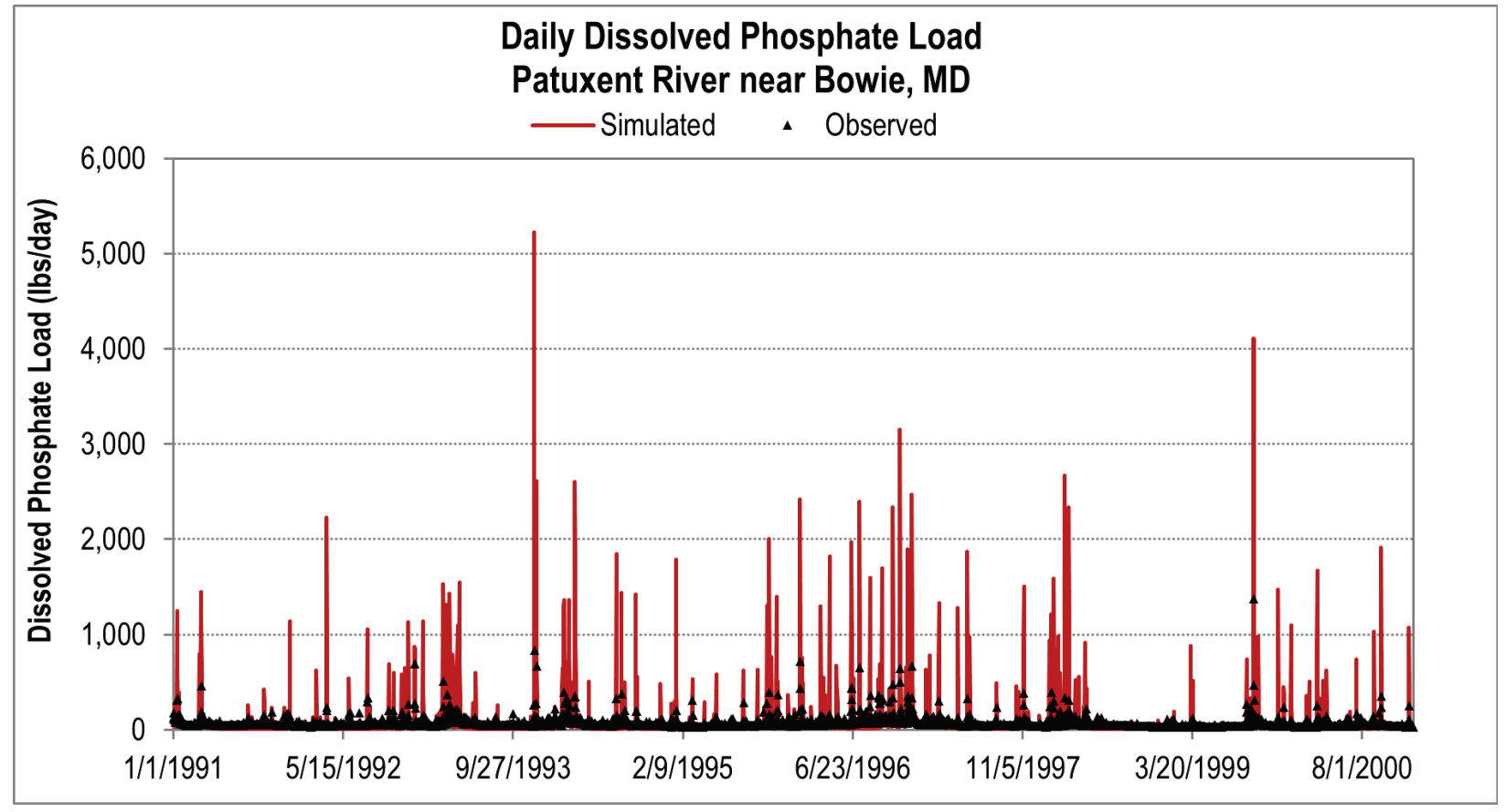


Figure C-35. Monthly average observed versus linked HSPF/HEC-RAS modeled algae concentrations near Bowie, Maryland for the calibration period.

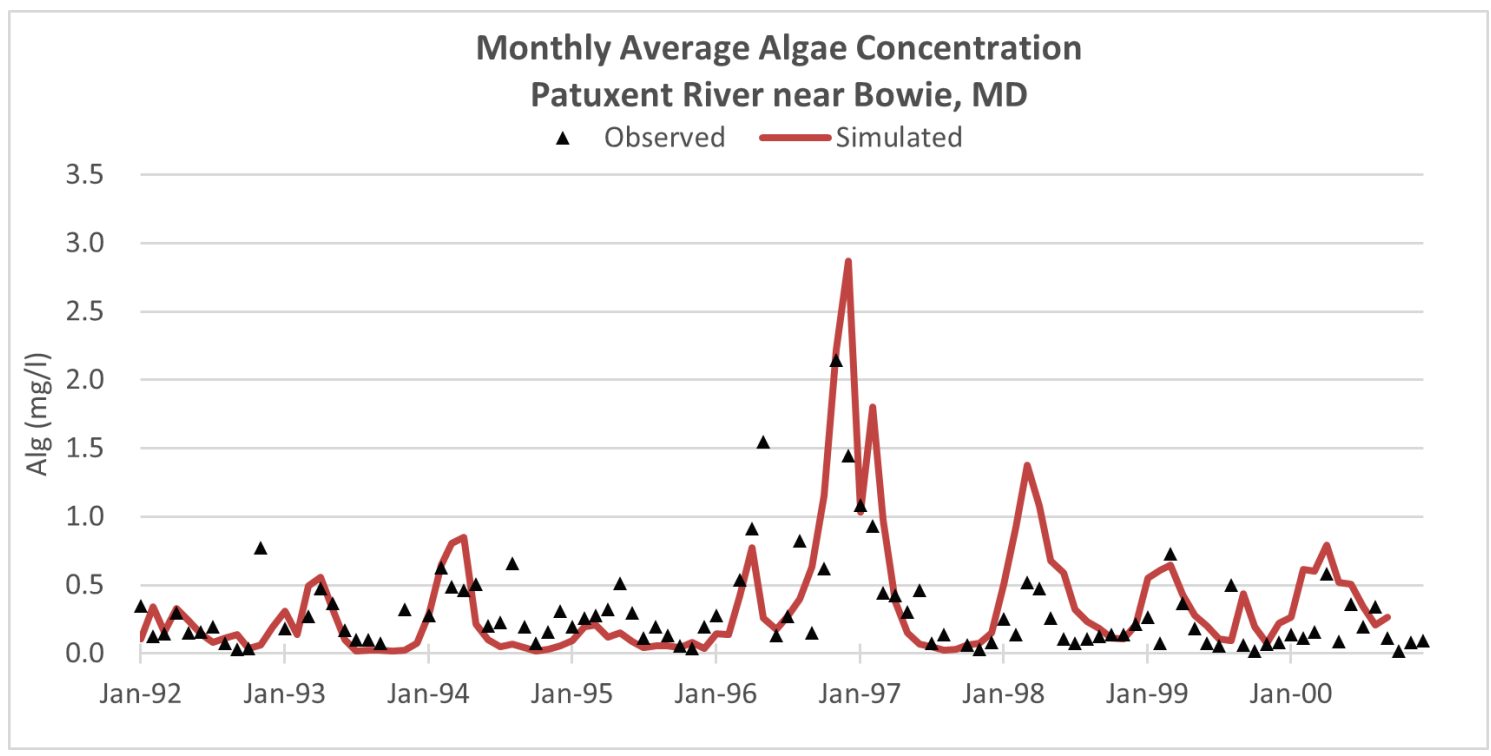

Figure C-36. Daily average observed versus linked HSPF/HEC-RAS modeled algae concentrations near Bowie, Maryland for the calibration period.

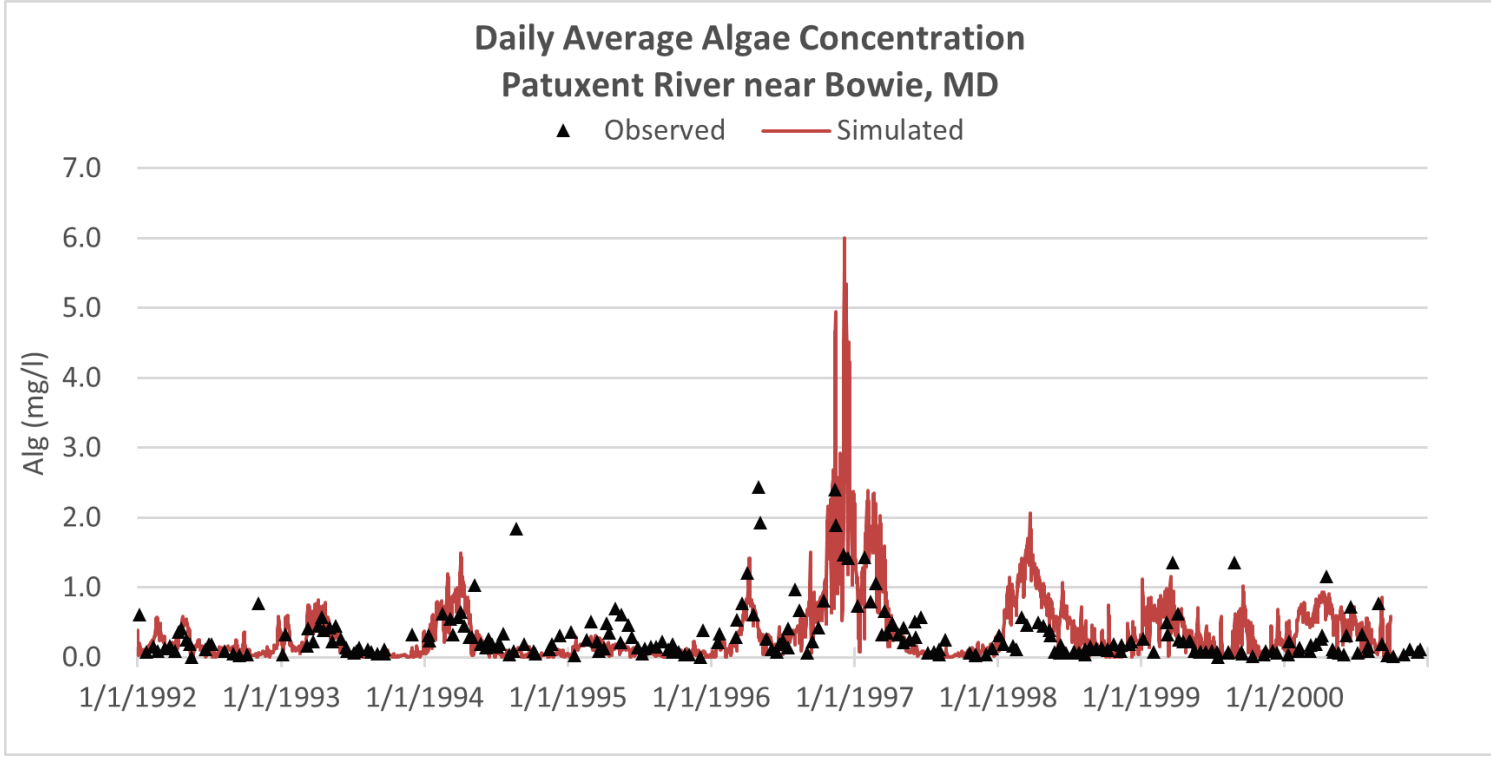


Figure C-37. Monthly average observed versus linked HSPF/HEC-RAS modeled dissolved oxygen concentrations near Bowie, Maryland for the calibration period.

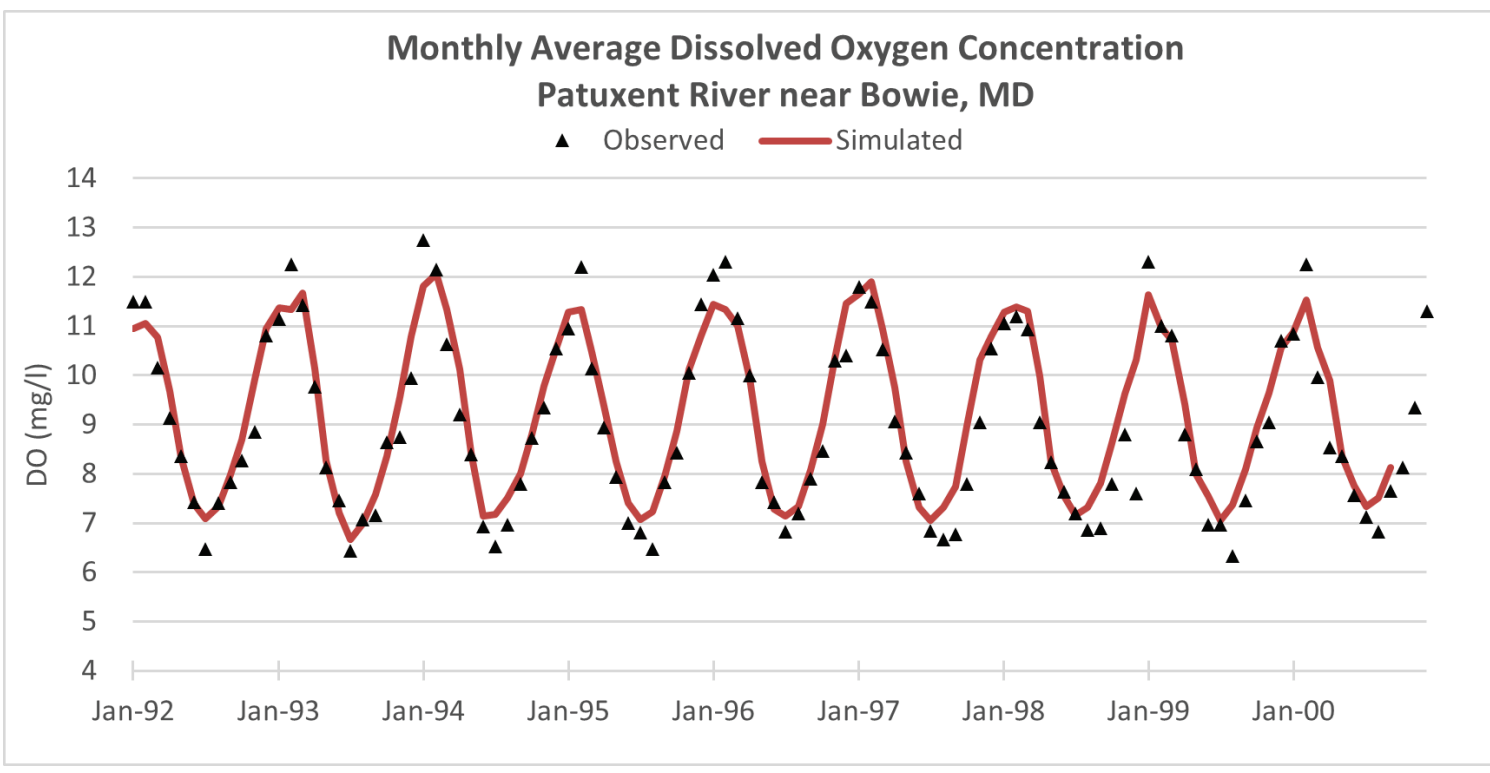

Figure C-38. Daily average observed versus linked HSPF/HEC-RAS modeled dissolved oxygen concentrations near Bowie, Maryland for the calibration period.

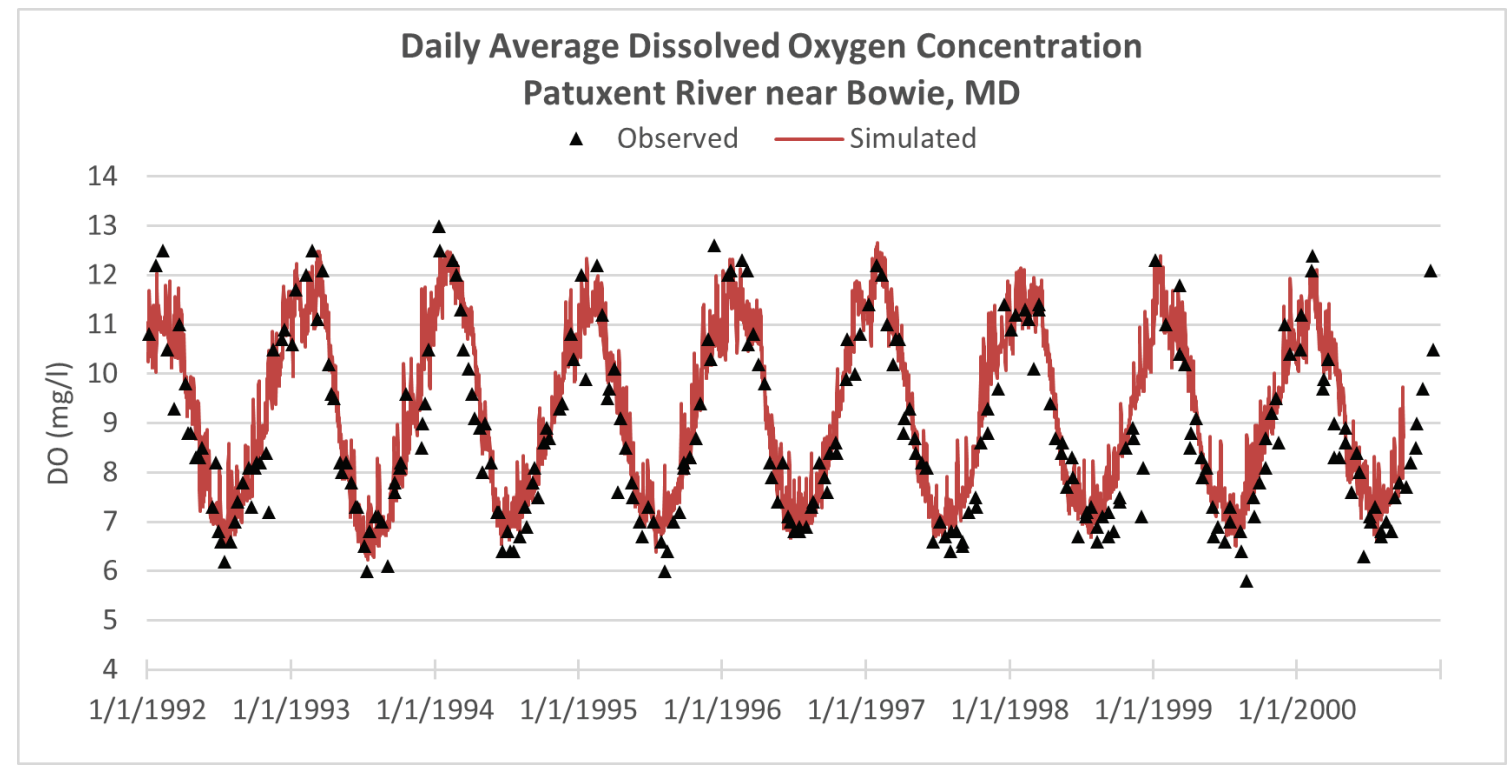


Figure C-39. Monthly average observed versus linked HSPF/HEC-RAS modeled organic nitrogen concentrations near Bowie, Maryland for the calibration period.

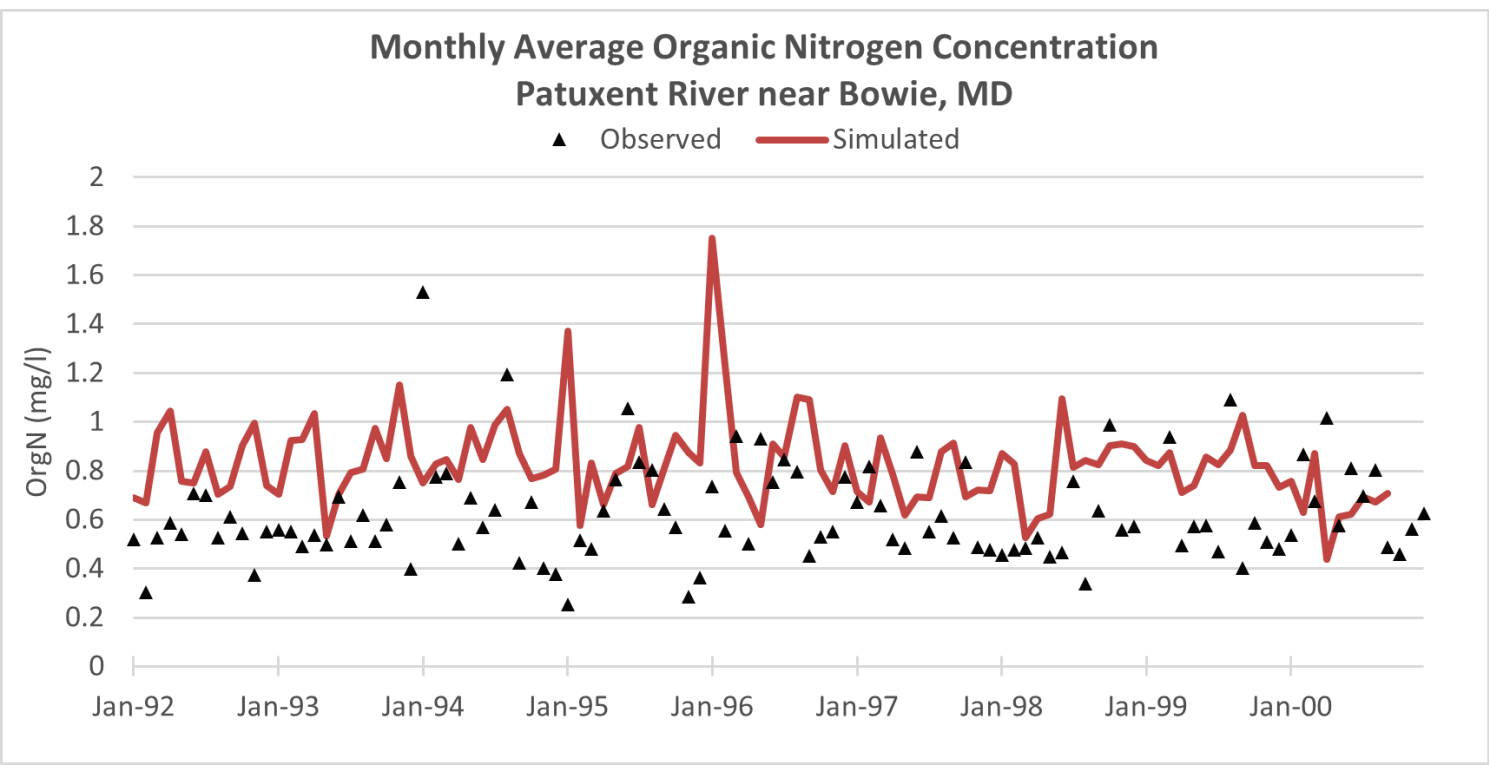

Figure C-40. Daily average observed versus linked HSPF/HEC-RAS modeled organic nitrogen concentrations near Bowie, Maryland for the calibration period.

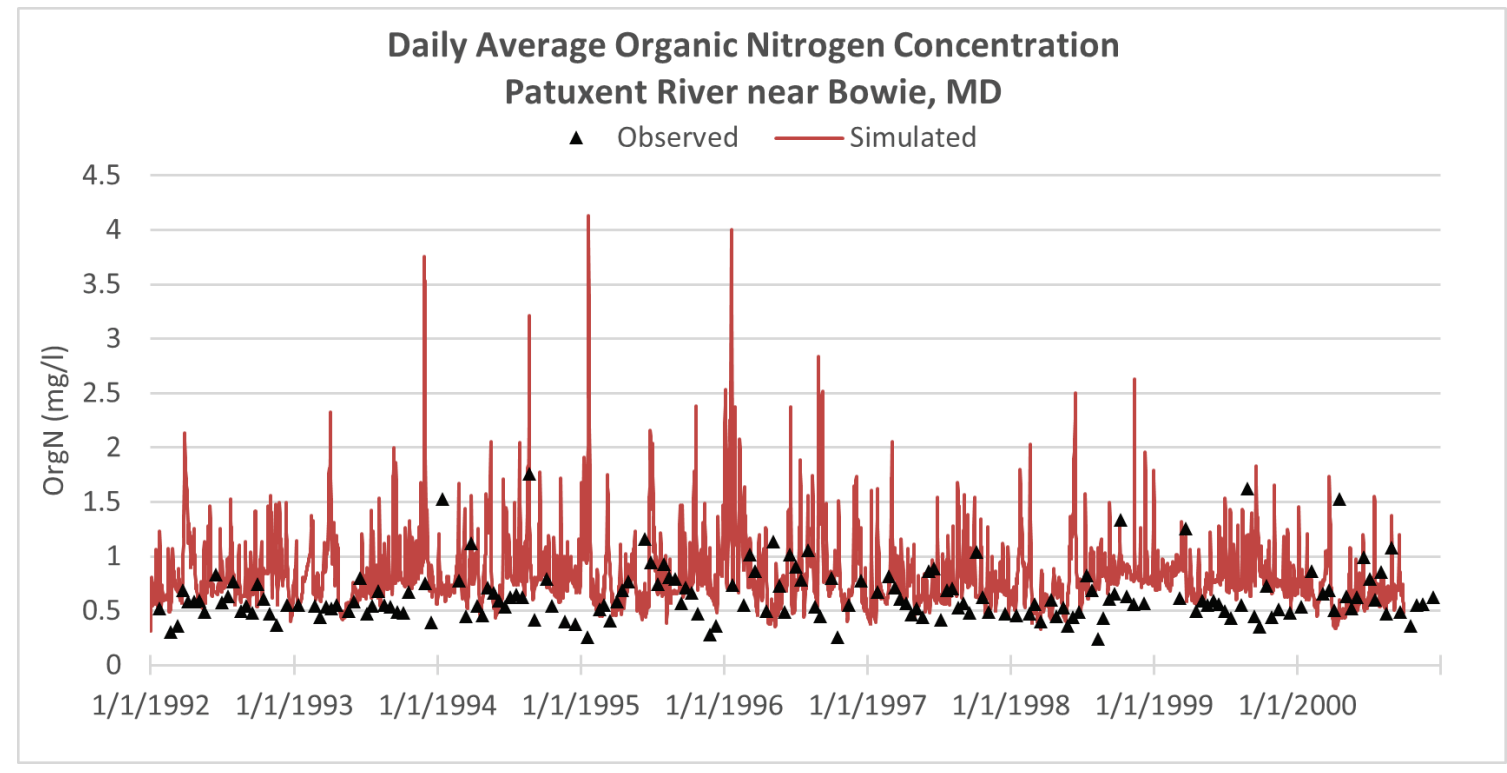


Figure C-41. Monthly average observed versus linked HSPF/HEC-RAS modeled ammonium concentrations near Bowie, Maryland for the calibration period.

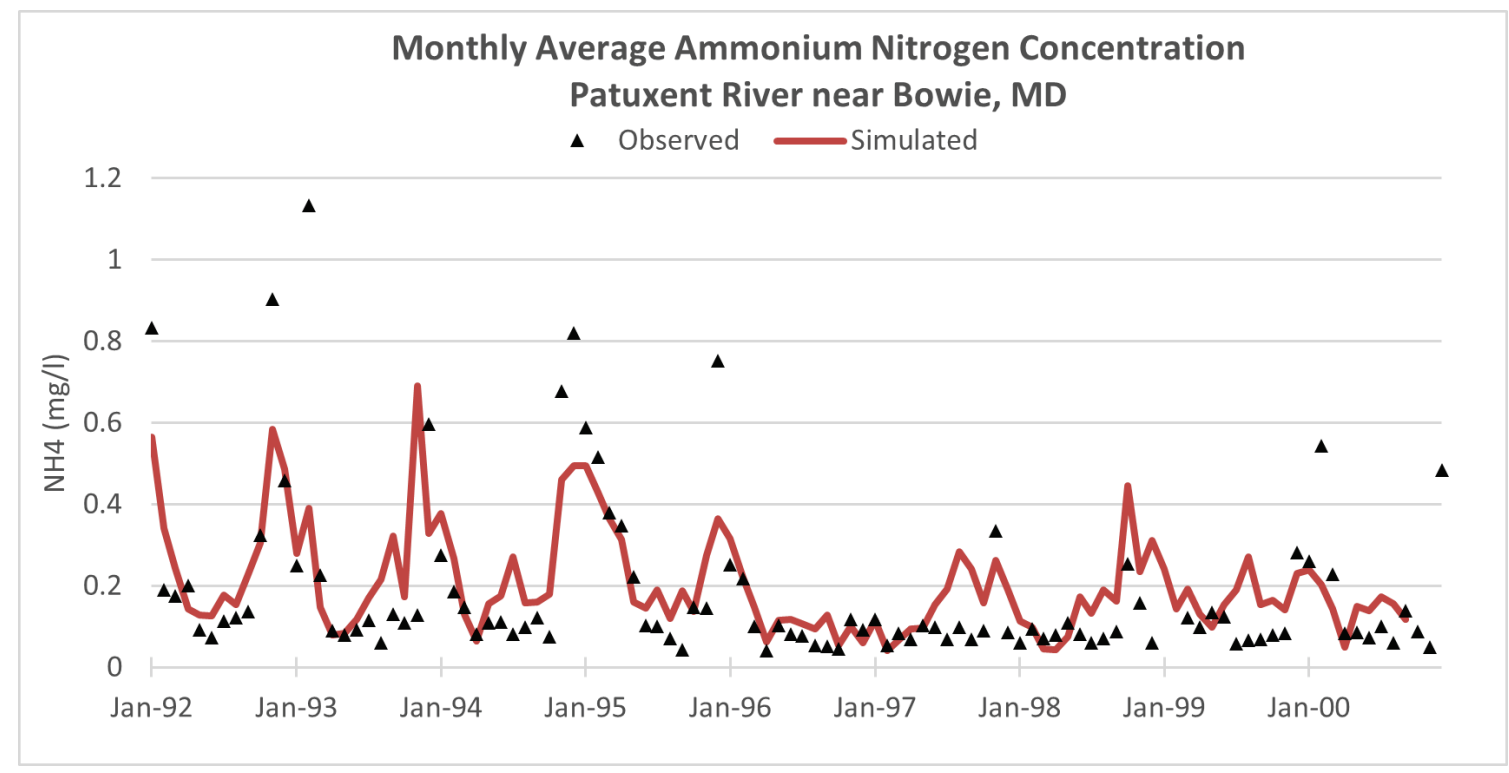

Figure C-42. Daily average observed versus linked HSPF/HEC-RAS modeled ammonium concentrations near Bowie, Maryland for the calibration period.

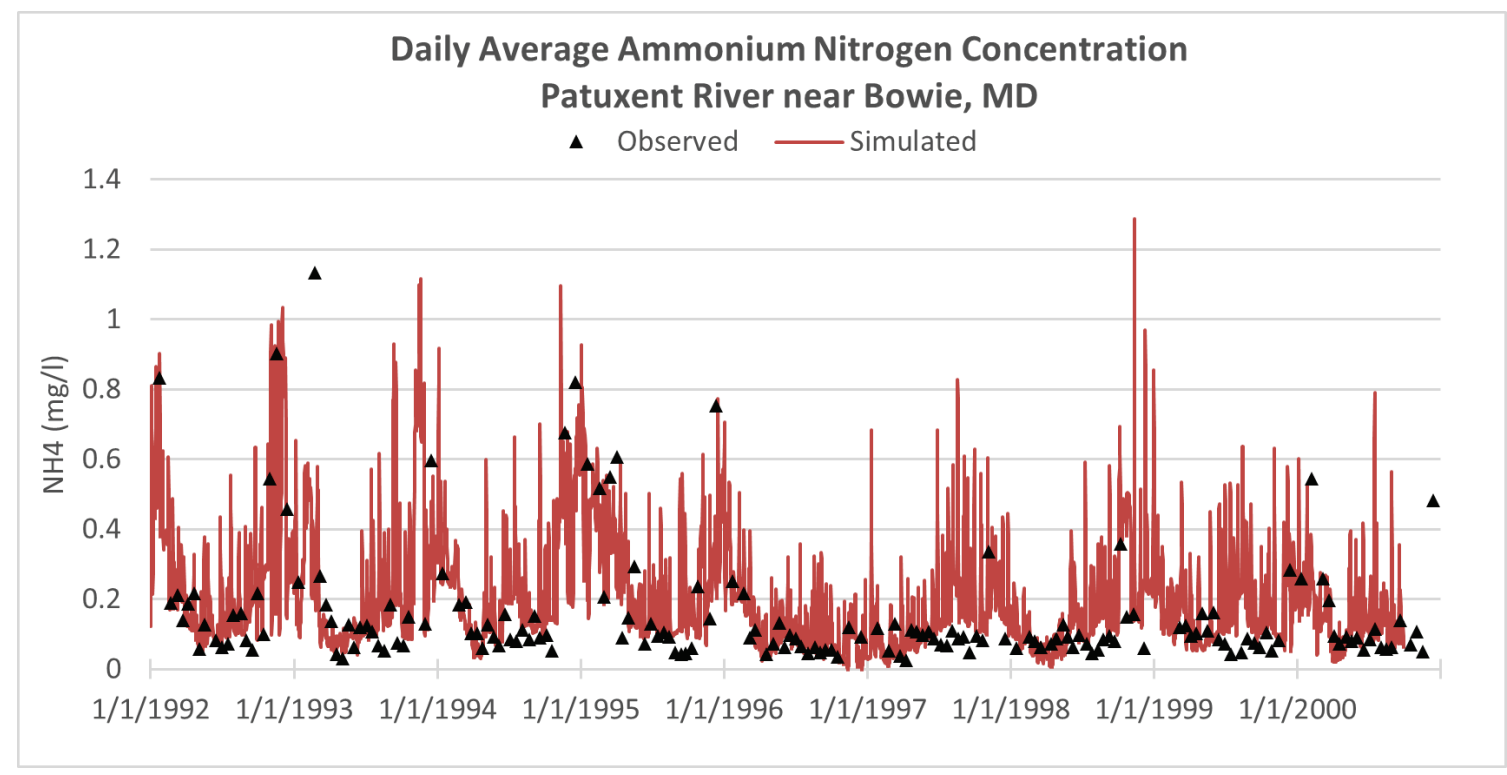


Figure C-43. Monthly average observed versus linked HSPF/HEC-RAS modeled nitrate concentrations near Bowie, Maryland for the calibration period.

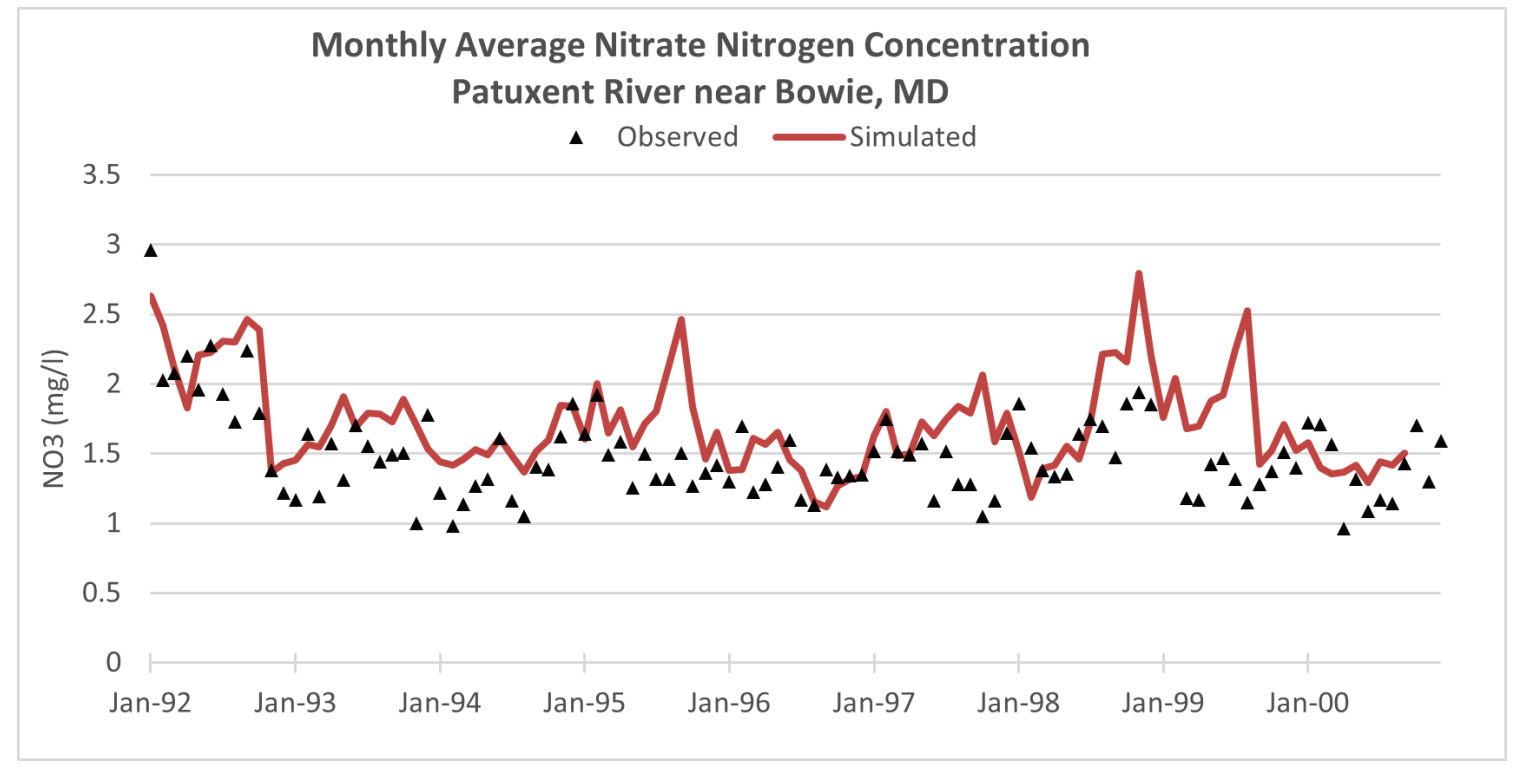

Figure C-44. Daily average observed versus linked HSPF/HEC-RAS modeled nitrate concentrations near Bowie, Maryland for the calibration period.

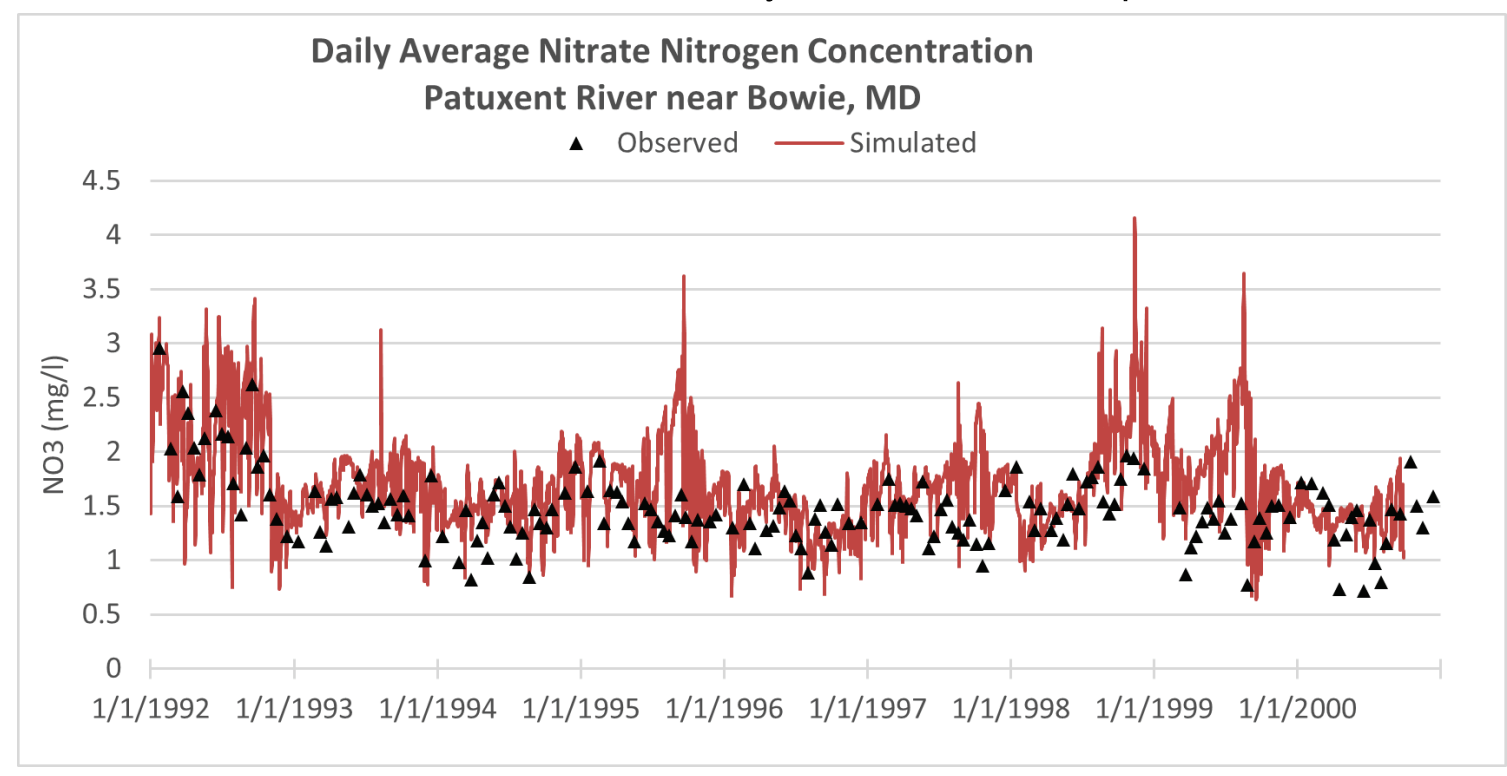


Figure C-45. Monthly average observed versus linked HSPF/HEC-RAS modeled organic phosphorus concentrations near Bowie, Maryland for the calibration period.

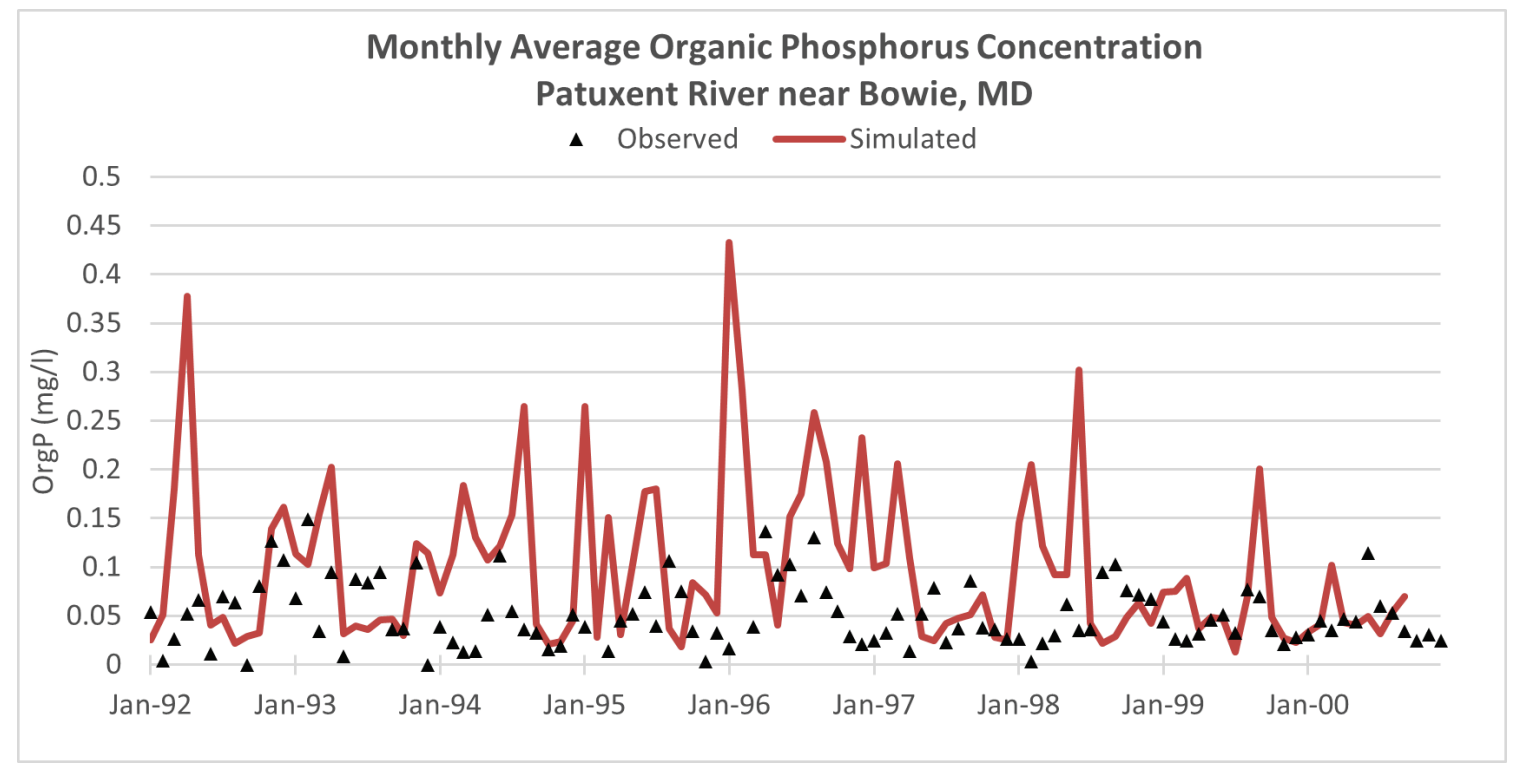

Figure C-46. Daily average observed versus linked HSPF/HEC-RAS modeled organic phosphorus concentrations near Bowie, Maryland for the calibration period.

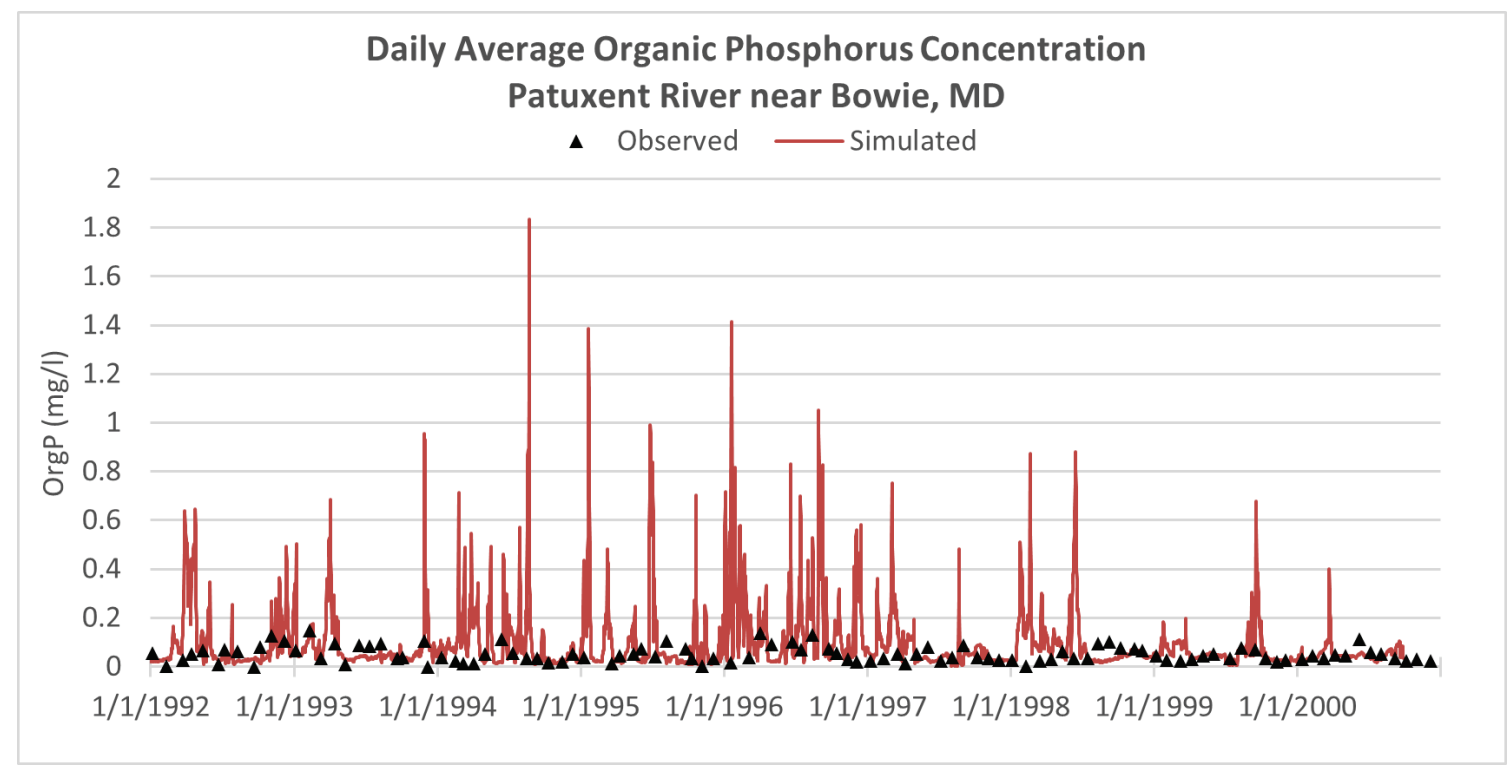


Figure C-47. Monthly average observed versus linked HSPF/HEC-RAS modeled inorganic phosphorus concentrations near Bowie, Maryland for the calibration period.

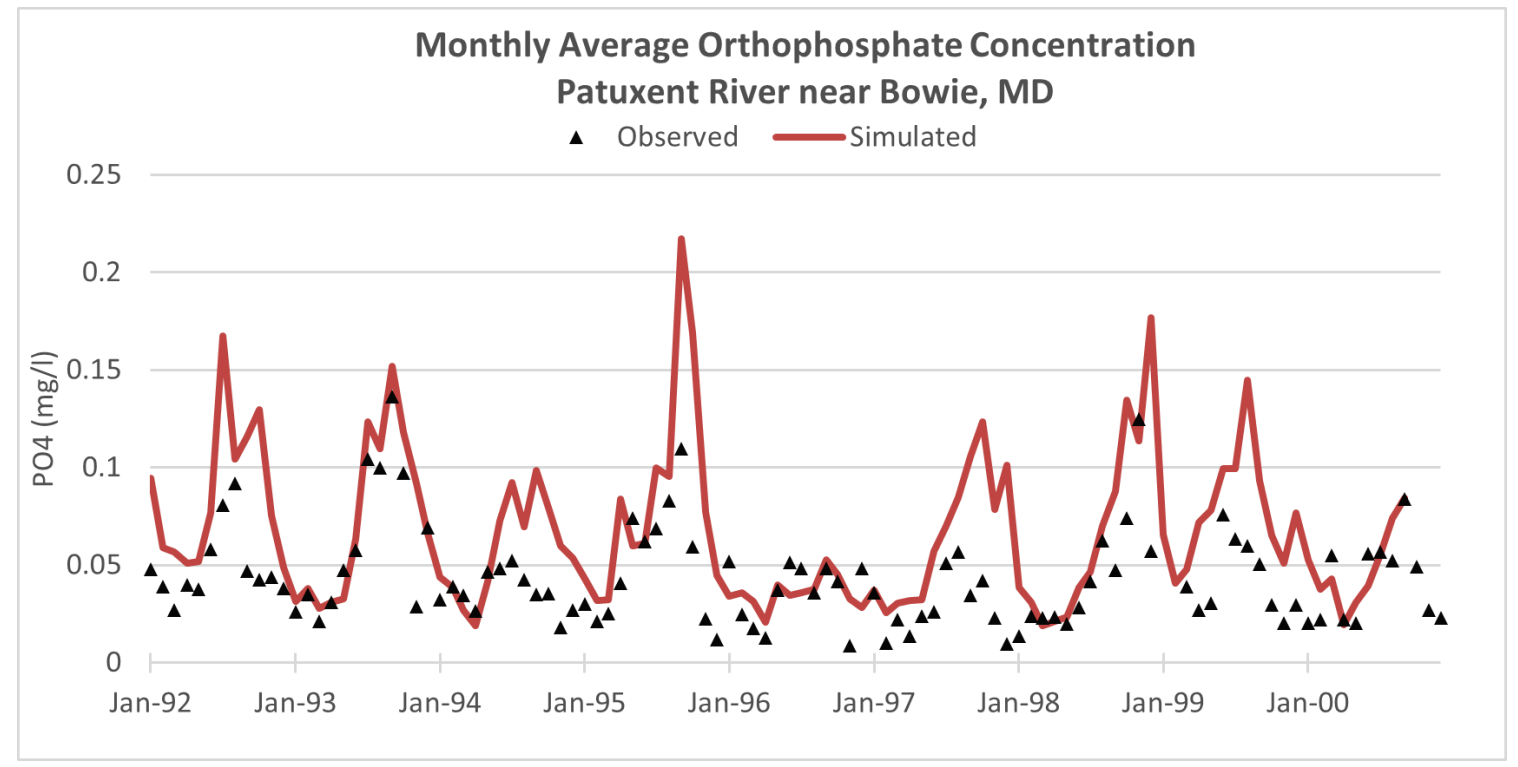

Figure C-48. Daily average observed versus linked HSPF/HEC-RAS modeled inorganic phosphorus concentrations near Bowie, Maryland for the calibration period.

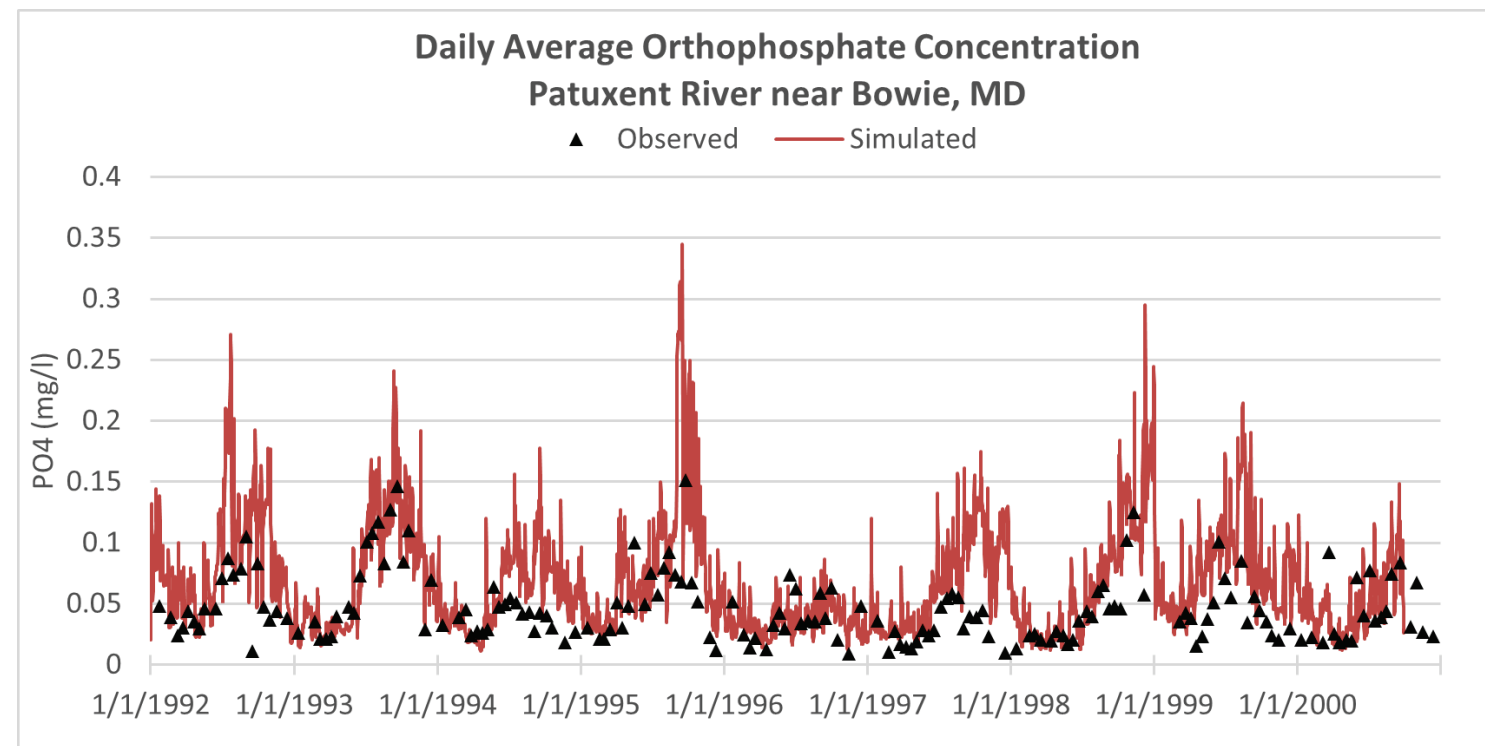




\section{Appendix D: Validation Model Results}

Figure D-1. Monthly Streamflow Time Series for Western Branch at Upper Marlboro MD (Segment: XL1_4690_0001).

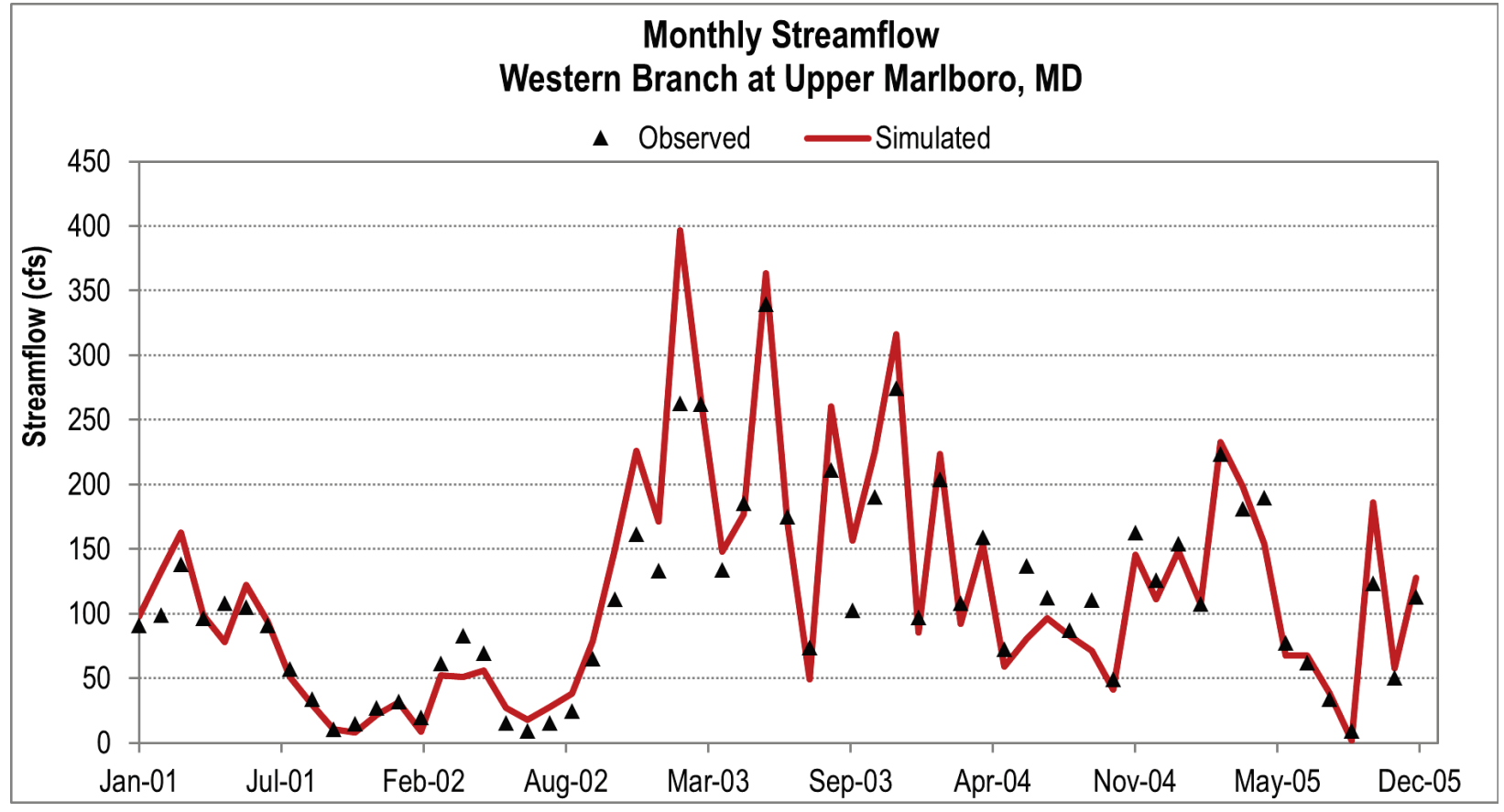

Figure D-2. Monthly Streamflow Time Series for Patuxent River near Unity, Maryland

(Segment: XU0_4130_4070).

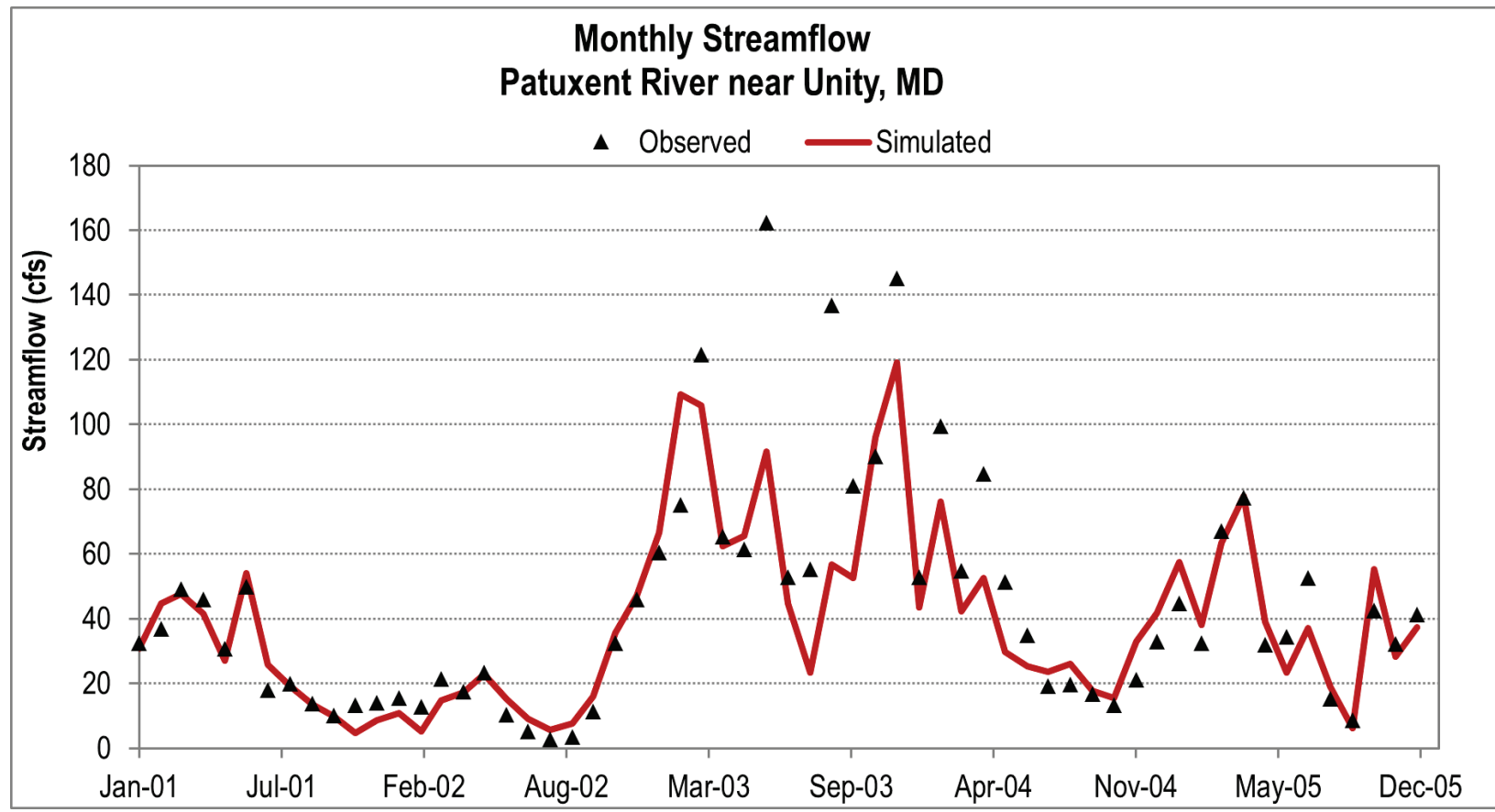


Figure D-3. Monthly Streamflow Time Series for Patuxent River near Brighton, Maryland

(Segment: XU2_4070_4330).

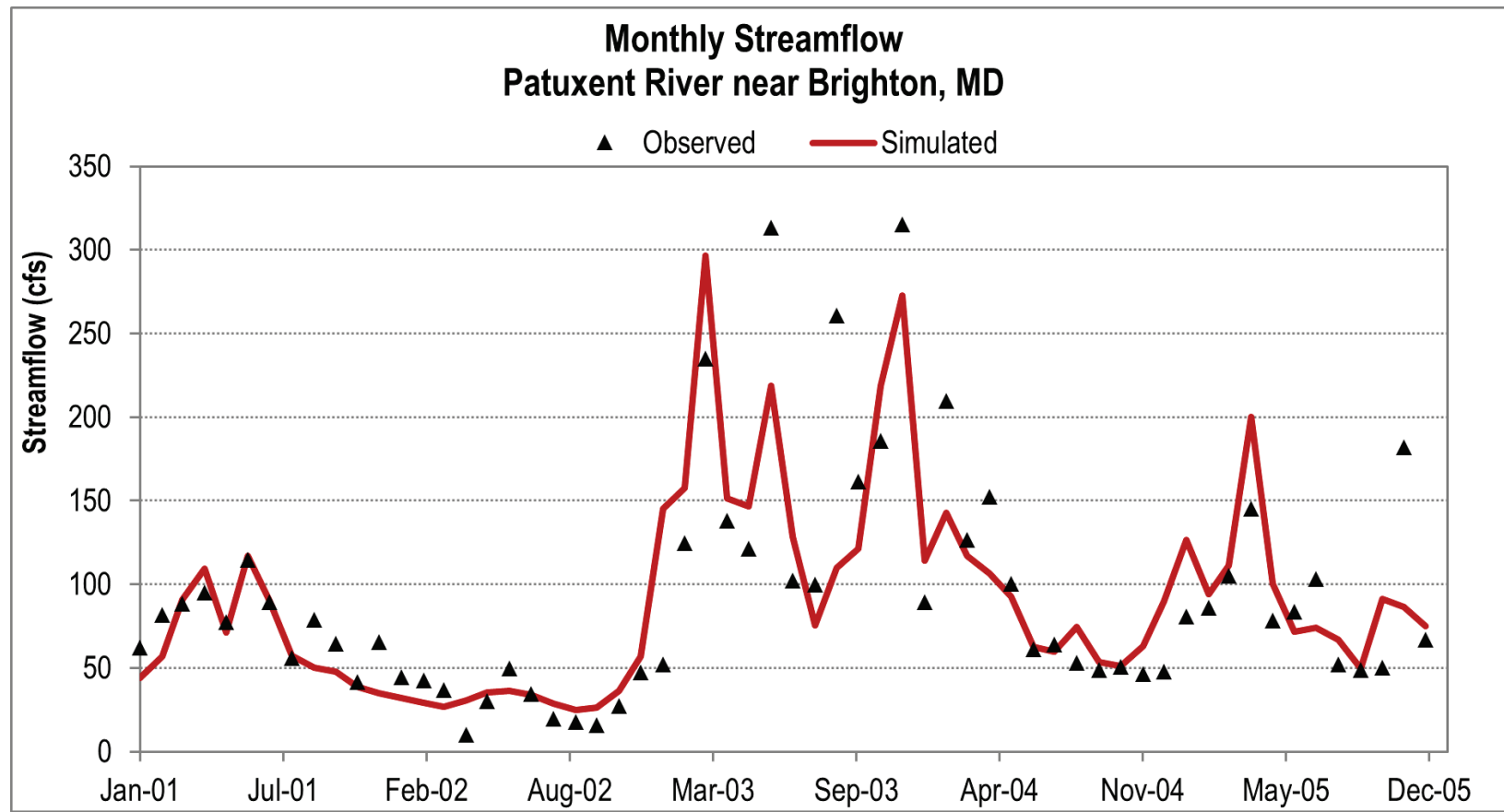

Figure D-4. Monthly Streamflow Time Series for Little Patuxent River at Savage, Maryland (Segment: XU2_4270_0003).

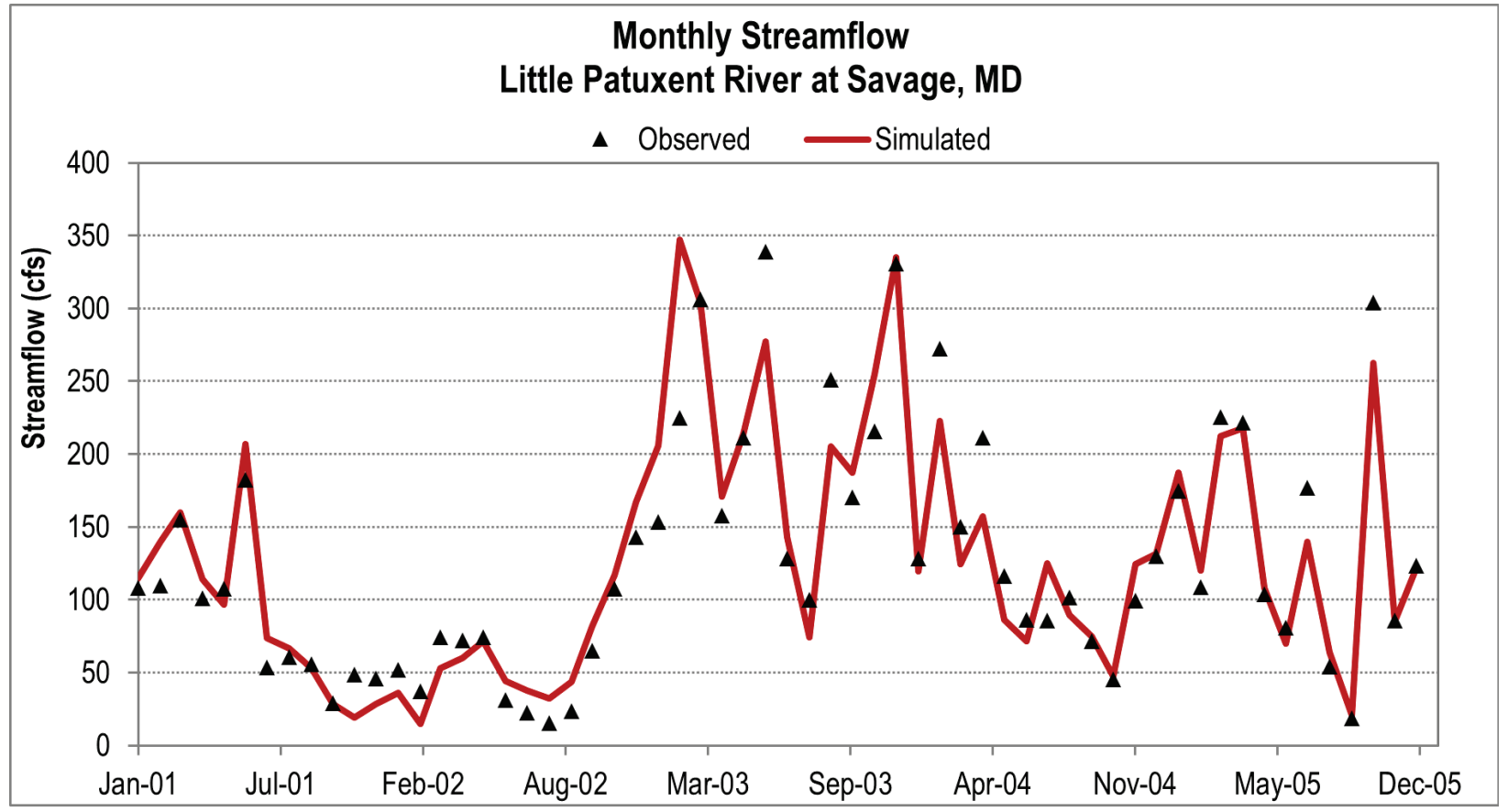


Figure D-5. Monthly Streamflow Time Series for Patuxent River near Laurel, Maryland (Segment: XU2_4330_4480).

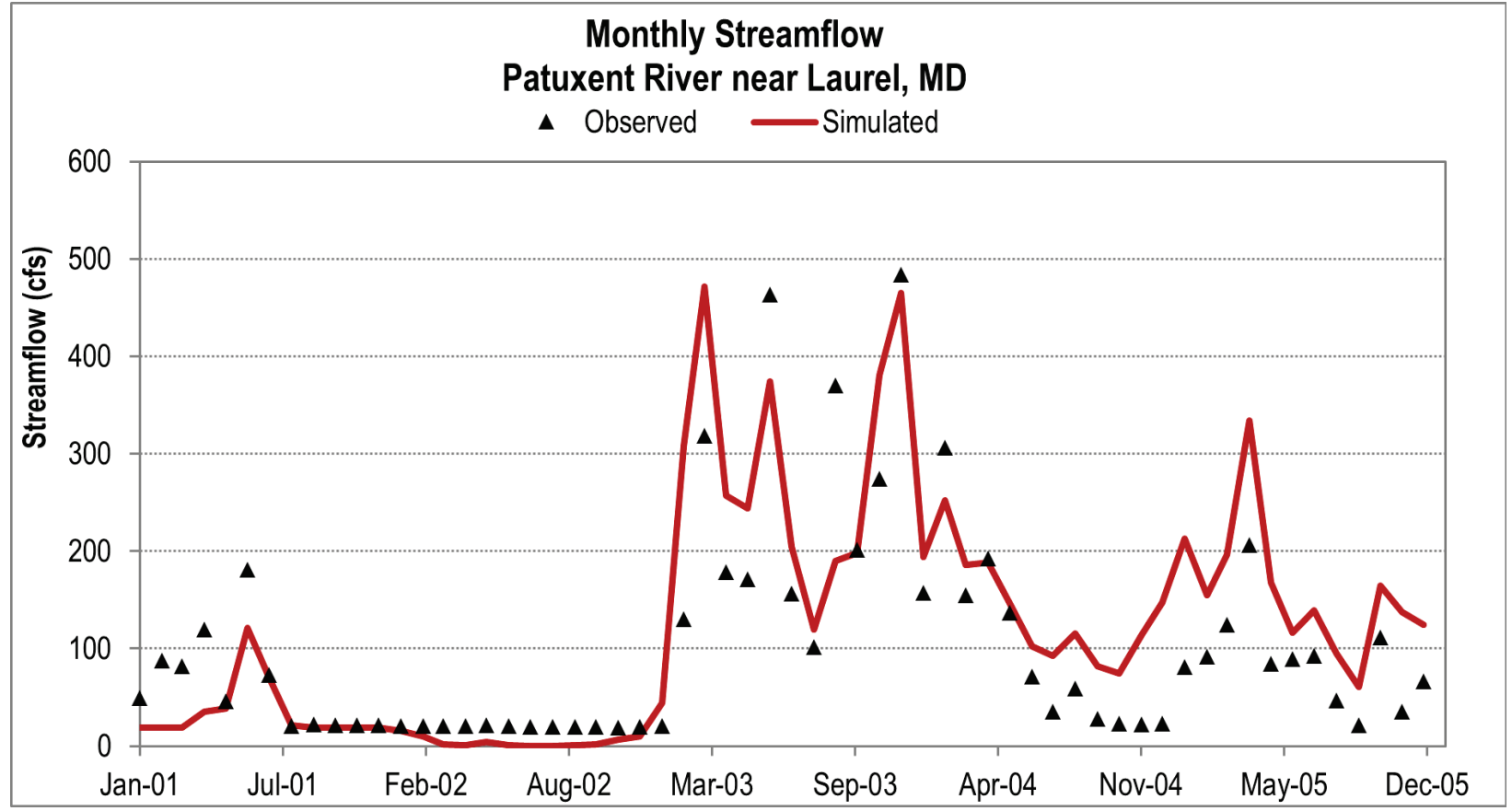

Figure D-6. Monthly Streamflow Time Series for Patuxent River near Bowie, Maryland (Segment: XU3_4650_0001).

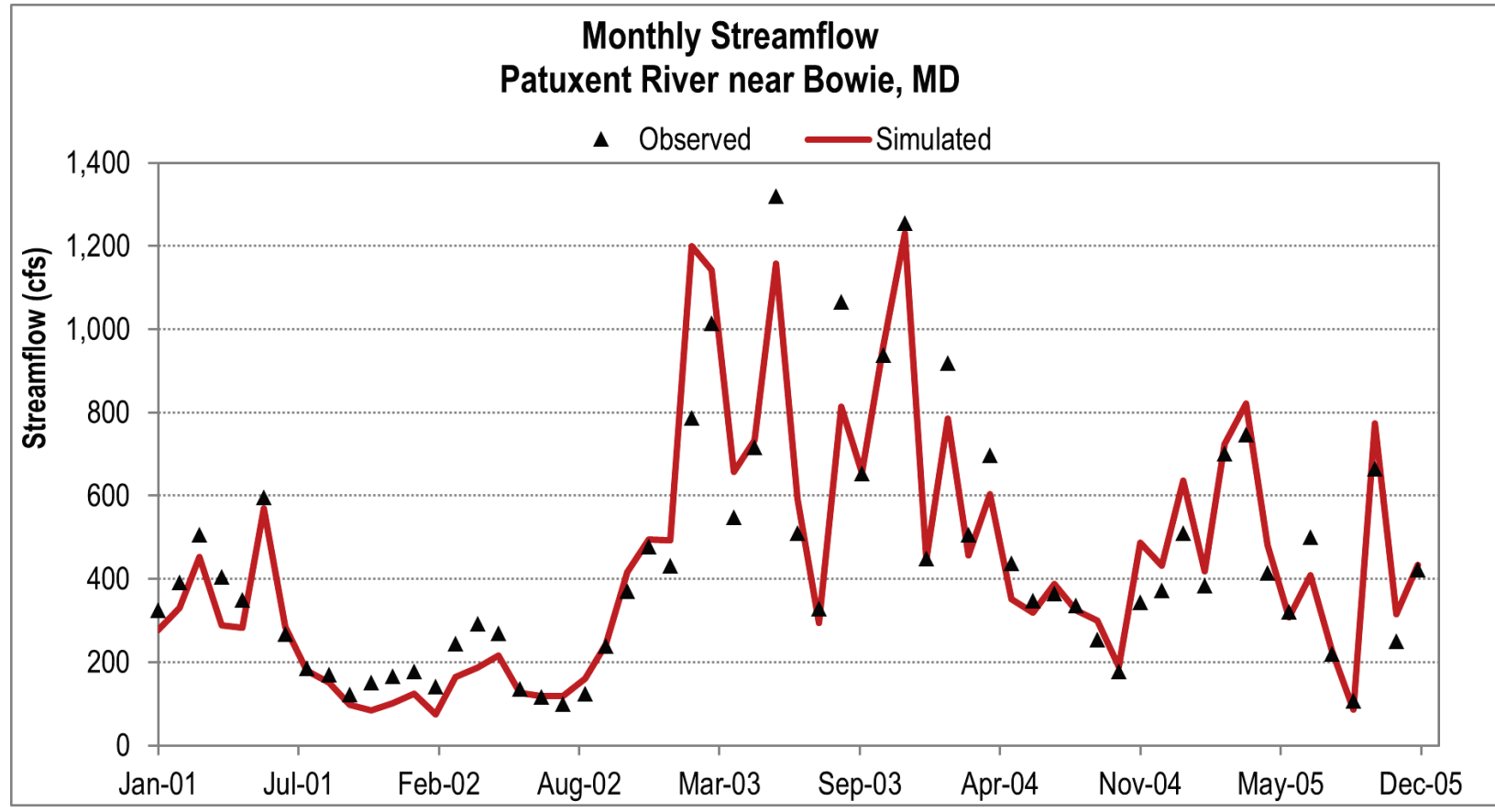


Figure D-7. Daily Average Streamflow Time Series for Western Branch at Upper Marlboro MD (Segment: XL1_4690_0001).

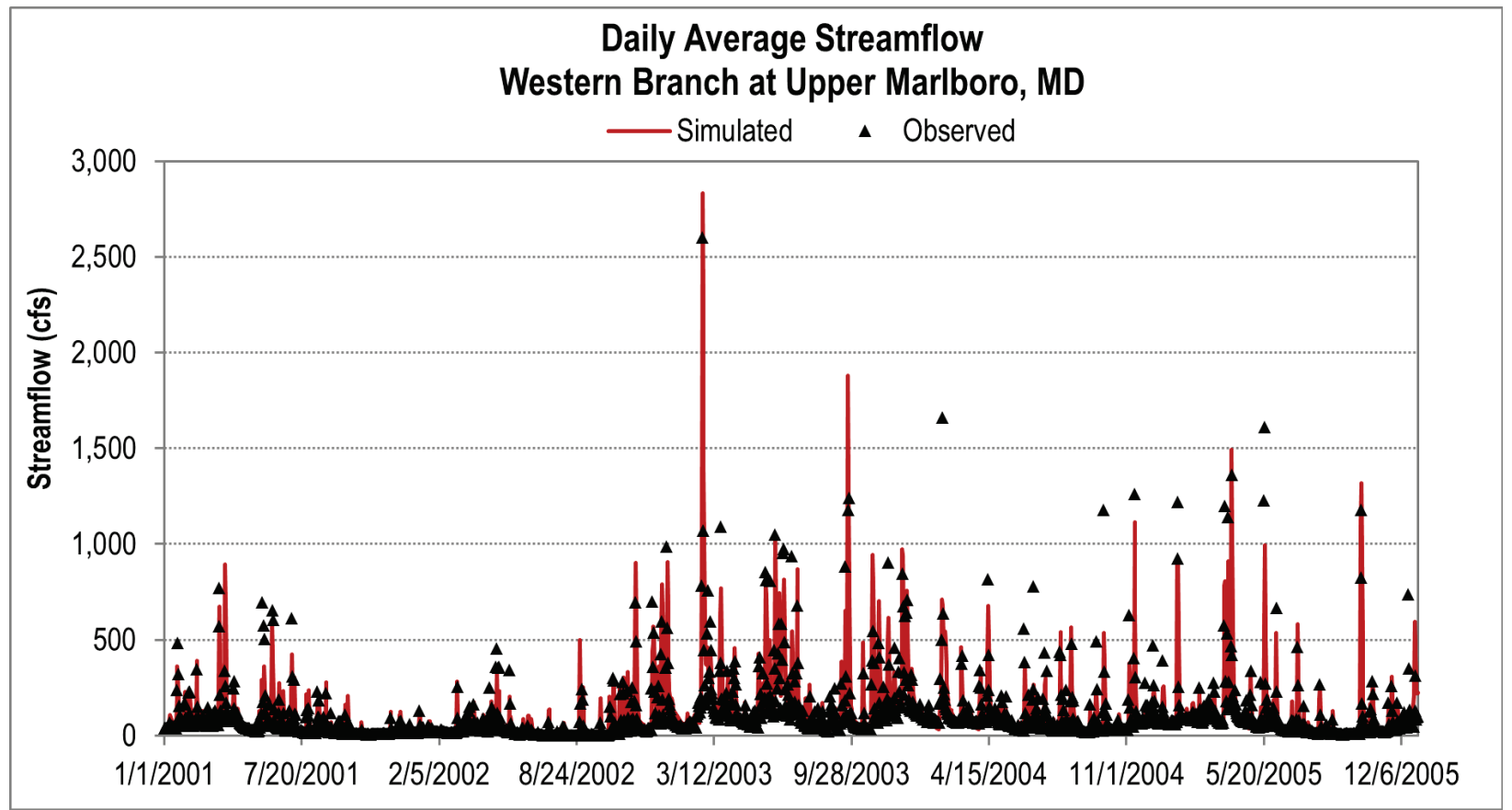

Figure D-8. Daily Average Streamflow Time Series for Patuxent River near Unity, Maryland (Segment: XU0_4130_4070).

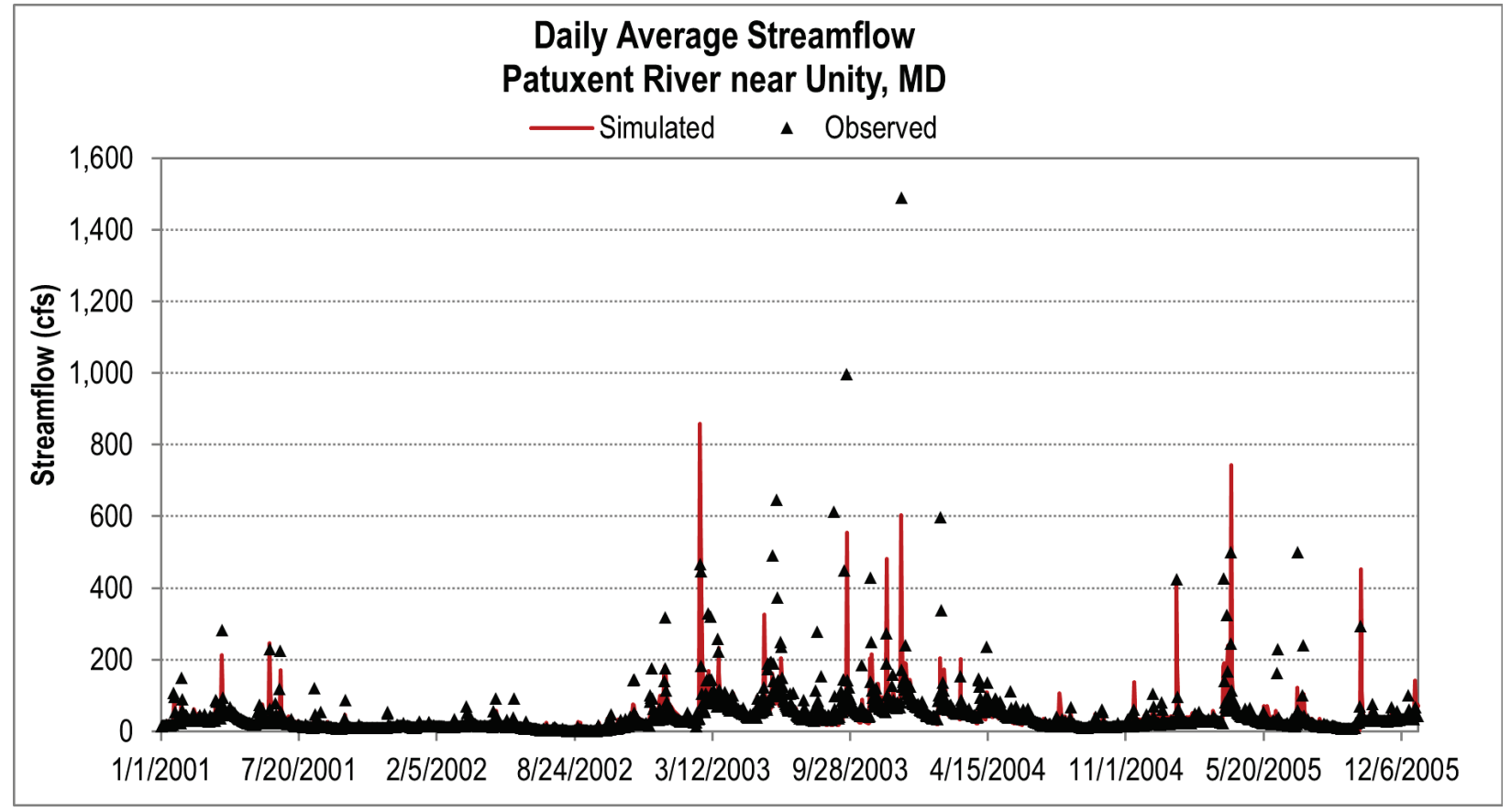


Figure D-9. Daily Average Streamflow Time Series for Patuxent River near Brighton, Maryland (Segment: XU2_4070_4330).

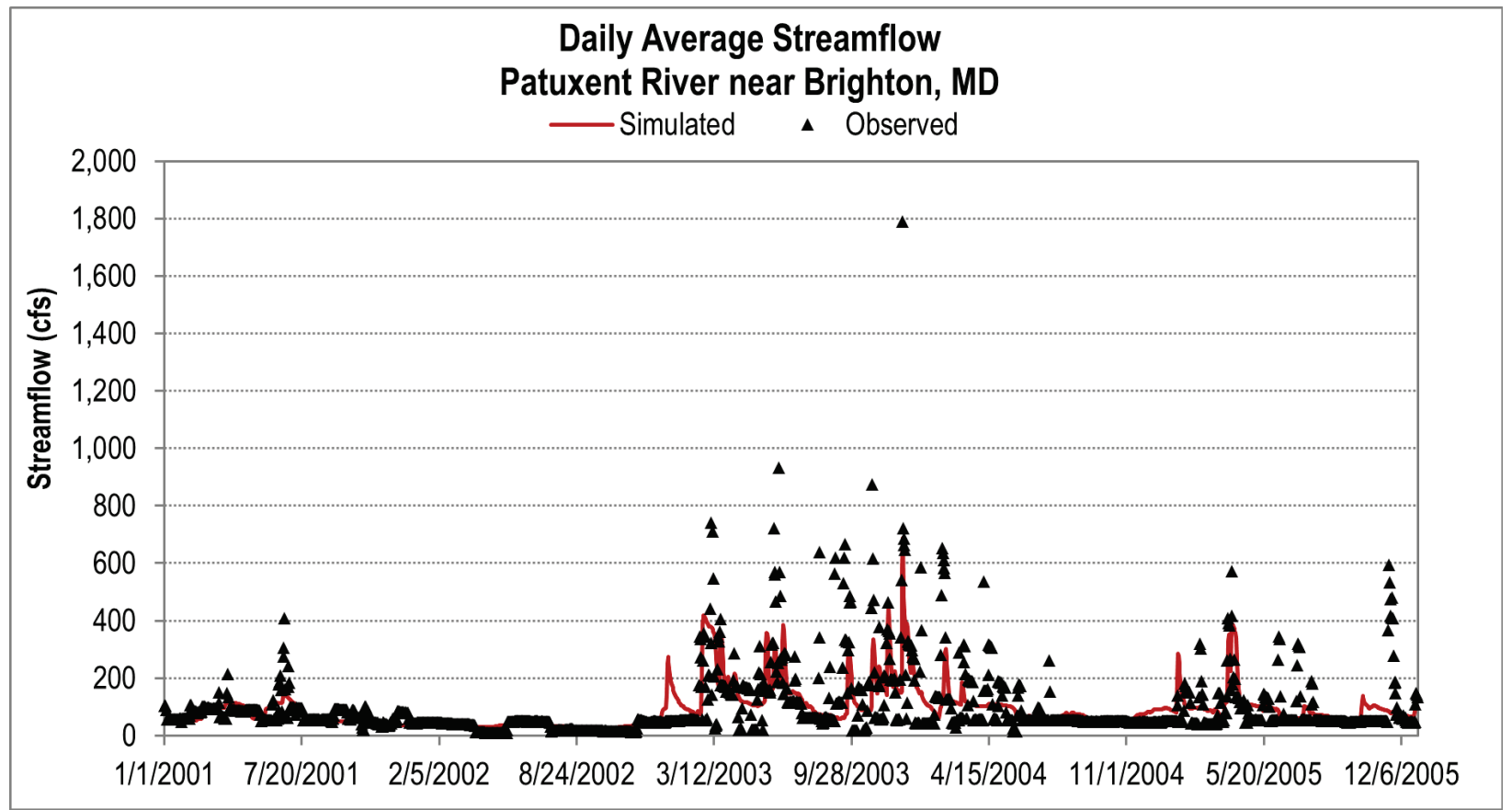

Figure D-10. Daily Average Streamflow Time Series for Little Patuxent River at Savage, Maryland (Segment: XU2_4270_0003).

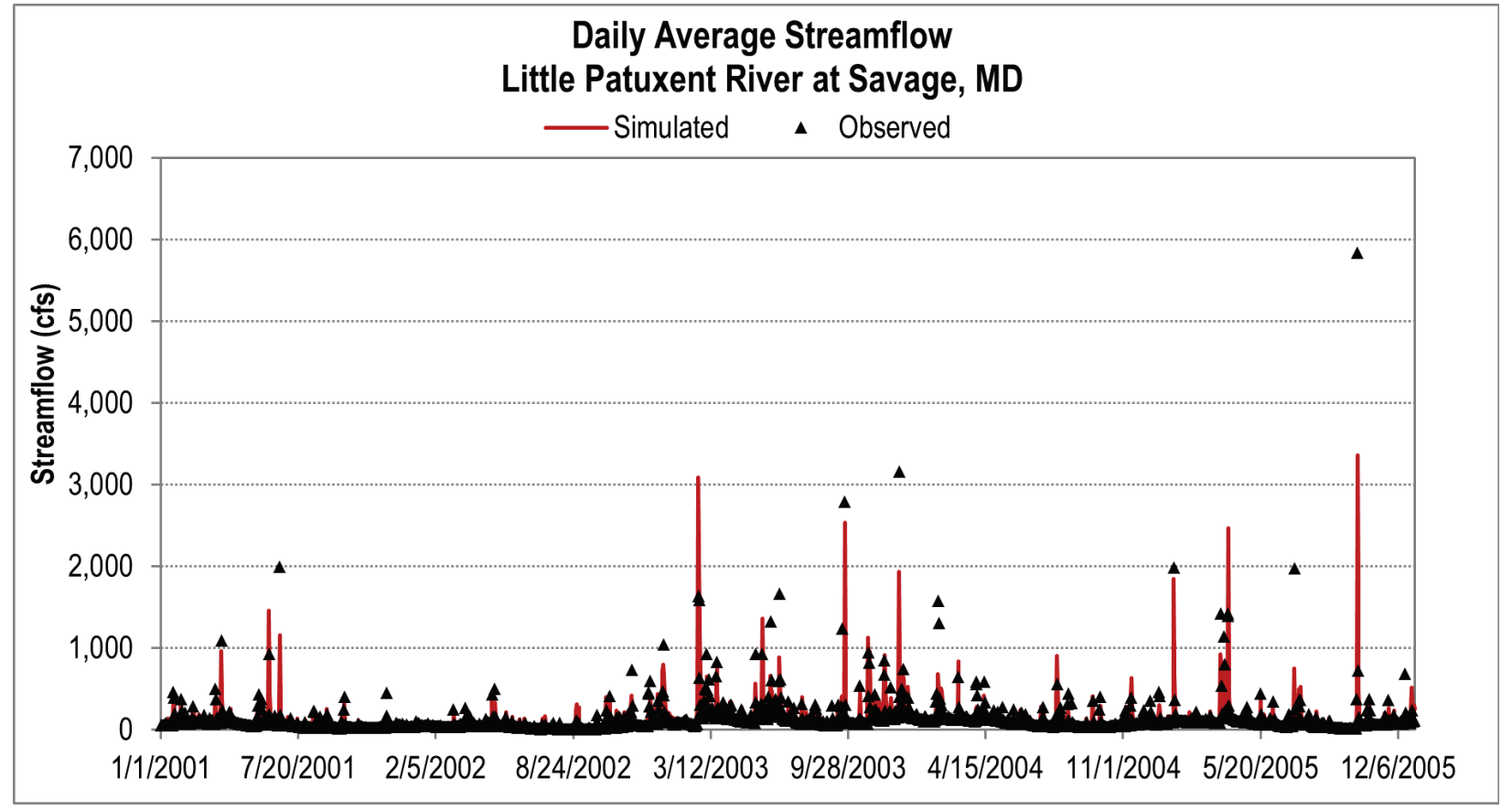


Figure D-11. Daily Average Streamflow Time Series for Patuxent River near Laurel, Maryland (Segment: XU2_4330_4480).

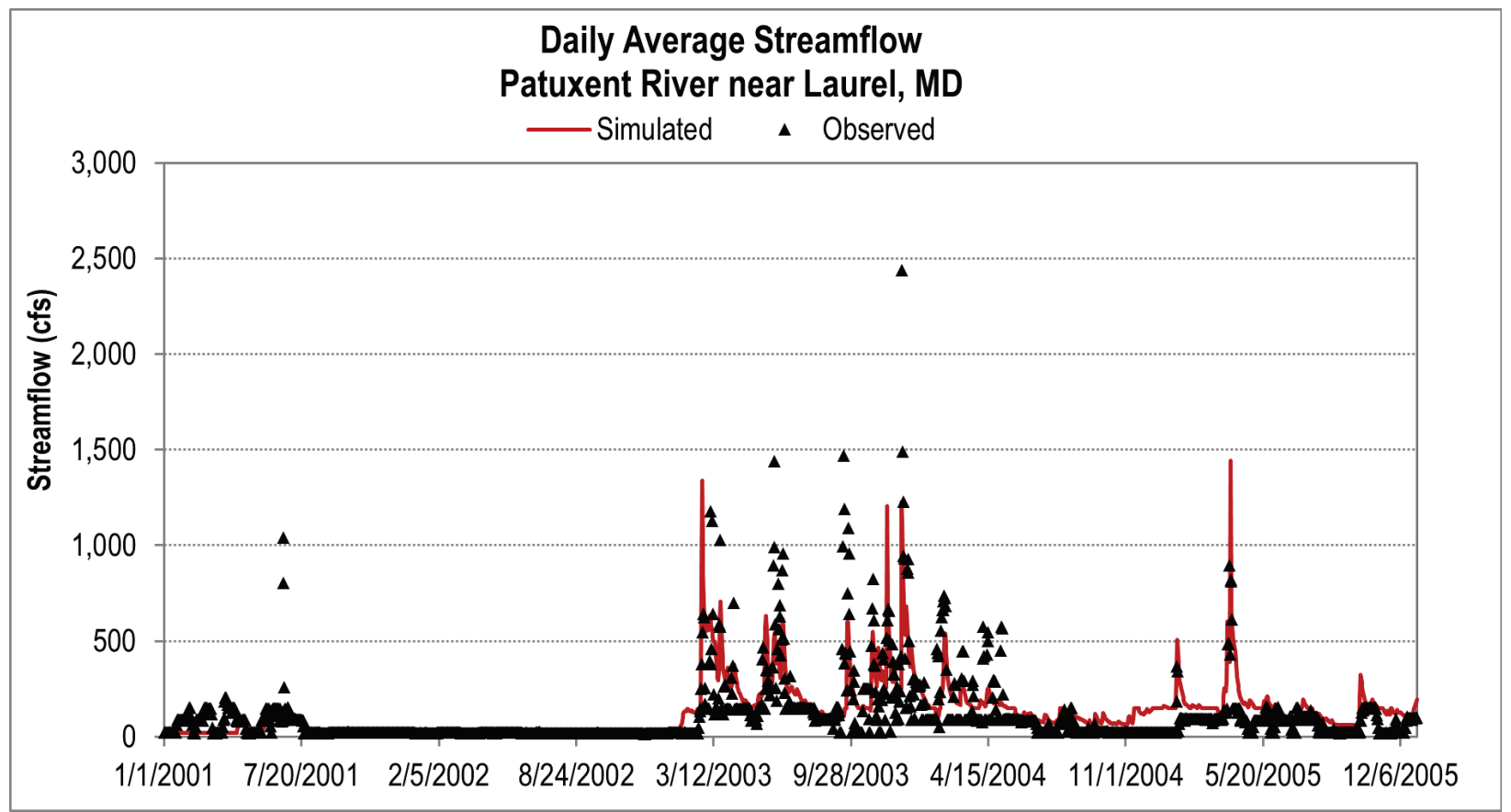

Figure D-12. Daily Average Streamflow Time Series for Patuxent River near Bowie, Maryland (Segment: XU3_4650_0001).

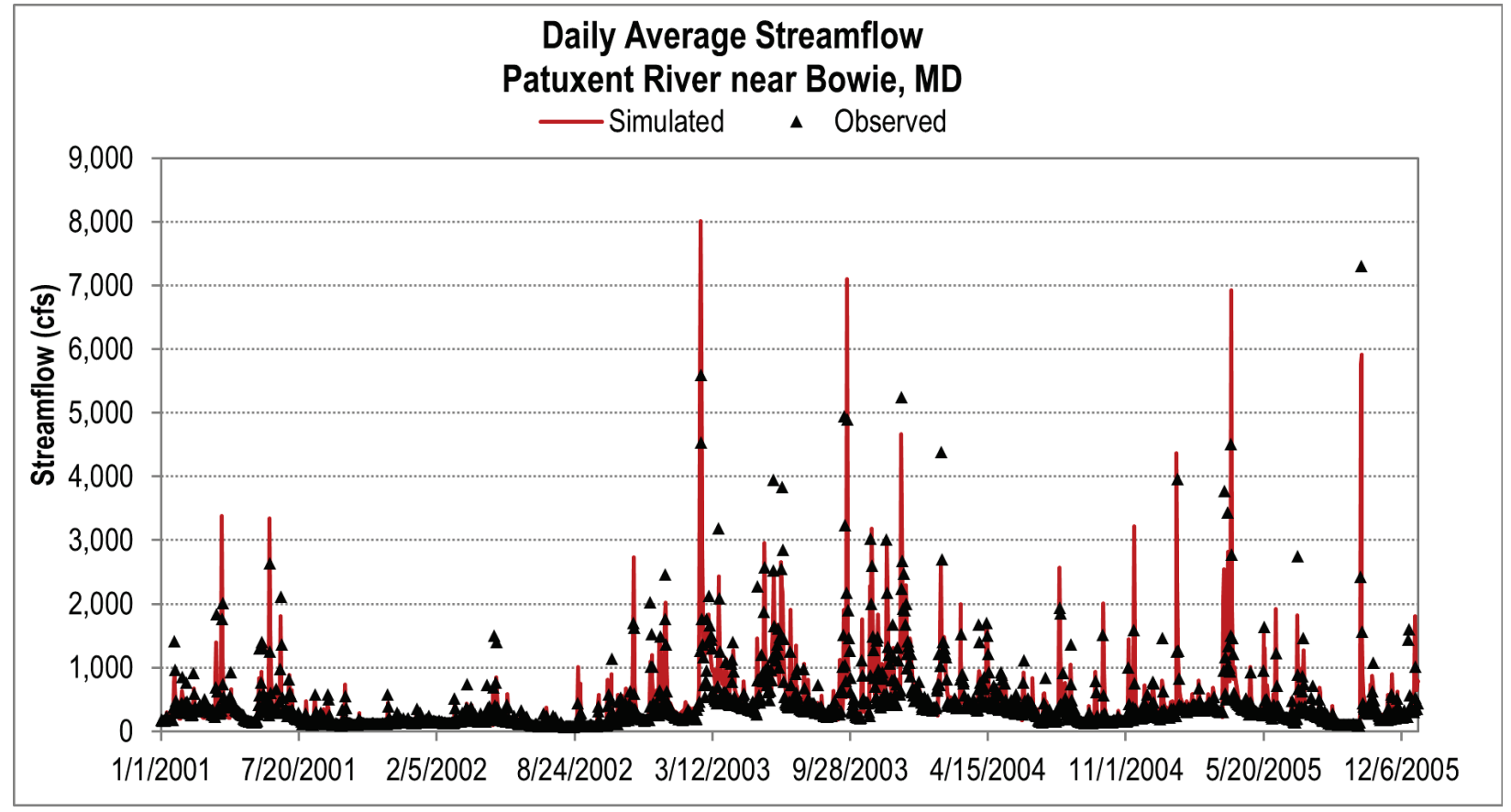


Figure D-13. Monthly average observed versus linked HSPF/HEC-RAS modeled streamflow near Bowie, Maryland for the validation period.

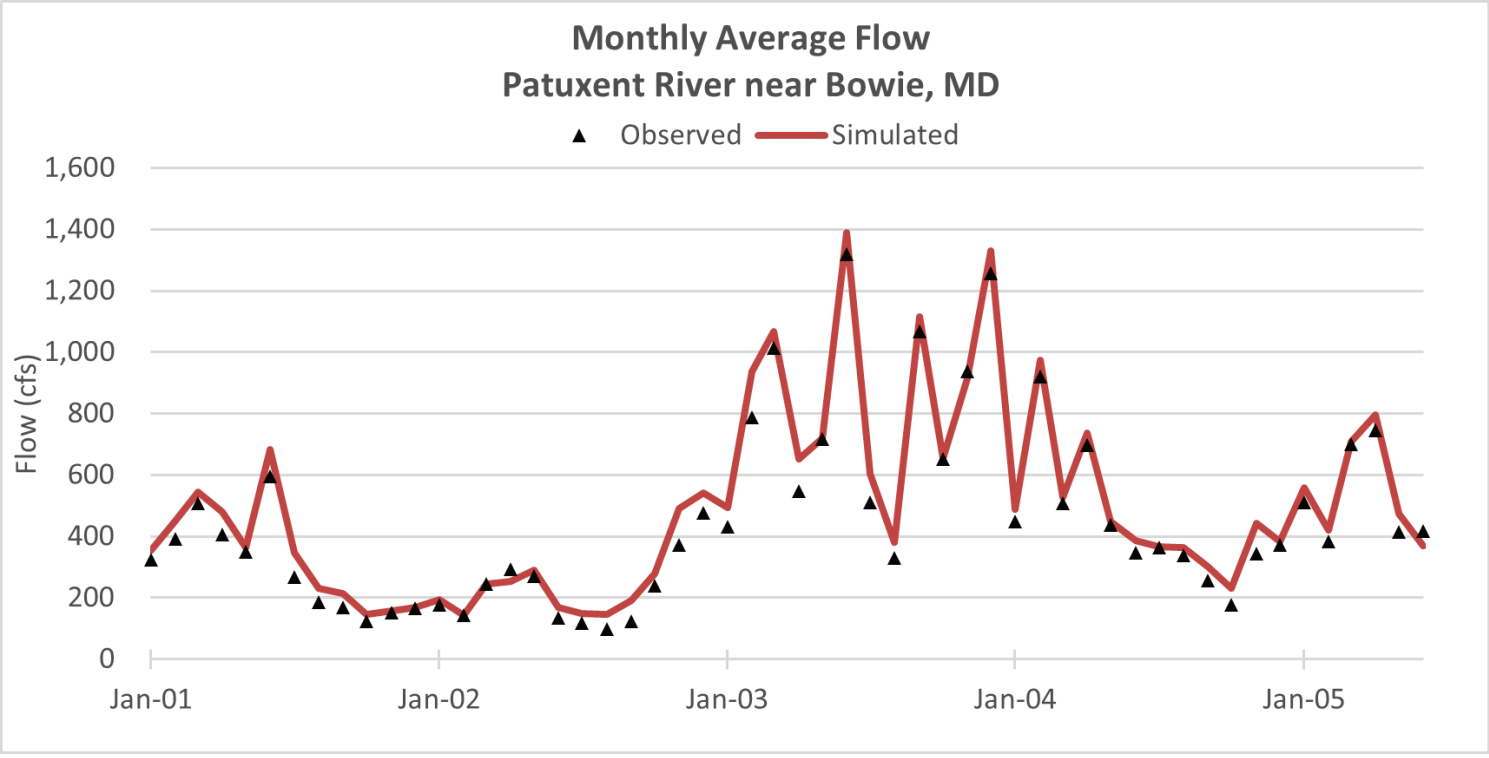

Figure D-14. Daily average observed versus linked HSPF/HEC-RAS modeled streamflow near Bowie, Maryland for the validation period.

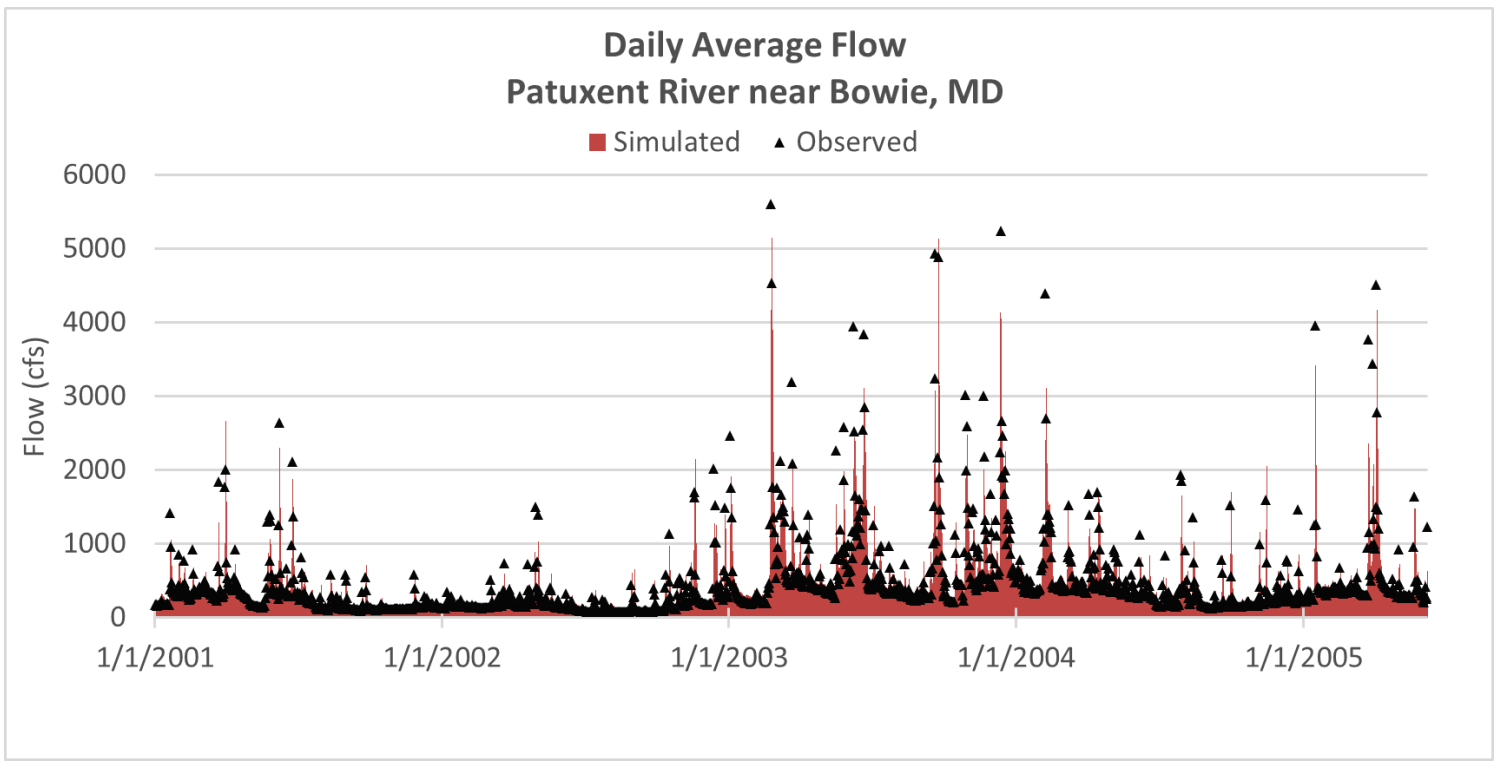


Figure D-15. Monthly Sediment Load Time Series for Patuxent River near Laurel, Maryland (Segment: XU2_4330_4480).

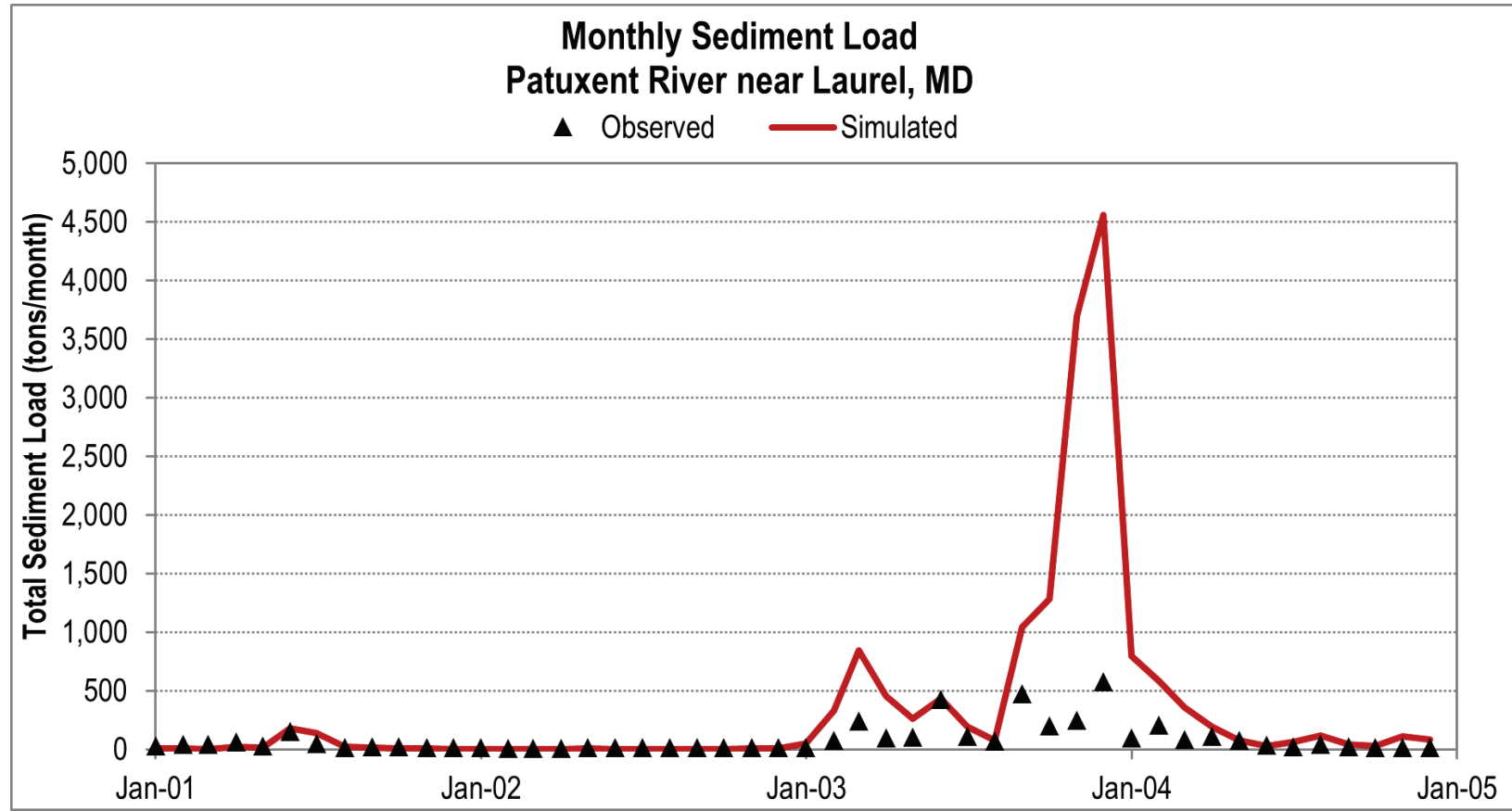

Figure D-16. Monthly Sediment Load Time Series for Patuxent River near Bowie, Maryland (Segment: XU3_4650_0001).

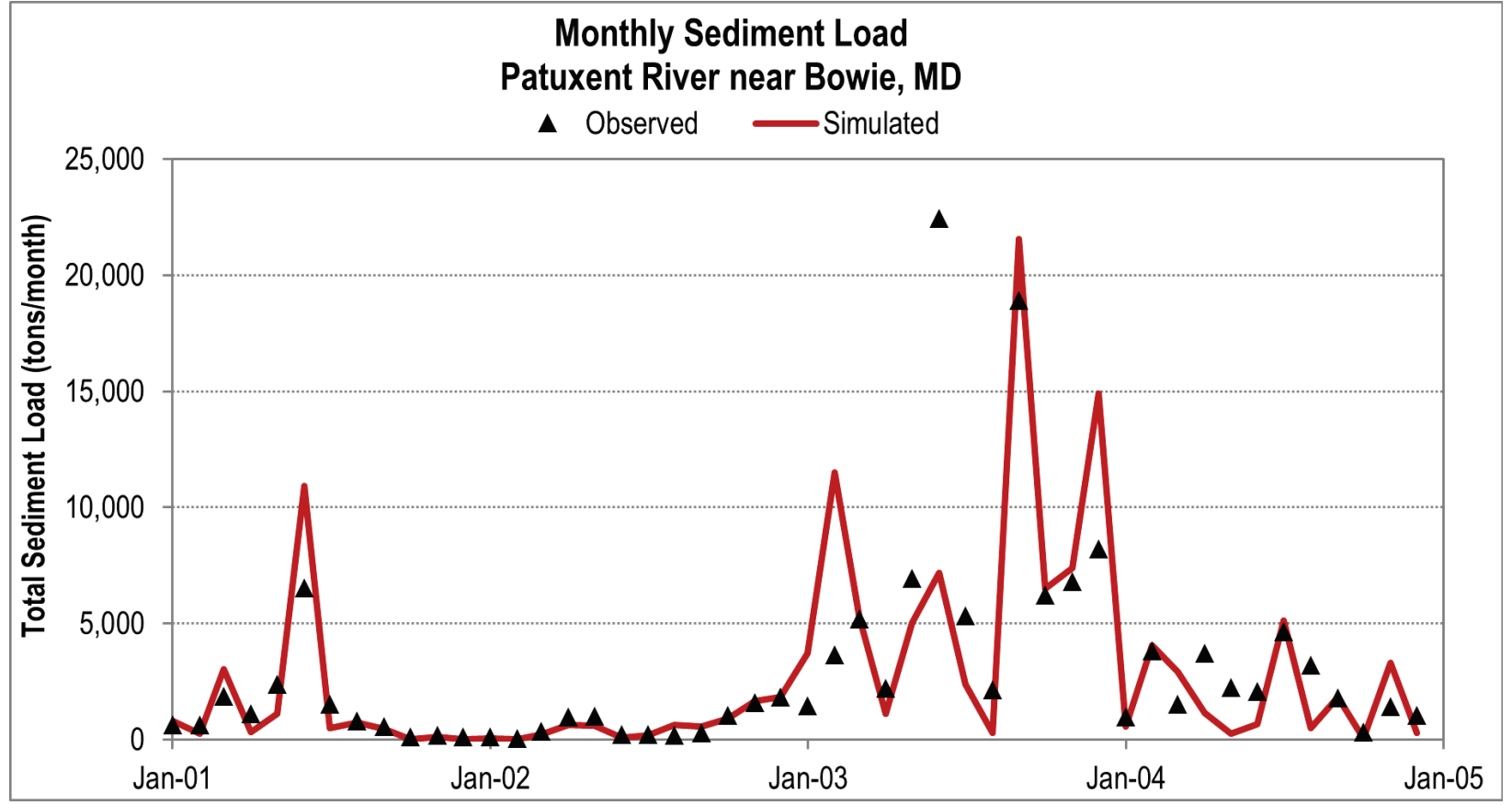


Figure D-17. Daily Sediment Load Time Series for Patuxent River near Laurel, Maryland (Segment: XU2_4330_4480).

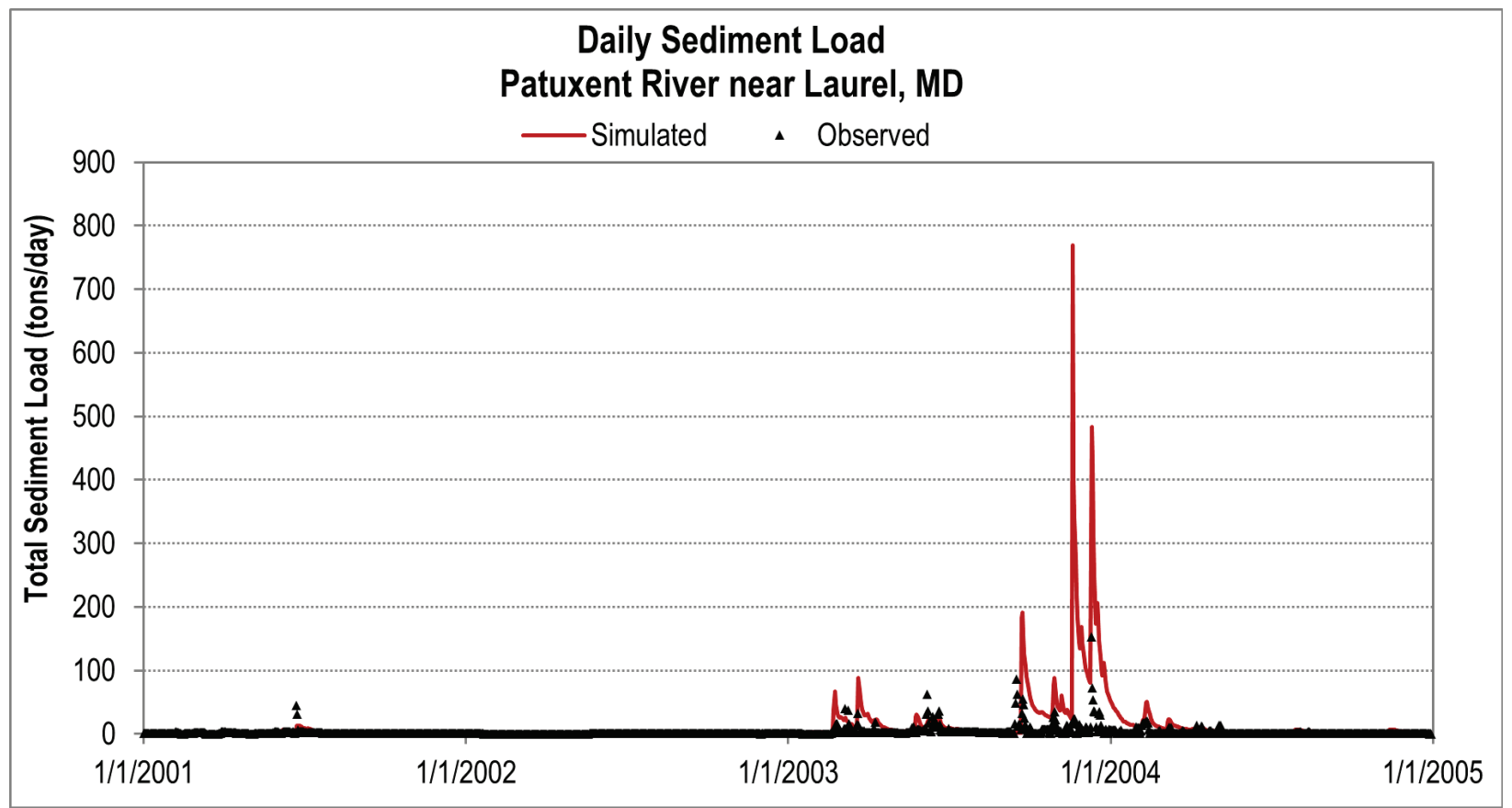

Figure D-18. Daily Sediment Load Time Series for Patuxent River near Bowie, Maryland (Segment: XU3_4650_0001).

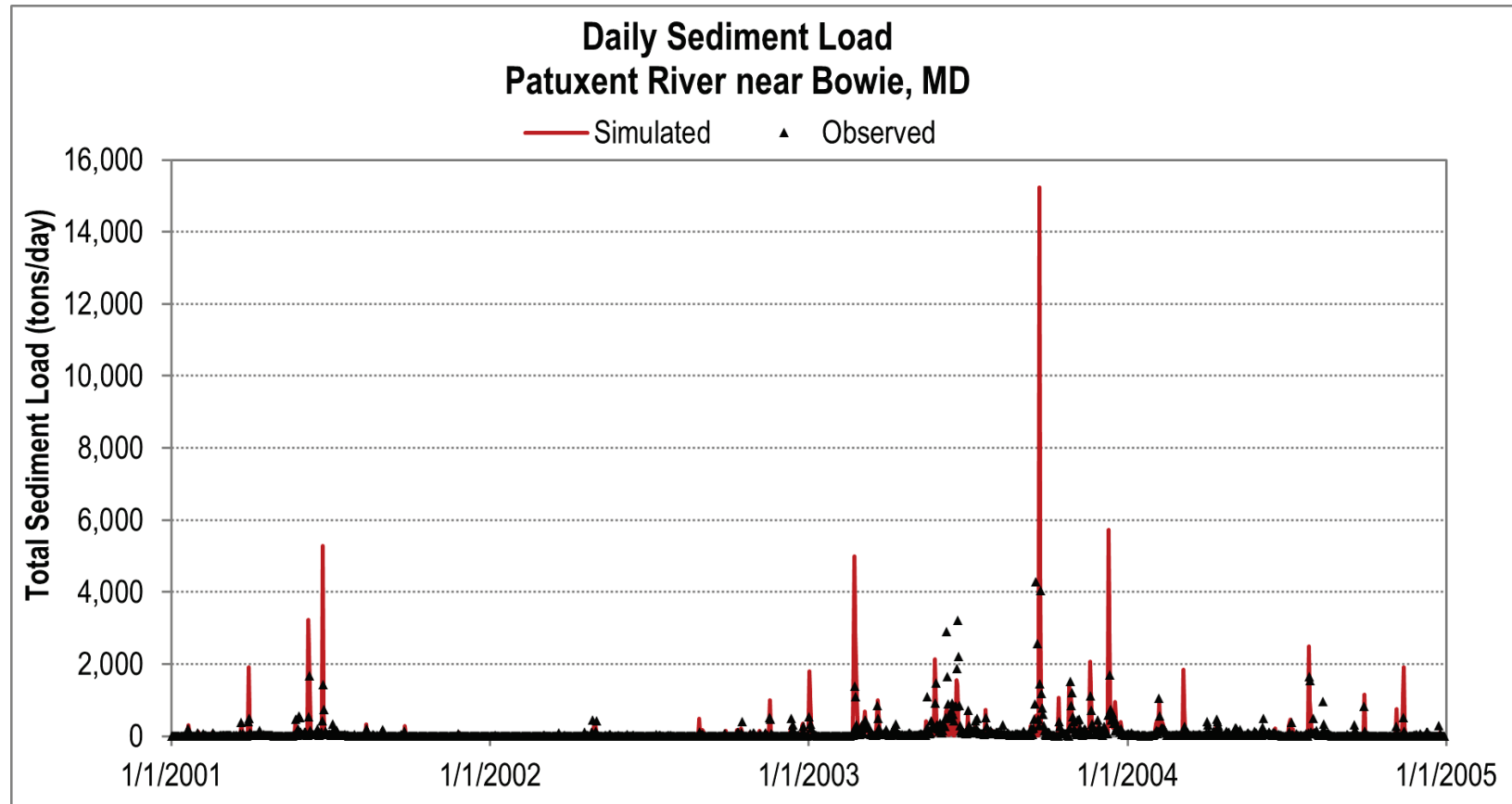


Figure D-19. Monthly average observed versus linked HSPF/HEC-RAS modeled suspended sediment concentration near Bowie, Maryland for the validation period.

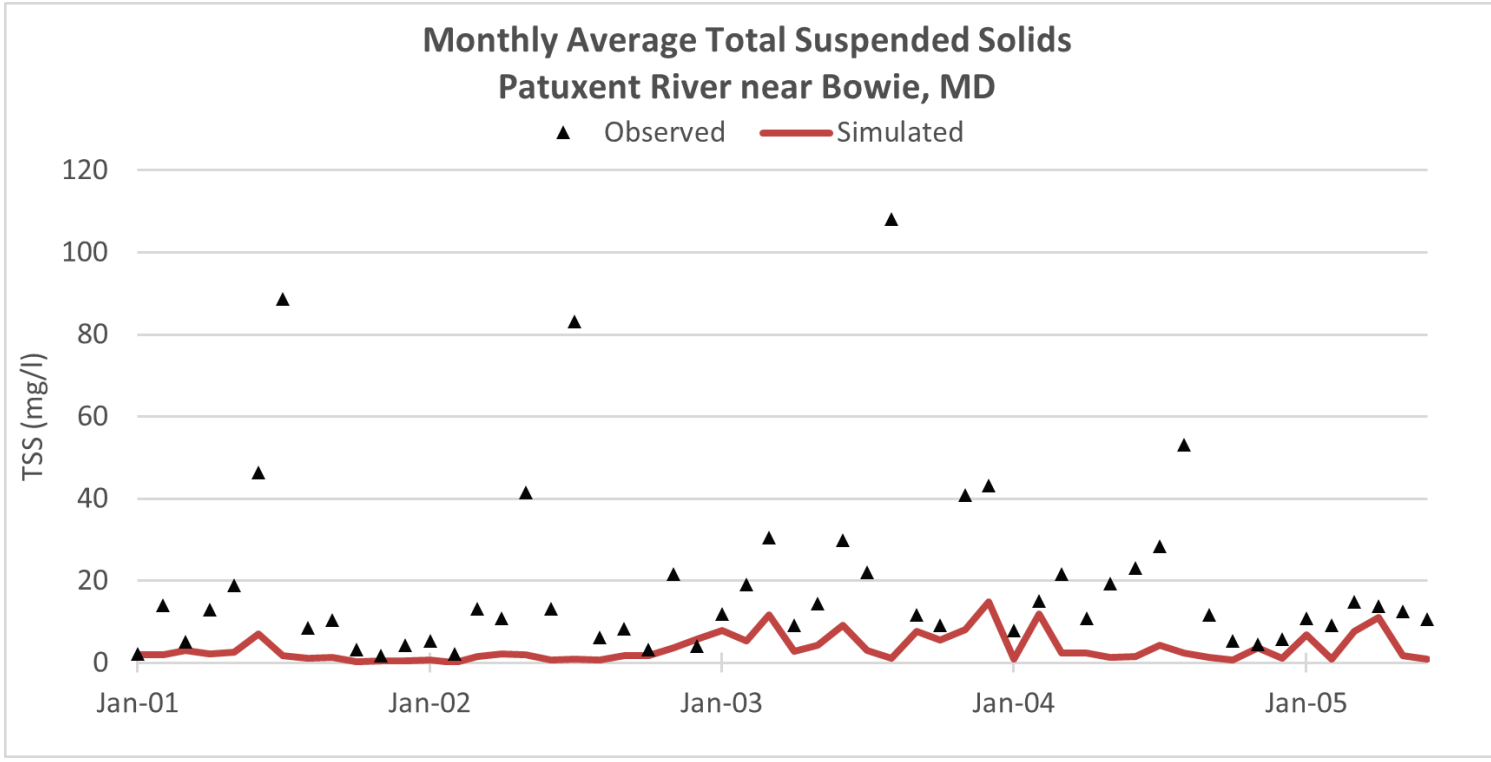

Figure D-20. Daily average observed versus linked HSPF/HEC-RAS modeled suspended sediment concentration near Bowie, Maryland for the validation period.

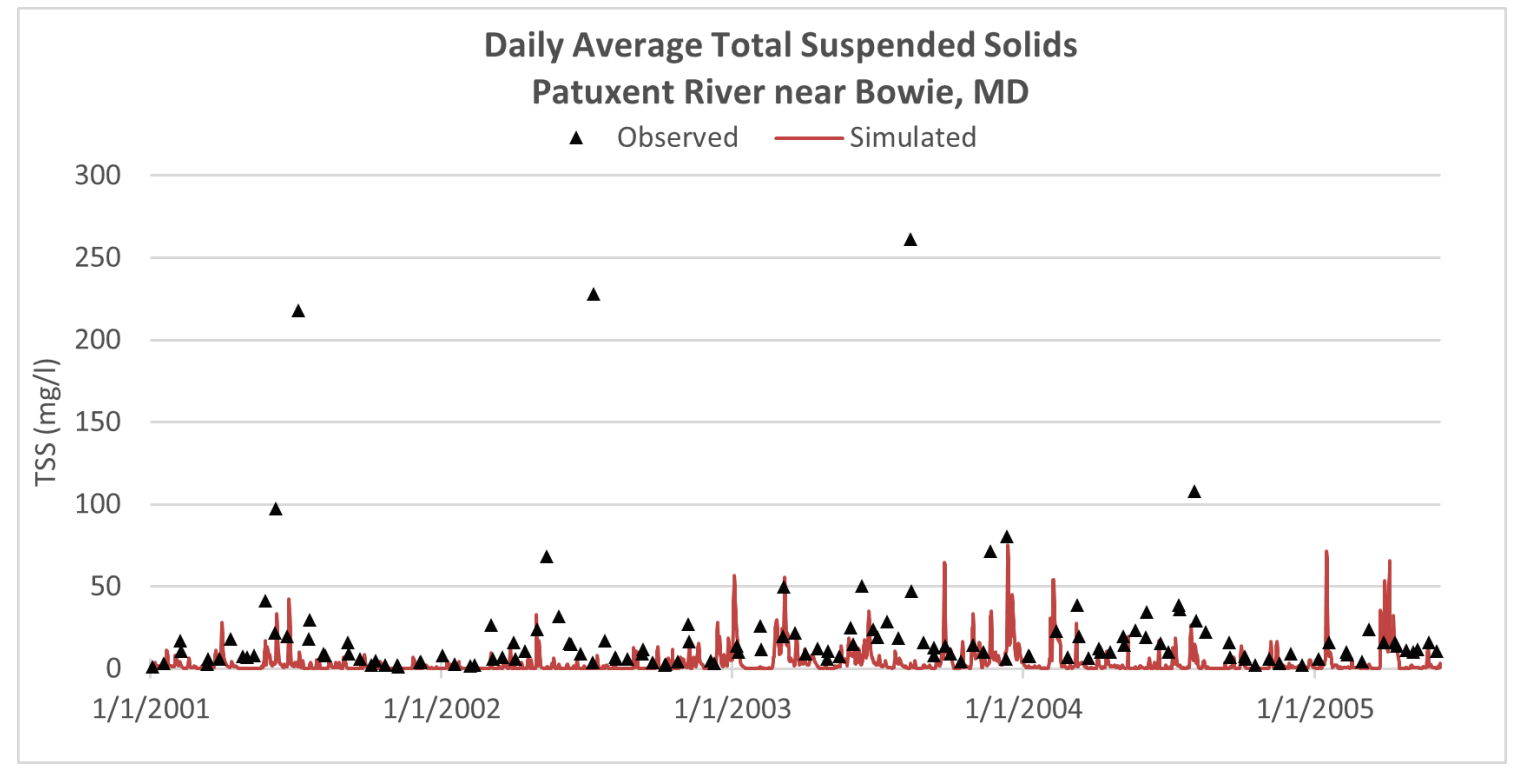


Figure D-21. Monthly Total Nitrogen Load Time Series for Patuxent River near Laurel, Maryland (Segment: XU2_4330_4480).

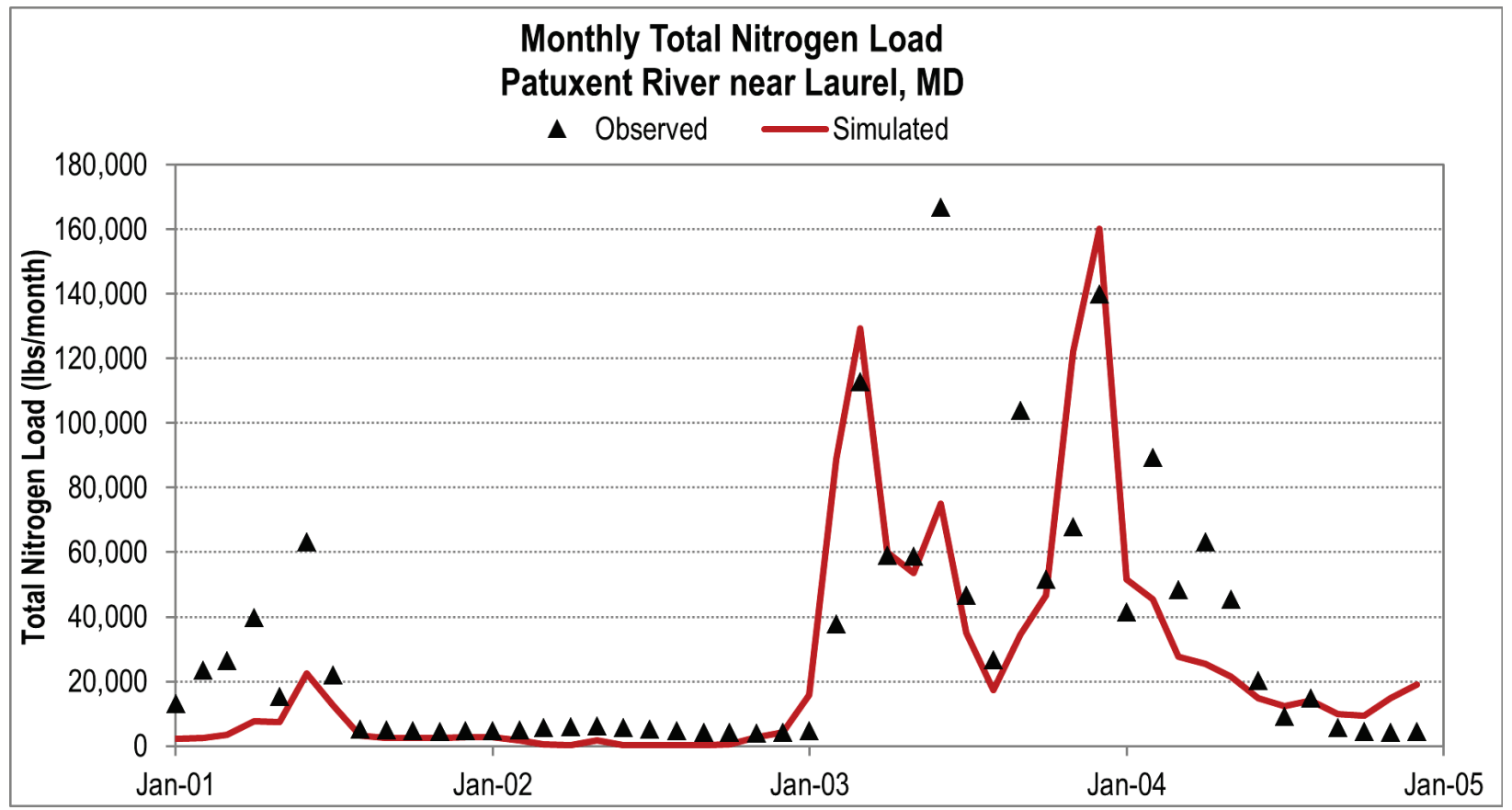

Figure D-22. Monthly Total Nitrogen Load Time Series for Patuxent River near Bowie, Maryland (Segment: XU3_4650_0001).

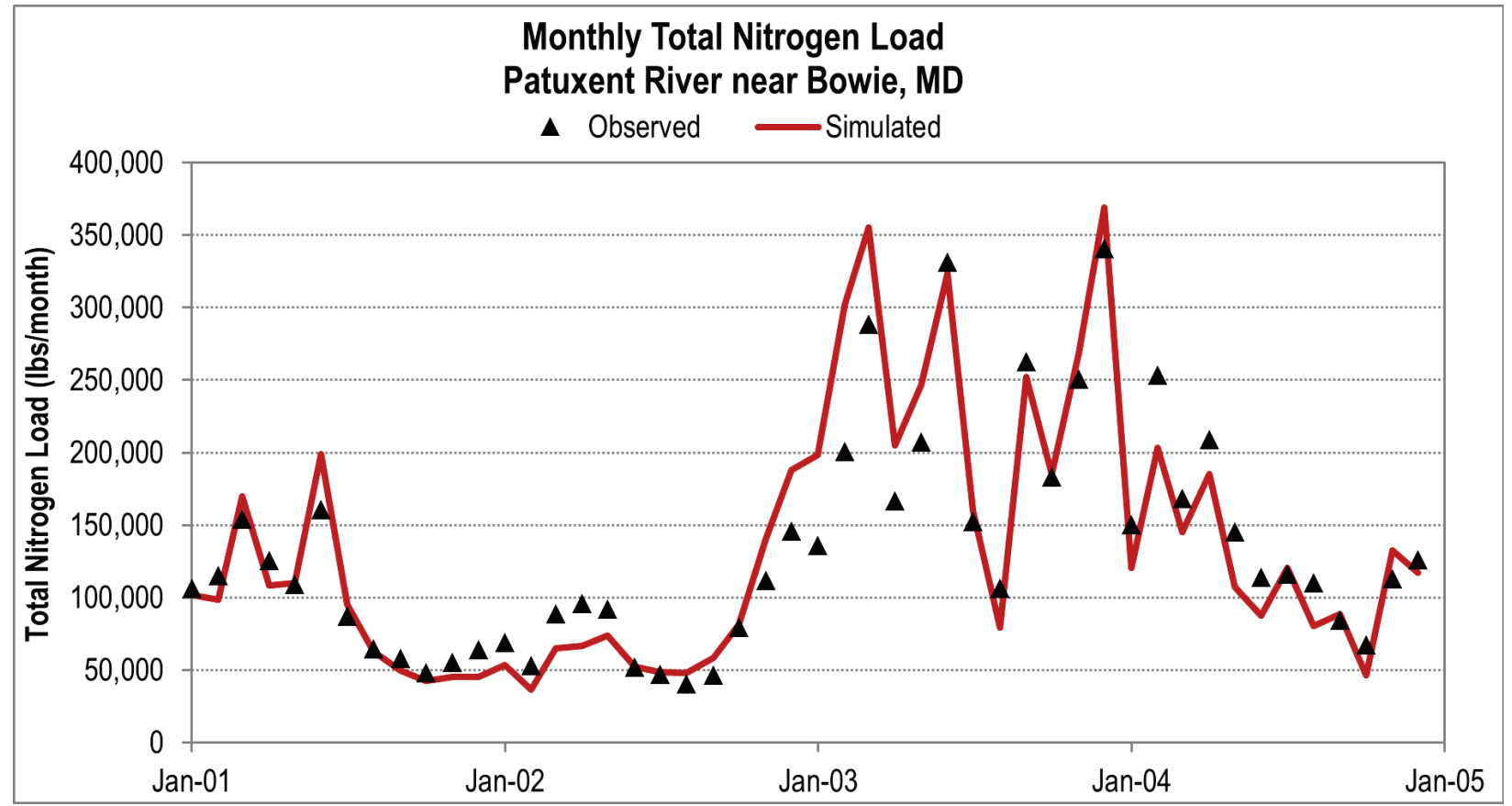


Figure D-23. Daily Total Nitrogen Load Time Series for Patuxent River near Laurel, Maryland (Segment: XU2_4330_4480).

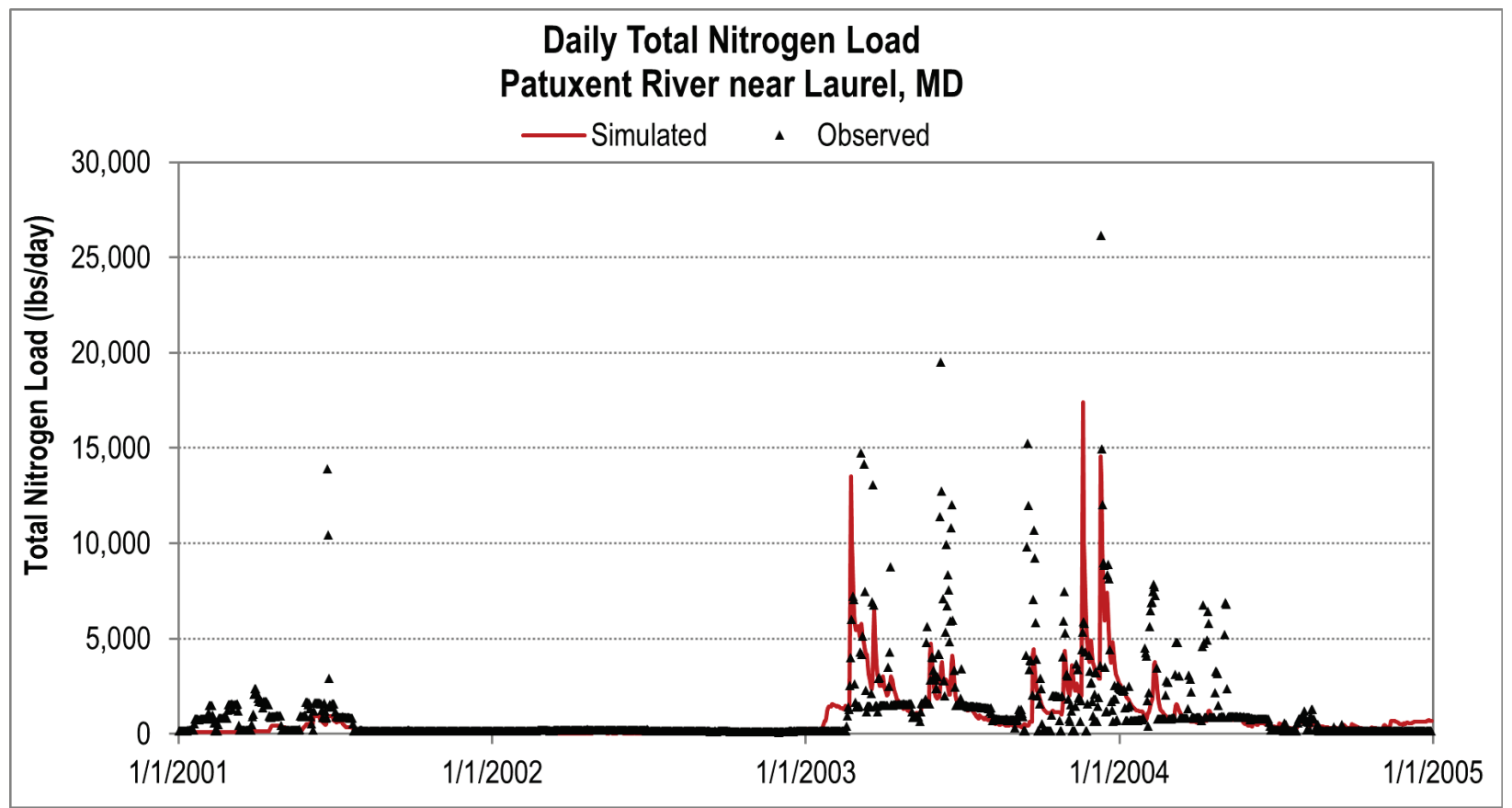

Figure D-24. Daily Total Nitrogen Load Time Series for Patuxent River near Bowie, Maryland (Segment: XU3_4650_0001).

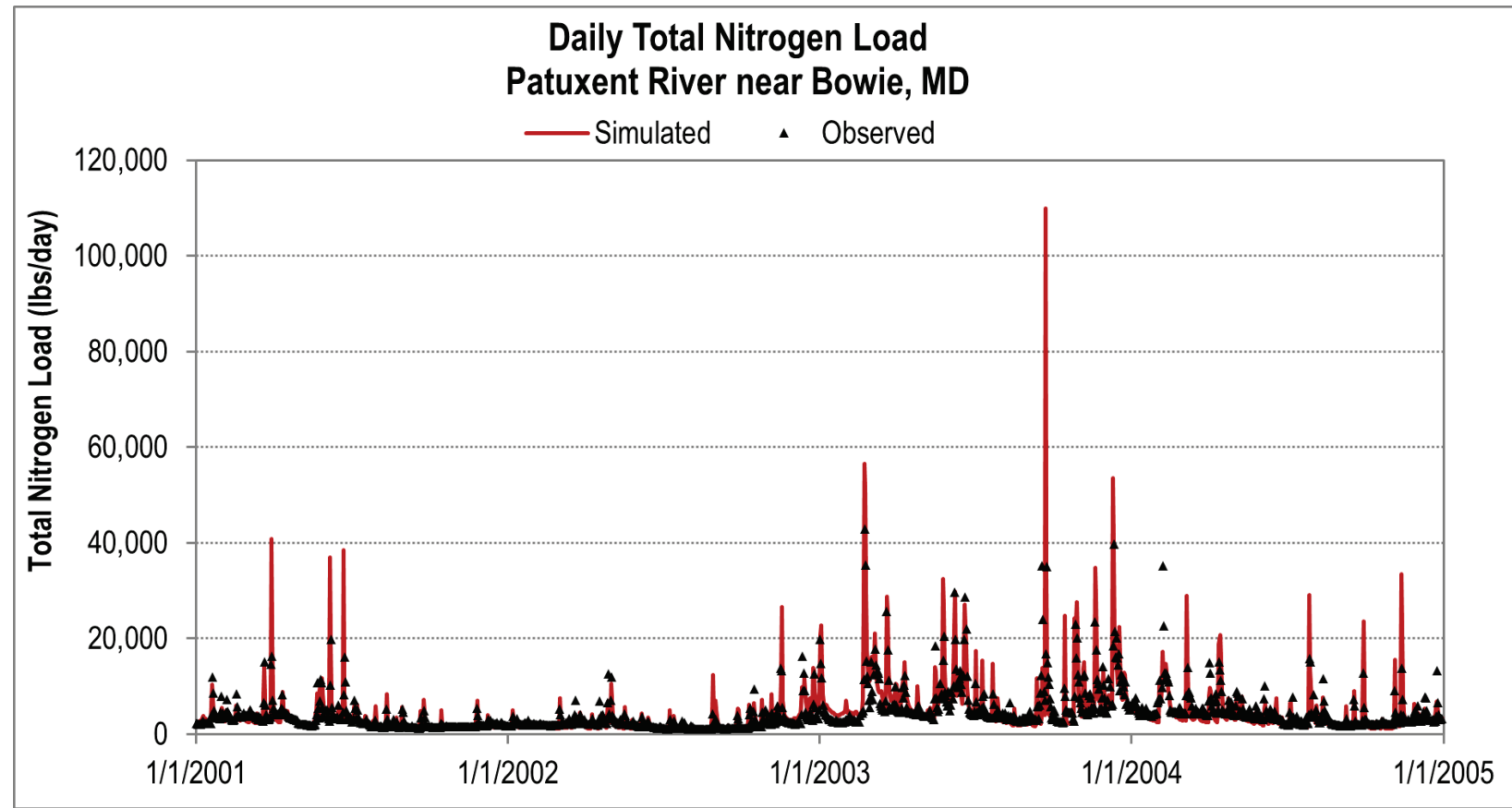


Figure D-25. Monthly Nitrate-Nitrogen Load Time Series for Patuxent River near Bowie, Maryland (Segment: XU3_4650_0001).

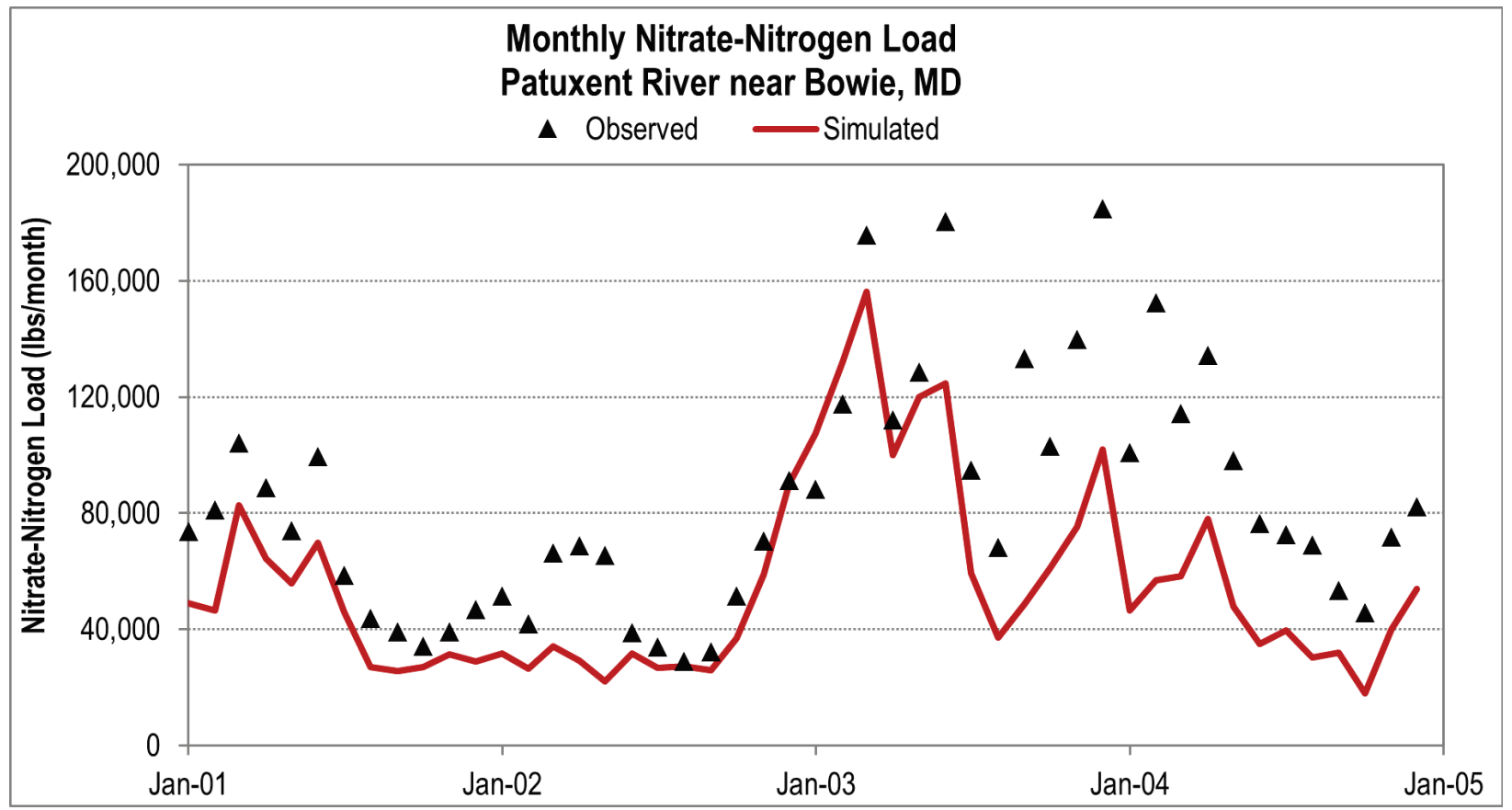

Figure D-26. Daily Nitrate-Nitrogen Load Time Series for Patuxent River near Bowie, Maryland (Segment: XU3_4650_0001).

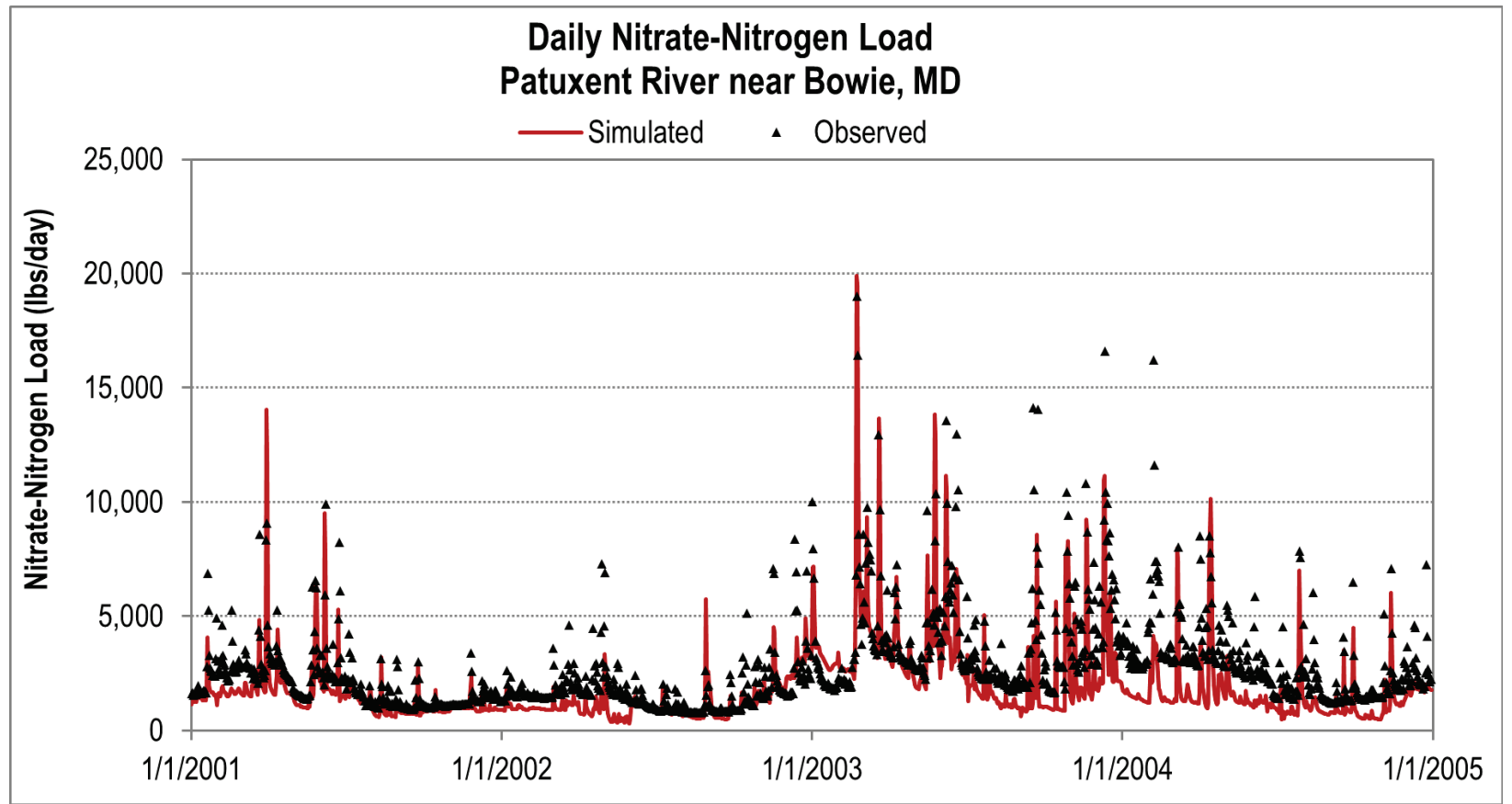


Figure D-27. Monthly Total Phosphorus Load Time Series for Patuxent River near Laurel, Maryland (Segment: XU2_4330_4480).

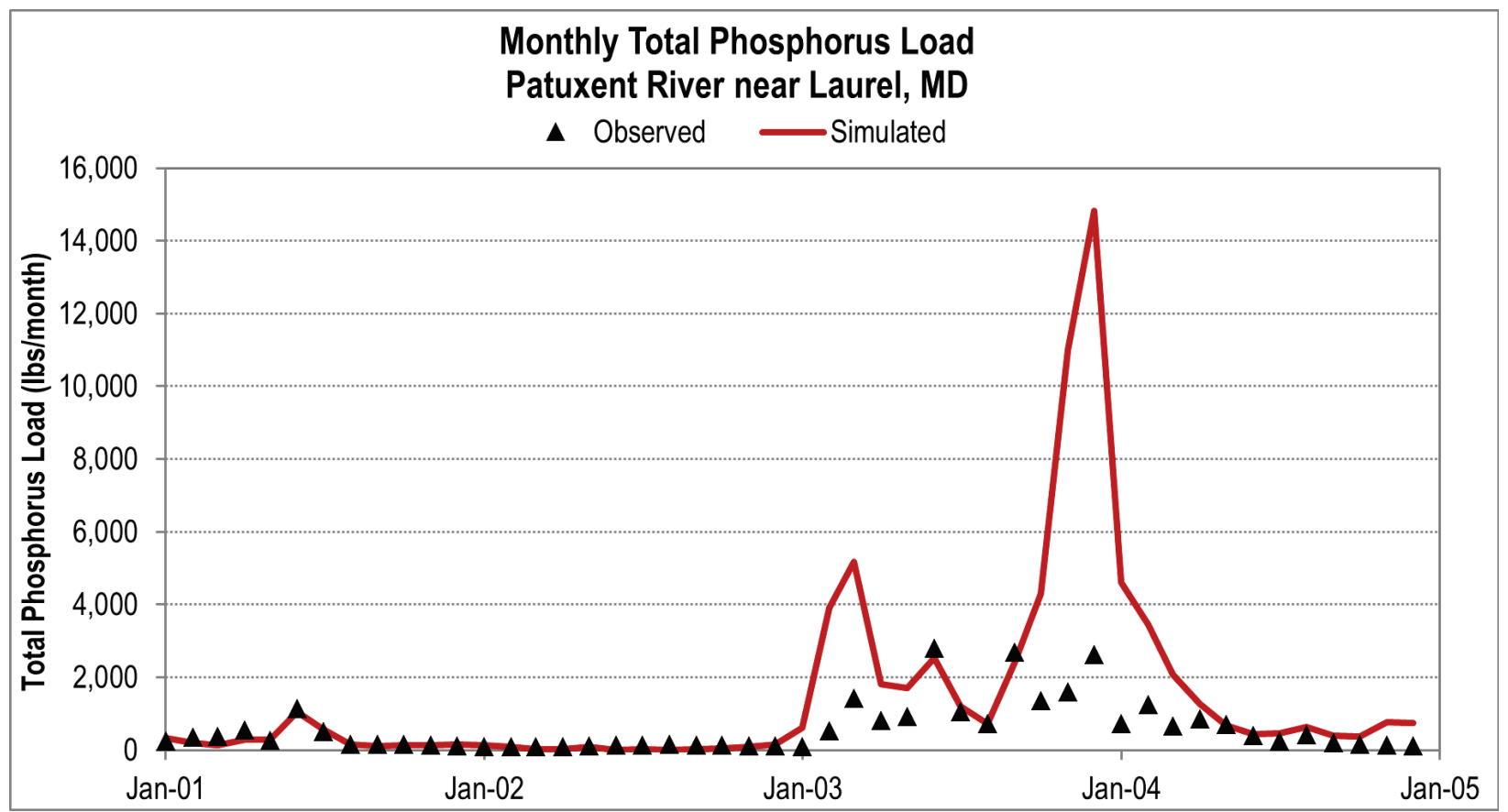

Figure D-28. Monthly Total Phosphorus Load Time Series for Patuxent River near Bowie, Maryland (Segment: XU3_4650_0001).

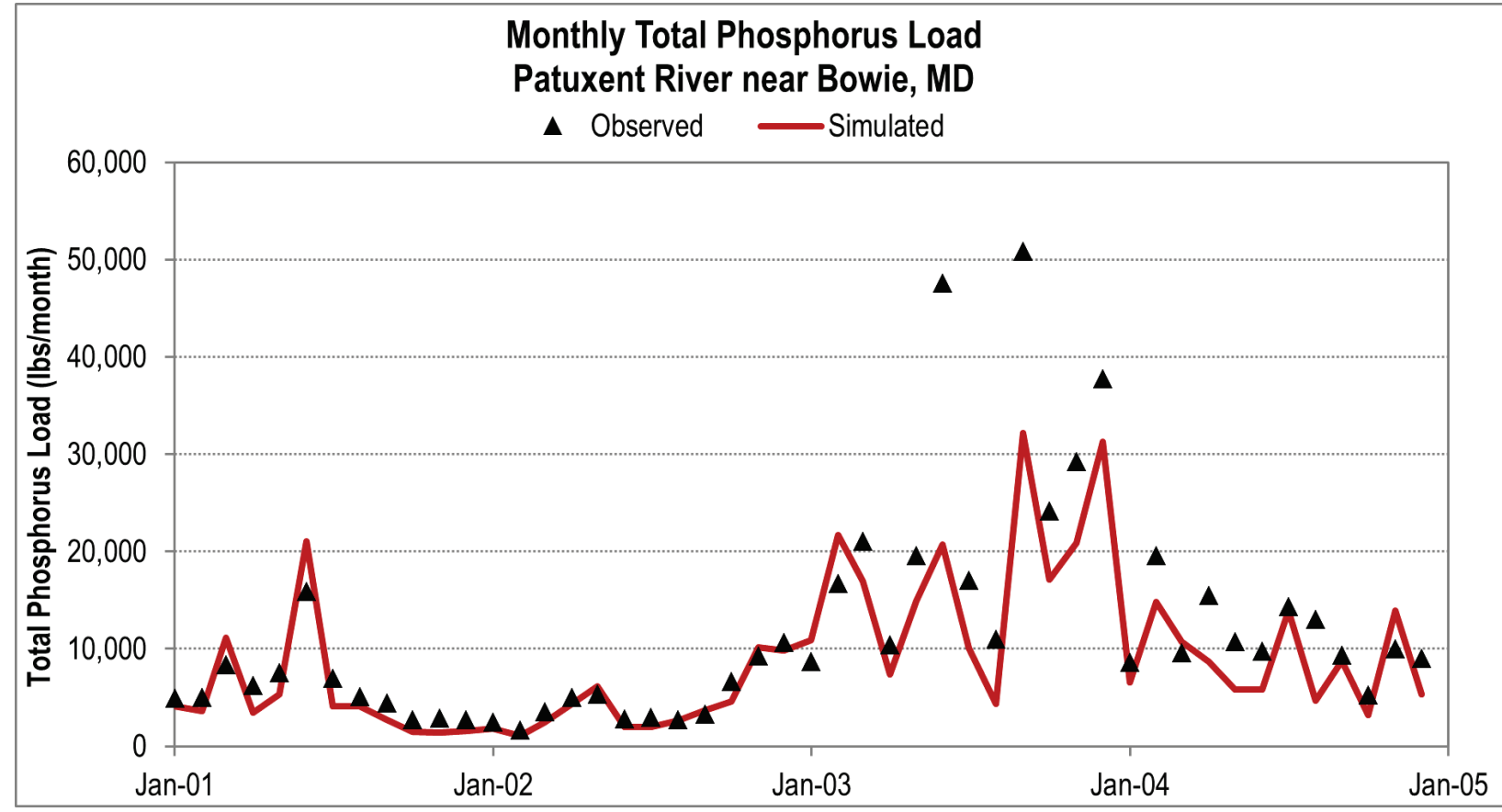


Figure D-29. Daily Total Phosphorus Load Time Series for Patuxent River near Laurel, Maryland (Segment: XU2_4330_4480).

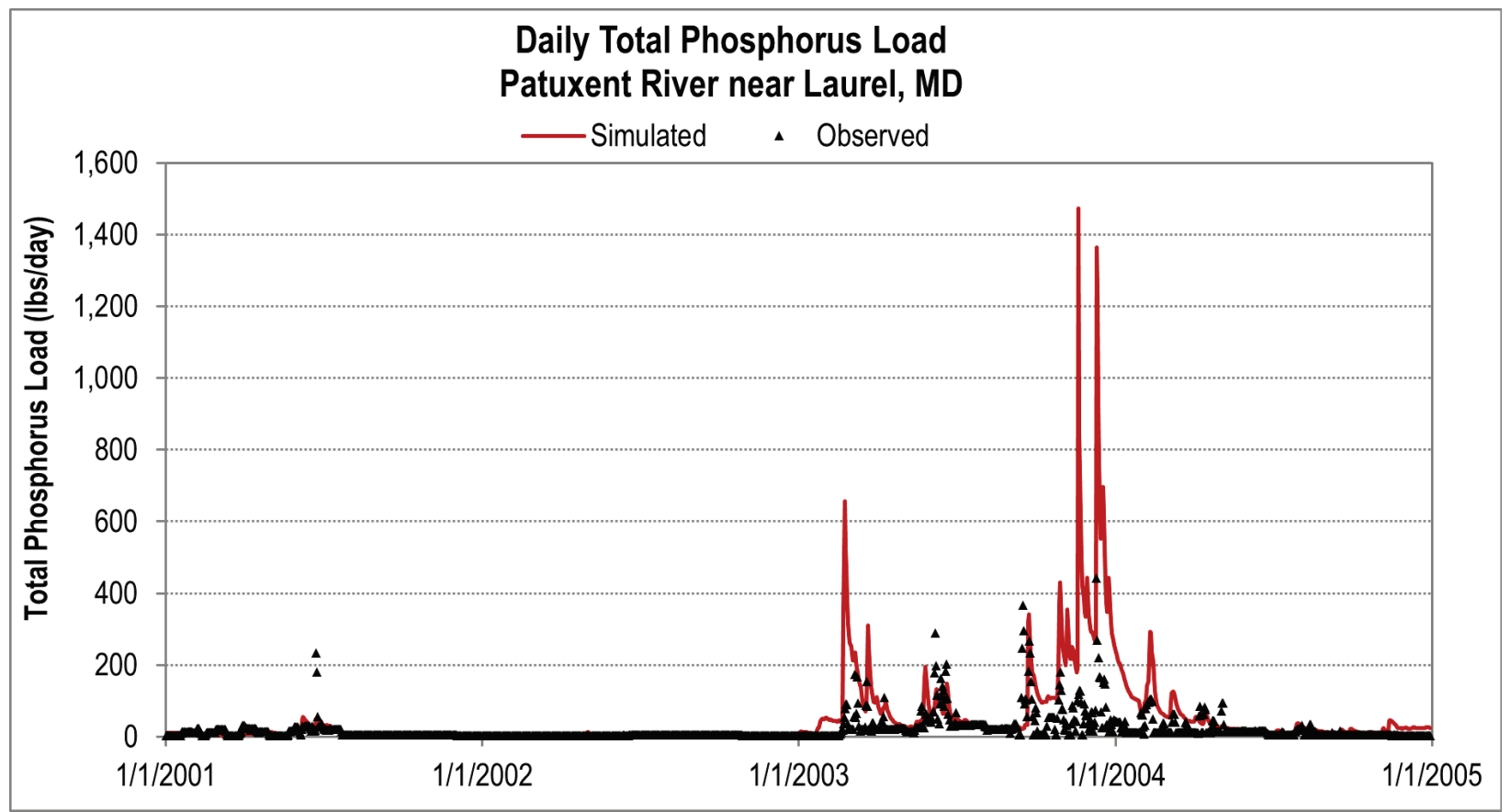

Figure D-30. Daily Total Phosphorus Load Time Series for Patuxent River near Bowie, Maryland (Segment: XU3_4650_0001).

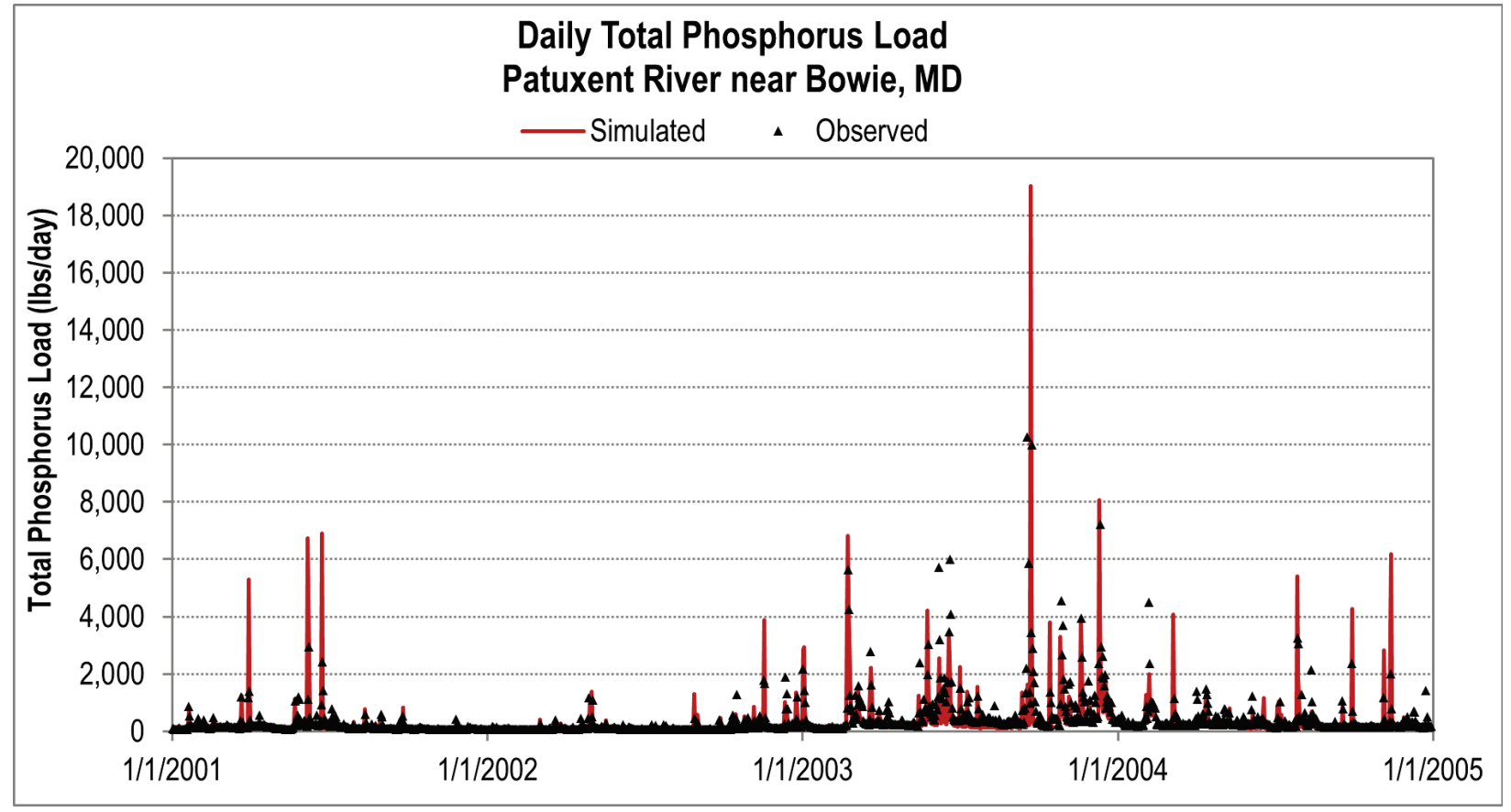


Figure D-31. Monthly Dissolved Phosphate Load Time Series for Patuxent River near Bowie, Maryland (Segment: XU3_4650_0001).

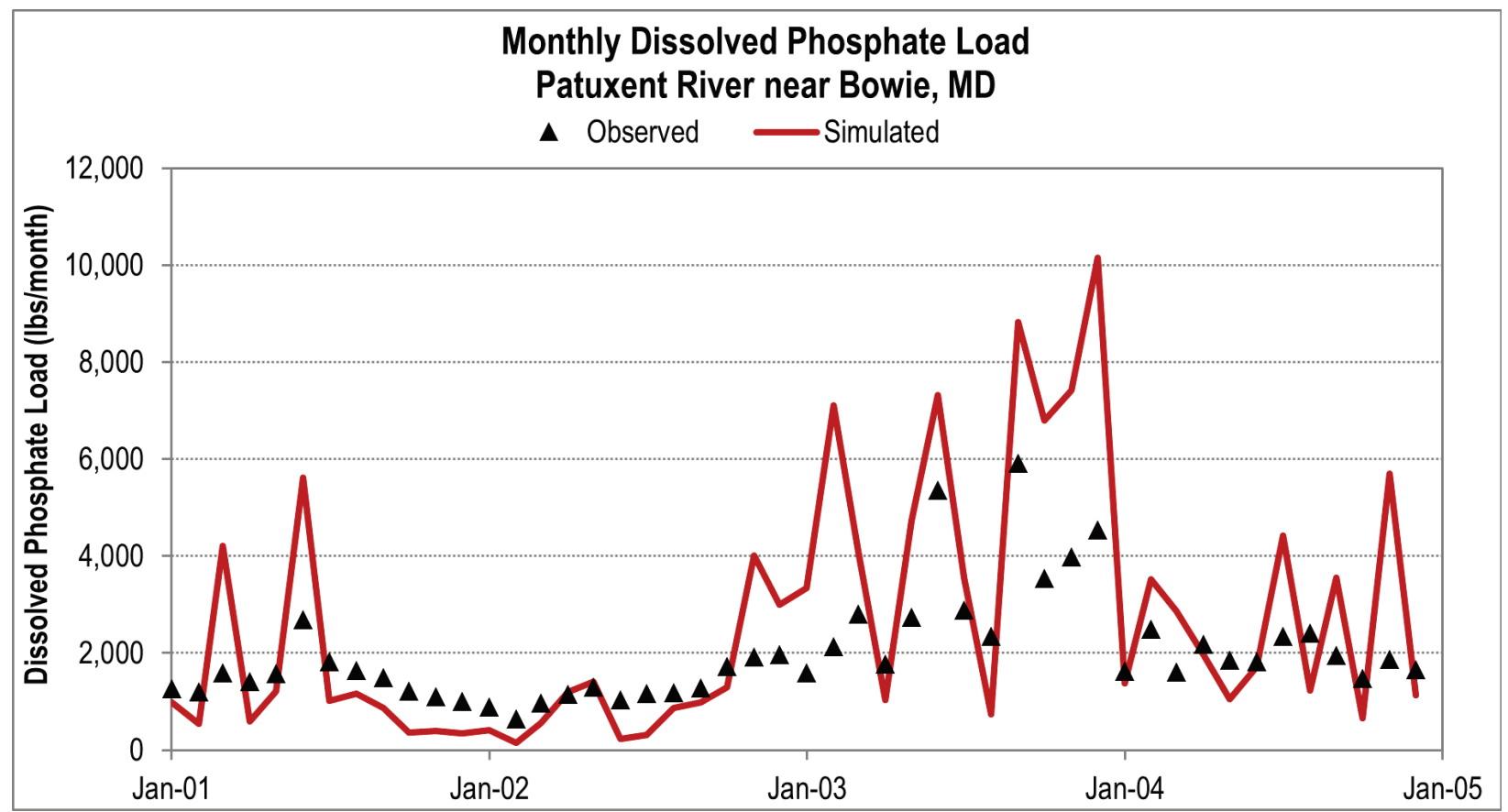

Figure D-32. Daily Dissolved Phosphate Load Time Series for Patuxent River near Bowie, Maryland (Segment: XU3_4650_0001).

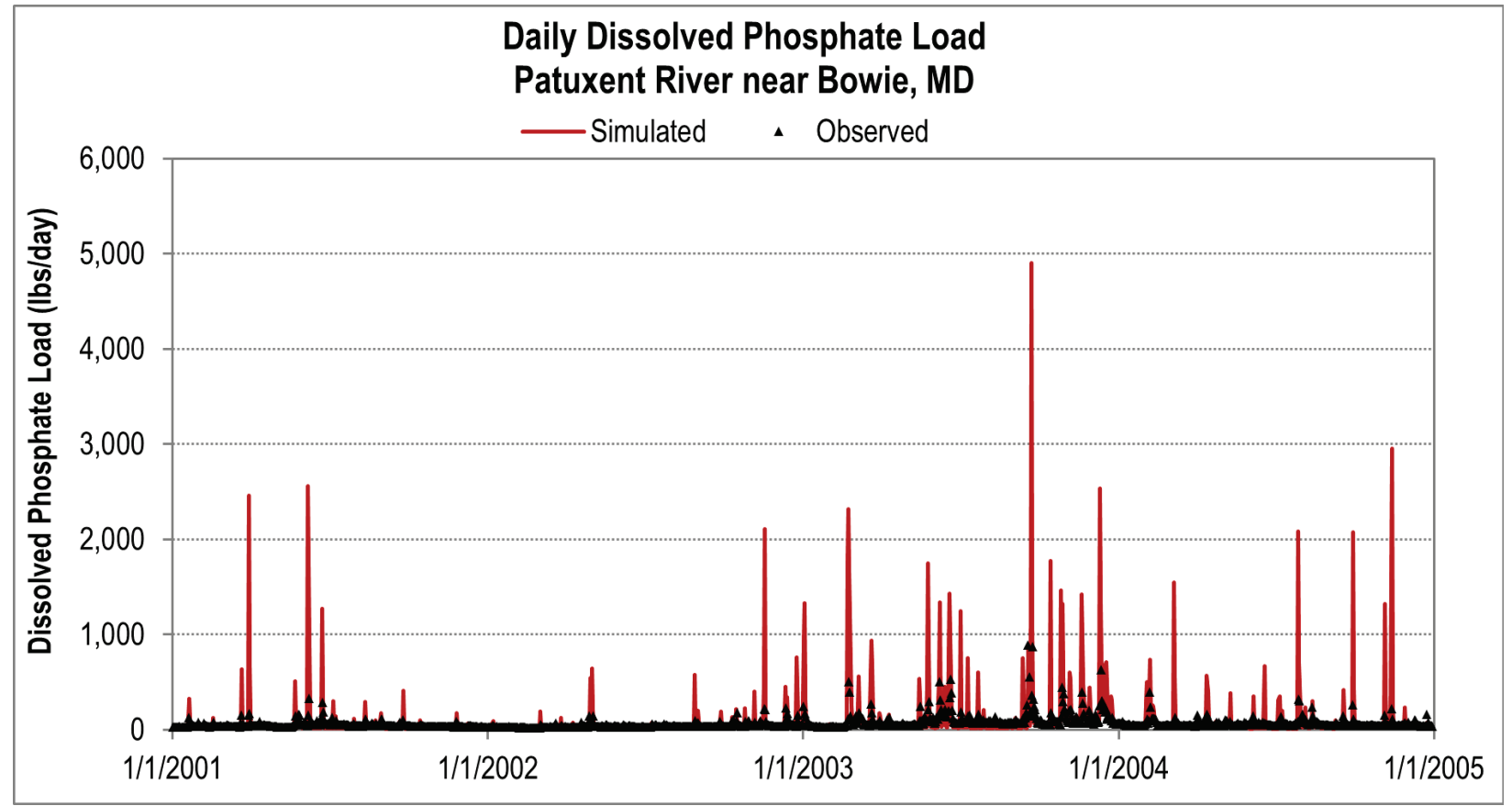


Figure D-33. Monthly average observed versus linked HSPF/HEC-RAS modeled algae concentration near Bowie, Maryland for the validation period.

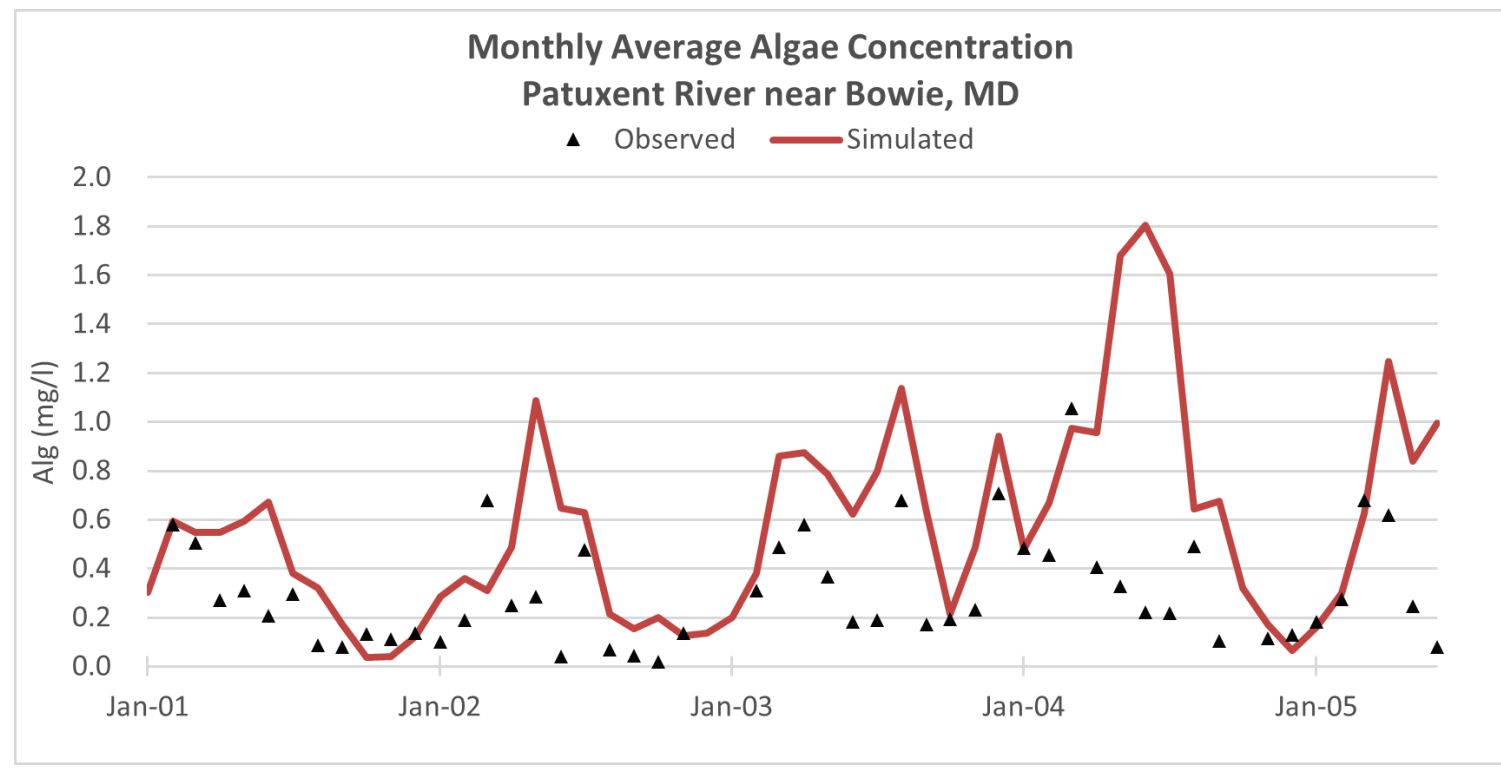

Figure D-34. Daily average observed versus linked HSPF/HEC-RAS modeled algae concentration near Bowie, Maryland for the validation period.

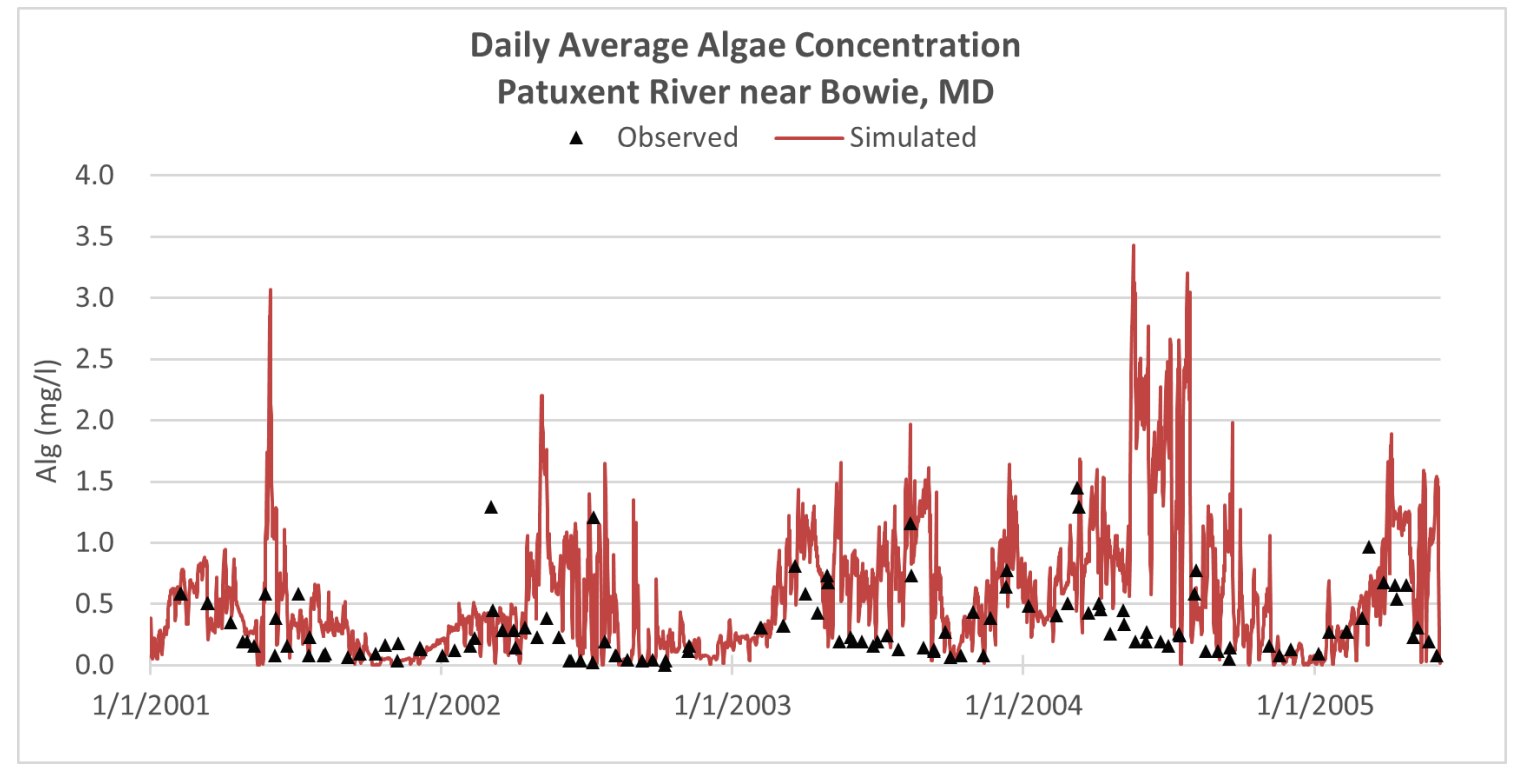


Figure D-35. Monthly average observed versus linked HSPF/HEC-RAS modeled dissolved oxygen concentration near Bowie, Maryland for the validation period.

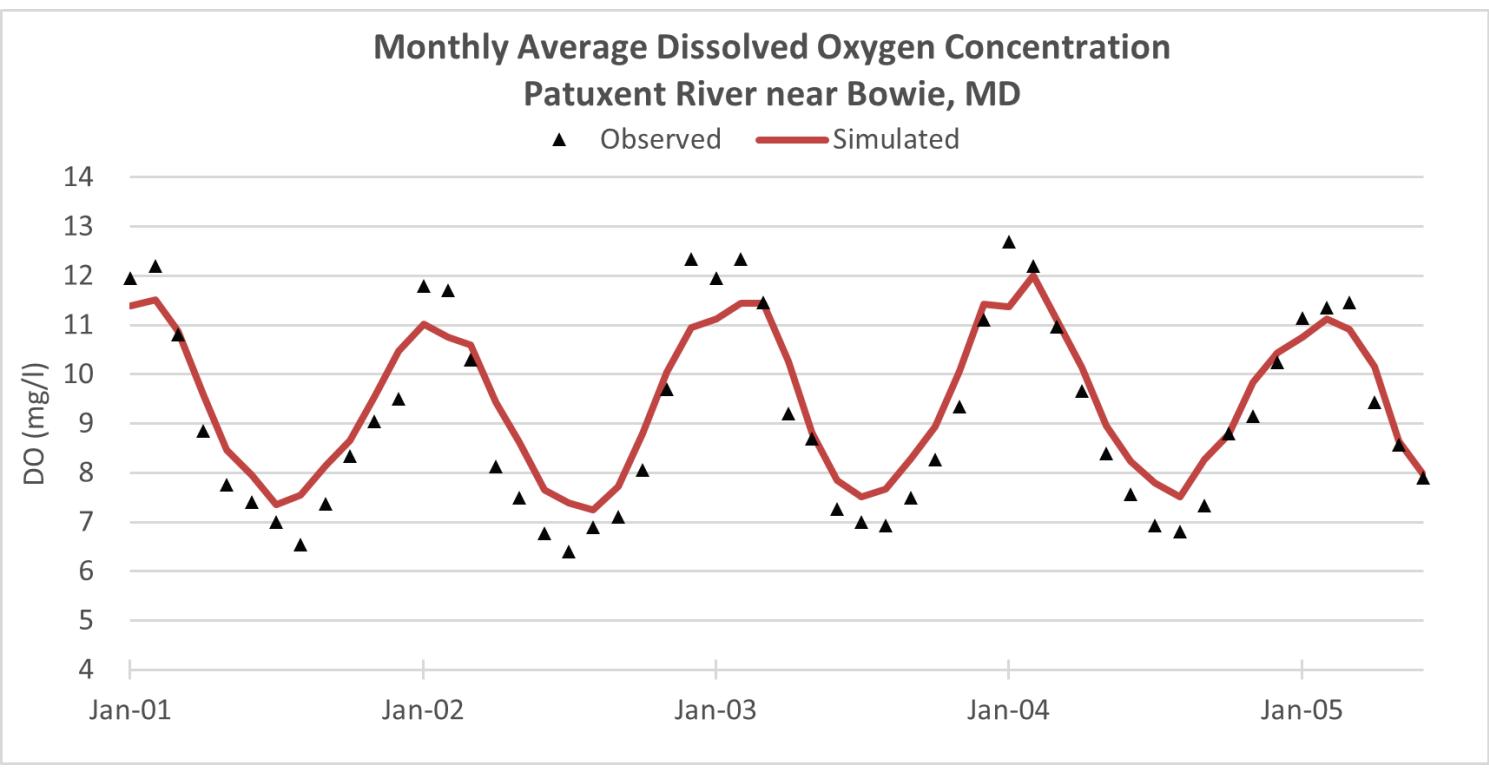

Figure D-36. Daily average observed versus linked HSPF/HEC-RAS modeled dissolved oxygen concentration near Bowie, Maryland for the validation period.

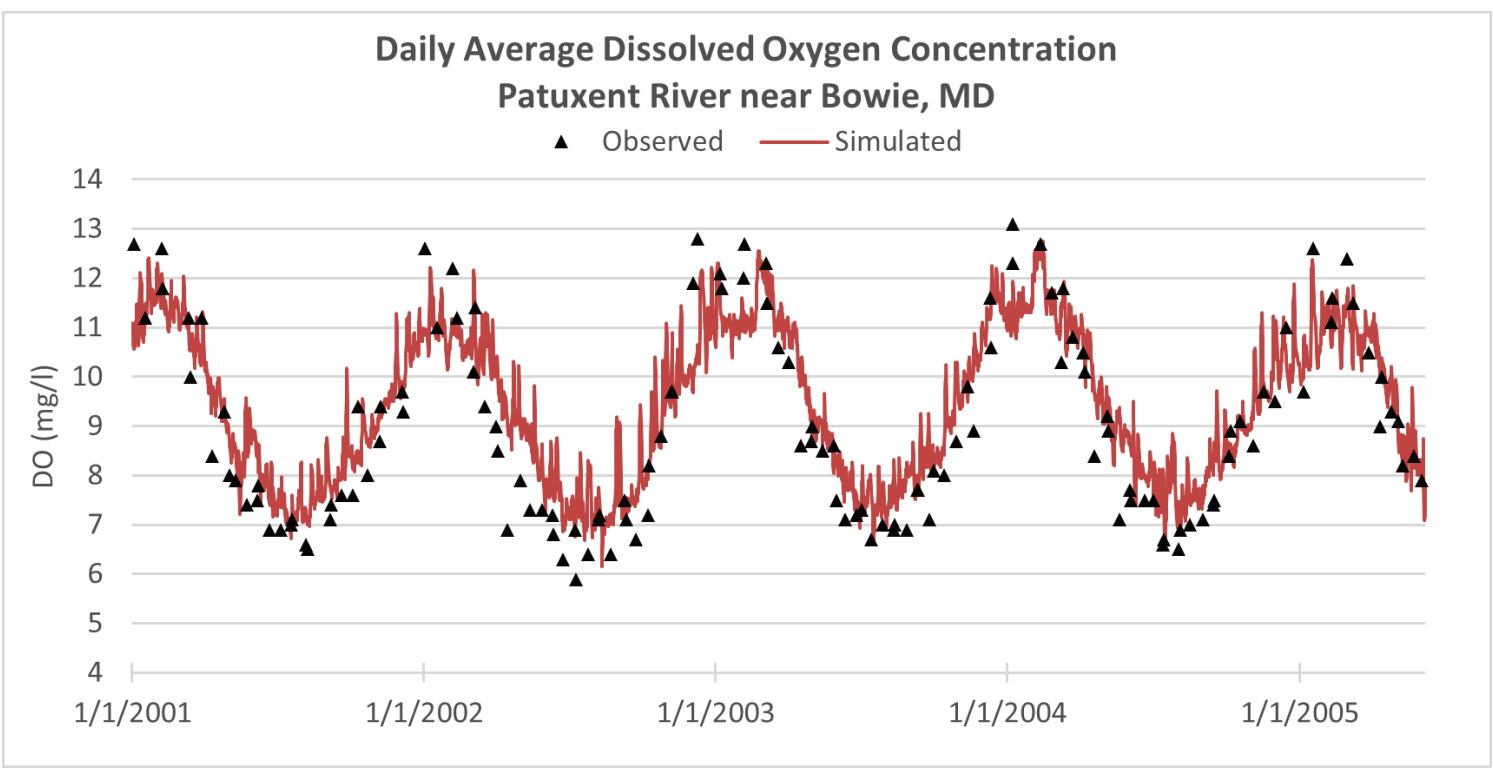


Figure D-37. Monthly average observed versus linked HSPF/HEC-RAS modeled organic nitrogen concentration near Bowie, Maryland for the validation period.

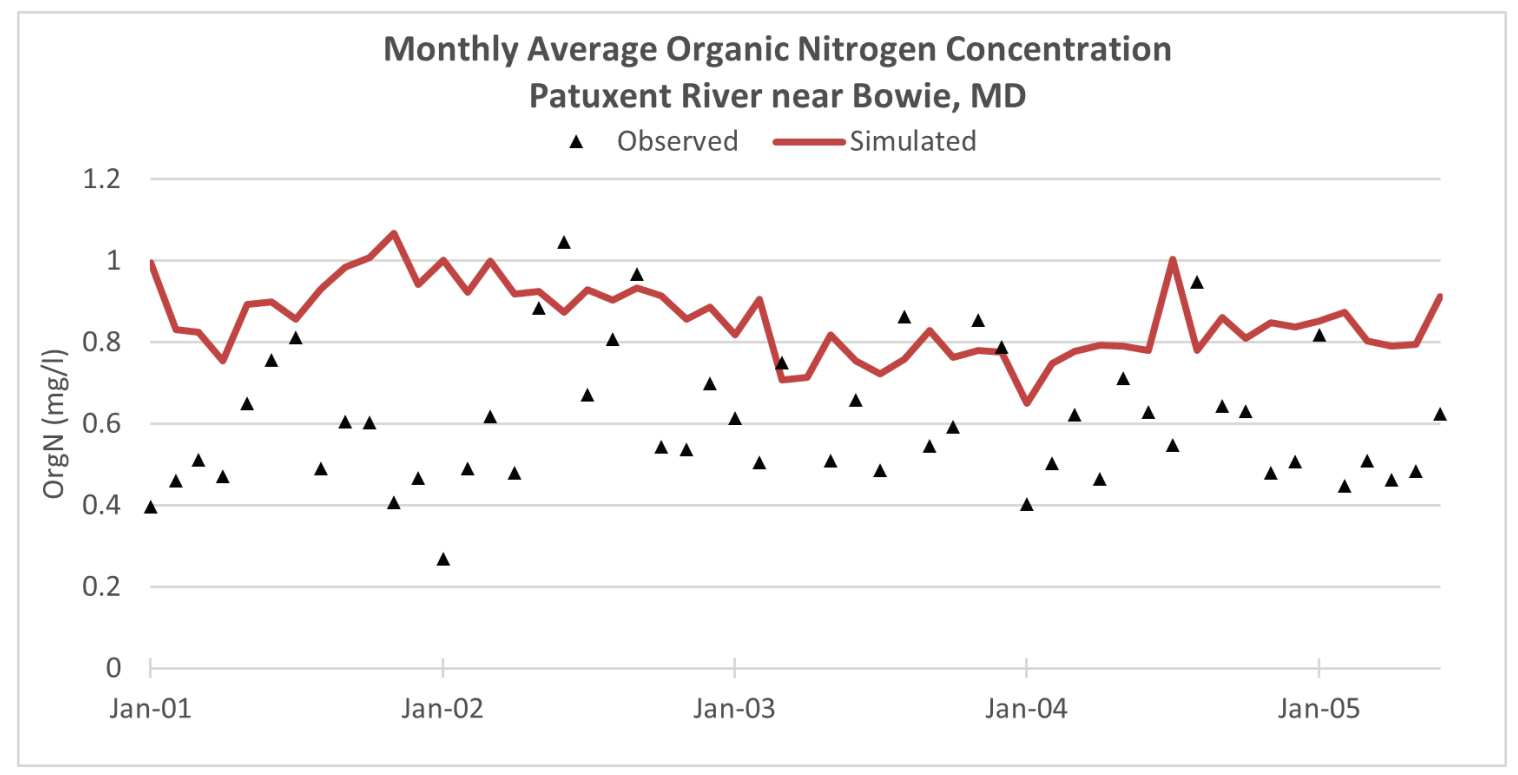

Figure D-38. Daily average observed versus linked HSPF/HEC-RAS modeled organic nitrogen concentration near Bowie, Maryland for the validation period.

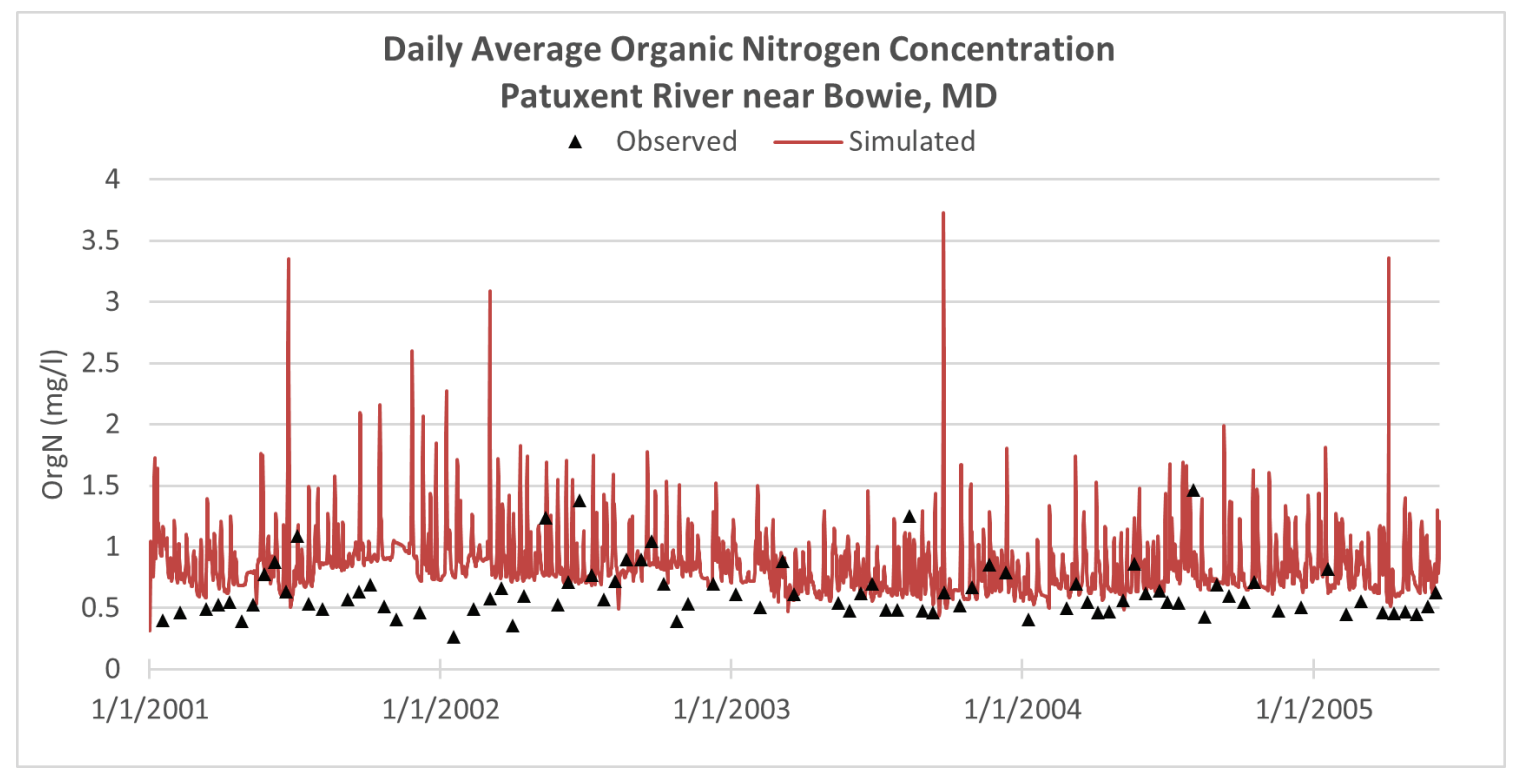


Figure D-39. Monthly average observed versus linked HSPF/HEC-RAS modeled ammonium concentration near Bowie, Maryland for the validation period.

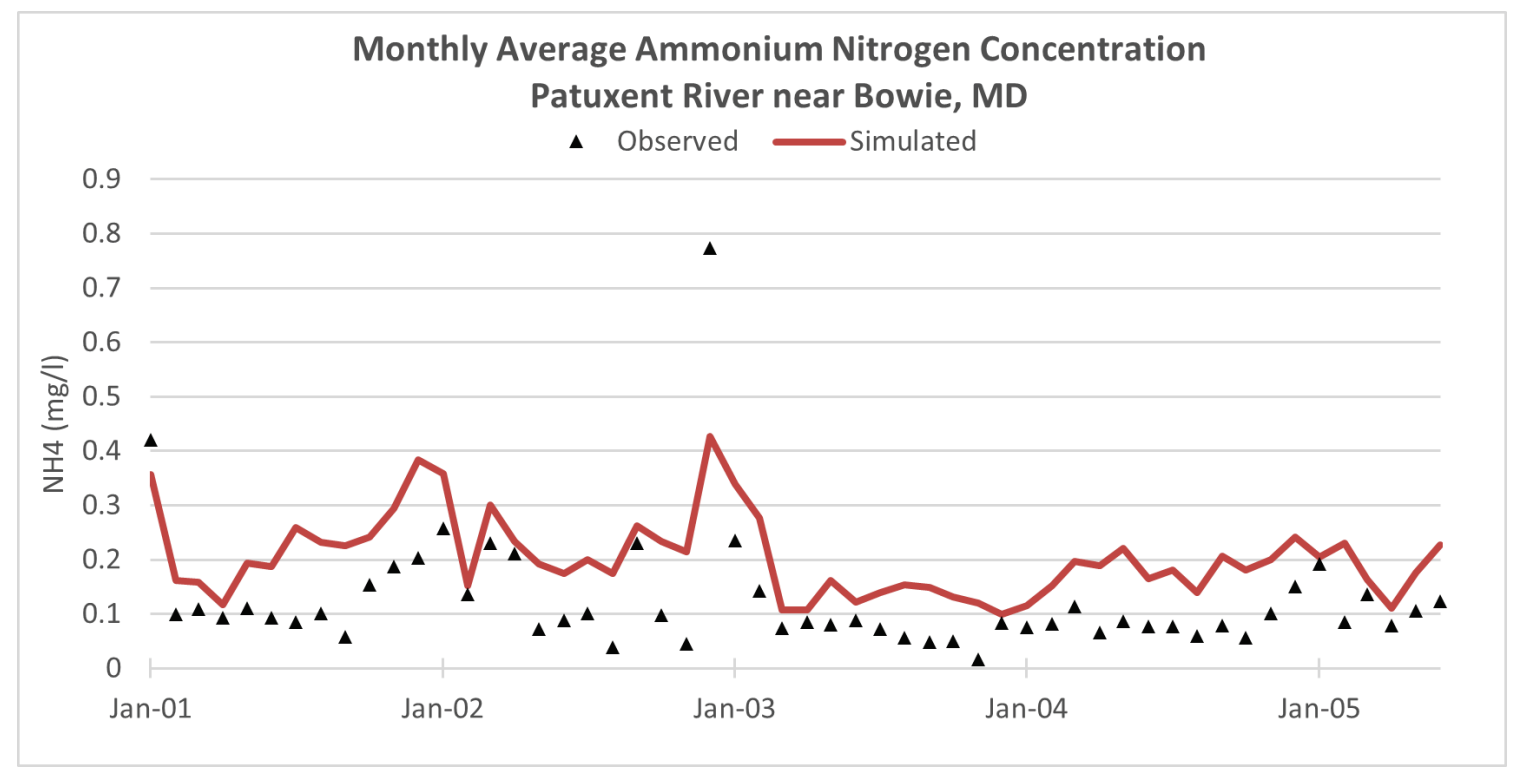

Figure D-40. Daily average observed versus linked HSPF/HEC-RAS modeled ammonium concentration near Bowie, Maryland for the validation period.

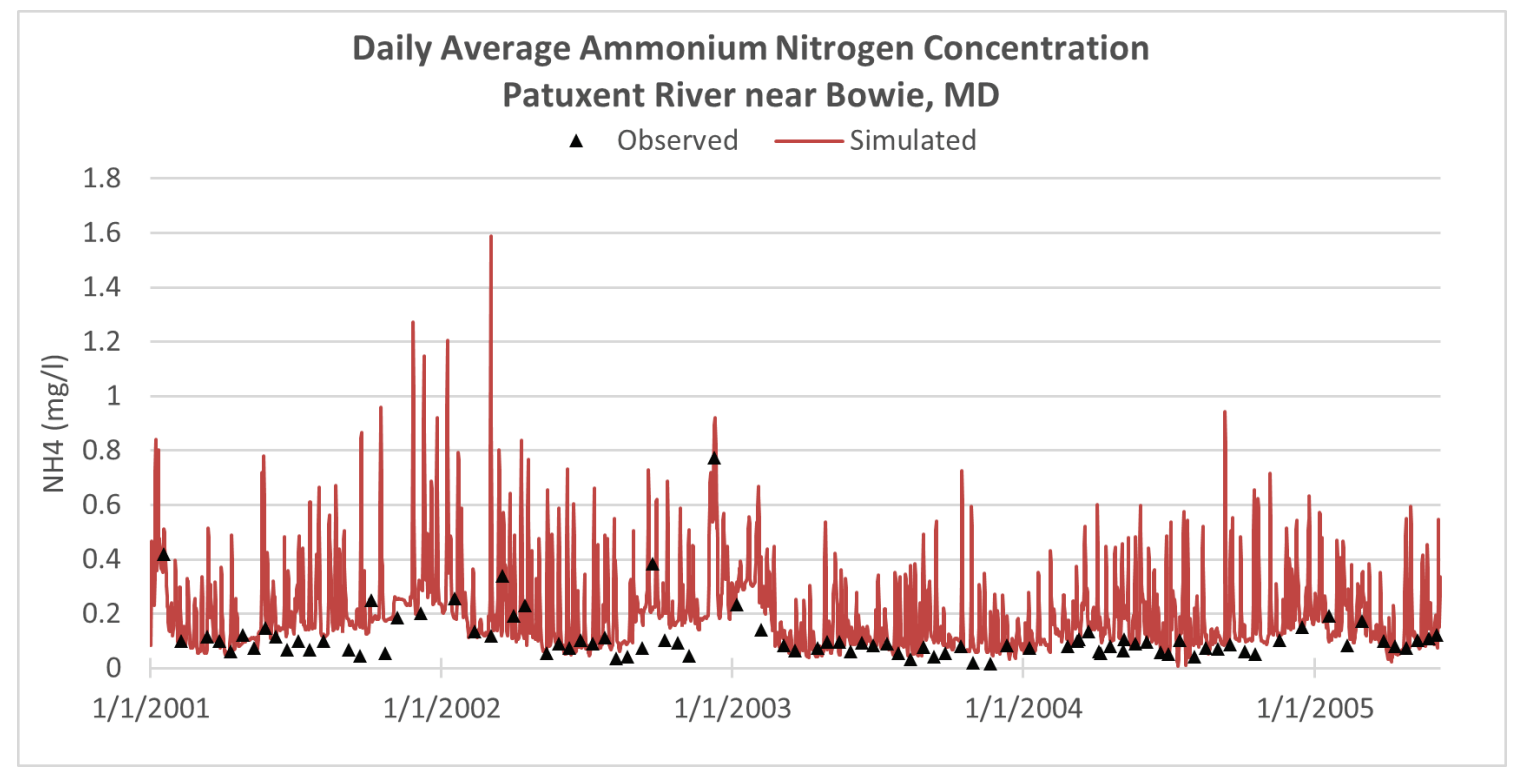


Figure D-41. Daily average observed versus linked HSPF/HEC-RAS modeled nitrate concentration near Bowie, Maryland for the validation period.

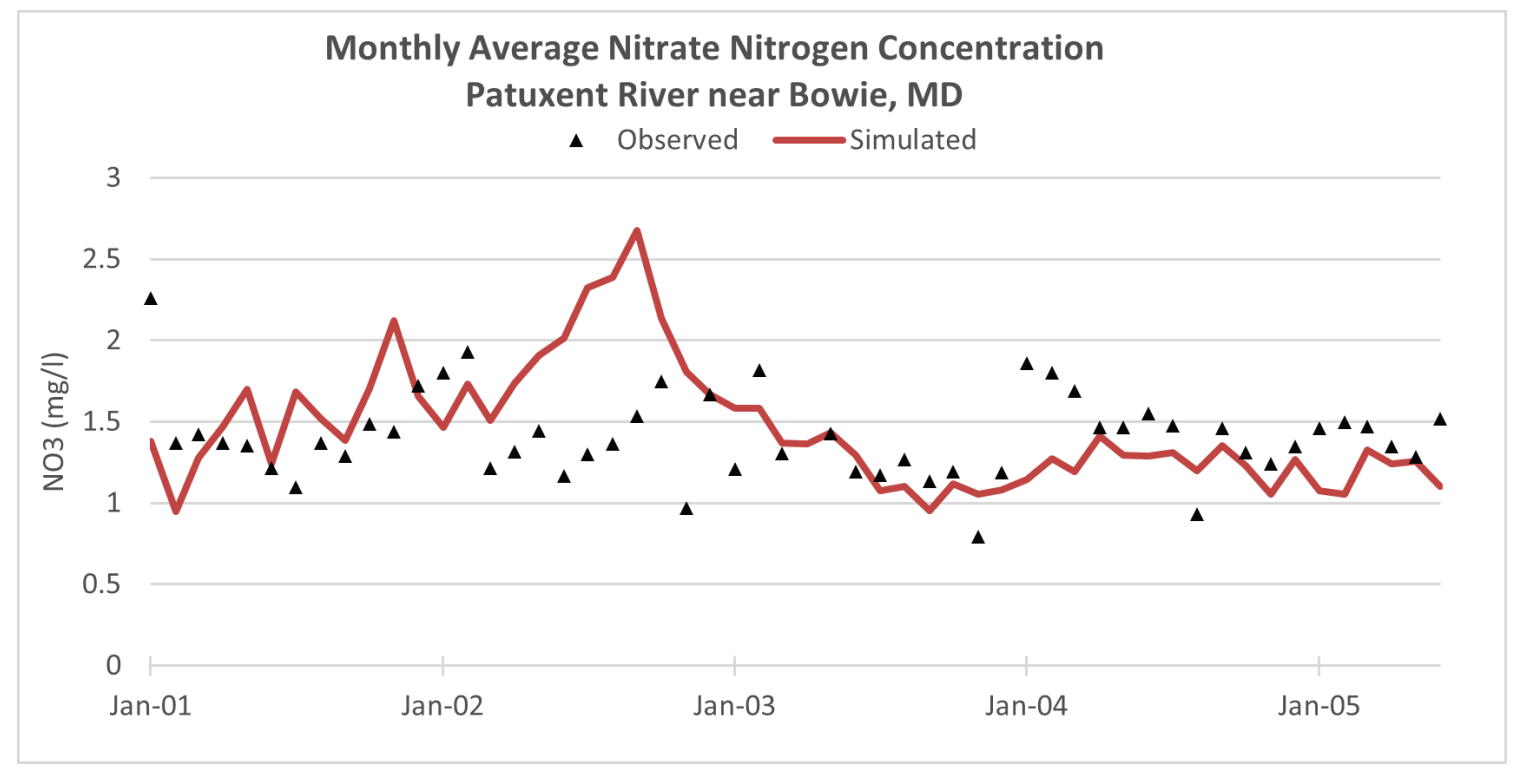

Figure D-42. Daily average observed versus linked HSPF/HEC-RAS modeled nitrate concentration near Bowie, Maryland for the validation period.

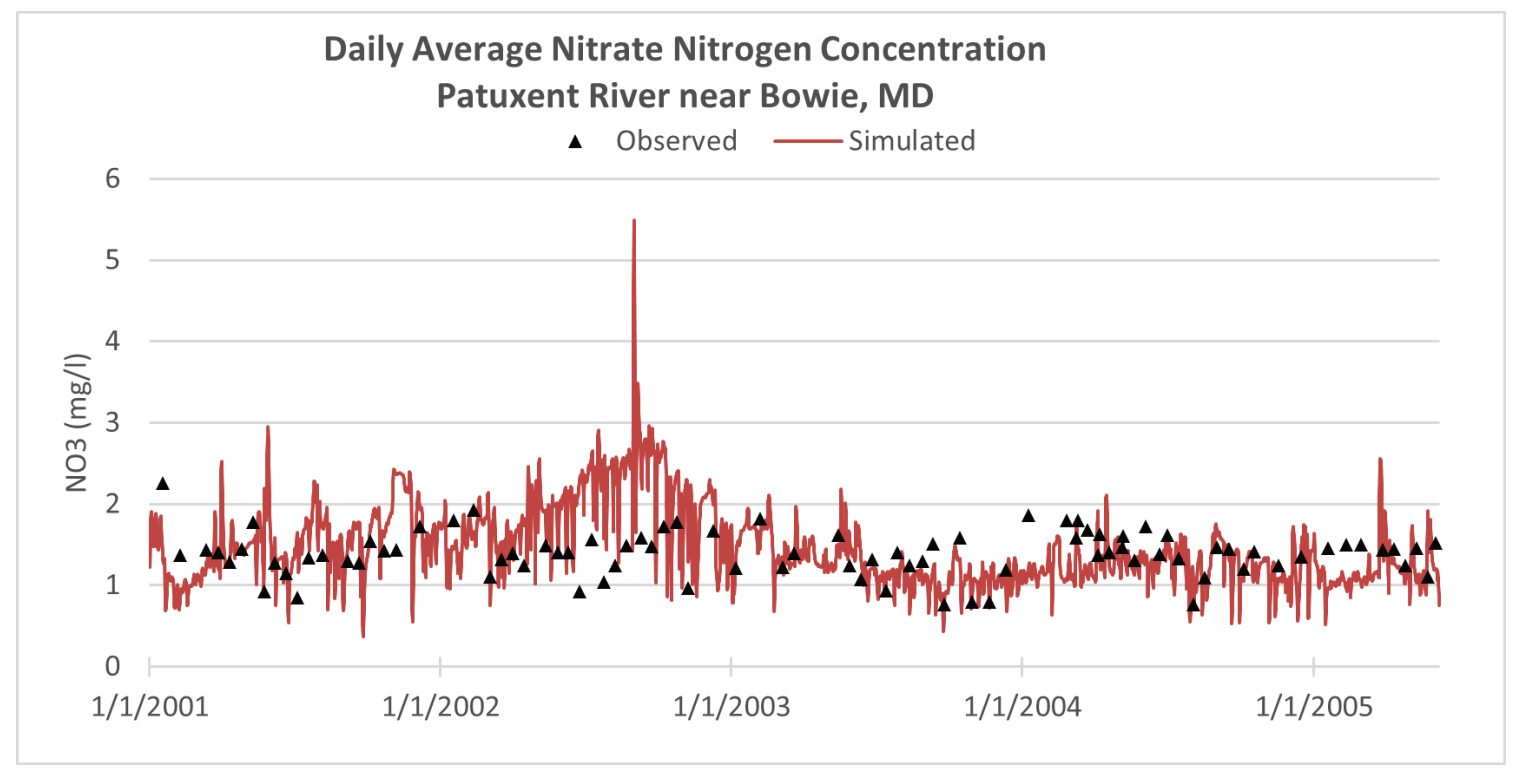


Figure D-43. Monthly average observed versus linked HSPF/HEC-RAS modeled organic phosphorus concentration near Bowie, Maryland for the validation period.

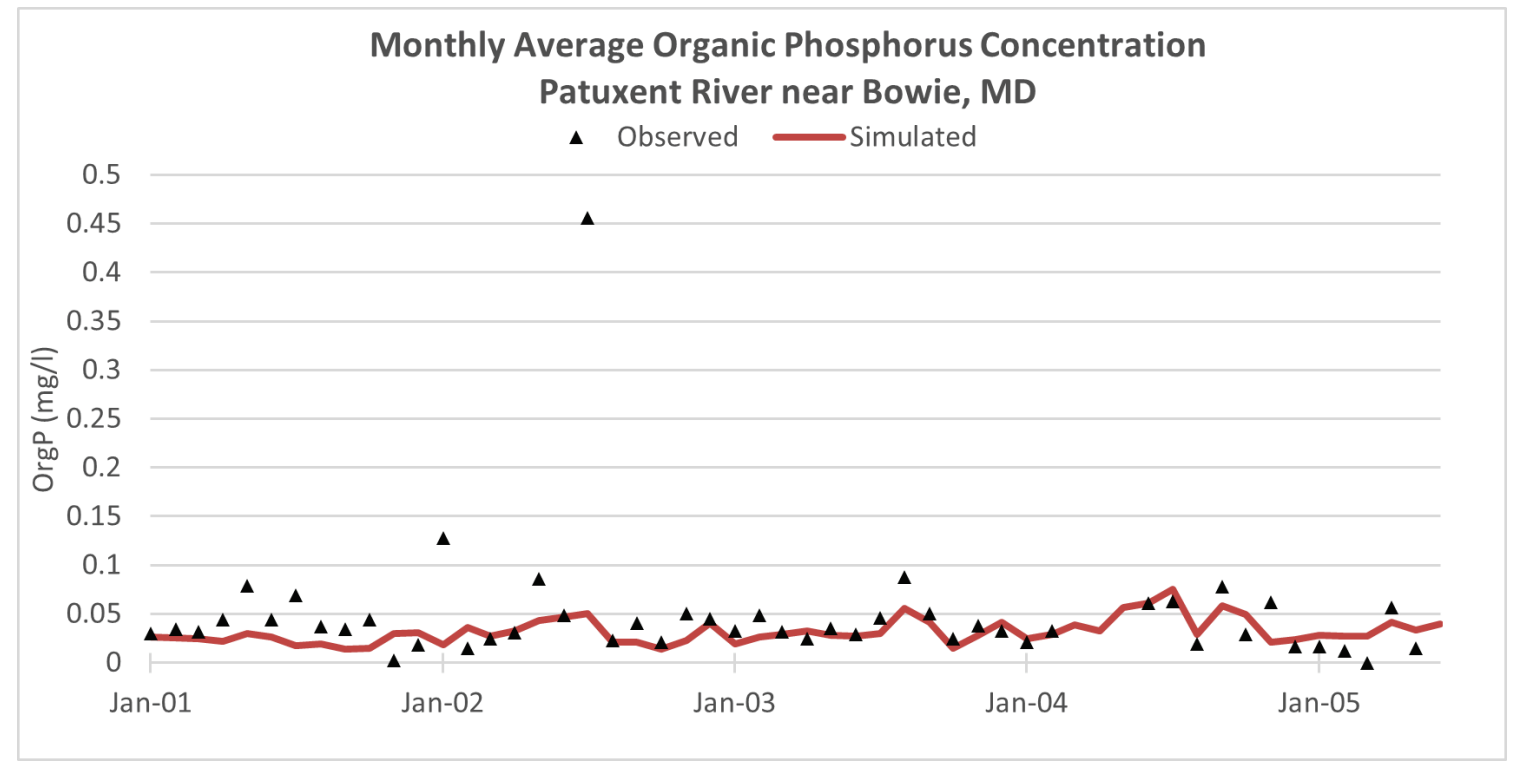

Figure D-44. Daily average observed versus linked HSPF/HEC-RAS modeled organic phosphorus concentration near Bowie, Maryland for the validation period.

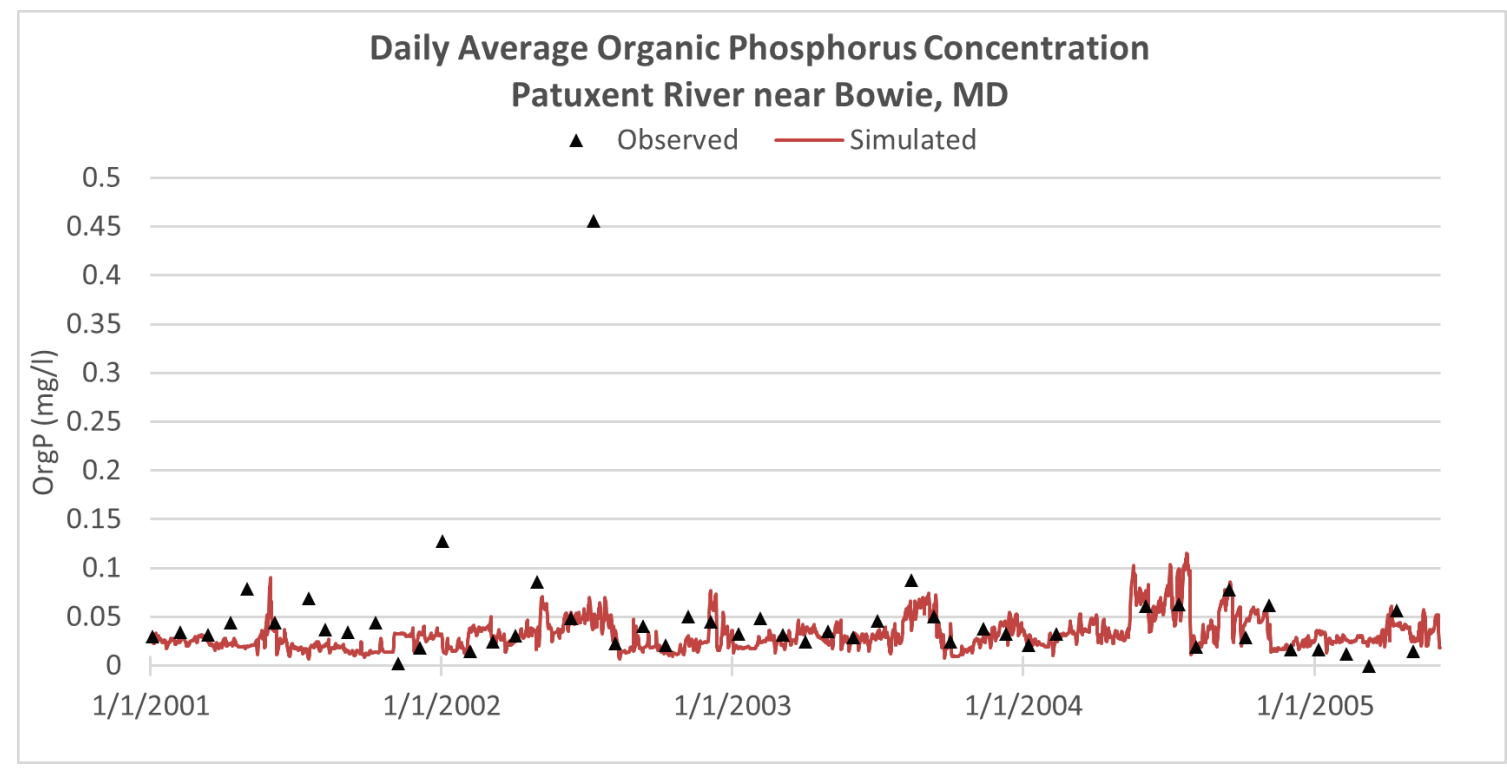


Figure D-45. Monthly average observed versus linked HSPF/HEC-RAS modeled inorganic phosphorus concentration near Bowie, Maryland for the validation period.

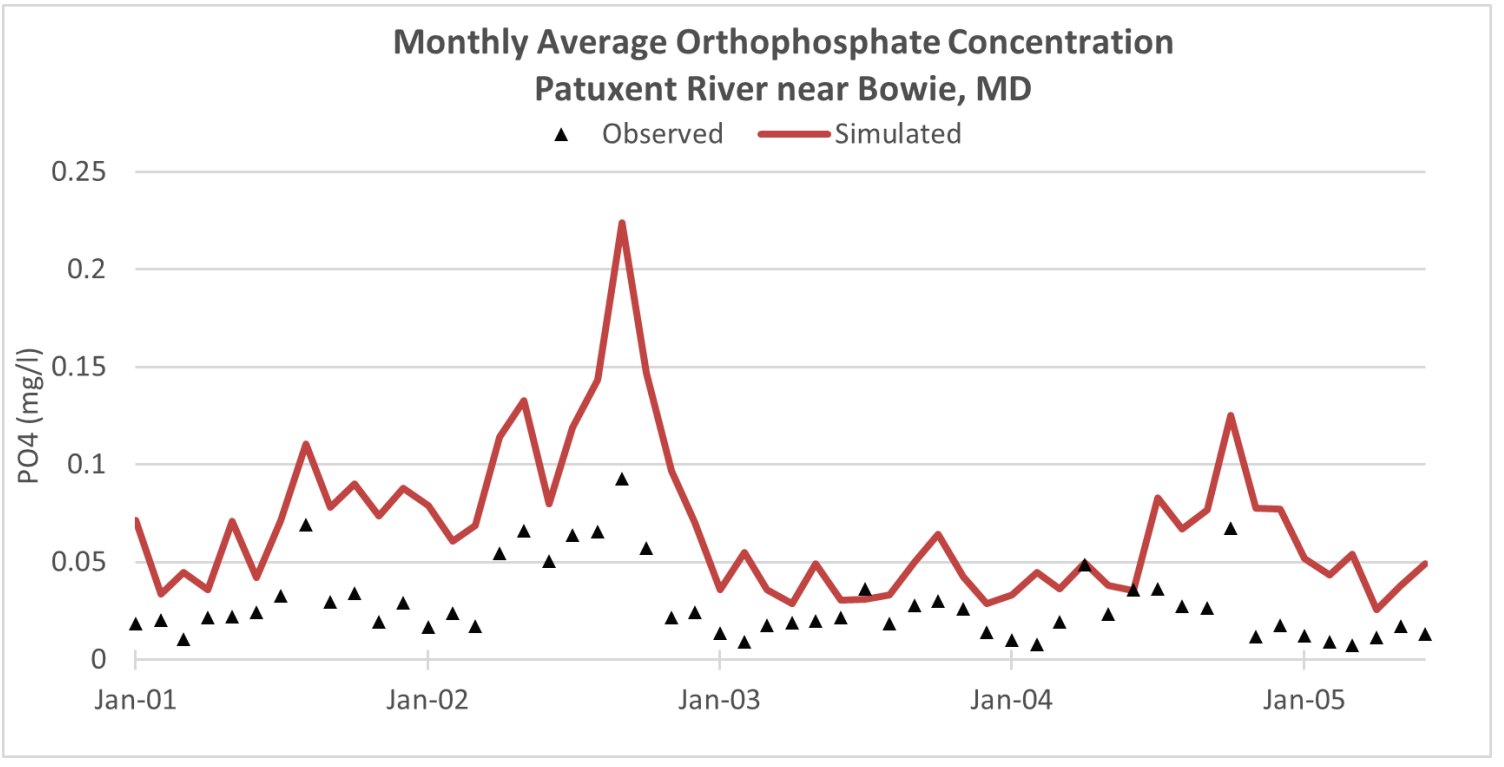

Figure D-46. Daily average observed versus linked HSPF/HEC-RAS modeled inorganic phosphorus concentration near Bowie, Maryland for the validation period.

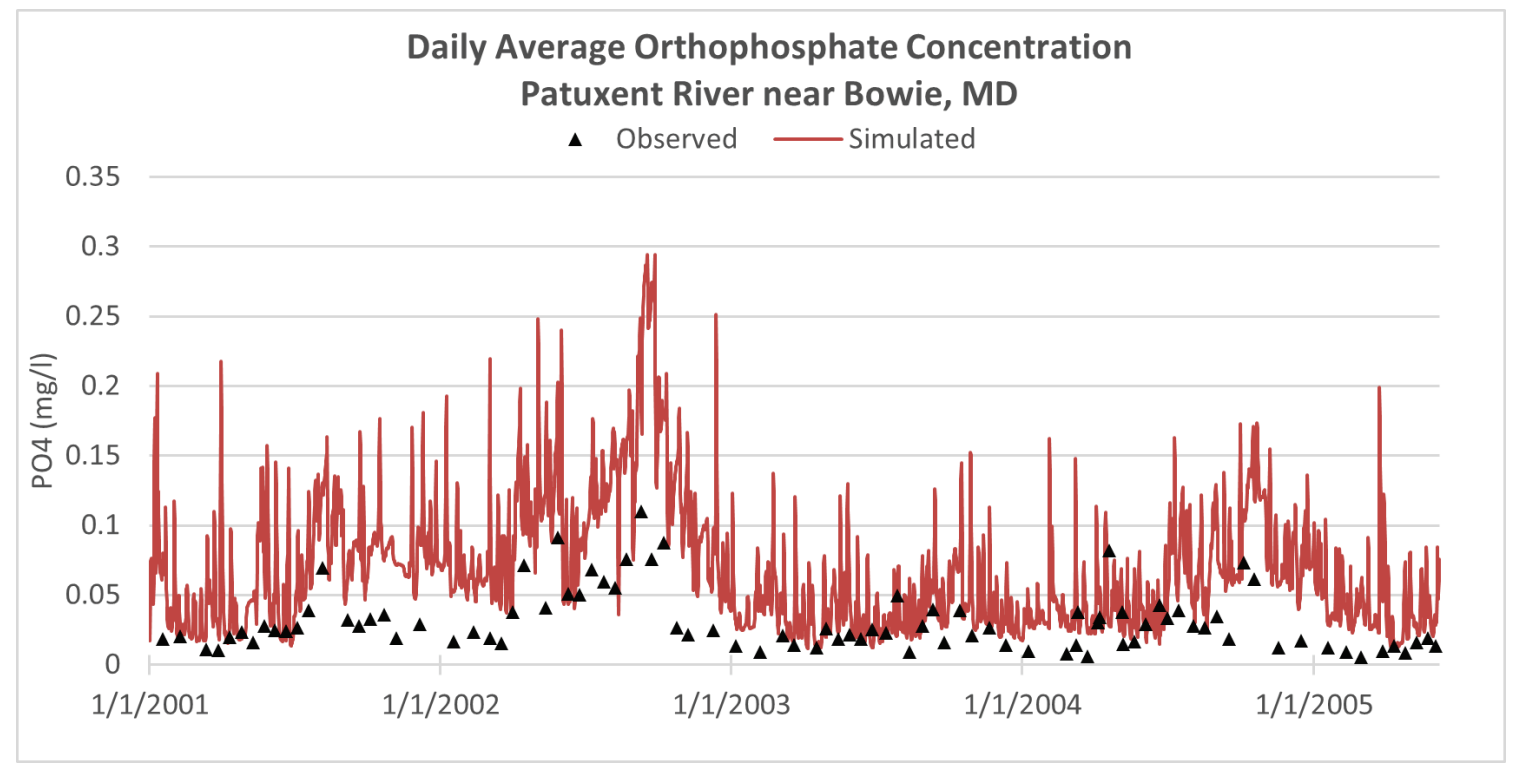




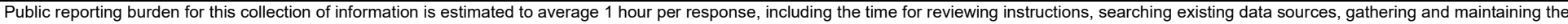

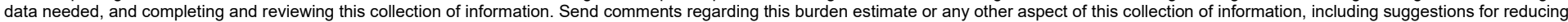

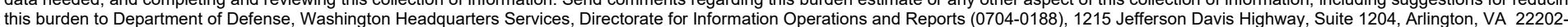

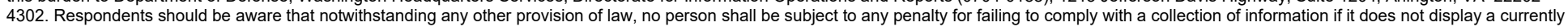
valid OMB control number. PLEASE DO NOT RETURN YOUR FORM TO THE ABOVE ADDRESS
1. REPORT DATE (DD-MM-YYYY) $09 / 01 / 2020$

\section{REPORT TYPE Final Technical Report (TR)}

\section{Title And Subtitle}

The Demonstration and Validation of a Linked Watershed-Riverine Modeling System for DoD

Installations - Patuxent Watershed, Maryland

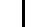

\section{AUTHOR(S)}

Billy E. Johnson and Zhonglong Zhang

\section{DATES COVERED (From - To)}

\section{5a. CONTRACT NUMBER}

5b. GRANT NUMBER

5c. PROGRAM ELEMENT

ESTCP

5d. PROJECT NUMBER

RC-201302

5e. TASK NUMBER

5f. WORK UNIT NUMBER

8. PERFORMING ORGANIZATION REPORT NUMBER

\section{PERFORMING ORGANIZATION NAME(S) AND ADDRESS(ES)}

U.S. Army Engineer Research and Development Center (ERDC)

Environmental Laboratory (EL)

3909 Halls Ferry Road

Vicksburg, MS, 39180
ERDC/EL TR-20-8

10. SPONSOR/MONITOR'S ACRONYM(S) SERDP/ESTCP

11. SPONSOR/MONITOR'S REPORT NUMBER(S)

\section{DISTRIBUTION / AVAILABILITY STATEMENT}

Approved for public release; distribution is unlimited.

\section{SUPPLEMENTARY NOTES}

\section{ABSTRACT}

This work evaluated a linked watershed and riverine modeling system for the Patuxent River Watershed, Maryland against observed field data and model output from a watershed model. The performance objectives were computed for streamflow, sediment, total phosphorus, orthophosphorus, total nitrogen, ammonium, and nitrate using daily and monthly average model predictions and measured data. Hydrological Simulation Program - Fortran (HSPF) was used to compute runoff, sediment, and nutrient loadings, whereas the Hydrologic Engineer Center - River Analysis System (HEC-RAS) was used to evaluate instream flow, channel sedimentation, and the fate/transport of nutrients. Model results were successful for calibration, validation, and management scenario analysis. Contaminants were not simulated for this watershed due to a lack of observed data to compare against. The study identified two implementation issues. First, while the Patuxent River did not experience dry bed conditions, where a stream may be intermittent, one can incorporate a very narrow slot at the low point in the cross-section to numerically keep the channel wet during very low flows. Second, to set up the linked model, there needs to be more observed water quality data to better constrain the HSPF output being used as boundary conditions to the HEC-RAS model.

\section{SUBJECT TERMS}

Rivers, Watersheds, Watershed management, Hydrologic models, Water quality, Military bases, Patuxent River Watershed (Md.)

\section{SECURITY CLASSIFICATION OF:}

\section{a. REPORT}

Unclassified

\section{b. ABSTRACT}

Unclassified

\section{LIMITATION OF ABSTRACT}

c. THIS PAGE

Unclassified
18. NUMBER OF PAGES

\begin{tabular}{l|l} 
SAR & 142
\end{tabular}

19a. NAME OF RESPONSIBLE PERSON

19b. TELEPHONE NUMBER (include area code) 